\title{
Molecular mechanisms of azole resistance in human pathogenic fungi
}

Citation for published version (APA):

Marichal, P. (1999). Molecular mechanisms of azole resistance in human pathogenic fungi. [Doctoral Thesis, Maastricht University]. Universiteit Maastricht. https://doi.org/10.26481/dis.19990929pm

Document status and date:

Published: 01/01/1999

DOI:

10.26481/dis.19990929pm

Document Version:

Publisher's PDF, also known as Version of record

\section{Please check the document version of this publication:}

- A submitted manuscript is the version of the article upon submission and before peer-review. There can be important differences between the submitted version and the official published version of record.

People interested in the research are advised to contact the author for the final version of the publication, or visit the DOI to the publisher's website.

- The final author version and the galley proof are versions of the publication after peer review.

- The final published version features the final layout of the paper including the volume, issue and page numbers.

Link to publication

\footnotetext{
General rights rights.

- You may freely distribute the URL identifying the publication in the public portal. please follow below link for the End User Agreement:

www.umlib.nl/taverne-license

Take down policy

If you believe that this document breaches copyright please contact us at:

repository@maastrichtuniversity.nl

providing details and we will investigate your claim.
}

Copyright and moral rights for the publications made accessible in the public portal are retained by the authors and/or other copyright owners and it is a condition of accessing publications that users recognise and abide by the legal requirements associated with these

- Users may download and print one copy of any publication from the public portal for the purpose of private study or research.

- You may not further distribute the material or use it for any profit-making activity or commercial gain

If the publication is distributed under the terms of Article $25 \mathrm{fa}$ of the Dutch Copyright Act, indicated by the "Taverne" license above, 
Molecular mechanisms of azole resistance in human pathogenic fungi 
ISBN 90-12951-0

Druk: JAP Advertising 


\title{
Molecular mechanisms of azole resistance in human pathogenic fungi
}

\author{
Proefschrift
}

ter verkrijging van de graad van doctor aan de Universiteit Maastricht, op gezag van de Rector Magnificus, Prof. dr. A.C. Nieuwenhuijzen Kruseman, volgens het besluit van het College van Decanen, in het openbaar te verdedigen op woensdag 29 september 1999 om 16.00 uur

door

\section{Patrick Marichal}

Geboren op 31 januari 1958 te Antwerpen, België 
Promotores:

Prof. dr. M. Borgers

Prof. dr. F.C.S. Ramaekers

Co-promotor: Ing. H. Vanden Bossche

Beoordelingscommissie: Prof. dr. C.A.M. Bruggeman (voorzitter)

Prof. dr. M. P. van Dieijen-Visser

Prof. dr. A. Goffeau

(Université Catholique de Louvain)

Prof. dr. H.A.J. Struijker-Boudier

Dr. M. de Waard

(Landbouw Universiteit Wageningen)

The investigations described in this thesis were carried out at the Anti-Infectives Research Departments of the Janssen Research Foundation, Beerse, Belgium. 




\section{Contents}

Chapter 1 General Introduction

Chapter 2 Contribution of mutations in the cytochrome P450 14 $\alpha$-demethylase (ERG Ll, CYPSL) to azole resistance in Candida albicans. 47

Chapter 3 Accumulation of 3-ketosteroids induced by itraconazole in azoleresistant clinical Candida albicans isolates.

Chapter 4 Synergic effects of tacrolimus and azole antifungal agents against azole-resistant Candida albicans strains

Chapter 5 Molecular biological characterization of an azole-resistant Candida glabrata isolate.

Chapter 6 Effects of itraconazole on cytochrome P-450-dependent sterol $14 \alpha$-demethylation and reduction of 3-ketosteroids in Cryptococcus neoformans

Chapter 7 Origin of differences in susceptibility of Candida krusei to azole antifungal agents.

Chapter 8 Hypothesis on the mechanism of resistance to fluconazole in Histoplasma capsulatum.

Chapter 9 General discussion and summary

Samenvatting

Curriculum vitae

List of publications

Dankwoord 


\section{Abbreviations}

\begin{tabular}{|c|c|}
\hline 2D-GE & : 2-Dimensional gel electrophoresis \\
\hline $\mathrm{ABC}$ & : ATP binding cassette \\
\hline $\mathrm{ABI}$ & : Applied biosystems incorporated \\
\hline$A C T I$ & : Actin gene \\
\hline AIDS & : Auto-immune deficiency syndrome \\
\hline ATCC & : American Type Culture Collection \\
\hline$B E N^{r}$ & : Candida albicans MFS gene (= CaMDRI) \\
\hline bp & : Basepairs \\
\hline $\mathrm{Ca} 3$ & : Moderately repetitive probe from Candida albicans \\
\hline CaMDRI & : Candida albicans MFS gene \\
\hline $\mathrm{CCCP}$ & : Carbonyl cyanide m-chlorophenyl hydrazone \\
\hline$C D R I$ & : Candida albicans $\mathrm{ABC}$-type transporter gene \\
\hline$C D R 2$ & : Candida albicans ABC-type transporter gene \\
\hline CHEF & : Contour-clamped homogeneous electric field \\
\hline $\mathrm{CMC}$ & : Chronic mucocutaneous candidiasis \\
\hline $\mathrm{CO}$ & : Carbon monoxide \\
\hline CPE & : Citric acid-phosphate-EDTA buffer \\
\hline CUPl & : Metallothionein gene \\
\hline CYPIOI & : Pseudomonas putida cytochrome $\mathrm{P} 450$ gene \\
\hline CYPSI & : Cytochrome P450 14 $\alpha$-demethylase gene \\
\hline CYP6I & : Cytochrome P450 $\Delta^{22}$-desaturase gene \\
\hline DMSO & : Dimethyl sulfoxide \\
\hline EBI & : Ergosterol biosynthesis inhibitors \\
\hline EDTA & : Ethylenediamine tetraacetic acid \\
\hline$E R G I$ & : Squalene epoxidase gene \\
\hline$E R G 2$ & $\Delta^{8.7}$ isomerase gene \\
\hline ERG3 & $: \Delta^{5,6}$ desaturase gene \\
\hline$E R G 5$ & : Cytochrome P450 $\Delta^{22}$-desaturase gene \\
\hline ERG7 & : Oxidosqualene cyclase gene \\
\hline ERGII & : cytochrome P450 14 $4 \alpha$-demethylase gene \\
\hline $\begin{array}{l}\text { ERGI6 } \\
\text { gene) }\end{array}$ & : cytochrome P450 I $4 \alpha$-demethylase (old name for the Candida albicans \\
\hline$E R G 24$ & $: \Delta^{14}$-reductase gene \\
\hline ERG25 & : C4-sterol methyl oxidase gene \\
\hline ERG26 & : C4-decarboxylase gene \\
\hline GALIO & : UDP-glucose 4-epimerase gene \\
\hline GCMS & : Gas chromatography coupled mass spectrometry \\
\hline GFP & : Green fluorescent protein \\
\hline HIV & : Human immunodeficiency virus \\
\hline HPLC & : High pertormance liquid chromatography \\
\hline HSE & : Heat shock responsive element \\
\hline
\end{tabular}




\begin{tabular}{|c|c|}
\hline $\mathrm{IC}_{50}$ & : Inhibitory concentration at $50 \%$ level \\
\hline IEF & Isoelectric focusing \\
\hline kbp & : Kilobasepairs \\
\hline MDR & Multi-drug resistance \\
\hline MFS & : Major facilitator superfamily \\
\hline MIC & : Minimal inhibitory concentration \\
\hline MOPS & : Morpholino propanesulfonic acid \\
\hline $\mathrm{MW}$ & : Molecular weight \\
\hline NAD & : Nicotinamide adenine dinucleotide \\
\hline NADP & : Nicotinamide adenine dinucleotide phosphate \\
\hline NADPH & : Nicotinamide adenine dinucleotide reduced \\
\hline NCCLS & : National Committee for Clinical Laboratory Standards \\
\hline NCPF & : National Collection of Pathogenic Fungi \\
\hline OPC & : Oropharyngeal candidiasis \\
\hline ORF & : Open reading frame \\
\hline PBS & : Phosphate buffered saline \\
\hline PCR & : Polymerase chain reaction \\
\hline PDR & : Pleiotrophic drug resistance \\
\hline PDR5 & Saccharomyces cerevisiae ABC-type transporter gene \\
\hline PMSF & : Phenylmetyl sulfonfluoride \\
\hline RFLP & : Restriction fragment length polymorphism \\
\hline SDS & : Sodium dodecyl sulphate \\
\hline SSC & : Sodium chloride-sodium citrate \\
\hline TBE & : Tris-boric acid-EDTA buffer \\
\hline TE & : Tris-EDTA buffer \\
\hline TEM & : Transmission electron microscopy \\
\hline TRIS & : Tris-hydroxy amino methane \\
\hline UV & : Ultra-violet \\
\hline
\end{tabular}





\section{General introduction}

This chapter is based partly on three reviews:

Marichal P. 1999. Mechanisms of resistance to azole antifungal compounds. Curr. Op. Anti-Infect. Invest. Drugs 1(3):: 318-333.

Marichal P. and H. Vanden Bossche. 1995. Mechanisms of resistance to azole antifungals. Acta Biochim. Pol. 42(4): 509-516.

Vanden Bossche H., P. Marichal, F. C. Odds. 1994. Molecular mechanisms of drug resistance in fungi. Trends Microbiol. 2: 393-400. 


\section{Fungal infections}

The fungal kingdom comprises over 100,000 species throughout the world of which up to 150 have been documented as causes of infections in humans (57). The severity of fungal disease varies from "cosmetic" superficial infections to life-threatening systemic infections. Most of the infections are opportunistic because the infecting agent is found as a commensal (10) or is ubiquitous in the environment (e.g. Aspergillus spp.) and can easily gain access to debilitated patients. In addition to the opportunistic pathogenic fungi, a limited number of fungi exist with a true pathogenic potential for normal hosts. They cause life threatening infections restricted to their endemic region. These pathogens, e.g. Histoplasma capsulatum, Paracoccidioides brasiliensis, Penicillium marneffei and Coccidioides immitis, are therefore classified in biohazard class 3 (19). Until now, no fungal species has been regarded as a class 4 pathogen.

The incidence of systemic fungal infections is high and has increased over the last decades $(16,48,81,116)$. Several factors contribute to the increased incidence of fungal infections. One is the increase in the size of the susceptible population as a result of increased use of chemotherapy, and, long-term use of broad-spectrum antibacterial agents and immunosuppressive drugs. The prevalence of AIDS, malignancies, rising numbers of elderly people, invasive surgical interventions and, perhaps paradoxically, the progress and sophistication of medical treatments have all contributed to the rising toll of fungal morbidity and mortality. Another factor is the greater clinical awareness of the importance of fungal infections that is reflected by an increased motivation to search for the presence of fungal pathogens. Candida albicans is the species most frequently associated with fungal infections in humans $(16,116,119)$. The history of candidiasis dates back to the fourth century B. C. when Hippocrates described oral aphthae in two patients with severe underlying disease in his book Epidemics (41). Candida vulvovaginitis is found in $10 \%$ of women of childbearing age: its prevalence increases to up to $30 \%$ during pregnancy (61). Ninety per cent of AIDS patients have at least one episode of mycosis during their illness (26). Pfaller et al. reported that Candida spp. have become the fourth leading cause of nosocomial blood stream infections in the USA (81). About $50 \%$ were due to 
C. albicans. A trend towards rising frequencies of non-albicans. Candida spp. has been noted but this is seen primarily in immunocompromised patients, neonates and the elderly $(39,79)$. A similar situation was found in the Netherlands although less pronounced (119). There seem to be geographical differences in the prevalences of fungal pathogens. For example, Pfaller et al. found that, in Canada and in South America, the most common Candida sp. after C. albicans was C. parapsilosis, whereas in the United States, C. glabrutu was found more frequently (80).

\section{Antifungal compounds}

In spite of the clinical importance of fungal infections only a limited number of classes of antifungal compounds is available for treatment. The compounds can be classified into four groups on the basis of their general molecular mechanism of action. The chemical structures of key examples for each group are given in FIG. 1 .

\section{Inhibitors of mitosis}

\section{Griseofulvin}

Griseofulvin (FIG. 1.) was isolated from Penicillium griseofulvum and is used against dermatophyte infections only (77). In susceptible species, griseofulvin interferes with the mitotic separation of the chromosomes, probably through interference with the sliding of microtubules (95).

\section{Nucleic acid synthesis inhibitors}

\section{Flucytosine}

The second class of antifungals, exemplified by flucytosine (FIG. 1.), interferes with the synthesis of RNA and/or DNA macromolecules. Flucytosine, an ana- 


\section{Chapter 1}

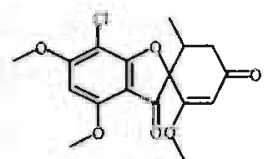

A) Griseofulvin

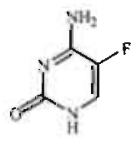

B) Flucytosine

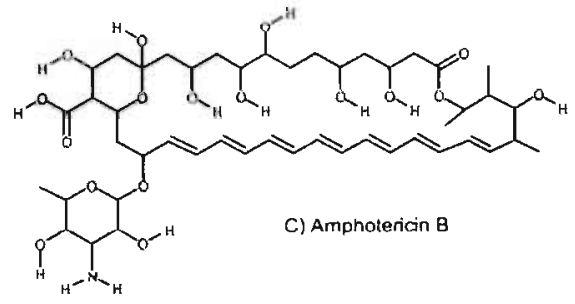

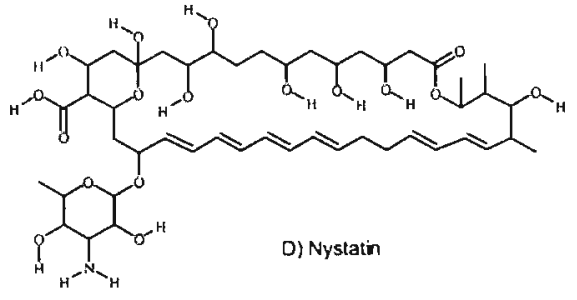<smiles>CCC(C)(C)c1ccc(CC(C)CN2CC(C)OC(C)C2)cc1</smiles>

E) Amorolfine<smiles>CN(C/C=C/c1ccccc1)Cc1cccc2ccccc12</smiles>

F) Naftifine<smiles>CN(C/C=C/C#CC(C)(C)C)Cc1cccc2ccccc12</smiles>

G) Terbinafine

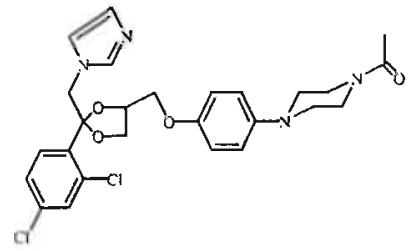

H) Ketoconazole

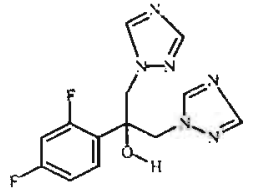

1) Fluconazole<smiles></smiles>

FIG. 1. Chemical structures of representative members of different classes of antifungal compounds used in medicine. A) griseofulvin, B) flucytosine, C) amphotericin $B$, D) nystatin, E) amorolfine, F) naftifin G) terbinafine, H) ketoconazole, I) fluconazole and J) itraconazole 
log of the pyrimidine, cytosine, enters the fungal cell with the aid of a cytosine permease, after which it is immediately deaminated into its active form 5-fluorouracil (5FU). 5FU is converted into 5-fluorouridylic acid, phosphorylated and incorporated into RNA, resulting in aberrant RNA and as such inhibiting fungal growth. At the same time, 5FU is converted into 5-fluorodeoxyuridine monophosphate. This is a potent non-competitive inhibitor of thymidylate synthase and therefore of DNA synthesis. The combined action of DNA and RNA inhibition results in fungicidal activity (82).

\section{Ergosterol biosynthesis inhibitors}

\section{Sterols: synthesis and function}

The most widely used antifungal compounds interfere with the biosynthesis of ergosterol. Ergosterol is the fungal counterpart of the cholesterol found in mammalian membranes. Both are derived from lanosterol. The structures of all three sterols are shown in figure 2 , with the conventional numbering of important carbon atoms added to the skeleton. Ergosterol fulfills membrane related functions such as the maintenance of appropriate membrane fluidity, regulation of membrane permeability and influence on the activity of membrane bound enzymes. In addition, a hormonal "sparking" function in cell cycle completion is ascribed to sterols with stringent structural requirements $(63,73,108,111)$. In decreasing importance these are the presence of a $3 \beta-\mathrm{OH}$ group, the absence of 4 or 14 methyl groups, unsaturation of the B-ring, a 24-methyl group in the side chain and a $\Delta 22$ double bond (8). The metabolic synthesis of this important fungal metabolite is shown in figure 3. The enzymatic steps that are targets for current antifungal compounds as well as for compounds at an experimental stage are annotated. If available, the designations of the genes encoding the enzymes are also given.

\section{Squalene epoxidase inhibitors}

Squalene epoxidase catalyzes the conversion of squalene into 2,3-oxidosqualene and the fungal enzyme is inhibited non-competitively by allylamines (e.g. 


\section{Chapter 1}

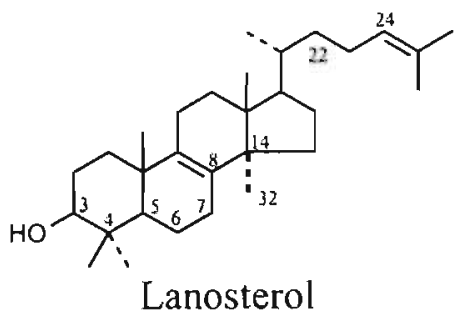

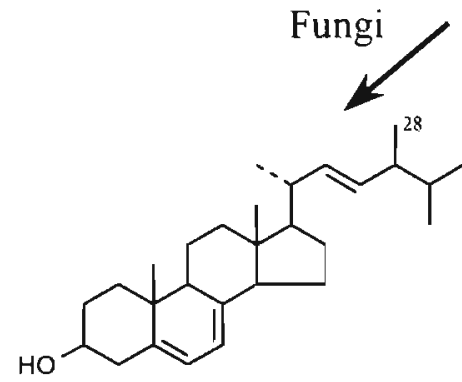

Ergosterol

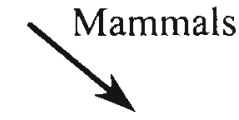<smiles>CC(C)CCCC(C)C1CCC2C3CC=C4CC(O)CCC4(C)C3CCC12C</smiles>

Cholesterol

FIG. 2. Chemical structures of lanosterol, ergosterol and cholesterol. Important carbon atoms are numbered according to the IUPAC convention.

naftifine and terbinafine (FIG. 1.)) (84) and thiocarbamates (e.g. tolciclate and tolnaftate) $(7,74,85)$. The mammalian squalene epoxidase is competitively inhibited but only at much higher concentrations. $E R G I$ is the gene coding for the fungal enzyme and it is an essential gene (45) in S. cerevisiae, i.e. one whose deletion leads to cell death. Oxidosqualene cyclase converts 2.3 oxidosqualene into lanosterol.

\section{Cytochrome P450 inhibitors}

The transformation of lanosterol into ergosterol is a multi-step process in which the order of sequential reactions depends on the availability of the substrates and the substrate specificity of individual enzymes, which are found to vary between fungal species. It is therefore not surprising that inhibitors that interfere with this last part of the pathway induce the accumulation of intermediates that vary between species (113). The antifungal activity of azoles arises from a complex 
General introduction
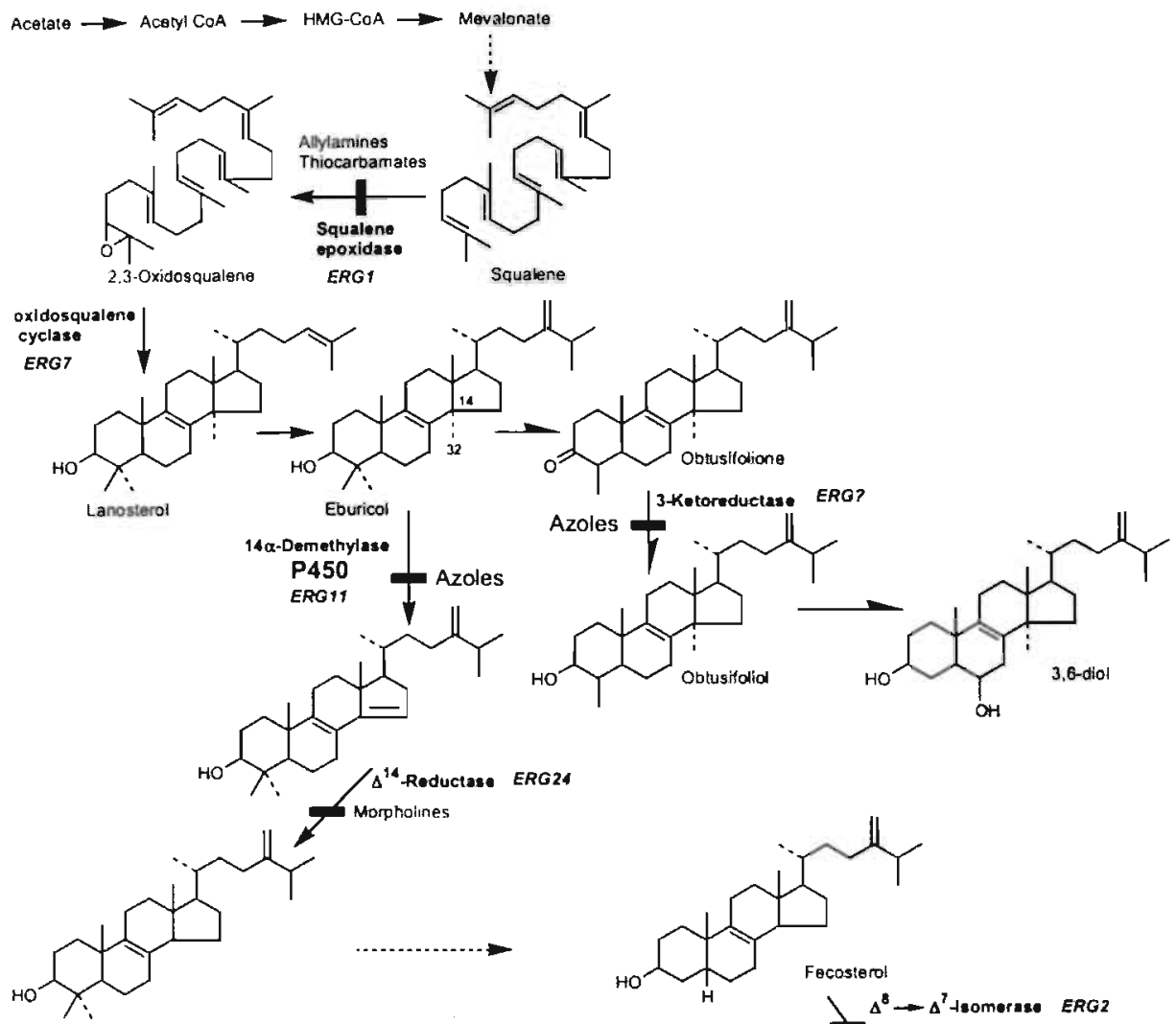

$$
\begin{aligned}
& \text { Ald -Reductase ERG 24 } \\
& \text { Morphoines }
\end{aligned}
$$

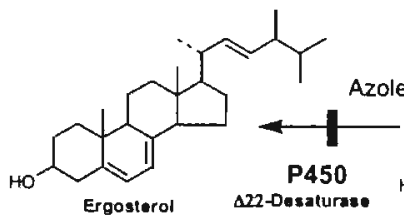

Morpholines;<smiles>CC(C)C(C)CCC(C)C1CCC2C3=CC=C4CC(O)CCC4(C)C3CCC21C</smiles><smiles>C=C(CCC(C)C1CCC2C3=CCC4CC(O)CCC4(C)C3CCC21C)C(C)C</smiles>

ERG 5

FIG. 3. Schematic biosynthetic pathway of ergosterol formation. The sites where antifungal compounds interfere are indicated. The precise order of the steps beyond lanosterol formation is species dependent. Dashed arrow, multistep reaction; half arrow, reaction in the presence of an azole; filled rectangle, site of inhibition.

multi-mechanistic process initiated by the inhibition of the cytochrome P450s catalyzing the $14 \alpha$-demethylation step, encoded by ERG II (ER GI6,CYP5I), and the $\triangle 22$-desaturase, encoded by ERG5 (CYP6I). A cytochrome P450 is a

17 
heme-containing protein named after its absorption peak at $450 \mathrm{~nm}$ after binding $\mathrm{CO}$ to the protein in the reduced state. The azoles bind with their unhindered nitrogen atom $\left(\mathrm{N}_{3}\right.$ of an imidazole such as ketoconazole, FIG. 1.; or $\mathrm{N}_{4}$ of the triazole ring as in, e.g. fluconazole and itraconazole, FIG. 1.) to the sixth coordination position of the central iron atom of the heme group and thus prevent the activation of oxygen which is necessary for the demethylation process (FIG. 4.). Specificity and stability of the inactive complex formation arises through interaction of the $\mathrm{N}_{1}$-ligand portion of the azole with the apoprotein (110). Inhibition results in both the gross depletion of membrane ergosterol content and the accumulation of membrane-disturbing 14-methylated precursors. The combination of these events deregulates membrane organization and/or fluidity and thus alters the activity of membrane-localized enzymes. Indeed an uncoordinated synthesis and deposition of chitin is observed after azole treatment, demonstrated by specific staining with a stilbene type dye in C. albicans and in Aspergillus fumigatus $(62,104)$. Transmission electron microscopy of

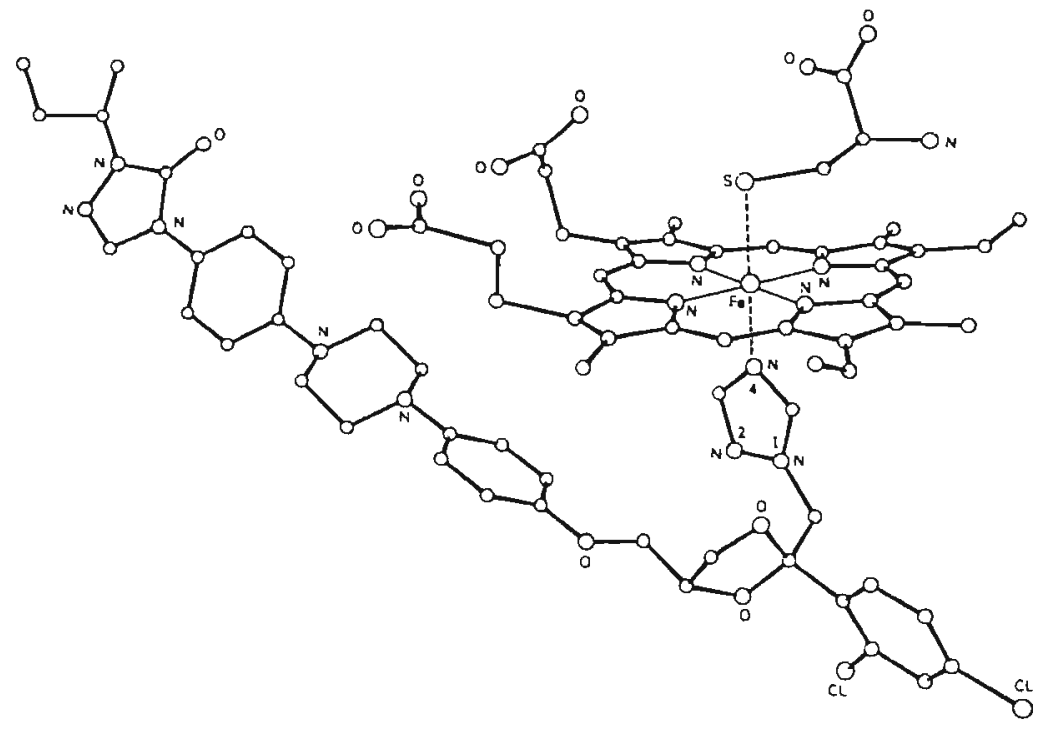

FIG. 4. Computer perspective ball-stick drawing of the iron protoporphyrin in interaction with itraconazole. The fifth ligand is a thiolate anion of cysteine $\left(\mathrm{C}_{470}\right)$ in the main $\mathrm{P} 450$ protein. The sixth coordination position of the heme iron is taken by the $\mathrm{N}_{4}$-atom of the triazole of itraconazole. ( After ref. 103) 

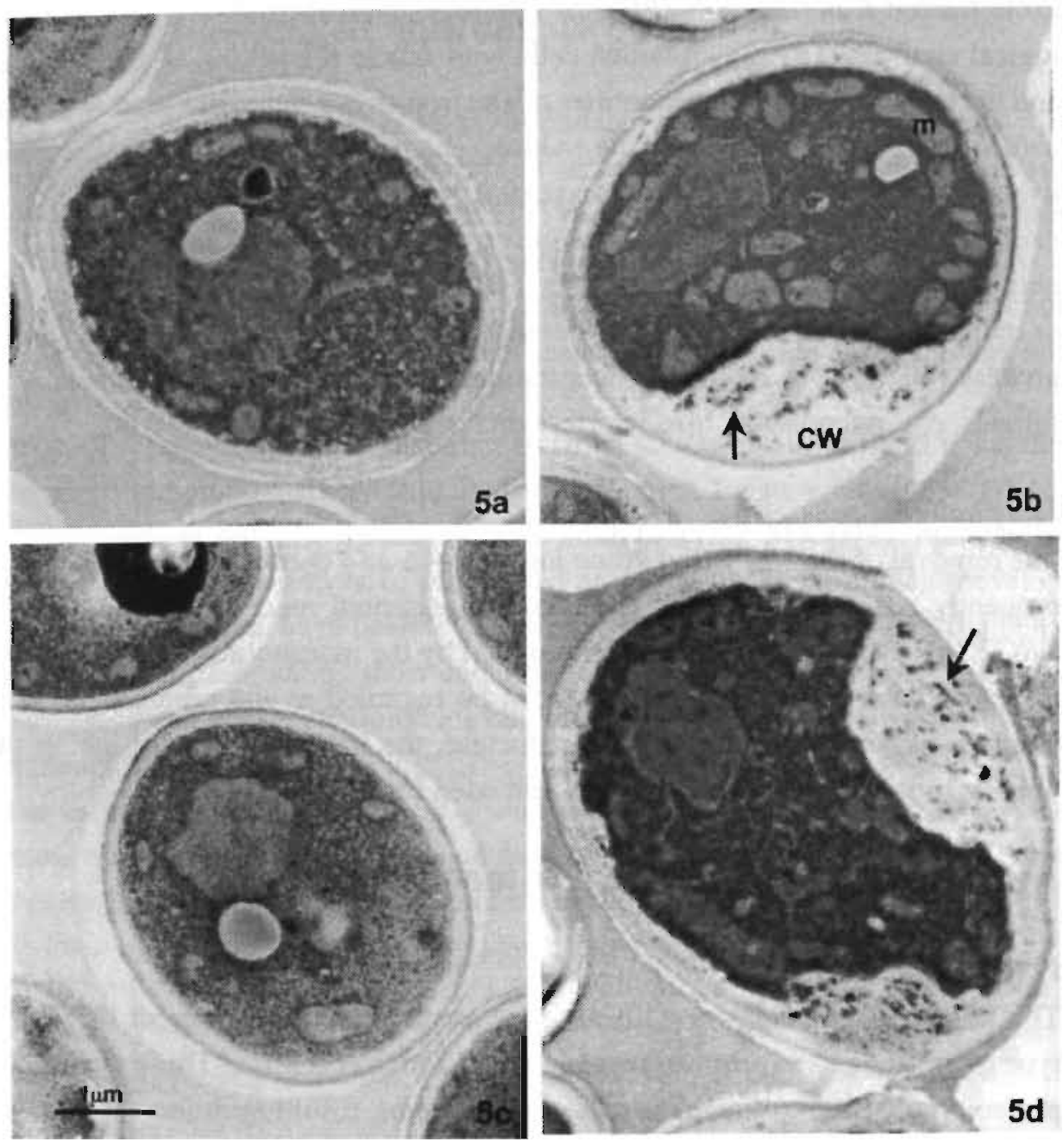

FIG. 5. Transmission electron microscopic examination of azole-sensitive Candida albicans cells (strains ATCC $44858(a, b)$ and C33 (c, d) grown for $24 \mathrm{~h}$ in CYG medium in control conditions $(a, c)$ or in the presence of $3 \mu \mathrm{M}$ itraconazole (b, d) for $24 \mathrm{~h}$ in CYG medium (casein hydrolysate-yeast extractglucose). $\mathrm{CW}=$ cellwall, electron dense particles are indicated by an arrow, $\mathrm{m}=$ mitochondria. Bar is $1 \mu \mathrm{M}$. 
azole-treated Candida cells (FIG. 5) visualizes typical azole-induced morphological changes $(15,22)$. Swollen cells with severe thickening of the cell wall and the occurrence of large quantities of electron-dense, lipid-like material in the cell wall are observed. The azole-induced changes also result in a hypersensitivity towards oxygen-induced damage (94). In some species, e.g. Cryptococcus neoformans and Histoplasma capsulatum, azoles induce the accumulation of obtusifolione or 14-methylfecosterone (FIG. 3.), suggesting an additional, direct or indirect, interference with the 3-ketoreductase reaction in the 4-demethylation process $(107,112)$. At high concentration, the earliest known imidazole antifungals, e.g. miconazole, also interfere directly with membranes (103).

\section{Morpholines}

The removal of the 14-methyl group introduces a $\Delta 14$ double bond which is subsequently reduced by the $\Delta^{14}$-reductase, an essential reaction encoded by the $E R G 25$ gene (59). This reaction is inhibited by the morpholine class of antifungals for which amorolfine (FIG. L.) can be regarded as the representative. In addition to their effects on the $\Delta^{14}$-reductase, the morpholines also inhibit the non-essential $\Delta^{8-7}$ isomerase reaction, encoded by ERG2 (3).

\section{Antifungals that damage cell membranes}

\section{Polyene Macrolides}

The polyene macrolides, e.g. nystatin or amphotericin B represent the fourth type of antifungals in terms of mechanism of action (FIG. 1.). These macrolides preferentially bind to fungal sterols in membranes, resulting in increased membrane permeability, leakage of cellular components and changes in nutrient transport and activity of membrane bound enzyme activities (35). Fungicidal activity may originate from polyene-induced hypersensitivity to oxidative damage (13). In the patient, amphotericin B's immunostimulating properties may also contribute to its efficacy (14). 


\section{Non-commercialized antifungals}

The increase of fungal infections has stimulated the search for antifungals with a distinct mode of action. Inhibitors of other steps in the ergosterol pathway have been found. The squalestatins (11) and zaragosic acids (29) inhibit squalene synthase. Several inhibitors have been described that attack oxidosqualene cyclase $(8,37)$, and 6-amino-2-n-pentylthiobenzothiazole was claimed to act on the 4-demethylationstep (56). None of these compounds has made its way into the clinic.

Because it does not exist in mammalian cells, the cell wall, in fungi is another attractive target extensively exploited in the search for new antifungal agents. At this moment only the glucan synthase inhibitors (e.g. MK-0991, now known as caspofungin) seem to have progressed as far as phase III clinical development. Nikkomycins have been found to inhibit chitin synthase (66). The benanomicins and pradimicins show calcium-dependent interference with the organization of cell wall mannoproteins but have been abandoned for further development (120).

The sordarins interfere specifically with the fungal protein elongation process through interference with elongation factor 2 (EF2)(27). Aureobasidin (32) and khafrefungin (60) were found to interfere with the inositol phosphoceramide synthase enzyme in the sphingolipid synthesis pathway.

\section{Resistance}

\section{Definitions}

The focus of this work is the mode of resistance by fungi to azole antifungal agents. Major mechanisms of resistance to other, non-azole antifungals will also be included, especially when those mechanisms have not yet been demonstrated to pertain to azoles. Until the late 1980 's, only sporadic resistance to antifungals was reported, whereas by contrast, a plethora of studies appeared in the last decade. Multiple attempts were made to define what is meant by "resistance". The proposal of Kerridge et al. (51) was: "a drug-resistant pathogenic fungus is 


\section{Chapter 1}

an organism that will grow and produce clinical symptoms of disease in the presence of the drug at the maximal concentration at the site of infection". Johnson 't al. gave a three-part definition (47). Resistance is clinical failure of a patient to respond to azole therapy; it involves strains where MIC values of the agent in vitro are well in excess of those for other strains; and it is a therapeutic failure in association with high or rising MIC values (47). Dupont made a distinction between clinical resistance (treatment failure), defined as "persistence of clinical lesions despite the treatment prescribed at a dose known to be usually effective" and mycological resistance, defined as "a decrease of in vitro susceptibility compared to MICs for isolates easily cleared by the antifungal" (30). From a mycological viewpoint, different classifications of resistance can be made. A species will be regarded as "intrinsically" resistant when it is not included in the normal spectrum of a given antifungal compound. For example C. krusei (115) and $C$. norvegensis (87) can be regarded as intrinsically resistant to fluconazole, and $C$. parapsilosis and Trichosporon beigelii are refractory, or intrinsically resistant, to amphotericin B (2l). By contrast, "acquired" resistance is found in isolates belonging to a species which is normally susceptible to the compound. It is this form of resistance, caused by mutation or adaptation, that is the major concern in the clinic. "Selective" resistance can occur when a patient is colonized with multiple species or strains. During treatment, the most sensitive isolates are eradicated, favoring the growth and selection of less sensitive or resistant ones. "Phenotypic" resistance is used when a strain develops a progressive increase in resistance during continued incubation in the presence of antifungal compound. In contrast, "genotypic" resistance is a feature of the clone and is inherited by daughter cells.

\section{Factors contributing to resistance}

From these definitions it is clear that the origin of antifungal resistance is multifactorial and results from a combination of circumstances related to the host, the antifungal and the pathogen as shown in FIG. 6. The immune competence status of the host is an important factor in the occurrence of resistance. Indeed, until the late 1980's, azole resistance was only sporadically reported and always in patients suffering from chronic mucocutaneous candidiasis (CMC), who 
received antifungal therapy over an unusually long period of time. It was the increase in the number of immunocompromised patients, particularly as a result of the AIDS pandemic, that preceded the sudden increase of reports on clinical failure to antifungal therapy. The crucial importance of an intict immune system can be related to the fungistatic mode of action of azole antifungals, which implies that part of the clearance of the infection is accomplished by host related factors. A defect in these systems allows residual fungal growth and could provide ideal circumstances for the selection or induction of resistant isolates. The site and severity of infection could also favor residual colonization because the pharmacokinetics of azoles are such that not all organs reach the sime level of antifungal concentration. The patients' compliance with the prescribed drug regimen is another reason why insufficient antifungal may reach the focus of infection. Insufficient dosage, decreased absorption from the gut, abnormal distribution or increased metabolic degradation of the antifungal agent in the patient all result in an insufficient concentration of active drug at the site of infection. Biofilm formation on catheters, prosthetic equipment or dentures has been shown to be a cause of persistent infection and is difficult to treat (38). Removal is usually the only solution to eradicate the infection. If fungal infection was diagnosed erroneously, it is clear that no clinical improvement is to be expected, but this situation can create a false impression of resistance to treatment.

The precise identification, to species level, of the fungus causing clinical symptoms is also of importance because of differences in the antifungal susceptibility spectrum, even within a single class of antifungals. As stated above, e.g. fluconazole is regarded as intrinsically inactive against a number of Candida species; infection caused by these organisms will not be cleared with this azole, but could be improved just by changing to a azole compound that does include these species into its spectrum.

Several factors related to susceptibility test methods can contribute to a false perception of resistance in a fungus. As with antibacterial susceptibility tests, differences in medium composition and $\mathrm{pH}$, inoculum size, incubation temperature, test duration and endpoint assessment lead to differences in reported outcome: interlaboratory differences of three orders of magnitude have been noted 


\section{Antifungal}

\author{
Spectrum \\ Fungistatic-fungicidal \\ pharmacokinetics \\ Adequate dosage
}

\section{Pathogen}

Susceptibility

Species

Genomic stability

Biofilm formation

Extent of infection

\section{Host}

Immune competence Site and severity of infection Use of catheters. prosthetics Compliance to treatment Underlying diseases Metabolic activity
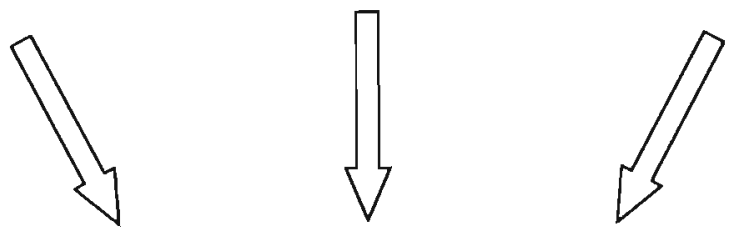

\section{Clinical Resistance}

FIG. 6. Factors that contribute to clinical resistance can be classified in three groups: host-related, antifungal drug-related and related to the colonizing pathogen.

in antifungal MICs despite good intralaboratory reproducibility $(43,72)$.

Through the $1990^{\circ}$ s, the U.S. National Committee for Clinical Laboratory Standards (NCCLS) strove to develop a stringent MIC reference method for yeast susceptibility testing that allowed different laboratories to achieve comparable results (72).

Some fungal isolates develop resistance readily upon exposure to certain antifungals, possibly indicating differences in genetic stability between species and strains. Primary resistance to 5-fluorocytosine is seen in about 5-10\% of C. albicans isolates. During treatment with $5 \mathrm{FC}$ as monotherapy, up to $67 \%$ of the yeasts isolated have developed resistance $(55,93)$. Fluconazole resistance is readily induced in Candida dubliniensis (68). The inherent insensitivity of some isolates to particular antifungal agents and the ease with which others alter to a phenotype of lowered susceptibility underpin the selection and overgrowth of 
less sensitive isolates in the clinic that was already mentioned previously. A distinction can thus be made between clinical failure of a patient to respond to antifungal treatment - often described as resistance but not always attributable to a truly resistant fungus - and microbiological resistance, in which a fungal isulate can be shown in vitro to have reduced susceptibility to a particular agent. The boundary between "resistant" and "susceptible" is not a sharp cut-off, as these words suggest. Indeed the concept of a clear difference between these properties based on a rational "breakpoint" of quantitative susceptibility is not supported by studies in which clinical treatment outcomes are related to breakpoint. Although rates of positive clinical responses tend to be lower for patients infected with organisms (bacteria or fungi) designed as "resistant" to an agent in vitro, by no means all such patients fail on treatment (75).

\section{Biochemical mechanisms of resistance}

From a biochemical point of view the only important factors are those attributed

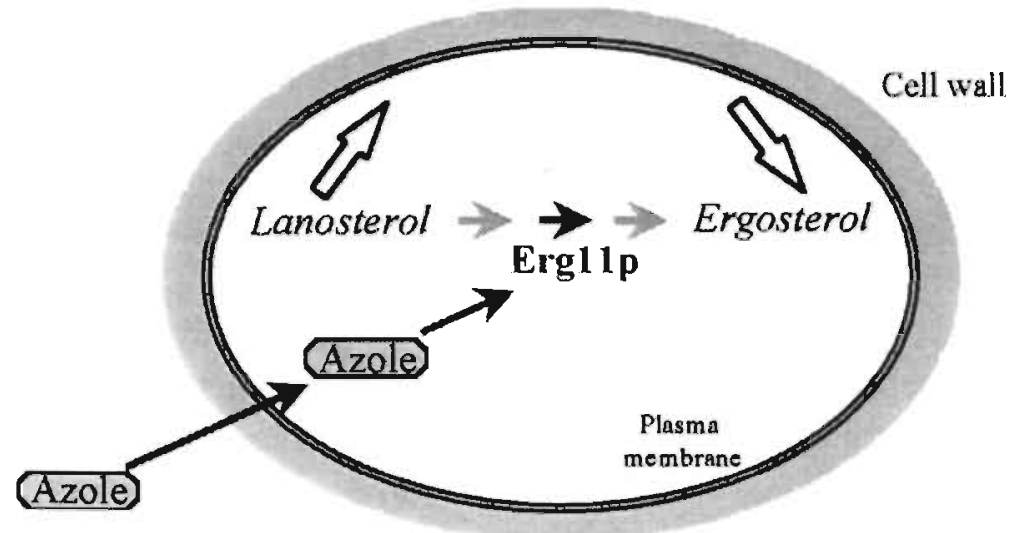

\section{Sensitive cell}

FIG. 7. Schematic presentation of prerequisites for antifungal activity. The compound should enter the cell and reach its target inside the cell. For the azoles this is the cytochrome P450 14a-demethylase enzyme (Erg11p) in the ergosterol pathway. This results in the depletion of ergosterol and the accumulation of membrane-disturbing sterol precursors. 


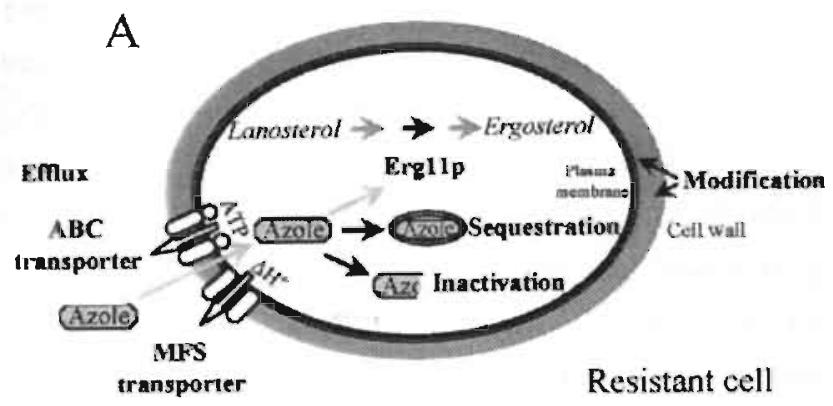

B

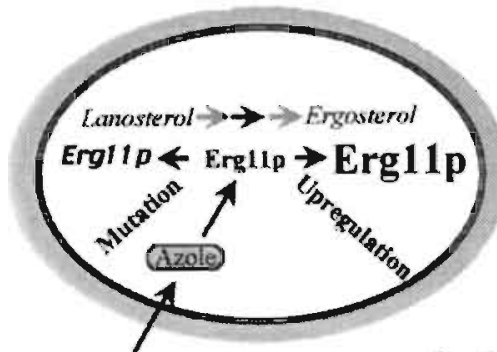

(ब20)

Resistant cell

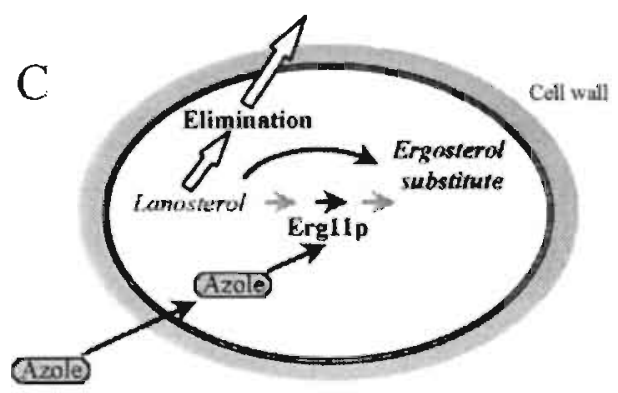

Resistant cell

FIG. 8. Factors that contribute to azole resistance. A) Factors that prevent activ azole from reaching its target: changes in the cell envelope (cell wall plasmamembrane), (over)-expression of efflux pumps either from the MFS type or from the ABC-type and, intracellular sequestration or inactivation B) Factors that interfere with the inhibition: upregulation or mutation of th target. C) Factors that nullify or compensate for the azole-induced toxi consequences: elimination of toxic intermediates, substitution of ergos terol. 
to the pathogen itself, which lead to a measurable decrease in susceptibility to an inhibitory agent in vitro. In the remaining part of the introduction I will list the possible factors that could contribute to antifungal resistance in vitro. with focus on the azoles. In a sensitive cell, an azole should cross the cell envelope and find its way inside the cell to the target, the cytochrome P450 14 $\alpha$-demethylase. Binding to this enzyme results in the depletion of ergosterol and accumulation of 14-methylated precursors (FIG. 7). These changes induce typical azole-related structural alterations and result, as described previously, in inhibition of growth.

The fungal pathogen can adopt three general mechanisms to become less susceptible to antifungal attack. The first mechanism (FIG. 8A) is to prevent an adequate amount of active antifungal from reaching its target. The second mechanism (FIG. 8B) is to interfere with the structure or quantity of the antifungal target and thus alter the stoichiometry of the inhibitory effects. The third way to reduce susceptibility (FIG. 8C) is to nullify or to compensate for the consequences of antifungal attack. The exchange of genetic material by transiluction or conjugation, frequently found to lead to antimicrobial resistance in prokaryotes, has not been demonstrated in clinical fungal isolates.

\section{1) Mechanisms to prevent the active antifungal from reaching its target}

\section{Uptake and efflux}

It is obvious that an impaired uptake of an antifungal agent directly decreases the concentration of azole at the target site. C. albicans and Aspergillus spp. are intrinsically resistant to griseofulvin because in these organisms, griseofulvin enters the cells with an energy-independent transport system, whereas dermatophytes are equipped with a prolonged energy-dependent transport system (31). Technical difficulties in measurement of real uptake of inhibitors are huge, because it necessitates separation of import from efflux mechanisms and this has not been done with azoles for any medically important fungi. Instead most pe(1ple measure the gross levels of drug inside the cell, often showing changes with time, but this measurement is the net result of import and efflux. Changes in cell 


\section{Chapter 1}

wall composition or in degree of cross-linking of the structural polymers have so far been shown to be of importance only for phenotypic resistance seen with stationary C. albicans cells to amphotericin B; not yet for azoles (52). Although Hitchcock et al. suggested that a higher sterol to phospholipid ratio in fungal membranes correlated with azole-resistant isolates (42), there is now a consensus that efflux pumps are a far more common cause of decreased intracellular content of azoles. This phenomenon was reported as far back as 1980 by De Waard and Van Nistelrooy, who described the energy dependent efflux of fenarimol in Aspergillus nidulans (23) and in 1984 by Ryley et al. in C. albicans (86). At the moment two types of efflux pumps are known, the "major facilitators superfamily" (MFS) which derive their energy from a proton gradient across the membrane (36) and the "ATP-binding cassette"-containing pumps (ABC), that utilize ATP as their source of energy (18). The pumps shown so far to be involved in antifungal resistance all have 12-membrane spanning helices in their protein structure $(33,83,88)$. A topological representation is shown in FIG. 9 for both types of pumps. The ABC-type transporters found in fungi have two homologous halves, each with a $\mathrm{N}$-terminal hydrophilic domain with consensus ATP-binding region and a $\mathrm{C}$-terminal hydrophobic domain with six transmembrane helices. They are mirror images of mammalian P-glycoproteins (18). The presence of numerous post-translational modification sites suggests that the activity of the pumps can be extensively regulated (88). It is hypothesized that the 12 membrane spans cluster together (28). In $C$. albicans more than ten different $A B C$-type transporters have been claimed (65), but until now only the pumps encoded by $C D R I$ and $C D R 2$ have been definitively shown to be linked to efflux of azole antifungals $(83,88)$. CaMDRI and Flul are genes identified in $C$. albicans, encoding for MFS type pumps $(33,69)$. Examples of both types of pumps have been found in other human pathogenic fungi. For example a Saccharomyces cerevisiae RGT2 homologue was found in Cryptococcus neoformans (96) and AfuMDRI is an ABC-type pump in A. fumigatus (99). Both types of pumps seem to be widely distributed in nature, as summarized in Table I. Because the systematic sequencing of the genome of Saccharomyces cerevisiae pointed to the presence of $29 \mathrm{ABC}$ transporters (18) and 28 MFS transporters (36), multiple efflux pump genes are probably yet to be detected in path- 
A
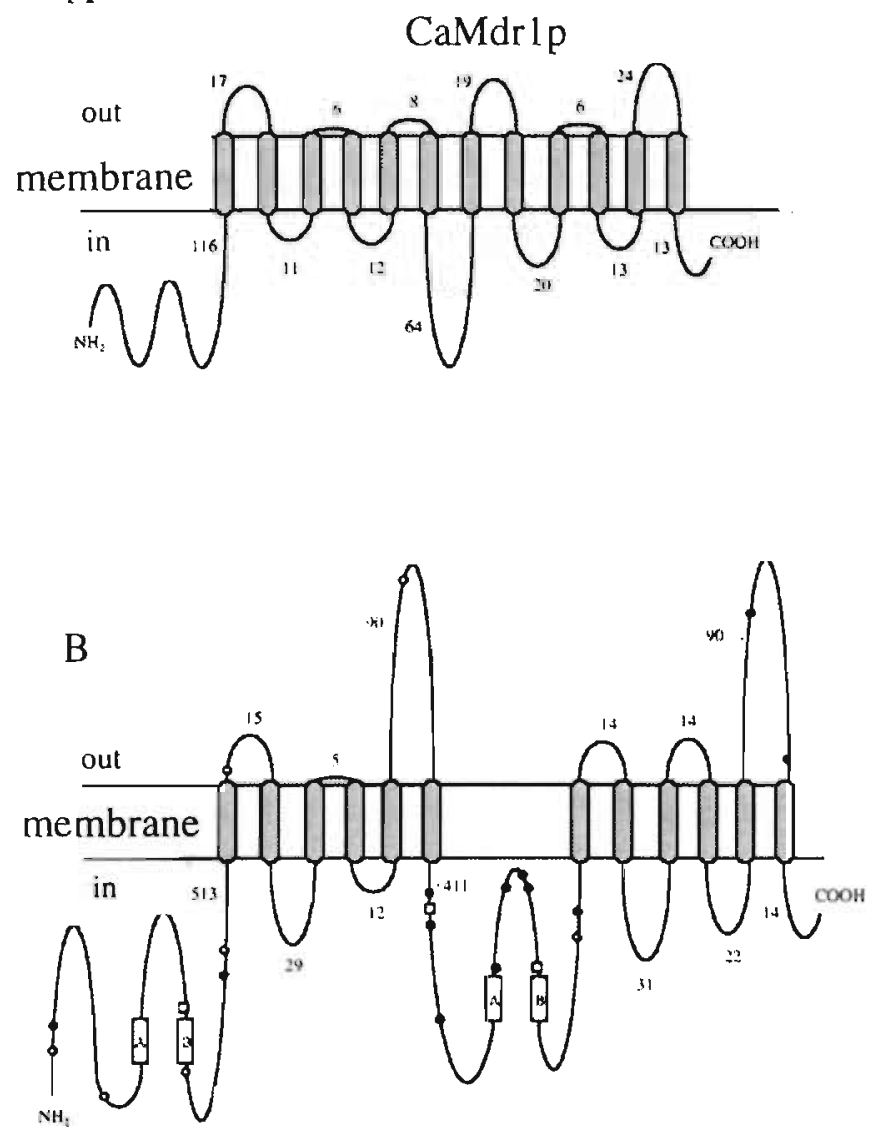

CaCDR $1 p$

FIG. 9. Predicted topology of A) the Candida albicans CaMdr1p, member of the major facilitator superfamily and, B) the Candida albicans $\mathrm{CaCdr} 1 \mathrm{p}$, member of the ATP-binding-cassette transporter family. The membrane spans are represented by filled ovals. The number of amino acids in the connecting loops are indicated next to each loop. Putative $\mathrm{N}$-glycosylation sites $(O)$, protein kinase $C$ phosphorylation sites $(O)$ and cAMP/cGMP dependent protein kinase phosphorylation sites $\square$ are indicated. The Walker A and Walker B ATP-binding sites are represented by boxes. Nineteen putative $\mathrm{N}$-myristylation sites or twenty five putative casein kinase II phosphorylation sites are not indicated. 
ogenic fungi. Although all these proteins are described as multi-drug resistant proteins, they each have a different range of substrate specificity (53). It was even experimentally demonstrated that not all compounds bind to the same transmembrane region (121).

Functional assays have demonstrated that $\mathrm{Cdr} \mathrm{lp}$ and $\mathrm{Cdr} 2 \mathrm{p}$ respond to itraconazole, fluconazole, ketoconazole, terbinafine and amorolfine as substrates, whereas CaMdr I $p$ only expels terbinafine and fluconazole, not molecules such as itraconazole. Because differences exist even within a single class of inhibitors, extrapolation of the known substrate specificity of a given pump to other antifungals or to homologous efflux pumps should be accompanied by experimental evidence. It has to be emphasized that not all members of the ABC-transporters or MFS are involved with drug efflux. Moreover, for the majority of them neither the precise cellular function is clear nor is it known how these proteins accomplish the export of compounds across the membranes (53).

In $S$. cerevisiae at least two networks of transcription factors are involved in the regulation of its MDR efflux pumps. One network is regulated by Yaplp and Yap2p, both having a leucine zipper dimerization domain ( 1 ). These transcription factors regulate at least the expression of $F L R I$, a MFS member in $S$. cerevisiae. A functional and structural homologue $C A P I$ was identified in C. albicans: its overexpression induced CaMDRI and fluconazole resistance (1). $\mathrm{Pdrl} p$ and $\mathrm{Pdr} 3 \mathrm{p}$ are two homologous transcription factors belonging to the $\mathrm{Zn}_{2}$ $\mathrm{Cys}_{6}$ binuclear zinc cluster family and have been shown to control the expression of the ABC-type transporters genes PDR5, SNQ2 and YORI (5). Recently the $C$. albicans genes $F C R I, F C R 2$ and $F C R 3$ were identified by functional complementation of fluconazole hypersensitivity in a $S$. cerevisiae strain lacking Pdrlp and Pdr3p (98). The FCRI gene also belongs to the $\mathrm{Zn}_{2}-\mathrm{Cys}_{6}$ binuclear zinc cluster family and was described as a negative regulator of drug resistance in C. albicans (98). The C. albicans CDRI gene is stress-inducible (54). The tandem repeat of heat shock elements (HSE) present in its promoter region could be located at the origin of the induction. These tandem repeats are also present in the promoters of the S. cerevisiae PDR5 and in several mammalian MDR proteins (83). Hernaez et al. used confocal microscopy to show that a yEGFPCdrlp chimeric protein (yeast enhanced green fluorescent protein) localized dif- 
Table I : Multidrug transporters identified in Fungi. ABC = ATP-binding cassette type of efflux pump; MFS = Major Facilitator Superfamily

\begin{tabular}{|c|c|c|c|c|c|c|c|}
\hline Species & gene & lype & ref & Species & gene & type & ref \\
\hline Candida albicans & $C a C D R I$ & $A B C$ & 83 & Saccharomyces cerevisiae* & PDR5 & $A B C$ & 4 \\
\hline Candida albicans & $C a C D R 2$ & $A B C$ & 88 & Saccharomyces cerevisiae & SNQ2 & $A B C$ & 17 \\
\hline Candida albicans & $\mathrm{CaCDR} 3$ & $A B C$ & 2 & Saccharomyces cerevisiae & FLRI & MFS & 1 \\
\hline Candida albicans & $\mathrm{CaCDR4}$ & $\mathrm{ABC}$ & 34 & Saccharomyces cerevisiae & YORI & $A B C$ & 17 \\
\hline Candida albicans & CaCDR5 & $A B C$ & 90 & & & & \\
\hline Candida albicans & CAYORI & $A B C$ & 76 & Schizosaccharomyces pombe & $B f r l$ & $A B C$ & 70 \\
\hline Candida albicans & CaMDRI/BEN $N^{r}$ & MFS & 33 & Schizosaccharomyces pombe & $H B A 2$ & $\mathrm{ABC}$ & 101 \\
\hline Cimdida albicans & Flul & MFS & 90 & Schizosaccharomyces pombe & CARI & MFS & 46 \\
\hline Candida glabrata & $C_{g} C D R I$ & $\mathrm{ABC}$ & 89 & Aspergillus fumigatus & AfulHDRI & $A B C$ & 99 \\
\hline Candida glabrala & $C_{g} C D R 2$ & $A B C$ & 89 & Aspergillus fumigatus & AfuMDR2 & $\mathrm{ABC}$ & 99 \\
\hline Candida glabrala & PDHI & $A B C$ & 67 & & & & \\
\hline Candida glabrasa & CgMDRI & MFS & 89 & Aspergillus flavus & A/MDRI & $A B C$ & 99 \\
\hline Candida dubliniensis & $C d C D R I$ & $A B C$ & 69 & Aspergillus nidulans & ATRA & $A B C$ & 20 \\
\hline Candida dubliniensis & CdCDR2 & $A B C$ & 69 & Aspergillus nidulans & $A T R B$ & $A B C$ & 20 \\
\hline \multirow[t]{2}{*}{ Candida dubliniensis } & CdMDRI & MFS & 69 & & & & \\
\hline & & & & Penicillium digiratum & PMRI & $\mathrm{ABC}$ & 71 \\
\hline Candida krusei & $A B C l$ & $A B C$ & 49 & & & & \\
\hline Candida krusei & $A B C 2$ & $\mathrm{ABC}$ & 49 & Botrytis cinerea & BMRI & $A B C$ & 97 \\
\hline Conptococcies neoform & ans HTLI & MFS & 96 & & & & \\
\hline
\end{tabular}

* For Saccharomyces cerevisiae only the genes known to be involved in antifungal drug resistance are shown.

ferently upon induction (40). It is clear that these efflux pumps will remain a topic of considerable attention in the scientific community.

\section{Inactivation and sequestration}

Once an antifungal agent has gained access to the cytoplasm, three other events could prevent a compound excerting its activity: degradation, inactivation or 


\section{Chapter 1}

Lapture or sequestration into membranes or organelles. Up to now, no evidence for degradation of an azole antifungal has been seen in fungal cells; only the original active ingredient has ever been recovered from fungal homogenates. Activity of the azoles depends partly on the binding of the unhindered and unprotonated nitrogen atom to the iron atom in the heme group of P450 (106). Imidazole compounds have a $\mathrm{pK}_{\mathrm{a}}$ of 6.5 and as such are prone to protonation at an acidic intracellular $\mathrm{pH}$. Acidification of the intracellular $\mathrm{pH}$ below the $\mathrm{pK}_{\mathrm{a}}$ value therefore results in inactivation of imidazole-based compounds. Triazole derivatives have a $\mathrm{pK}_{\mathrm{a}}$ of 2.0 or lower and are not susceptible to this kind of inactivation. This difference amounts to a type of "resistance" that could contribute to the lower activity of imidazoles against $A$. fumigatus (106). In theory, a cell could protect itself from antifungal attack by sequestration of the antifungal into vesicles, into an organelle such as the central vacuole or by facilitating binding of an agent to redundant proteins.

\section{2) Mechanisms to interfere with the interaction between an inhibitor and its target.}

Because azole molecules form a stoichiometric complex with their primary target, the cytochrome P450 14 $\alpha$-demethylase (Ergl lp), an increase in target concentration necessitates higher intracellular concentrations of the azole to achieve full inhibition. The cellular concentration of the Ergl lp is dependent on growth conditions and varies with carbon source, oxygen concentration and growth state. The $S$. cerevisiae promoter region contains two upstream activation sequences and possibly two upstream repressor sequences (100). Expression of the cytochrome is coordinately regulated with the NADPH-cytochrome P450 reductase (100). Overexpression of the cytochrome P450 14 $\alpha$-demethylase in $S$. cerevisiue results in mild resistance. Only when both the cytochrome and its reductase are overexpressed is maximal induction of resistance seen $(99 \alpha)$. This was recently corroborated in A. niger by Vanden Brink et al (102).

Point mutations that change the affinity of the azole to its target could also result in resistance. This was suggested by biochemical data (109) and by combination of biochemical information with sequence analysis. This latter approach identified $\mathrm{Y} 132 \mathrm{H}$ (tyrosine 132 is replaced by a histidine) (91), T315A (threonine 315 
replaced by alanine) (58) or R476K (arginine 476 replaced by lysine) (118) mutations that have been shown to decrease the affinity of the target for an azole. Numerous publications have listed other ERGI/ mutations, but unfortunately the effect of the mutation on azole sensitivity was not always tested.

Because azoles also inhibit the cytochrome P450-catalyzed $\triangle 22$ desaturation (114) (ERG5, CYP6I), it can be hypothesized that an increase of this non-essential enzyme would capture sufficient azole to prevent the inhibition of the 14demethylation reaction. So far, however, no biochemical evidence hats been presented to support this hypothesis.

\section{3) Mechamisms to by-pass the consequences of inhibition}

The third system the cell could use to achieve antifungal resistance is to circumvent or nullify the toxic consequences from the interference with sterol biosynthesis. Azole-induced growth inhibition is caused by both the depletion of ergosterol needed to perform some sparking hormonal function and the accumulation of membrane-disturbing precursors. If a cell can excrete or remove these toxic precursors into the vacuole, part of the azole effect is avoided. In the resistant strains examined so far, no differences in excretion of precursors from the cell were found. The sparking role of ergosterol can also be fulfilled by sufficient quantities of 14-methylfecosterol (117). This product will accumulate after azole treatment if the cell is deficient in the $\Delta^{8.7}$ isomerase and or $\Delta^{5,6}$ desaturase. Indeed, this effect has been described in the "Darlington" strain (44), an azole-resistant isolate studied by different laboratories and reported by Kelly et al. (50). In $S$. cerevisiae it has also been shown that a $14 \alpha$-demethylase deficiency could be rescued by a concomitant deficiency in another enzyme of the ergosterol pathway, the $\Delta^{5.6}$ desaturase (6). However, it is not reasonable to extrapolate findings from $S$. cerevisicie to Candida spp. or to other pathogens because there seems to be a species-dependent tolerance for certain sterol intermediates (50).

\section{Clonal relatedness of isolates}

For the analysis of molecular mechanisms of resistance in clinical isolates it is almost imperative to use clonally related pairs of isolates, a sensitive and a resis- 


\section{Chapter 1}

tant one. To demonstrate clonal relatedness several techniques can be used. Restriction fragment length polymorphism (RFLP) analysis (78), preferentially with subsequent hybridization with repetitive sequence oligonucleotide probes such as. Ca3 or $27 \mathrm{~A}$ for Candida albicans, is the most frequently used approach (92). Random amplified polymorphic DNA (RAPD) PCR (21) using repetitive primers, e.g. (GACA) $)_{4}$ or (GTG) 5 or arbitrarily primed PCR (AP-PCR) (87) are alternative techniques to produce isolate-dependent fingerprints. Other methods such as karyotyping $(24,25)$, multilocus enzyme electrophoresis enzyme (12) or direct sequencing of a piece of DNA (64) are also possible. For the sequencing it is, however, advisable to choose a gene that is not involved in the mode of action of the antifungals used. In practice it is common to use different methods to increase the probability of clonal relatedness.

\section{Aim of the study}

The goal of this study was to obtain further insights in fungal mechanisms of susceptibility or resistance to azole antifungal compounds in a variety of clinically important fungal pathogens, most of them refractory to treatment. In most of the studies, the triazoles fluconazole and itraconazole were used. Three chapters (2-4) deal with the $C$. albicans isolates, the most frequently found pathogen, whereas two chapters $(5,7)$ are devoted to other Candida spp. The two remaining chapters $(6,8)$ involve $C$. neoformans and $H$. capsulatum isolates. The final aim is to learn from these case studies, and to convert the identified key features into criteria and test systems to select for better and safer antifungal compounds. In addition, we would like to identify some guidelines to perform biochemical analysis of azole resistance in clinical isolates. 


\section{References}

I Alarco A.-M., I. Balan, D. Talibi, N. Mainville and, M. Raymond. 1997. API-mediated multidrug resistance in Saccharomyces cerevisiae requires FLRI encoding a transporter of the major facilitator superfamily. J. Biol. Chem. 272(31): 19304-19313.

Balan I., A. M. Alarco, M. Raymond. 1997. The Candida albicans CDR3 gene codes for an opaque-phase $\mathrm{ABC}$ transporter. J. Bacteriol. 179(23): 7210-7218.

Baloch R. I. and E. I. Mercer. 1987. Inhibition of sterol $\Delta^{8-7}$-isomerase and $\Delta^{14}$-reductase by fenpropimorph, tridemorph, and fenpropidin in cell-free enzyme systems from Saccharomyces cerevisiae. Phytochemistry 26: 663-668.

Balzi E., M. Wang, S. Leterme, L. Van Dyck, and A. Goffeau. 1994. PDR5, a novel yeast multidrug resistance conferring transporter controlled by the transcription regulator PDRI. J. Biol. Chem. 269: 2206-2214.

Balzi E. and A. Goffeau. 1995. Yeast multidrug resistance: the PDR network. J, Bioenerg. Biomembr. 27: 71-76.

Bard M., N. D. Lees, T. Turi, D. Craft, L. Cofrin, R. Barbuch, C. Koegel, and J. C. Loper. 1993. Sterol synthesis and viability of ERGIl (cytochrome P450 lanosterol demethylase) mutations in Sacharomyces cerevisiae and Candida albicans. Lipids 28 : $963-967$.

Barrett-Bee K. J., A. C. Lane, and R. W. Turner. 1986. The mode of action of tolnaftate. J. Med. Vet. Mycol. 24: 155-160.

Barrett-Bee K., and G. Dixon. 1995. Ergosterol biosynthesis inhibition: a target for antifungal agents. Acta Biochim. Pol. 42(4): 465-480.

Ben-Yaacov R., S. Knoller, G. A. Caldwell, J. M. Becker, and Y. Koltin. 1994. Candida albicans gene encoding resistance to benomyl and methotrexate is a multidrug resistance gene. Antimicrob. Agents Chemother. 38(4): 648-652.

Blinzler L., K. Fischer, H. M. Just, and D. Heuser. 1997. Importance of mycoses in intra-abdominal infections. Langenbecks Arch. Chir. 382 (4 suppl 1): S5-8.

11 Blows W. M., G. Foster, S. J. Lane, D. Noble, J. E. Piercey, P. J. Sidebottom, and G. Webb. 1994. The squalestatins, novel inhibitors of squalene synthase produced by a species of Phoma. J. Antibiot. 47: 740-54.

Boerlin P. 1997. Applications of multilocus enzyme electrophoresis in medical microbiology. J. of Microbiol. Methods 28: 221-231. 


\section{Chapter 1}

37 Hartman P. G., Sanglard D. 1997. Inhibitors of ergosterol as antifungal agents. Curr. Pharm. Des. 3: 177-211K.

38 Hawser S. P. and L. J. Douglas. 1995. Resistance of Candida albicans biofilms to antifungal agents in vitro. Antimicrob. Agents Chemother. 39(9): 2128-31.

39 Hazen K. C. 1995. New and emerging yeast pathogens. Clin. Microbiol. Rev. 8: 462-478.

4) Hernaez M. L., C. Gil., J. Pla, and C. Nombela. 1998. Induced expression of Candida albicans multidrug resistance gene $C D R I$ in response to fluconazole and other antifungals. Yeast 13: 517-526.

41 Hippocrates. Circa 460-377 B. C. Epidemics, book 3. Translated by F. Adams, 1939. Baltimore: Williams and Wilkins.

42 Hitchcock C. A., K. J. Barrett-Bee, and N. J. Russell. 1986. The lipid composition of azole-sensitive and azole-resistant strains of Candida albicans. J. Gen. Microbiol. 132: 2421-2431.

43 Hitchcock C. A. 1993. Resistance of Candida albicans to azole antifungal agents. Biochem. Soc. Trans. 21: 1039-1047.

44 Howel S. A., A. I. Mallet, and W. C. Noble. 1990. A comparison of the sterol content of multiple isolates of the Candida albicans Darlington strain with other clinically azole-sensitive and-resistant strains. J. Appl. Bacteriol. 69: 692-696.

45 Jandrositz A., F. Turnowsky, and G. Högenauer. 1991. The gene encoding squalene epoxidase from Saccharomyces cerevisiae : cloning and characterization. Gene 107: 155160.

46 Jia Z. P., N. McCullough, L. Wong and, P. G. Young. 1993. The amiloride resistance gene, CARl, of Schizosaccharomyces pombe. Mol. Gen. Genet. 241(3-4): 298-304.

47 Johnson E. M., and D. W. Warnock. 1995. Azole drug resistance in yeast. J. Antimicrob. Chemother. 36: 75।-755.

Karlowsky J. A., G. G. Zhanel, K. A. Klym, D. J. Hoban and, A. M. Kabani. 1997. Candidemia in a Canadian tertiary care hospital from 1976 to 1996. Diagn. Microbiol. Infect. Dis. 29(1): 5-9.

Katiyar S. K. and T. D. Edlind. 1998. Identification of Candida krusei Multidrug resistance genes: potential role in azole resistance. In Program and Abstracts of the $38^{\text {th }}$ Interscience Conference on Antimicrobial Agents and Chemotherapy. San Diego.California. US,, 1998. Abstract C-153. American Society for Microbiology, Washington, DC. 
50 Kelly S. L., D. C. Lamb, D. E. Kelly, N. J. Manning, J. Loeffler, H. Hebart, U. Schumacher, and H. Einsele. 1997. Resistance to fluconazole and cross-resistance to amphotericin B in Candida albicans from AIDS patients caused by defective sterol delta5,6-desaturation. FEBS Lett. 400(1): 80-82.

51 Kerridge D., R. O. Nicholas and, F. J. Wayman. 1987. Resistance to clinically important antimycotic drugs in Candida spp. Ann. Ist. Super Sanita 23(4): 827-834.

52 Kerridge D., M. Masoli, and F.J. Wayman. 1988. Drug resistance in Candida albicans and Candida glabrata. Ann. N. Y. Acad. Sci. 544: 245-259.

53 Kolaczkowski M., A. Kolaczkowska, J. Luczynski, S. Witek, and A. Gofreau.1998 In vivo characterization of the drug resistance profile of the major $\mathrm{ABC}$ transporters and other components of the yeast pleiotrophic drug resistance network. Microb. Drug Resist. 4(3): 143-158.

54 Krisnamurthy S., V. Gupta, R. Prasad, S. L. Panwar, and R. Prasad. 1998. Expression of $C D R I$, a multidug resistance gene of Candida albicans: transcriptional activation by heat shock, drugs and human steroid hormones. FEMS Microbiol. Lett. 160: 19I-197.

55 Krucers A., and N. Bennett. 1987. 5-Fluorocytosine. In: The use of antibiotics, ed 4., JB Lippincott, Philadelphia, 1446.

56 Kuchta T., K. Bartkova, and R. Kubinic. 1992. Ergosterol depletion and 4-methyl sterols accumulation in the yeast Saccharomyces cerevisice treated with an antifungal 6 amino-2-N-pentyl thiabenzothiazole. Biochem. Biophys. Res. Commun. 189: 85-91.

57 Kwon-Chung K. J., and J. E. Bennett. (1992). Medical Mycology, Lea \& Febiger, Philadelphia. p 3.

Lamb D. C., D. E. Kelly, W.-H. Schunck, A. Z. Shyadehi, M. Akhtar, D. Lowe, B. Baldwin, and S. L. Kelly. 1997. The mutation T315A in Candida albicans sterol 14 $\alpha$ demethylase causes reduced enzyme activity and fluconazole resistance through reduced affinity. J. Biol. Chem. 272: 5682-5688.

59 Lorenz T. and L. Parks. 1992. Cloning, sequencing, and disruption of the gene encoding sterol C-14 reductase in Saccharomyces cerevisiae. DNA Cell Biol. 11: 685-692.

60 Mandala S. M., R. A. Thornton, M. Rosenbach, J. Milligan, M. Garcia-Calvo, H. G. Bull, and M. B. Kurtz. 1997. Khafrefungin, a novel inhibitor of sphingolipid synthesis. J. Biol. Chem. 272: 32709-32714.

61 Margariti P. A., A. L. Astorri, C. Mastromarino, and G. Morace. 1997. Mycotic vulvovaginitis. Recenti Prog. Med. 88(10): 479-484. 
Marichal P., J. Gorrens, H. Vanden Bossche. 1985. The action of itraconazole and ketoconazole on growth and sterol synthesis in Aspergillus fumigatus and Aspergillus niger. Sabouraudia. 22: 13-21.

Marichal P., H. Vanden Bossche, H. Moereels, and R. Brasseur. 1990. Mode of insertion of azole antifungals and sterols in membranes. In: "Molecular Description of biological membranes by computer aided conformational analysis, vol 2, R. Brasseur, ed., CRC Press, Boca Raton., pp 27-42.

Marichal P., J. Gorrens, L. Laurijssens, K. Vermuyten, C. Van Hove, L. Le Jeune, P. Verhasselt, D. Sanglard, M. Borgers, F. C. S. Ramaekers, F. C. Odds, and H. Vanden Bossche. 1999. Chapter 3.

Marr K., C. N. Lyons, T. Rustad, R. A. Bowden, and T. White. 1998. Rapid, transient fluconazole resistance in Candida albicans is associated with increased mRNA levels of CDR. Antimicrob. Agents Chemother. 42(10): 2584-2589.

McCarthy P. J., P. F. Troke, K. Gull. 1985. Mechanism of action of nikkomycin and the peptide transport system of Candida albicans. J. Gen. Microbiol. 131(4):775-780.

Miyazaki H., Y. Miyazaki, A. Geber, T. Parkinson, C. Hitchcock, D. J. Falconer, D. J. Ward, K. Marsden, and J. E. Bennett. 1998. Fluconazole resistance associated with drug efflux and increased transcription of a drug transporter gene, PDHI, in Candida glabrata. Antimicrob. Agents Chemother. 42(7): 1695-1701.

Moran G. P., D. J. Sullivan, M. C. Henman, C. Mc Creary, B. J. Harrington, D. B. Shanley, and D. C. Coleman. 1997. Antifungal drug susceptibilities of oral Candida dubliniensis isolates from Human Immunodeficiency Virus (HIV)-infected and non-HIVinfected subjects and generation of stable fuconazole-resistant derivatives in vitro. Antimicrob. Agents Chemother. 41(3): 617-623.

69 Moran G. P., D. Sanglard, S. M. Donnelly, D. B. Shanley, D. J. Sullivan, and D. C. Coleman. 1998. Identification and expression of multidng transporters responsible for fuconazole resistance in Candida dubliniensis. Antimicrob. Agents Chemother. 42(7): $1819-1830$.

70 Nagao K., Y. Taguchi, M. Arioka, H. Kadokura, A. Takatsuki, K. Yoda, and M. Yamasaki. 1995. bfr', a novel gene of Schizasaccharomyces pombe which confers brefeldin A resistance, is structurally related to the ATP-binding cassette superfamily. J. Bacteriol. 177(6): 1536-1543.

7 Nakaune R., K. Adachi, O. Nawata, M. Tomiyama, K. Akutsu, and T. Hibi. 1998. A novel ATP-binding cassette transporter involved in multidrug resistance in the phytopathogenic fungus Penicilliam digitatum. Appl. Environ. Microbiol. 64: 3983-3988. 
National Committee for Clinical Laboratory Standards. 1995. Reference method for broth dilution susceptibility testing of yeasts. Tentative standard M27-A. National Committee for Clinical Laboratory Standards, Villanova, $\mathrm{Pa}$.

73 Nes W. R., B. C. Sekula, W. D. Nes, and J. H. Adler. 1978. The functional importance of structural teatures of ergosterol in yeast. J. Biol. Chem. 253: 6218-6225.

74 Nozawa Y., and T. Morita. 1992. Biochemical aspects of squalene epoxidase inhibition by a thiocarbamate derivative, naphtiomate $T$. In: Recent progress in antifungal Chemotherapy. Yamaguchi H., G. S. Kobayashi, and H. Takahashi (Eds.), Marcel Dekker Inc., New York, pp 53-64.

Odds F. C. 1998. Should resistance to azole antifungals in vitro be interpreted as predicting clinical non-response? Drug resistance Updates 1: 11-15.

Ogawa A., T. Hashida-Okado, M. Endo, H. Yoshioka, T. Tsuruo, K. Takesako, and I. Kato. 1998. Role of ABC tranporters in Aureobasidin A resistance. Antimicrob. Agents Chemother. 42(4): 755-761.

Oxford G. A. E., H. Raistrick, and P. Simonart. 1939. Studies in biochemistry of microorganisms: LX. Griseofulvin $\mathrm{C}_{17} \mathrm{H}_{17} \mathrm{O}_{6} \mathrm{Cl}$, metabolic product of Penicillium griseofulvin, Dierckx. Biochem. J. 33: 240.

78 Pearce M., and S. Howell. 1991. RFLP analysis of azole-resistant and azole-susceptible Candida albicuns strains. J. Clin. Microbiol. 29: 1364-1367.

Pfaller M. A.. 1996. Nosocomial candidiasis: emerging species, reservoirs, and modes of transmission. Clin. Infect. Dis. 22 (Suppl 2): S89-94.

Pfaller M. A., R. N. Jones, G. V. Doern, H. S. Sader, R. J. Hollis, S. A. Messer. 1998. International surveillance of bloodstream infections due to Candida species: frequency of occurrence and antifungal susceptibilities of isolates collected in 1997 in the Inited States, Canada, and South America for the SENTRY program. The SENTRY participant group. J. Clin. Microbiol. 36(7): 1886-1889.

81 Pfaller M. A., R. N. Jones, S. A. Messer, M. B. Edmond, and R. P. Wenzel. 1998. National surveillance of nosocomial blood stream infection due to Candida albicans: frequency of occurrence and antifungal susceptibility in the SCOPE program. Diagn. Microbiol. Infect. Dis. 31(1): 327-332.

82 Polak A. 1990. Mode of action studies. In: Chemotherapy of fungal diseases. Ryley J. F. (ED) Berlin. Springer-Verlag, pp 153-182. 
Prasad R., W. P. De Wergifosse, A. Goffeau, and E. Balzi. 1995. Molecular cloning and characterization of a novel gene of Candida albicans, $C D R 1$, conferring multiple resistance to drugs and antifungals. Curr. Genet. 27: 320-329.

Ryder N. S. 1986. Biochemical mode of action of the allylamine antimycotic agents naftifine and SF-86-327. In: In vitro and in vivo evaluation of antifungal agents, Iwata, K., Vanden Bossche, H. (Eds.), Elsevier Science Publishers, Amsterdam, pp 89-99.

Ryder N. S., I. Frank, and M. C. Dupont. 1986. Ergosterol biosynthesis inhibition by the thiocarbamate antifungal agents tolnaftate and tolciclate. Antimicrob. Agents Chemother. 29: $858-860$.

Ryley J. F., R. G. Wilson, and K. J. Barrett-Bee. 1984. Azole resistance in Candida albicans. Sabouraudia 22: 53-93.

Sandven P., K. Nilsen, A. Digranes, T. Tjadeand, and J. Lassen. 1997. Candida norvegensis: a fluconazole-resistant species. Antimicrob. Agents Chemother. 41(6): 1375-1376.

Sanglard D., F. Ischer, M. Monod, and J. Bille. 1997. Cloning of Candida albicans genes conferring resistance to azole antifungal agents: characterization of $C D R 2$, a new multidrug ABC transporter gene. Microbiology 143: 405-4I6.

Sanglard D., F. Ischer, and J. Bille. 1998. The ride of the ABC transporter genes $\mathrm{CgCDRI}$ and $\mathrm{Cg}_{\mathrm{g}} \mathrm{CDR} 2$ in the resistance of $C a n d i d a$ glabrata to azole antifungal agents. In Program and Abstracts of the $38^{\text {th }}$ Interscience Conference on Antimicrobial Agents and Chemotherapy. San Diego.California. US.. 1998. Abstract C-148. American Society for Microbiology, Washington, DC:

Sanglard D., F. Ischer, D. Calabrese, M. de Micheli, and J. Bille. 1998. Multiple resistance mechanism to azole antifungals in yeast clinical isolates. Drug Resist. Updates I: 255-265.

Sanglard D., F. Ischer, L. Koymans, and J. Bille. 1998. Amino acid substitutions in the cytochrome P450 lanosterol 14alpha-demethylase (CYPSI) from azole-resistant Candida albicans clinical isolates contributing to the resistance to azole antifungal agents. Antimicrob. Agents Chemother. 42: 241-253.

Schmid J., F. C. Odds, M. J. Wiselka, K. G. Nicholson, and D. R. Soll. 1992. Genetic similarity and maintenance of Candida albicans strains from a group of AIDS patients, demonstrated by DNA fingerprinting. J Clin. Microbiol. 30(4): 935-941. John wiley \& Sons Ltd. pp 35-106. 
Shimokawa O., and H. Nakayama. 1992. Increased sensitivity of Candida albicans cells accumulating $14 \alpha$-methylated sterols to active oxygen: possible relevance to in vivo efficacies of azole antifungal agents. Antimicrob. Agents Chemother. 36: 1626-1629.

Sloboda R. D., G. van Blaricom, W. A. Creasey, J. L. rosenbaum, and S. E. Malawista. 1982. Griseofulvin: association with tubulin and inhibition of in vitro mictotubule assembly. Biochem. Biophys. Res. Commun. 105: 882-888.

Spitzer S. G, and E. D. Spitzer. 1997. Identification of a Cryptococcus neoformans sequence belonging to the major facilitator superfamily (MFS). In Program and Abstracts of the $97^{\text {th }}$ Genera meeting of the American Society for Microbiology; Miami beach. Florida, US, 1997. Abstract F-26. American Society for Microbiology, Washington, DC.

97 Stehmann C. and, M. A. De Waard. 1995. Accumulation of tebuconazole by isolates of Botrytis cinerea differing in sensitivity to sterol demethylation inhibiting fungicides. Pestic. Sci. 45: 311-318.

Talibi D., and M. Raymond. 1999. Isolation of a putative Candida albicans transcriptional regulator involved in pleiotropic drug resistance by functional complementation of a prdl prd3 mutation in Saccharomyces cerevisiae. J. Bacteriol. 181: 2312-240.

Tobin M. B., R. B. Peery, and P. L. Skatrud. 1997. Genes encoding multiple drug resistance like proteins in Aspergillus fumigatus and Aspergillus flavus. Gene 200: 11-23.

99a Truan G., C. Cullin, P. Reisdorf, P. Urban, and D. Pompon. 1993. Enhanced in vivo monooxygenase activities of mammalian $\mathrm{P} 450$ s in engineered yeast cells producing high levels of NADPH-P450 reductase and human cytochrome $b_{5}$. Gene 125: 49-55.

100 Turi T. G., and J. C. Loper. 1992. Multiple regulatory elements control expression of the gene encoding the Saccharomyces cerevisiae cytochrome P450, lanosterol 14-alphademethylase (ERGII). J. Biol. Chem. 267: 2046-2056.

101 Turi T. G. and, J. K. Rose. 1995. Characterization of a novel Schizosaccharomyces pombe multidrug resistance transporter conferring brefeldin A resistance. Biochem. Biophys. Res. Commun. 213: 410-418.

102 van den Brink H. M. , M. A. De Waard, J. G. Van Nistelrooy, C. A. van den Hondel, and R. F. van Gorcom. 1996. Increased resistance to $14 \alpha$-demethylase inhibitors (DMIs) in Aspergillus niger by coexpression of the Penicillium iralicum eburicol $14 \alpha$-demethylase (cyp5I) and the A. niger cytochrome P450 reductase (cprA) genes. J. Biotech. 49: 13-18.

103 Vanden Bossche H., J. M. Ruysschaert, F. Defrise-Quertain, G. Willemsens, F. Cornelissen, P. Marichal, W. Cools and J. Van Cutsem. 1982. The interaction of miconazole and ketoconazole with lipids. Biochem. Pharmacol. 31: 2609-2617. 
104 Vanden Bossche H., G. Willemsens, P. Marichal, W. Cools, and W. Lauwers. 1984. $\mathrm{N}$-substituted azole derivatives. Focus on R51211. In : Mode of action of antifungal agents, eds. A. P. J. Trinci and J. F. Ryley (Eds.), Britisch Mycological Society, Great Britain, pp 321-341.

105 Vanden Bossche H. 1987. Itraconazole: a selective inhibitor of the cytochrome P-450 dependent ergosterol biosynthesis. In: recent trends in the discovery and evaluation of antifungal agents. R. A. Fromtling (Ed.), J. R. Prous science Publishers, pp 207-221.

106 Vanden Bossche H., P. Marichal, J. Gorrens, H. Geerts, and P. A. J. Janssen. 1988. Mode of action studies. Basis for the search of new antifungal drugs. Ann. N. Y. Acad. Sci. 544: 191-207.

107 Vanden Bossche H., P. Marichal, J. Gorrens, D. Bellens, M.-C. Coene, W. Lauwers, L. Le Jeune, H. Moereels, and P. A. J. Janssen. 1990. Mode of action of antifungals of use in immunocompromised patients. I $n$ Mycoses in AIDS patients, H. Vanden Bossche, D.W.R. MacKenzie, G. Cauwenbergh, J. Van Cutsem, E. Drouhet, and B. Dupont (eds.). Plenum Press. New York. N. Y., pp. 223-243.

108 Vanden Bossche H. 1990. Importance and role of sterols in fungal membranes. In: Biochemistry of cell walls and membranes in fungi. P. J. Kuhn, A. P. J. Trinci, M. J. Jung, M. W. Goosey, and L. G. Copping Eds. Springer-Verlag, Berlin. pp 135-157.

109 Vanden Bossche H., P. Marichal, J. Gorrens, D. Bellens, H. Moereels, and P. A. J. Janssen. 1990. Mutation in cytochrome P450-dependent 14 $\alpha$-demethylase results in decreased affinity for azole antifungals. Biochem. Soc. Trans. 18: 56-59.

110 Vanden Bossche H. and P. Marichal. 1992. Azole antifungals: mode of action. In: Recent progress in antifungal chemotherapy (Yamaguchi H., G. S. Kobayashi, and $H$. Takahashi. eds.) Marcel Dekker, New York, pp 25-40.

111 Vanden Bossche H. and P. Marichal. 1993. Is there a role for sterols and steroids in fungal growth and transition from yeast to hyphal-form and vice-versa? An overview. In: Dimorphic Fungi in biology and medicine. Vanden Bossche, H., Odds, F. C., and Kerridge D., eds., Plenum Press, New York, pp 177-190.

112 Vanden Bossche H., P. Marichal, L. Le Jeune. M.-C. Coene, J. Gorrens, and W. Cools. 1993. Effects of itraconazole on cytochrome P-450-dependent sterol 14 $\alpha$-demethylation and reduction of 3-ketosteroids in Cryptococcus neoformans. Antimicrob. Agents Chemother. 37: 2101-2105.

113 Vanden Bossche H., P. Marichal, and H. Moereels. 1993. Molecular mechanisms of antifungal activity and fungal resistance: focus on inhibitors of ergosterol biosynthesis. In: Molecular biology and its application to medical mycology. B. Maresca and G. S. Kobayashi and H. Yamaguchi Eds. Springer-Verlag Berlin, pp 179-197. 
II4 Vanden Bossche H. and L. Koymans. 1998. Cytochrome P450 in fungi. Mycoses 41(suppl.1): 32-38.

115 Venkateswarlu K., D. W. Denning, N. J. Manning, and S. L. Kelly. 1996. Reduced accumulation of drug in Candida krusei accounts for itraconazole resistance. Antimicrob. Agents Chemother. 40(11): 2443-2446.

116 Voss A., J. A. Kluytmans, J. G. Koeleman, L. Spanjaard, C. M. VandenbrouckeGrauls, H. A. Verbrugh, M. C. Vos, A. Y. Weersink, J. A. Hoogkamp-Korstanje, and J. F. Meis. 1996. Occurrence of yeast bloodstream infections between 1987 and 1995 in five Dutch university hospitals. Eur. J. Clin. Microbiol. Infect. Dis. 15(2): 909-912.

117 Watson P. F., M. E. Rose, S. W. Ellis, H. England, and S. L. Kelly. 1989. Defective sterol C5-6 desaturation and azole resistance: a new hypothesis for the mode of action of azole antifungals. Biochem. Biophys. Res. Commun. 164: 1170-1175.

118 White T. C. 1997 . The presence of an R467K amino acid substitution and loss of allelic variation correlate with an azole-resistant lanosterol $14 \alpha$-demethylase in Candida albicans. Antimicrob. Agents Chemother, 41: 1488-1494.

119 Wrigth W. L. and R. P. Wenzel. 1997. Nosocomial Candida. Epidemiology, transmission, and prevention. Infect. Dis. Clin. North Am. 11(2): 4! 1-425.

120 Yamaguchi H. 1997. Unique biological and physiochemical properties of benanomicin A implicated in its antifungal action. In: Fungal cells in biodefense mechanism Shigeo Suzuki and Masuko Suzuki eds. Saikon publishing Co. Ltd. Tokyo, Japan. pp 199-208.

121 Zang X., K. I. Collins, and L. M. Greenberger. 1995. Functional evidence that transmembrane 12 and the loop between transmembrane 11 and 12 form part of the drug-binding domain in P-glycoprotein encoded by MDRI J. Biol. Chem. 270(10): 5441-5448. 


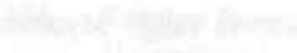




\section{Contribution of mutations in}

\section{the cytochrome P450 14 $\alpha$-demethylase}

\section{(ERG11, CYP51) to azole resistance}

\section{in Candida albicans.}

Patrick Marichala,e, Luc Koymans ${ }^{b}$, Staf Willemsens ${ }^{a}$, Danny Bellens', Peter Verhasselt $^{c}$, Walter Luyten ${ }^{d}$, Marcel Borgers ${ }^{e}$, Frans C. S. Ramaekers ${ }^{\mathrm{e}}$, Frank C. Odds $^{a}$ and Hugo Vanden Bossche ${ }^{a}$

a Departments of Anti-infectives Research, ${ }^{b}$ Center for Molecular Design, 'Biotechnology Department, d Functional Genomics Department; Janssen Research Foundation, Beerse, Belgium. ${ }^{~}$ Department of Molecular Cell Biology \& Genetics, University Maastricht, The Netherlands.

Running title: Azole resistance and CYP5I mutations.

Microbiology (in press) 


\section{Chapter 2}

\section{Summary}

The cytochrome P450 14 $\alpha$-demethylase, encoded by the ERGII (CYP5I) gene, is the primary target for the azole class of antifungals. Changes in the azole affinity of this enzyme caused by amino acid substitutions have been reported as a resistance mechanism. Nine Candida albicans strains were used in this study. We determined the ERGIl base sequence of seven isolates, of which only two were azole-sensitive. The $E R G I I$ base sequences of the other two strains were already published. In these seven isolates, twelve different amino acid substitutions were identified, of which 6 have not been described previously (Al49V, D153E, E165Y, S279F, V452A and G465S). In addition 16 silent mutations were found. Two different biochemical assays, subcellular sterol biosynthesis and carbon monoxide binding to reduced microsomal fractions were used to evaluate the sensitivity of the cytochromes for fluconazole and itraconazole. Enzyme preparations from 4 isolates showed reduced itraconazole susceptibility, whereas more pronounced resistance to fluconazole was observed in five isolates. A 3D-model of the C. albicans CYP51 was used to position all 29 reported substitutions, 98 in total identified in 53 sequences. These 29 substitutions were not randomly distributed over the sequence but clustered in three regions from amino acid 105-165, from 266-287 and from 405-488, suggesting the existence of hotspot regions. Of the mutations found in the two $\mathrm{N}$-terminal regions only $\mathrm{Y} 132 \mathrm{H}$ was demonstrated to be of importance for azole resistance. In the $\mathrm{C}$-terminal region three mutations are associated with resistance, suggesting that the non-characterized substitutions found in this region should be prioritised for further analysis. 
Azole resistance and CYP51 mutations

\section{Introduction}

Partly as a result of the acquired immunodeficiency syndrome (AIDS) epidemic, the incidence of fungal infections has increased during the last decade. Oropharyngeal candidiasis is the most common fungal infection in AIDS patients. Only a few classes of antifungal compounds are available to treat these infections. One important class consists of inhibitors of ergosterol biosynthesis (EBI). Several enzymes in this pathway are targets for commercialised antifungals, such as squalene epoxidase, inhibited by the allylamines, $\Delta^{14}$-reductase and $\Delta^{8.7}$-isomerase, both inhibited by the morpholines, and cytochrome P450s catalysing $14 \alpha$-demethylation and $\Delta^{22}$-desaturation which are inhibited by the azoles. A combination of factors such as the fungistatic nature of the inhibition of Candida albicans observed for azole compounds, impaired host immune responses in infected patients, long treatment periods, and use of low antifungal doses, creates favourable breeding conditions for mutation and selection of less susceptible isolates. (Cartledge et al., 1997)

Over the last five years multiple biochemical studies have been published to elucidate the underlying causes of azole resistance in pathogenic fungi. These studies resulted in a series of reviews dedicated to this subject (Bodey, 1997; De Muri et al., 1995; Denning et al., 1997; Dupont, 1995; Frosco \& Barrett, 1998; Hartman \& Sanglard, 1997; Johnson \& Warnock, 1995; Joseph-Horn \& Hollomon, 1997; Marichal \& Vanden Bossche, 1995a; Odds, 1998; Rex et al., 1995; Sanglard et al., 1998a; Vanden Bossche et al., 1994, 1997, 1998; White et al., 1998). Several mechanisms have been identified that contribute to azole resistance. Probably the most common mechanism is to effect a diminution in the concentration of active compound at the target site. In the majority of cases studied recently, this was the result of overexpression of efflux pumps. So far, two types of efflux transporters have been reported in resistant isolates. The ATP-binding-cassette type (ABC transporters; e.g. $C D R l$ and $C D R 2$ ) can export a wide variety of azoles and unrelated chemicals (Kolaczkowski \& Goffeau, 1997) and the so-called "major facilitators" (e.g. CaMDRL, previously described as $B E N^{r}$ ) with a much narrower substrate spectrum (Sanglard et al., 1995). 
The second way in which fungi achieve effective resistance to azoles is to circumvent or compensate for the toxic consequences of the changes in sterol composition. Azole-induced growth inhibition results from both the depletion of sterol molecules able to perform some sparking hormonal function (Rodriguez et al., 1985), e.g. ergosterol and, coincidental accumulation of membrane-disturbing 14-methylated precursors. As well as ergosterol, sufficient quantities of 14-methylfecosterol can also fulfil this sparking function. (Watson et al., 1989), Accumulation of this 14-methylfecosterol is achieved if cells are deficient in $\Delta^{8.7}$ isomerase and or $\Delta^{5.6}$ desaturase. This effect has been described in an azoleresistant C. albicans isolate (Kelly et al., 1997) as well as in Saccharomyces cerevisiae (Bard et al., 1993).

A third general type of mechanism for azole resistance involves changes at the level of the antifungal target. The primary target for the azole class of antifungals is the cytochrome P450 catalysed 14 $\alpha$-demethylation of ergosterol precursors. This enzyme is encoded by ERGII (also described as ERGI6, CYP5I). An overexpression of this enzyme induced either by enhanced transcription or by gene or chromosomal amplification results in a decreased sensitivity for this class of antifungals (Marichal et al., 1997; Doignon et al., 1993). Point mutations in ERGII (suggested by biochemical data (Vanden Bossche et al., 1990) or by sequence analysis) such as Y $132 \mathrm{H}$ (tyrosine 132 is replaced by a histidine) (Sanglard et al, 1998b), T315A (threonine 315 replaced by alanine) (Lamb et al., 1997) or R476K (arginine 476 replaced by lysine) (White, 1997) have been shown to decrease the affinity of the target for an azole. Numerous publications have listed other ERGII mutations, but unfortunately the effect of the mutation on azole sensitivity was not always tested.

In this study, we sequenced the ERG $I /$ gene from a selection of five azole-resistant isolates and two sensitive isolates and evaluated the effects of amino acid substitutions on subcellular sterol biosynthesis and azole sensitivity. Computer modelling and sequence analysis were used to position the mutations found in the $3 \mathrm{D}$ model available and to predict their possible importance for resistance. 


\section{Materials and Methods}

\section{Strains, media and compounds}

Nine strains of Candida albicans were used in this study. Two of them, ATCC 28516 and ATCC 44858, were extensively used in previous biochemical studies (Vanden Bossche et al., 1980) and were azole sensitive. The seven other strains were azole resistant: NCPF 3363 (Smith et al., 1986) was isolated from a patient suffering from chronic mucocutaneous candidiasis (CMC); J913004/T was isolated in France from an AIDS patient; B59626 and B59630 were sequential isolates from an AIDS patient in Germany, strains C40 and C26 were isolated from AIDS patients with oropharyngeal candidiasis and maintained at the Institute of Microbiology, Centre Hospital Universitaire Vaudois, Switserland (Sanglard et al., 1995); strain 6406/8 was a spontaneous, laboratory-derived polyene-resistant mutant of strain 6406 and was obtained from Dr. D. Kerridge, University of Cambridge, England. Identity of the isolates as Candida albicans was confirmed by standard procedures. Yeasts were maintained as glycerol stocks at $-80^{\circ} \mathrm{C}$. The inocula for each individual experiment were prepared from these glycerol stocks to minimise the possible influences of genotypic or phenotypic instability. Itraconazole (Janssen Research Foundation, Beerse, Belgium) and fluconazole (Pfizer Central Research, Sandwich, Kent, United Kingdom) were dissolved and diluted in dimethylsulfoxide (DMSO).

\section{MIC determination.}

MICs were determined spectrophotometrically by a broth microdilution method (Odds et al., 1995) based on the NCCLS M27A protocol (National Committee for Clinical Laboratory Standards, 1995). In brief, cells were inoculated in RPMI buffered to $\mathrm{pH} 7.0$ with $1.65 \mathrm{M}$ MOPS. Results were read after $48 \mathrm{~h}$ at $37^{\circ} \mathrm{C}$ in a microplate reader (model 3550: Biorad Richmond, Calif.). The MIC was the lowest concentration that inhibited growth by more than $50 \%$; this endpoint showed the best reproducibility and correlation with results from the NCCLS broth macrodilution method. Quality control yeasts Candida krusei 
ATCC 6258 and Candida parapsilosis ATCC 22019 were tested in parallel and were inhibited at MICs in the correct ranges for the antifungals tested (National Committee for Clinical Laboratory Standards, 1995).

\section{Sterol synthesis by subcellular fractions}

To prepare the subcellular fractions, the $C$. albicans isolates were grown for $8 \mathrm{~h}$ in static culture and then $8 \mathrm{~h}$ in a reciprocating shaker set at 100 strokes per minute in $200 \mathrm{ml}$ of $\mathrm{PYG}_{2}$ medium ( $10 \mathrm{~g}$ of polypeptone, $10 \mathrm{~g}$ of yeast extract, $40 \mathrm{~g}$ of glucose per liter) in $500 \mathrm{ml}$ Erlenmeyer flasks at $30^{\circ} \mathrm{C}$. This method yields cells in the late exponential phase. Cells were collected by centrifugation at $1,500 \times \mathrm{g}$, washed and resuspended at a density of $10^{9}$ cells. $\mathrm{ml}^{-1}$ in cold homogenisation buffer containing $0.1 \mathrm{M}$ potassium phosphate buffer, $30 \mathrm{nM}$ nicotinamide, $5 \mathrm{mM} \mathrm{MgCl}$, $5 \mathrm{mM}$ reduced glutathione and $1 \mathrm{mM}$ phenylmethylsulfonyl fluoride (PMSF). Cells were broken in a $350 \mathrm{ml} \mathrm{Bead-Beater}{ }^{(8)}$ receptacle (Biospec Products, Bartlesville, Oklahoma, USA) filled with $200 \mathrm{~g}$ prechilled acid-washed glass beads (diameter $0.40-0.45 \mathrm{~mm}$ ) by three cycles of I min agitation with intermittent cooling. To prevent heating of the samples the outer jacket of the Bead-Beater ${ }^{\otimes}$ was filled with ice-cold water. The homogenate was differentially centrifuged at $4^{\circ} \mathrm{C}$ first for 5 min at $1500 \times g$ and then for $20 \mathrm{~min}$ at $8000 \times \mathrm{g}$ in a Sorvall ${ }^{\otimes} \mathrm{SS} 34$ rotor. Protein content of the S8000 supernatant fraction was measured according to the Biorad method using bovine serum albumin as a standard (Bradford et al., 1976). To measure sterol biosynthesis, $900 \mu \mathrm{l}$ of the resultant $S 8000$ fraction was added to $100 \mu \mathrm{l}$ of cofactor buffer to achieve final concentrations of $1 \mu \mathrm{M}$ NADP, $1 \mu \mathrm{M}$ NAD, 3 $\mu \mathrm{M}$ glucose-6-phosphate, $5 \mu \mathrm{M}$ ATP, $2 \mu \mathrm{M} \mathrm{MnCl}_{2}, 3 \mu \mathrm{M} \mathrm{MgCl}_{2}$, and $0.25 \mu \mathrm{Ci}$ $\left[{ }^{14} \mathrm{C}\right]$ mevalonic acid. One $\mu \mathrm{l}$ of inhibitor stock solution and/or DMSO was added to the incubation tubes prior to the addition of the S8000 extract. Tubes were incubated for $2 \mathrm{~h}$ in an orbital New Brunswick shaker set at $300 \mathrm{rpm}$ at $30^{\circ} \mathrm{C}$. Reactions were stopped by the addition of $1 \mathrm{ml}$ of $15 \% \mathrm{KOH}$ dissolved in $90 \%$ ethanol and were saponified for $1 \mathrm{~h}$ at $84^{\circ} \mathrm{C}$. Non-saponifiable lipids were extracted with $3 \mathrm{ml}$ of n-heptane. Heptane extracts were then dried with a stream of $\mathrm{N}_{2}$ and sterols were separated by thin layer chromatography as described previously tanden Bossche et al., 1992). All experiments were 
repeated at least three times with different cell extracts.

\section{Spectrophotometric analysis of cytochrome $\mathbf{P 4 5 0}$.}

Microsomes were isolated from C. albicans as described previously (Vanden Bossche et al., 1986). In summary, C. alhicans cells, grown in semianaerobic conditions, were harvested by centrifugation, then washed and resuspended in ice-cold 0.65 M mannitol. All subsequent steps were done at $4^{\circ} \mathrm{C}$. PMSF was added to a concentration of $\mathrm{I} \mathrm{mM}$. Then the suspension was immediately homogenised in a Bead-Beater as described above. The homogenate was differentially centrifuged for $5 \mathrm{~min}$ at $1,500 \mathrm{xg}, 20 \mathrm{~min}$ at $10,000 \mathrm{xg}$, and $1 \mathrm{~h}$ at $100,000 \times \mathrm{g}$. The pellet thus obtained was resuspended in $0.05 \mathrm{M}$ potassium

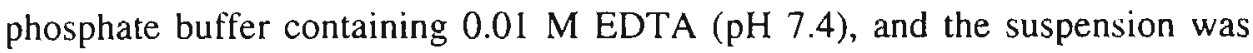
recentrifuged for $1 \mathrm{~h}$ at $100,000 \times g$ (Vanden Bossche et al., 1986). The final pellet was suspended in $0.1 \mathrm{M}$ potassium phosphate buffer ( $\mathrm{pH} 7.4$ ). The $\mathrm{P}-450$ content and the effects of azoles on the interaction of $\mathrm{CO}$ with the reduced heme iron of P-450 were measured as described previously (Vanden Bossche et al., 1986).

\section{PCR amplification and sequence analysis of the C. albicans ERGII gene.}

To amplify the ERGII gene encoding the cytochrome P450 14 $\alpha$-demethylase we used as a sense primer 5'TAATACGACTCACTATAGGGAAGATCATAACTCAATATGGCTATTGTTG3' composed of a 19 bp $T 7$ sequence and the nucleotides 131-161 from the Lai \& Kirsch (1989, accession number X13296) sequence, including the first four codons of the ORF and as antisense primer we used 5'ATTTAGGTGACACTATAGGAAAGTTGCCGTTTTATTAAAACATAC3' composed of the SP6 sequence (18 BP) and the 1724-1750 region of the published sequence surrounding the stop codon of the ORF. The heat activatable AmpliTaq Gold (0.5 units; Perkin Elmer) was used with $2.5 \mathrm{mM}$ $\mathrm{MgCl}_{2}$. DNA from all Candida albicans strains was prepared by the Qiagen ${ }^{3}$ DNA extraction method according to the procedures of the manufacturer with zymolyase (60 U; $5000 \mathrm{U} \mathrm{g}^{-1}$; Arthrohacter luteus; Seikagaku Kogyo, Tokyo, Japan) used as the cell-wall-degrading enzyme. The PCR parameters were 10 min at $94^{\circ} \mathrm{C}$ to activate the polymerase and then 30 cycles of $1 \mathrm{~min}$ annealing at 
$60^{\circ} \mathrm{C}, 2$ min elongation at $72^{\circ} \mathrm{C}$ and 1 min denaturation at $92^{\circ} \mathrm{C}$. After the reaction. the 16.57 bp PCR product was purified with a Qiagen ${ }^{\otimes}$ PCR cleanup kit and a sample was separated on a $1 \%$ agarose gel in $0.5 \times$ TBE with Boehringer molecular weight standard VI. The 1657 bp amplification products from the different isolates were sequenced on both strands using the PCR primers and internal primers every 300 bp (name, sequence, nucleotide numbering according to Lai \& Kirsch (1989, accession number X13296), direction; Ca ERGI1-01, TTAGGTCCAAAAGGTC, 432, sense; Ca ERG1 l-02. CATGACCTTTTGGACC, 451, antisense; Ca ERG11-03; GACCGTTCATTTGCTC, 787, sense; Ca ERG11-04, GAGCAAATGAACGGTC, 802, antisense; Ca ERG1l-05, ATTCTTATGGGTGGTC, 1057, sense; Ca ERG1 1-06, GCAGAAGTAGAAGCAG, 1097, antisense; Ca ERG11-07, TCTCCAGGTTATGCTC, 1360, sense; Ca ERG1 1-08, CCCATCTAGTTGGATC, 1439, antisense). Primers were designed by visual inspection of the sequence for stretches of 16-18 nucleotides of normal composition $(40 \%-60 \% \mathrm{GC}$, no palindromes, no homopolymeric stretches). Primers were ordered from Eurogentec (Seraing, Belgium) and were synthesised according to the B-cyanoethylphosphoramidite method. Sequencing reactions were performed with the ABI Prism BigDye Terminator Cycle Sequencing Ready Reaction Kit used according to the instructions of the manufacturer (Perkin-Elmer, Foster City, Ca), except that half of the volume of terminator mix was replaced by HalfTerm (GenPak Ltd, Brighton, UK). Sequencing reactions were run on an Applied Biosystems 377 XL DNA sequencer (Perkin-Elmer). Sequences were assembled from the individual runs into single contig sequences by means of the Sequencher software (Gene Codes Corporation. Ann Arbor, MI). Ambiguity positions were scored by setting the threshold as low as $30 \%$ (i.e. secondary peaks at $30 \%$ of primary peak results in ambiguity call) and by inspecting all of the ambiguity calls on all available readings. The GenBank entries for the sequences are AF153844-AFI53850. 


\section{Results}

\section{MIC determination}

The MIC values obtained with the NCCLS compatible methodology confirmed the previous reported susceptibility of the different strains, except for isolate 6406/8. For both sensitive ATCC reference strains, MIC values of $0.13 \mu \mathrm{g} \cdot \mathrm{ml}^{-1}$ were found for fluconazole and $0.016 \mu \mathrm{g} \cdot \mathrm{ml}^{-1}$ or lower for itraconazole (Table I). In these test conditions isolate 6406/8 was also inhibited at low concentrations of both fluconazole and itraconazole, but showed a pronounced trailing growth effect. Complete inhibition was seen in this spontaneous laboratory mutant only at a concentration of $32 \mu \mathrm{g}$ of fluconazole $\mathrm{ml}^{-1}$ and $2 \mu \mathrm{g}$ of itraconazole $\mathrm{ml}^{-1}$. All other strains had high MIC values for fluconazole $(>32)$ and itraconazole $(\geq 0.5)$ and as such fell either at the high end of the dose-dependent sensitivity range or into the resistant range, according to the NCCLS breakpoints. The difference in ratios of MIC values obtained for fluconazole versus itraconazole for the isolates studied (Table I) suggests that resistance for fluconazole was more pronounced in the isogenic strains B59626, B59630 and in isolates $\mathrm{J} 913004 / \mathrm{l}$ and C40. In case of this last isolate it was shown that overexpression of ( $a M D R I$, a major facilitator pump that takes fluconazole and not itraconazole as a substrate, contributed to this fluconazole resistance (Sanglard et al., 1995).

\section{ERGII Sequence analysis}

Both strands of the coding region of the ERGII genes of all eight strains were sequenced and compared to the Lai \& Kirsch (1989) sequence. Each strain examined carried from 9 to 12 nucleotide changes of which at least one and up to four resulted in an amino acid substitution relative to the reference sequence as shown in Table I. For the representation of the substitution we used the amino acid found in the reference sequence, followed by its position and the amino acid substitute found (all amino acids are designated by the conventional one-letter amino acid code). In total 12 different amino acid substitutions were identitied. 
Amino acid polymorphisms found in sensitive and resistant isolates together with the MICs, sensitivity of the subcellular sterol biosynthesis and cytochrome P450 CO-binding for fluconazole and itraconazole

Results shown are from representative experiments. Each experiment was repeated at least three times, variation was less than $10 \%$

\begin{tabular}{|c|c|c|c|c|c|c|c|c|c|c|c|c|}
\hline \multirow[t]{2}{*}{ Sirain } & \multicolumn{3}{|c|}{$\begin{array}{c}\text { Growth } \\
\text { MICs (ug/ml) }\end{array}$} & \multicolumn{2}{|c|}{ Fluconazole } & \multicolumn{3}{|c|}{ Subcellular slerol biosynthesis } & \multicolumn{3}{|c|}{$\begin{array}{c}\text { Cytochrome P450 CO } \\
\text { displacement" } \\
\text { IC50 nM }\end{array}$} & \multirow{2}{*}{$\begin{array}{l}\text { Amino acid point } \\
\text { mutation } \\
\text { (additional silent } \\
\text { nucleotide variations) } \\
\text { XNNNxy' }\end{array}$} \\
\hline & Fluconazole & |traconazole & ratio & IC50 nM & $\begin{array}{l}{[100]} \\
1000 n M\end{array}$ & $1050 \mathrm{~nm}$ & $100 \mathrm{nM}$ & & Fluconazo & conazole & ratio & \\
\hline ATCC 28516 & 0.13 & $\leq 0.008$ & $>16$ & 41 & [5] & 44 & [2] & 0.9 & 145 & 38 & 3.9 & F72F几,E266D (10) \\
\hline ATCC 44858 & 0.13 & 0.016 & 8 & 42 & [3] & 37 & [2] & 1.1 & 203 & 36 & 5.6 & D153E, E266D (10) \\
\hline B59626 & $>64$ & 1 & $>64$ & 87 & [5] & 33 & [1] & 2.6 & 270 & 40 & 6.8 & $\begin{array}{l}\text { D116E, K128T. } \\
\text { A149V (8) }\end{array}$ \\
\hline 859630 & 64 & 0.5 & 128 & 65 & [4] & 21 & [5] & 3.1 & 530 & 54 & 9.8 & $\begin{array}{l}\text { D116E, K128T, } \\
\text { A149V (8) }\end{array}$ \\
\hline NCPF 3363 & 32 & 2 & 16 & 220 & [21] & 92 & [48] & 2.4 & 221 & 55 & 2.4 & $\begin{array}{l}\text { Y132H, S279SIF, } \\
\text { G465G/S (8) }\end{array}$ \\
\hline J913004/1 & 64 & 1 & 64 & 172 & {$[17]$} & 22 & {$[7]$} & 7.8 & & cient P4 & & $\begin{array}{l}\text { DI16E, K128T, } \\
\text { V452A, G464S (8) }\end{array}$ \\
\hline $6406 / 8$ & $\leq 0.032$ & $\$ 0,008$ & & 90 & [19] & 14 & [14] & 6.4 & & cient P4. & & E165Y (7) \\
\hline $\mathrm{C} 26$ & $>128$ & $>2$ & & 4880 & [78] & 20 & [24] & 244 & 3080 & 30 & 103 & $\begin{array}{l}\text { D116E, Y132H, } \\
\text { S405F (8) }\end{array}$ \\
\hline C40 & 128 & 1 & 128 & 378 & [37] & 34 & {$[19]$} & 11 & 5030 & 44 & 114 & $\begin{array}{l}\text { Y132YM, G464S, } \\
\text { R467K }(9)^{4}\end{array}$ \\
\hline
\end{tabular}

- Results obtained with $0.1 \mathrm{nmol}$ cytochrome P450 per $\mathrm{ml}$ in the cuvette

' $\mathrm{x}$ is the amino acid found in the published ERG11 sequence, NNN is the position in the ORF, $\mathrm{y}$ is the amino acid found in the isolate, if both alleles differ in sequence a slash is used to indicale this helerozygosity

'Despite several attempts and the addition of protease inhibitor, insufficient cylochrome P450 was isolated to test the sensitivity

${ }^{5}$ Mutations taken from Sanglard et al. (1998b)

$\varepsilon$ concentration needed to reach $50 \%$ inhibition

$*[\% \mathrm{C}] 1000 \mathrm{nM}$ : percentage of control at a concentration of $1000 \mathrm{nM}$ 


\section{Azole resistance and CYP51 mutations}

Six have already been reported: F72L (Ryder \& Favre, 1997), D1 16E (Kallakuri et al., 1996; Manavathu et al., 1996; Ryder \& Favre, 1997; Sanglard et al., 1998b; Marr et al., 1998), K128T (Kallakuri et al., 1996; Manavathu et al., 1996; Löffler et al., 1997; Sanglard et al., 1998b), Y132H (Ryder \& Favre, 1997; Sanglard et al., 1998b; Okonogi et al., 1998), E266D (Kallakuri et al.. 1996; Löffler et al., 1997; Ryder \& Favre, 1997), and G464S (Manavathu 't al.. 1996; Löffler et al., 1997; Sanglard et al., 1998b; Marr et al., 1998;), but the other six were novel (A149V, D153E, E165Y, S279F, V452A, and G465S). To verify our sequencing technique, we also included strain $\mathrm{C} 26$, for which the ERG1l sequence has been published (Sanglard et al., 1998b). All three mutations, D1 16E, Y 132H and S405F were confirmed as well as the other eight silent nucleotide changes, endorsing the validity of the sequencing analysis. Both sensitive reference strains, ATCC 28516 and ATCC 44858 contained an E266D variation. Strain ATCC 28516 was in addition heterozygous with respect to a phenylalanine/leucine substitution present on only one of its alleles, represented as F72F/L. Both alleles of strain ATCC44858 carried a novel DI53E mutation. Strains B59626 and B59630 were isolated from the same patient and their sequence was identical (in the three amino acid substitutions found as well as in 8 silent nucleotide changes) supporting the isogenicity of these strains, as was demonstrated by hybridisation with the $\mathrm{Ca} 3$ repetitive probe (results not shown). The alanine/valine substitution (A149V) in these strains has not been reported previously. Strain NCPF 3363 was the first strain for which Vanden Bossche et al. (1990) suggested a mutation in ERG1/ based on biochemical evidence such as a diminished affinity for azole antifungals and a red shift in the maximum of the CO-absorption spectrum from 448 to $450 \mathrm{~nm}$. This strain contained the already identified $\mathrm{Y} 132 \mathrm{H}$ mutation on both of its ERGIl alleles and two heterozygotic substitutions S279S/F and G465G/S. The importance of this $\mathrm{Y} 132 \mathrm{H}$ mutation for azole susceptibility was previously demonstrated (Sanglard et al., 1998b). Strain J9 13004/1, isolated from an AIDS patient, contained four inutations, of which only V452A has not been reported previously. The laboratory mutant $6406 / 8$ contained only one mutation E165Y. This mutation was the result of a double nucleotide change in a single codon, GAA into TAC. 


\section{ERG11 activity and sensitivity determination}

In recent papers Lamb et al. (1997) and Singlard et al. (1998b) described elegant strategies to test for alterations in affinity of variant cytochrome P450 14demethylases for azole derivatives. Both used heterologous expression in a Saccharomyces cerevisiae host using a strong GAL promoter to overexpress the Candida ERGI1. In the Lamb et al.(1997) system, the recombinant protein was purified and analysed with biochemical assays, whereas in the Sanglard et al. (1998b) method, affinity changes were directly correlated with changes in MIC values obtained with the engineered Saccharomyces strains. In this study we used biochemical assays with subcellular extracts prepared from the different isolates to look for the effects of different azole concentrations on either the incorporation of $\left[2-{ }^{14} \mathrm{C}\right]$-mevalonic acid into sterols or on the CO-complex formation of reduced microsomal cytochrome $\mathrm{P} 450$ fractions. Because two strains of the Sanglard et al. (1998b) paper, C26 and C40, were included in this study, the results obtained with the different strategies could be compared.

The results obtained with the subcellular sterol biosynthesis method are summarised in Table I. In the case of J913004/I and 6406/8, addition of PMSF to the homogenisation buffer was found to be essential for enzyme activity, whereas no improvement was observed for the other isolates tested. For consistency reasons, PMSF was added to all preparations. According to the $\mathrm{IC}_{50}$ values obtained for itraconazole, only strain NCPF 3363, previously reported to contain a mutated cytochrome P450 (Vanden Bossche et al., 1990), was less sensitive, having an $\mathrm{IC}_{50}$ value of $92 \mathrm{nM}$. All other isolates gave $\mathrm{IC}_{50}$ values in the range 14-40 $\mathrm{nM}$ and as such can be regarded as itraconazole sensitive. However, differences were seen at concentrations above the $I_{50}$ value, as shown in Table I. [ndeed at $100 \mathrm{nM}$, a near complete inhibition was seen with the susceptible ATCC reference strains 28516 and 44858, and with isolates B59626, B59630 and J913004/I. A leaky ergosterol biosynthesis inhibition (14-24\% of control) at this concentration was seen with extracts from 6406/8, C26 and C40, suggestive of a decreased affinity for itraconazole. For fluconazole, more pronounced differences were observed. $\left[C_{50}\right.$ values ranged more than 100 -fold, from $41 \mathrm{nM}$ for the most sensitive isolate up to $4880 \mathrm{nM}$ for the C26 isolate. As well as in this $\mathrm{C} 26$ strain, reductions in affinity were seen for three other isolates, NCPF 
3363, J913004/I and C40. Fluconazole was as active as itraconazole with regards to inhibition of subcellular sterol biosynthesis for both reference ATCC strains, whereas for all other azole-resistant strains tested, a 2.4-fold to 244-fold difference was observed in favour of itraconazole, suggesting that fluconazole binding is more sensitive to the amino acid variations present in these isolates. Incomplete inhibition of ergosterol biosynthesis was more pronounced with fluconazole because even at $1000 \mathrm{nM}$, isolates NCPF 3363, J913004/1, 6406/8, $\mathrm{C} 26$ and $\mathrm{C} 40$ still produced $16-78 \%$ of the amounts found in control conditions. Prevention of CO-complex formation in the reduced microsomal cytochrome P450 preparations is another assay to test the affinity of the protein for an azole (Vanden Bossche et al., 1987; Yoshida, 1988). With this method a constant content of $0.1 \mathrm{nmol}$ cytochrome $\mathrm{P} 450 \mathrm{per} \mathrm{ml}$ is used, enabling direct comparison of susceptibility among different isolates. Fluconazole was consistently found to be less active compared to itraconazole, even in the sensitive reference ATCC strains 28516 and 44858. Itraconazole was able to prevent CO-cytochrome complex formation in all isolates from which an active extract could be isolated. For strains J913004/I and 6406/8 we consistently failed to obtain a fraction suitable for analysis. The addition of a protease inhibitor such as PMSF, or a protease inhibitor mix (leupeptin, PMSF, APMSF) did not sufficiently improve the yield of active cytochrome P450. For the other strains, as seen in the sterol biosynthesis assays, differences were far more pronounced for fluconazole, $\mathrm{IC}_{5_{0}}$ values ranged almost 35 -fold from 140 up to $5030 \mathrm{nM}$. Again, microsomes isolated from C26 and C40 showed the largest shifts, although the C40-microsomal fraction was the least sensitive in this assay. The cytochrome P450 isolated from NCPF 3363 was as sensitive as that isolated from susceptible strains.

\section{Computer-aided sequence analysis of identified mutations.}

In Table II the published sequence variations of Candida albicans ERGII alleles are summarised next to the available growth sensitivity data. In total 53 full sequences were obtained, resulting in 98 variations relative to the Lai \& Kirsch (1989) sequence at 29 different locations, in addition to the PCR-induced T315A mutation reported by Lamb et al. (1997). This is an average of 1.85 mutations per sequence. Because not all authors mention the silent nucleotide mutations 


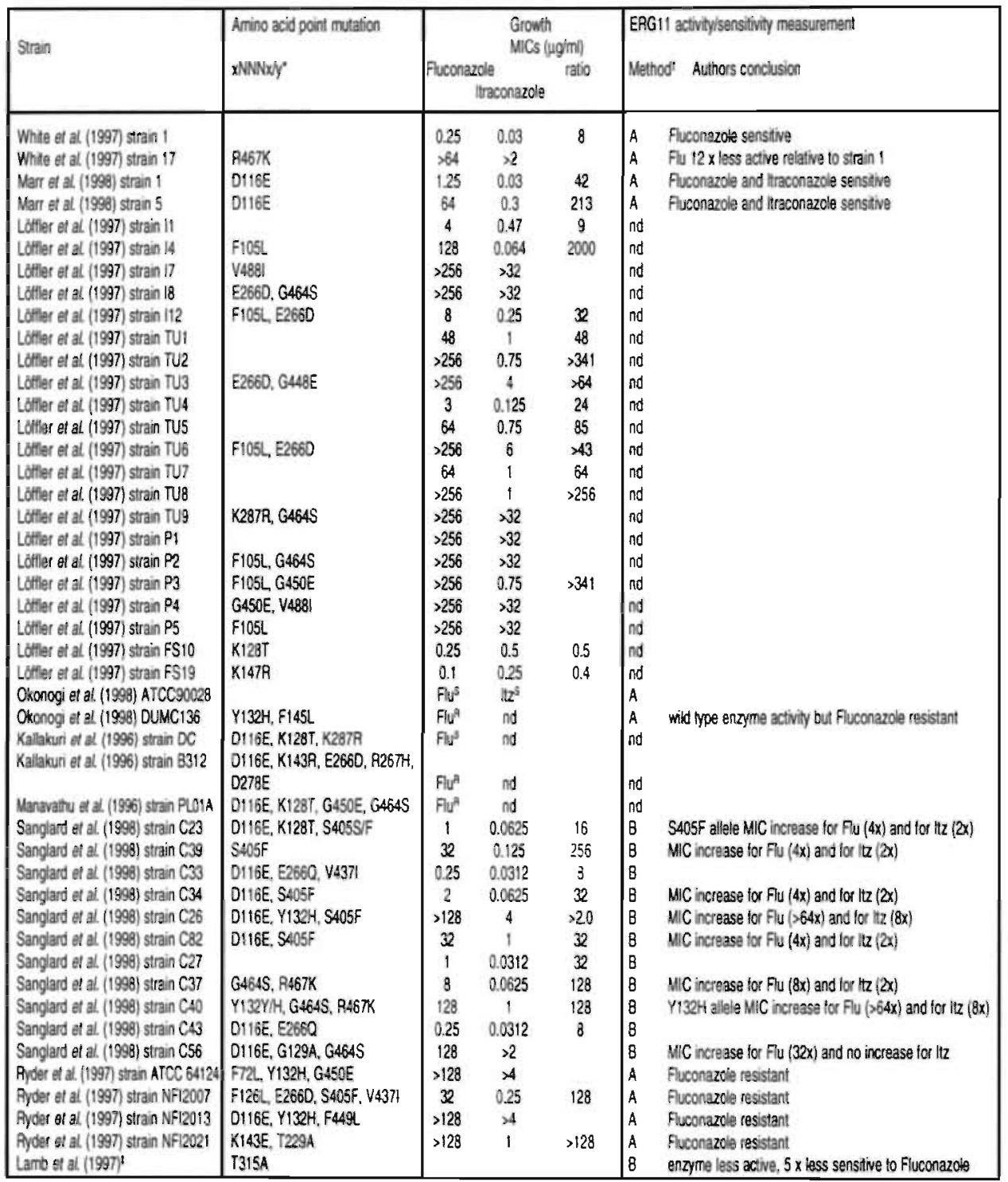

- $x$ is the amino aciof lound in the published EAGI1 sequence, NNN is the position in the ORF, $y$ is the amino acid tound in the isolate. If both alleles ditter in sequence a slash is used to indicate this heterozygosity

1. A: [14C-mevalonic acid incorporation into sterols using a subcelular fraction B: heterologous overexpression (gal-promoter) of the cloned ERG II in a Saccharomyces cerevisiae host. Senstivity is measured as an increase of MC relative to the parant allele.

Flu is fluconazole, iz is traconazole

nd: no dala availabla

I. Nutation created oy PCR 
found, a precise number of nucleotide changes cannot be given. For the seven strains sequenced in this study, 59 silent mutations were found (16 positions) compared to 18 amino acid changes (12 different); which suggests a three-fold higher frequency of silent mutations. To visualise the position and the ficquency of the amino acids substitutions reported, a graphical representation was made (Figure 1). At the top of the figure, the aligned sequences of the gene products of Candida albicans ERGII and that of the bacterial Pseudomonas putida CYPIOI (P450 cam $)$ and their helical secondary structures are visualised. The alignment is taken from the model of Boscott \& Grant (1994). Gaps are represented as thin lines and predicted $\alpha$-helices are represented by boxes, for which the starting position and length are indicated. The letter code for the helices is indicated above the boxes. The mutations are represented by bars, for which the length is proportional to the frequency of occurrence. Different filling patterns are used to categorise the mutation: mutations found both in azolesensitive and -resistant strains are represented by open bars and are probably not important for azole affinity. These substitutions could reflect allelic or strain variation. A filled bar is used for the mutations experimentally demonstrated to be important for the affinity of an azole for the cytochrome P450. Non-characterised mutations are shown represented by hatched bars. The PCR-induced mutation is represented by an arrow. From figure $\mathrm{l}$ it is clear that the majority of the mutations were found in three regions, region I from amino acid 105-165, region 2 from 266- 287 and region 3 from 405-488. This last region also contains $\mathrm{C}_{470}$, the $5^{\text {th }}$ ligand of the haem. Three of the four mutations found with the highest frequency, D116E, K128T and E266D were found also in azole-sensitive strains; only G464S has been seen exclusively in resistant strains. No spontaneous mutation was found in the I-helix, which is highly conserved over the 14-demethylase cytochrome P450 family. A molecular three-dimensional model of C. albicans ERGII was proposed by Boscott \& Grant (1994, coordinates are available from these authors) after homology modelling onto the bacterial crystal structure of Cyp101p. In figure 2 views from two different angles are given of the ribbon model. The haem is shown in green and, as orientation aid, the central I-helix is represented in orange. Because of the projection onto the plane of the paper, localisation of the mutations can be misleading. To cir- 


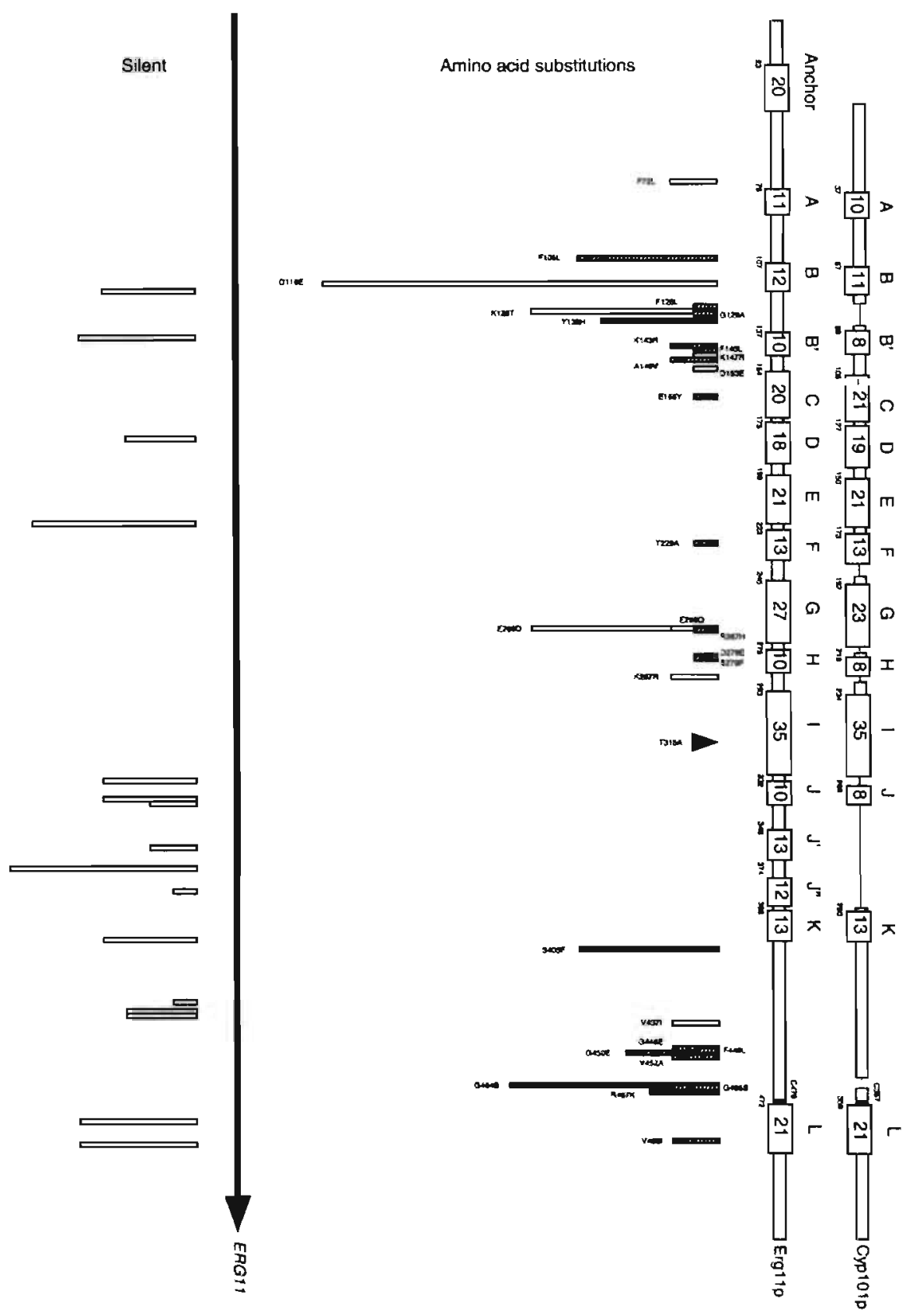


Figure 1: $\quad$ Visualisation of the localisation and trequency of mutations in the ERG11 (CYP51) sequence. At the top of the figure, the aligned sequences of Candida albicans Erg11p and that of the bacterial Pseudomonas putida Cyp101p and their secondary structure are visualised. Gaps are repr: sented as thin lines and predicted $\alpha$-helices are represented by boxes, for which the starting position and length are indicated. The letter code for the helices is indicated above the boxes. The amino acid mutations found are represented by bars, for which the length is proportional to the frequency of occurrence. Different filling patterns are used to categorise the mutation: mutations found both in azole-sensitive and -resistant strains are indicated by open bars; filled bars are used for the mutations for which it is experimentally demonstrated that they were important for the affinity of an azole for the cytochrome $\mathrm{P} 450$; non-characterised mutations are shown with hatched bars. The PCR-induced mutation is shown with an arrow. The fifth ligand of the haem, the $\mathrm{C}_{470}$ is also indicated. At the bottom of the figure, the ERG11 ORF is represented by a horizontal arrow. Silent mutations found in this study are represented by open bars. Again the length of the bars is proportional to the frequency of occurrence. The graph was made on scale with ClarisDRAW V1.0B

cumvent these optical artefacts, stereo views were included to allow a more precise 3D localisation. The mutations discussed in this paper are placed onto this ribbon model as solid spheres with a diameter of the VanderWaals interaction range of a carbon atom. The substitutions are again categorised according to the same principle as in figure 1. however, a colour code is used in this model: substitutions found in both azole-sensitive and azole resistant are represented by blue spheres. substitutions experimentally demonstrated to be important for azole affinity are shown in red, non-characterized mutations are shown in black and the PCR-induced mutation is shown in green. The cytochrome P450 Ergl lp catalyses the oxidative removal of the 14-methyl-group of ergosterol precursors. The prosthetic haem molecule is positioned between the proximal I-helix and the distal L-helix in the inner part of the enzyme as is shown in figure 2. This necessitates both the entry and positioning of the substrate such that its 14-methylgroup is in close proximity to the activated sixth ligand of the central haem. This suggests that the substrate should position below the l-helix and proximal to the haem. Because in this model no access channel is found of sufficient size to enable entry and exit of the substrate, it is hypothesised that sonne movement of 
Chapter 2
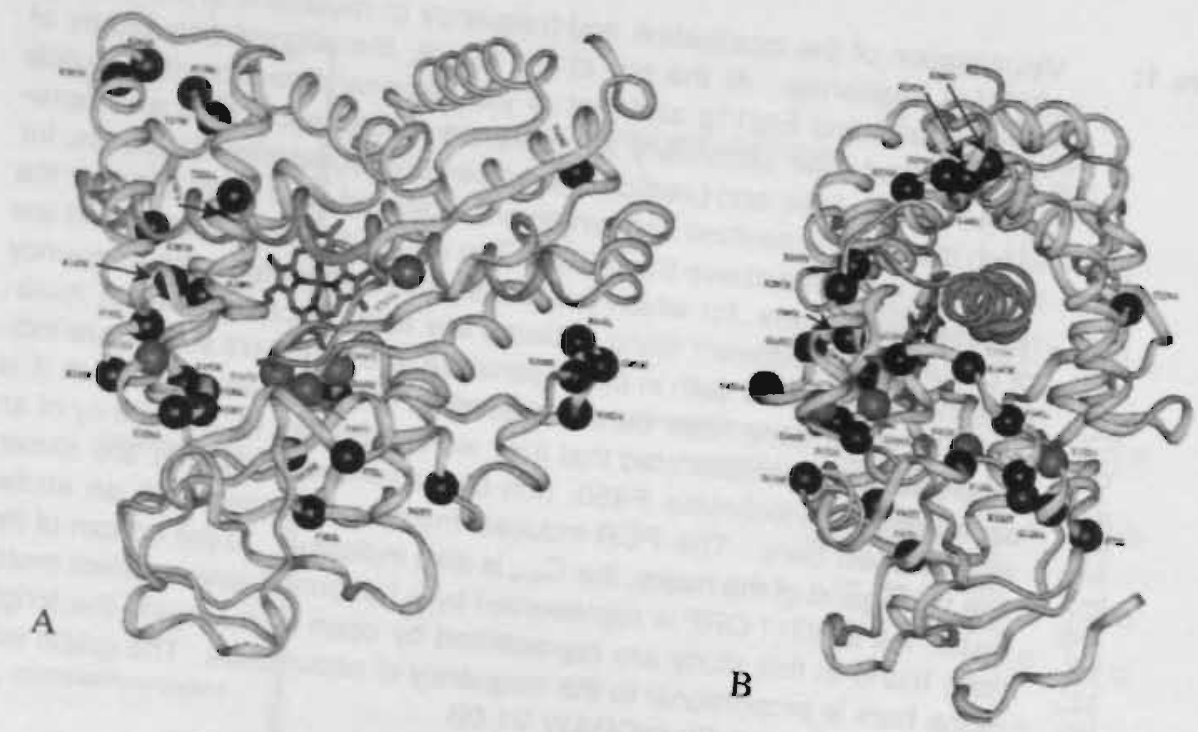

C
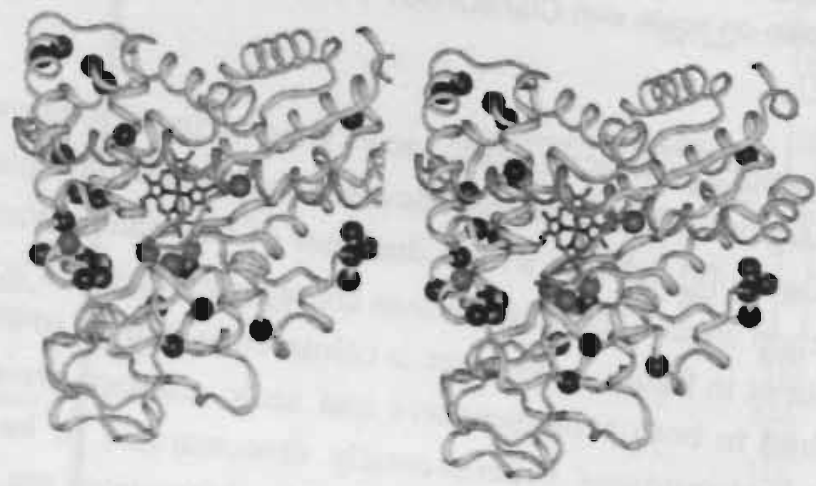

D

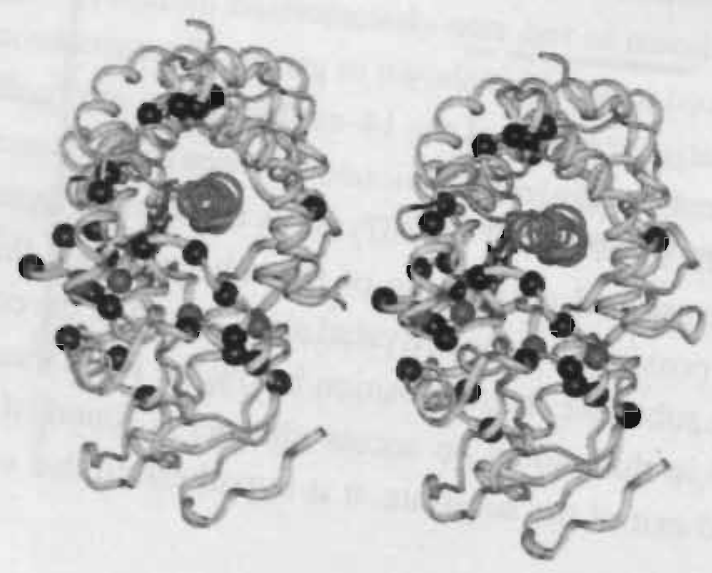


Figure 2: Ribbon presentation of the three-dimensional model of $C$. albicans CYP51A1 structure from two different viewpoints ( $A$ and $B$ ). The central I helix is shown in orange, the haem is shown in green. The mutations described in this study are marked by spheres and are categorised according to the same principle as in figure 1, however, al colour code is used in this model; substitutions found in both azole-sensilive and azole resistant are represented by blue spheres, substitutions experimentally demonstrated to be important for azole affinity are shown in red, non-characterized mutations are shown in black and the PCR-induced mutation is shown in green and labelled as described in Table I. To allow a more precise spatial localisation, stereo pictures of both views are shown in $C$ and $D$.

the $\mathrm{B}^{\prime}$ helix and/or the coil between the $\mathrm{F}$ and $\mathrm{G}$ helices is necessary for the entry. However, because of poor sequence similarity in this region between the fungal sequences and the bacterial models, no precise entry point can be identified. The antifungal azoles are believed to enter through the same access channel and inhibit the cytochrome $\mathrm{P} 450$ by binding with their unprotonated $\mathrm{N}$-atom to the sixth co-ordination site of the haem and occupy the substrate binding pocket (Vanden Bossche \& Koymans, 1997). An important fraction of the stability and specificity of the binding of different azoles, originates from their interaction of the N1-ligand moiety of the azole with the apoprotein. Mutations in the protein could alter the affinity for an azole by interference with the entry of the azole or could change interaction points either directly or indirectly by a repositioning of the tertiary structure through changes in the positions of the structural helices as was demonstrated by the G310D mutation in Saccharomyces cerevisiae Erg I lp (Vanden Bossche \& Koymans, 1997). The substitutions F126L, KI28T. G129A. Y132H. KI43R. F145L and Ki47R are close to this access channel and could interfere with the entry of the inhibitor. The G464S, G465S and R467K mutations are positioned behind the plane of the haem. The G465S and R467K mutations are probably too far away from the haem to interfere directly with the interaction of the azoles but G464S is in very close proximity. The S405F substitution is positioned just after the K-helix and is close to the substrate and azole binding pocket. Mutations E266D. R267H, D278E and S279F localise at the end of the G-helix and start of the H-helix on 
the surface of the protein. This region could act as a pivot for the G- and Fhelices to enlarge the access channel. Mutation T229A is on the F-helix, but rather distant from the I-helix. The V488I substitution is found at the end of the L-helix. The four mutations G448E, F449L, G450E and V452A are close to the site where the I-helix ends. No mutations are seen in the bottom part of the protein below the F105L mutation. This region of the protein is likely to be buried into the membrane.

It is likely that an amino acid that is important for azole interaction is conserved in the Ergllp sequences from other sensitive species. To investigate this, we first aligned all 19 known sterol 14-demethylases (13 Ergllp sequences from fungal origin, 3 Cyp5lp sequences from mammalian origin and 3 plant Cyp5lp's) using the Clustal-W multiple alignment algorithm. Table III lists the aligned amino acids obtained for all 29 identified mutations. The full sequence alignment is available from the corresponding author upon request. Only three amino acids were conserved for all available 14DM sequences, F126, G464 and R467. If the plant sequences were excluded, K143, K147, and E165 are conserved across the fungal and mammalian Cyp51p's and amino acids F145. G448, and G450 are conserved across all fungal Cyp51p'ss. Among the amino acid substitutions found in azole sensitive strains, D116E, D153E, E266D and V437I vary even among the yeast sequences, as do the non-characterised F105L, R267H, S279F, V452A and V488I substitutions. It is therefore unlikely that these substitutions are on their own of importance for azole binding. 


\section{Genbark- EMBL. \\ Acossion number

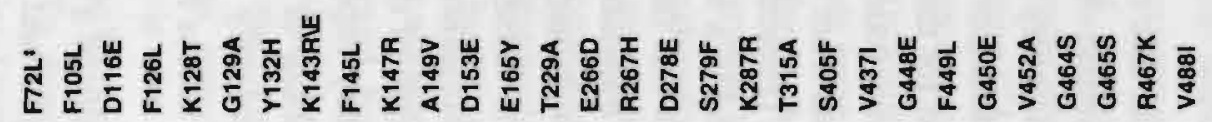

\section{Canodia abians}

Saccharomyces cerevisiae

Candida glebrata

Candida topicals

Candata hrusel

Candida parapsibsis"

Candida guilemoner

\section{Candida kelfr}

Pchia unomala*

Schicosaccharamyces pombe

Paniclimm tatom

Usilugo maydis

Uncinule necator

A

at

humb

Sanghum bicoidr

Tritioum aestivin

Arabiopses thatiana

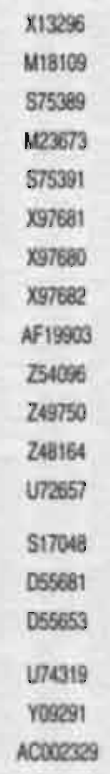

- partial sequence available

1 - indicative of a GAP in the sequence alignment

s amino acid numbering from the Candida albicans sequence 


\section{Discussion}

Strain 6406/8 was previously described as azole resistant but this could not be confirmed in this study. The different conditions in which sensitivity was measured could be at the origin of this discrepancy. Another possibility is that longterm storage and/or distribution of the isolate to different laboratories, resulted in changes. Indeed a similar phenomenon was demonstrated for the Darlington strain, for which isolates obtained from different locations were found to behave differently with regard to their sensitivity, and small variations were seen in their restriction fragment length polymorphism (RFLP) patterns (Pearce \& Howell, 1991). It is unlikely that the double nucleotide change found in a single codon was introduced at the same time. If the first mutation event was the GAA into TAA, this would introduce a stop codon interrupting the translation process. After homologous recombination, this would result in a 14-demethylase deficient strain as was reported by Hitchcock et al. (1987). The subsequent introduction of a second mutation TAA into TAC would be advantageous for the isolate because it would restore the transcription of the full length of the ORF and the 14-demethylase activity. The 14-demethylase deficiency reported could, however, also originate from the absence of a protease inhibitor in the enzyme preparation procedure, because we found such addition necessary for enzyme activity. To verify the different hypotheses we should need access to the different subcultured specimens from the original 6406/8 strain.

Three different methods are available to investigate the affinity of a cytochrome P450 for an azole inhibitor, and each method has its strengths and limitations. The $\mathrm{CO}$ binding assay is very easy to perform and allows immediate comparison between different isolates because a standard amount of cytochrome P450 is used. A drawback of this method is that preparations must be made from strains growing in high glucose and with oxygen limitation. Moreover, the preparation could contain non-14-demethylase cytochrome P450 and the long preparation time needed to obtain the washed microsomal preparation increases exposure to proteolysis. The subcellular ergosterol bioassay requires less preparation and as such is less sensitive to proteolysis. With both of these methods the enzymes are 
in their natural Candida membrane environment. This is in contrast with the third method: heterologous expression in Saccharomyces cerevisiae. This heterologous expression method allows measurements of single allele products but because of differences in preferred codon usage between Candida and Saccharomyces could also introduce contributions from silent mutations. The use of a strong $G A L$-promoter could also introduce unnaturally high concentrations of the cytochrome. Indeed Lamb et al. found concentrations of 2.5 $\mathrm{nmol} / \mathrm{mg}$ microsomal protein, at least 25 times the basal level (Lamb et al., 1997). This huge overexpression of membrane-bound protein forces cells to hyperproliferate their membranes, which often form multilamellar membrane structures around the nucleus (karmella) (Vergeres et al., 1993; Supply et al., 1993). It is therefore not surprising that the results obtained with the three methods do not match perfectly. The C26 ERGII variant has a lower affinity for fluconazole according to all three methods. In contrast, the 8-fold decrease in affinity for itraconazole suggested by the heterologous expression system was not confirmed by $\mathrm{CO}$-binding or by a decrease in $\mathrm{IC}_{50}$ in the subcellular assay. The incomplete enzyme inhibition at $100 \mathrm{nM}$ itraconazole observed in the subcellular assay could, however, be of importance because for growth inhibition in $C$. albicans a depletion of ergosterol is needed. If a leaky inhibition is sufficient for resistance, then 4 out of 9 isolates (NCPF 3363, 6406/8, C26 and C40) could be regarded as itraconazole refractory and in the case of fluconazole isolate J913004/1 is also resistant. These criteria suggest that the E165Y mutation found in the laboratory mutant interferes with both itraconazole and fluconazole binding. To demonstrate this, the E165Y mutation should be introduced by mutagenesis: if one envisages heterologous expression in a Saccharomyces host, one should moreover prevent the unintended $5263 \mathrm{~L}$ mutation resulting from the different translation of the CUG codon in Candida versus Saccharomyces. Three other refractory alleles contain the $\mathrm{Y} 132 \mathrm{H}$ stibstitution, corroborating its importance. As suggested by Sanglard et al. (1998) a concomitant substitutioni of $\mathrm{S} 405 \mathrm{~F}$ or R467K further decreases affinity, especially for fluconazole. The smaller. hydrophilic fluconazole molecule has fewer stabilisation sites in the active pocket compared to the lipophilic itraconazole molecule which may explain this difference in activity (Vanden Bossche \& Koymans, 1997). 


\section{Chapter 2}

Moreover, because the CO-binding assay did not reveal a diminished sensitivity for the NCPF 3363 isolate (having a homozygotic Y132H substitution), it is likely that a concomitant mutation is necessary for maximal effect. In this isolate, the originally reported shift in CO-binding sensitivity (Smith et al., 1986), comparable to that found in the $\mathrm{C} 26$ and $\mathrm{C} 40$ isolate for fluconazole, could not be reproduced on later occasions; this could be due to loss of a second mutation on one or on both alleles. Unfortunately, the isolate possessing the original phenotype could not be retrieved to investigate this hypothesis.

The sequence available for $C$. guilliermondii ERGII also contained a phenylalanine (F) aligning with the $\mathrm{S} 405$ from $C$. albicans. Because different $C$. guilliermondii isolates tend to vary substantially in their fluconazole susceptibility (Odds, 1992), it would be interesting to know the MIC of fluconazole for the isolate used for sequencing and to verify whether the presence of that phenylalanine correlates with higher fluconazole MIC values. From the substitutions identified in the J913004/I isolate, D1 16E and K128T probably do not contribute to the decrease in fluconazole activity because these substitutions were also found in multiple azole sensitive strains. In fact, it is likely that all substitutions found in azole-sensitive strains and presumably also a selection of the non-characterized substitutions found only in resistant strains so far, reflect strain variation. From the substitutions found in the $\mathrm{N}$-terminal and central region of the protein only the $\mathrm{Y} 132 \mathrm{H}$ was associated with resistance. In these regions a higher proportion of the substitutions was also found in azole-sensitive strains when compared to the $\mathrm{C}$-terminal region. No spontaneous substitutions have been found so far in the very conserved central I-helix. A reason for this could be that substitutions in this region induce loss of function of the enzyme, what would result in slower growth rates and therefore a disadvantage for survival. Such a mutation, G310D. was described in Saccharomyces cerevisiae (Ishida et al., 1988). The C-terminal part contains three substitutions associated with resistance and from the remaining substitutions only one was found in azole-sensitive strains. This region therefore looks to be of greater importance for azoleresistance. Further study is needed to verify to what extent V452A and G464S mutations contribute to the resistance. The fact that the G464S was found by several investigators in azole resistant strains makes this a prioritised substitu- 
tion for investigation. The V452A substitution, as well as the G448E, F449L and G450E mutations are situated near the end of the central I-helix and the Jhelix, an area of the protein that could be important for the docking of the cytochrome P450-reductase. Indeed it is hypothesised that this region, which is absent in the Cypl01 sequence, and as such also in the model, is creating the recognition and docking site for the reductase. It has to be stressed that the 3Dmodel used is based on a soluble isozyme of bacterial origin, with different substrate specificity. For this reason, only approximate locations of the mutations can be given. The Mycobacterium tuberculosis CYP5I gene, identified by in silico analysis of the full genome, could become a better model because this soluble enzyme could 14-demethylate dihydrolanosterol but crystallisation and structure determination has not been achieved yet (Aoyama et al. 1998, Bellamine et al. 1998). The availability of multiple sequences of $E R G I I$ from Candida krusei, a species with a $14 \alpha$-demethylase less susceptible for azoles (Marichal et al., 1995b, Orozco et al. 1998) could provide additional comparative material to identify important regions for binding of azoles to the cytochrome P450.

\section{Acknowledgements}

We thank B. Dupont (Paris, France), D. Sanglard (Lausanne, Switzerland), G. Just (Frankfurt. Germany) and D. Keriidge (Cambridge. UK) for the supply of isolates, L. Leijssen, I. Beyens, T. Verhulst, E. Nijenhuis and L. Van Nuffel for their excellent technical skills and I. Moelans for interesting discussions. 


\section{References}

1 Aoyama, Y., Horiuchi, T., Gotoh, O., Noshiro, M., \& Yoshida, Y. (1998). CYP51-like gene of Mycobacterium tuberculosis actually encodes a P450 similar to eukaryotic CYP51. J. Biochem. 124, 694-696.

2 Bard, M., Lees, N.D., Turi, T., Craft, D., Cofrin L., Barbuch, R., Koegel, C., \& Loper, J.C. (1993) Sterol synthesis and viability of ERG1I (cytochrome P450 lanosterol demethylase) mutations in Saccharomyces cerevisiae and Candida albicans. Lipids 28. 963-967.

3 Bellamine, A., Mangla, A.T., Nes, D., \& Waterman M. R. (1998). Is the Mycobacterium tuberculosis CYP51-like P450 a 14 $\alpha$-demethylase. In Program and Abstracts of theFourth International Symposium on P450 Biodiversity and Biotechnology, Strasbourg, France. IC-11.

4 Bodey, G. P. (1997). Resistance to antimicrobial agents revisited. Curr Opin Infect Dis 10. 419-421.

5 Boscott, P. E. \& Grant, G. H. (1994). Modeling cytochrome P450 14 $\alpha$-demethylase (Candida albicans) from P450cam. J Mol Graph 12, 185-192+195.

Bradford, M. (1976). A rapid and sensitive method for the quantitation of microgram quantities of protein utilizing the principle of protein-dye binding. Anal Biochem 72, 248254.

Cartlegde, J. D., Midgley, J. \& Gazzard, B. G. (1997). Clinically significant azole crossresistance in Candida isolates from HIV-positive patients with oral candidosis. AIDS 11(15), 1839-1844.

8 De Muri, G. P., Hostetter, M. K. (1995). Resistance to antifungal agents. Pediatr Clin North Am 42(3), 665-685.

9 Denning, D. W., Baily, G. G., Hood, S. V. (1997). Azole resistance in Candida. Eur . Clin Microbiol Infect Dis 16, 261-280.

10 Doignon, F., Aigle, M., \& Ribereau-Gayon, P. (1993). Resistance to imidazoles and triazoles in Saccharomyces cerevisiae as a new dominant marker. Plasmid 30, 224-233.

11 Dupont, B. (1995). Azole antifungal agents : emerging and inherent resistance. Curr Opin Infect Dis 8, 424-427. 
12 Frosco, M., \& Barrett, J. F. (1998). Importance of antifungal drug-resistance : clinincal significance and need for novel therapy. Exp. Opin Invest Drugs. 7(2), 175-198.

13 Hartman, P. G., Sanglard D. (1997). Inhibitors of ergosterol as antifungal agents. Curr Pharm Des 3, 177-208.

14 Hitchcock, C. A., Russell, N. J., \& Barrett-Bee, K. J. (1987). Sterols in Candida albicans mutants resistant to polyene or azole antifungals, and of a double mutant $C$. albicans 6.4. Crit Rev Microbiol. 15(1), 111-115.

15 Ishida,N. Y., Aoyama, Y., Hatanaka, R., Oyama, Y., Imajo, S., Ishiguro, M., Oshima, T., Nakazato, H., Noguchi, T., Maitra, U.S., Mohan, V.P., Sprinson, D. B. \& Yoshida, Y. (1988). A single amino substitution converts cytochrome P45014dm to an inactive form. cytochrome P450SG1: (complete primary structure deduced from cloned DNAs.) Biochem Biophys Res Commun 155, 317-323.

16 Johnson, E. M. \& Warnock, D. W. (1995). Azole drug resistance in yeast. J Antimicrob Chemother 36, 751-755.

17 Joseph-Horn, T. \& Hollomon, D. W. (1997). Molecular mechanisms of azole resistance in fungi. FEMS Microbiol Lett 149. 141-149.

18 Kallakuri, S., Manavathu, E. K., Arganoza, M. T., Vazquez, J. A. \& Sobel J. D. (1996). Molecular characterization of the gene encoding cytochrome P450-dependent lanosterol $14 \alpha$-demethylase from a fluconazole-resistant clinical isolate of Candida albicans. In Program and Abstracts of the $96^{\text {th }}$ American Society for Microbiology General Meeting, New Orleans, Lousiana, 1996. Abstract F-63, p. 84. American Society for Microbiology, Washington, DC.

19 Kelly, S. L., Lamb, D. C., Kelly, D. E., Manning, N. J., Loefller, J., Hebart, Schumacher, U., \& Einsele H. (1997). Resistance to fluconazole and cross-resistance to amphotericin B in Candida albicans from AIDS patients caused by defective sterol deltas,6-desaturation. FEBS Lett، 400(1), 80-82

20 Kolaczkowski, M., \& Goffeau. A. (1997). Active efflux by multidrug transporters as one of the strategies to evade chemotherapy and novel practical implications of yeast pleiotropic drug resistance. Pharmacol Ther 76, 219-242.

21 Lai, M. H., \& Kirsch. D. R. (1989). Nucleotide sequence of cytochrome P450 LIAI (lanosterol $14 \alpha$ demethylase) from Candida albicans, Nucleic Acids Res 17, 804.

22 Lamb, D. C., Kelly, D. E.., Schunck, W.-H., Shyadehi, A. Z., Akhtar, M. , Lowe, D., Baldwin, B. C. \& Kelly, S. L. (1997). The mutation T315A in Candida albicans sterol $14 \alpha$-demethylase causes reduced enzyme activity and fluconazole resistance through reduced affinity. J Biol Chem 272. 5682-5688. 
23 Löfler, J., Kelly, S. L., Hebart, H., Schumacher, U., Lass-Flörl, C. \& Einsele, H. (1997). Molecular analysis of cyp51 from fluconazole-resistant Candida albicans strains. FEMS Microbiol Lett 151, 263-268.

24 Manavathu, E. K., Kallakuri, S., Arganoza, M. T., Pierson, C. \& Vazquez, J. A. (1996). Amino acid variations of cytochrome P450-dependent lanosterol $14 \alpha$-demethylase (P450LDM) from a fluconazole-resistant clinical isolate of Candida albicans. In Program and Abstracts of the $36^{\text {th }}$ Interscience Conference on Antimicrobial Agents and Chemotherapy. New Orleans, Lousiana. 1996. Abstract C68, p. 46. American Society for Microbiology, Washington, DC.

25 Marichal, P.\& Vanden Bossche, H. (1995a). Mechanisms of resistance to azole antifungals. Acta Biochim Pol 42(4), 509-516.

26 Marichal, P., Gorrens, J., Coene, M.-C., Le Jeune, L., \& Vanden Bossche H. (1995b). Origin of differences in susceptibility of Candida krusei to azole antifungal agents. Mycoses 38, 111-117.

27 Marichal P., Vanden Bossche, H., Odds, F. C., Nobels, G. , Warnock, D. W., Timmerman, V., Van Broeckhoven, C., Fay, S. \& Mose-Larsen, P. (1997). Molecular biological characterization of an azole-resistant Candida glabrata isolate. Antimicrob Agents Chemother 41, 2229-2237.

28 Marr, K. A., Lyons, C. N., Rustad, T., Bowden, R. A. \& White, T. C. (1998). Rapid, transient fluconazole resistance in Candida albicans is associated with increased mRNA levels of CDR. Antimicrob Agents Chemother 42, 2584-2589.

29 National Committee for Clinical Laboratory Standards. (1995). Reference method for broth dilution susceptibility testing of yeasts. Tentative standard M27-A. National Committee for Clinical Laboratory Standards, Villanova, Pa.

30 Odds, F. C. (1992). Antifungal susceptibility testing of Candida spp. by relative growth measurement at single concentrations of antifungal agents. Antimicrob Agents Chemother. $36(8), 1727-1737$.

31 Odds, F. C. (1998). Should resistance to azole antifungals in vitro be interpreted as prediciting clinical non-response? Drug Res Updates 1. 11-15.

32 Odds, F. C., Vranckx, L., and Woestenborghs, F. (1995). Antifungal susceptibility testing of yeasts: Evaluation of technical variables for test automation. Antimicrob Agents Chemother 39, 2051-2060. 
Okonogi, K., Asia, K., Tsuchimori, N., Perfect, J. R., Gotoh, O., \& Y. Yoshida. (1998). A novel mechanism for emerging azole-resistant Candida albicans in AIDS patients. In Program and Abstracts of the Fourth International Symposium on P450 Biodiversity and Biotechnology, Strasbourg, France.

Orozco, A. S., Higginbotham, L. M., Hitcheock, C. A., Parkinson T., Falconer D., Ibrahim, A.S., Ghannoum, M.A., \& Filler, S.G. (1998). Mechanism of fluconazole resistance in Candida krusei. Antimicrob Agents Chemother 42. 2645-2649.

Pearce, M. A., \& Howell, S. A. (1991). Restriction fragment length polymorphism analysis of azole-resistant and azole-susceptible Candida albicans strains. J Clin Microbiol. 29(7), 1364-1367.

Rex, J. H., Rinaldi, M. G., \& Pfaller, M. A. (1995). Resistance of Candida species to fluconazole. Antimicrob Agents Chemother 39, 1-8.

Rodriguez, R., Low, C., Bottema, C., \& Parks, L. (1985) Multiple functions for sterols in Saccharomyces cerevisiae. Biochem Biophys Acta 837, 336-343.

Ryder, N.S. \& Favre, B. (1997). Resistance to azoles in Candida albicans caused by mutations in the lanosterol $14 \alpha$-demethylase gene. In Program and Abstracts of the $37^{\text {th }}$ Interscience Conference on Antimicrobial Agents and Chemotherapy, Toronto. Canada., 1997. Abstract C-13, p. 48. American Society for Microbiology, Washington, DC.

Sanglard, D., Kuchler, K., Ischer, F., Pagani, J. L., Monod, M.\& Bille, J. (1945). Mechanisms of resistance to azole antifungal agents in Candida albicans isolates from AIDS patients involve specific multidrug transporters. Antimicrob Agents Chemother 39. 2378-2386.

Sanglard D., Ischer, F., Calabrese, D., de Micheli, M., \& Bille, J. (1998a). Multiple resistance mechanisms to azole antifungals in yeast clinical isolates. Drug Res Updates $\mathbf{I}$. 255-265.

Sanglard, D., Ischer, F., Koymans, L. . \& Bille. J. (1998b). Amino acid substitutions in the cytochrome P450 lanosterol i4alpha-demethylase (CYP51) from azole-resistant Candida albicans clinical isolates contributing to the resistance to azole antifungal agents. Antimicrob Agents Chemother 42, 241-253.

Smith, K. J., Warnock, D. W., Kennedy, C. T. C.. Johnson, E. M., Hopwood, V., Van Cutsem, J. \& Vanden Bossche, H. (1986). Azole resistance in Candida albicans. J'Med Ver Mycol 24, 133-144.

Supply, P., Wach, A.. Thines-Sempoux, D. \& Goffeau, A. (1943). Proliferation of intracellular structures upon overexpression of the PMA2 ATPase in Saccharomyces cerevisiae. J Biol Chem 268(26), 19744-19752. 
44 Vanden Bossche, H. (1997). Mechanisms of antifungal resistance. Rev Iberoam. Micol 14. 44-49.

45 Vanden Bossche, H., \& Koymans, L. (1997). Cytochromes P450 in fungi. Mycoses 41(suppl. 1), 32-38.

46 Van den Bossche, H., Willemsens, G., Cools, W., Cornelissen, F., Lauwers, W. F. \& Van Cutsem, J. M. (1980). In vitro an in vivo effects of the antimycotic drug ketoconazole on sterol synthesis. Antimicrob Agents Chemother 17. 922-928.

47 Vanden Bossche, H., Bellens, D., Cools, W., Gorrens, J., Marichal, P., Verhoeven, H., Willemsens, G., De Coster, R., Beerens, D., Haelterman, C., Coene, M.-C., Lauwers, W. \& Le Jeune, L. (1986). Cytochrome P-450: target for itraconazole. Drug Dev Res 8. 287-298.

48 Vanden Bossche, H., Marichal, P., Gorrens, J., Bellens, D., Verhoeven, H., Coene, M.C.. \& et al. (1987). Interaction of azole derivatives with cytochrome P-450 isozymes in yeast, fungi, plants and mammalian cells. Pestic Sci 21, 1-13.

49 Vanden Bossche, H., Marichal, P., Gorrens, J., Bellens, D., Moereels, H. \& Janssen, P. A. J. (1990). Mutation in cytochrome P450-dependent. $14 \alpha$-demethylase results in decreased affinity for azole antifungals. Biochem Soc Trans 18, 56-59.

50 Vanden Bossche, H., Marichal, P., Odds, F. C., Le Jeune, L., \& Coene, M.-C.. (1992). Characterization of an Azole-Resistant Candida glabrata isolate. Antimicrob Agents Chemother 36, 2602-2610.

51 Vanden Bossche, H., Marichal, P., Odds, F. C. (1994). Molecular mechanisms of drug resistance in fungi. Trends Microbiol 2, 393-400.

52 Vanden Bossche, H., Dromer, F., Improvisi, L., Lozano-Chiu, M.. Rex. J. H. \& Sanglard, D. (1998). Antifungal drug resistance in pathogenic fungi. Med Mycol 36(suppl.1). 119-128.

53 Vergeres, G., Yen, T. S., Aggeler. J., Lausier, J. \& Waskell, L. (1993). A model system for studying membrane biogenesis. Overexpression of cytochrome b5 in yeast results in marked proliferation of the intracellular membrane. J Cell Sci 106 (1). 249-259

54 Watson, P.F., Rose, M. E., Ellis, S. W., England, H. \& Kelly, S. L.. (1989) Defective sterol C5-6 desaturation and azole resistance: a new hypothesis for the mode of action of azole antifungals. Biochem Biophys Res Commun 164. $1170-1175$.

White. T. C. (1907). The presence of an R467K amino acid substitution and loss of allelic variation correlate with an azole-resistant lanosterol. $14 \alpha$-demethylase in Candida albicans. Antimicrob Agents Chemother 41, 1488-1494. 


\section{Azole resistance and CYP51 mutations}

56 White T.C., Bowden, R. A., Marr, K. A. (1998). Clinical, cellular and molecular factors that contribute to antifungal drug resistance. Clin Microbiol Rev 11, 382-402.

57 Yoshida, Y. (1988). Cytochrome P450 of fungi, primary target for azole antifungal agents. In Current topics in Medical Mycology, (Mc Ginnis, M. R. , Ed.), pp. 388-418. Springer Verlag, Berlin,Germany. 



\section{Accumulation of 3-ketosteroids induced by itraconazole in azole-resistant clinical Candida albicans isolates.}

Patrick Marichal, ${ }^{1.6}$ Jos Gorrens, ${ }^{1}$ Leen Laurijssens, ${ }^{1}$ Karen Vermuyten, ${ }^{\prime}$ Carl Van Hove, ${ }^{2}$ Ludo Le Jeune, ${ }^{3}$ Peter Verhasselt, ${ }^{4}$ Dominique Sanglard, ${ }^{5}$ Marcel Borgers $^{6}$, Frans C. S. Ramaekers ${ }^{6}$, Frank Odds, ${ }^{1}$ and Hugo Vanden Bossche ${ }^{1}$

Anti-Infectives Research Departments, ${ }^{1}$ Immunology Department, ${ }^{2}$ Analytical Department, ${ }^{3}$ Biotechnology Department'; Janssen Research Foundation, Beerse, Belgium

Institut de Microbiologie, Centre Hospitalier Universitaire Vaudois, Lausanne, Switzerland, ${ }^{5}$ Department of Molecular Cell Biology \& Genetics, University Maastricht, The Netherlands'.

Running title: Itraconazole induced inhibition of the 3-ketoreductase.

Antimicrobial Angents and Chemotherapy (accepted) 


\section{SUMMARY.}

The effects of itraconazole on ergosterol biosynthesis were investigated in a series of 16 matched clinical Candida albicans isolates, which had been previously analyzed for mechanisms of resistance to azoles (Sanglard et al. AAC (1995) 39:2378-2386). In control conditions all isolates contained ergosterol as the predominant sterol except two strains (C48 and C56). In isolates $\mathrm{C} 48$ and $\mathrm{C} 56$, both less susceptible to azoles than their parent $\mathrm{C} 43$, substantial concen-

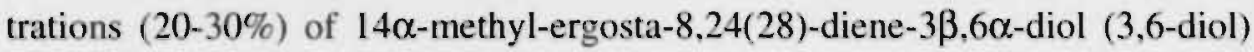
were found. Itraconazole treatment of $\mathrm{C} 43$ resulted in a dose-dependent inhibition of ergosterol biosynthesis ( $\mathrm{IC}_{50} 2 \mathrm{nM}$ ) and accumulation of 3,6-diol (up to $60 \%$ of total sterol) together with eburicol, lanosterol, obtusifoliol, $14 \alpha$-methylergosta-5,7,22,24(28)-tetraene-3 $\beta$ ol and $14 \alpha$-methyl-fecosterol. In strains C48 and C56 no further increase of 3,6-diol was observed after exposure to itraconazole. Ergosterol synthesis was less sensitive to itraconazole inhibition, as was expected for these azole-resistant isolates which overexpress the ABC-transporter genes $C D R I$ and $C D R 2$. In addition to the 3,6-diol, substantial amounts of obtusifolione were found after exposure to itraconazole. This toxic 3-ketosteroid was demonstrated previously to accumulate after itraconazole treatment in Cryptococcus neoformans and Histoplasma capsulatum but was so far not yet reported in Candida isolates. Accumulation of obtusifolione correlated with less trailing of growth inhibition in these azole-resistant strains compared to that found in the sensitive parent strain, although the onset of growth inhibition only occurred at higher concentrations of itraconazole. Up till now ERG25 and $E R G 26$ are the only genes assigned to the 4-demethylation process, of which the 3-ketoreductase is part. To verify whether mutations in these ERG25 genes contributed to obtusifolione accumulation, their nucleotide sequence was determined in all three related isolates. No mutations in ERG25 alleles of isolates C48 and C56 were found, suggesting that this gene is not involved in obtusifolione accumulation. The molecular basis for the accumulation of this sterol in these two strains remains to be established. 


\section{INTRODUCTION}

The incidence of fungal infections has increased during the last decade. Only a few classes of antifungal compounds are available to treat these infections. One important class consists of inhibitors of ergosterol biosynthesis (EBI). These include the allylamines, inhibitors of squalene epoxidase; the morpholines, which inhibit both the $\Delta^{14}$-reductase as well as the $\Delta^{8.7}$-isomerase; and the imidazoles and triazoles (azoles), which interfere with the cytochrome P450s catalyzing the lanosterol $14 \alpha$-demethylase and sterol $\Delta^{22}$-desaturation. In patients with impaired immune responses, e.g. AIDS patients, neutropenic patients and patients receiving bone-marrow or organ transplants, a higher incidence of nonresponse to treatment is found (40). Treatment failures may result from hostrelated factors, abnormal drug pharmacokinetics or from resistance of the infecting fungus to the agent used. Over the last five years a plethora of studies have been published to elucidate the underlying causes of clinical resistance to azoles. These studies have been extensively reviewed $(2,3,4,6,9,11,15,21,25,26$, $38-40,44)$. Several mechanisms have been identified that contribute to fungal resistance to azoles. Probably the most common mechanism is to effect a diminution in the concentration of active compound at the target site. In the majority of cases studied recently, this was the result of overexpression of efflux pumps $(8,20,27)$, but in earlier studies permeability changes of the plasma membrane were also found (12). So far, two types of efflux transporters have been reported. The ATP-binding-cassette type (ABC transporters; e.g. CDRI and $C D R 2$ ) can export a wide variety of azoles and unrelated chemica!s inciuding antifungal sterol synthesis inhibitors such as amorolifine and terbinafine which do not inhibit the action of cytochrome P450s (18, 28. 29). This group of proteins uses the energy freed by the hydrolysis of ATP to effect the effiux of compounds out of the cell. The so-called "major facilitators" (e.g. CaMDRI, previously described as $B E N^{r}$ ) identified so far in fungi have a much narrower substrate spectrum so that only hydrophilic azole compounds such as fluconazole are exported whereas lipophilic azoles such as itraconazole are not affected (27). The energy for this second class of pump is provided by the proton gradient across the membrane. 
A second general type of azole resistance mechanism involves changes at the level of the antifungal target. The primary target for the azole class of antifungal is the cytochrome P450 catalyzed $14 \alpha$-demethylation of ergosterol precursors. This enzyme is encoded by ERGII (also described as ERG16, CYP5I). Overexpression of this enzyme induced either by enhanced transcription or by gene or chromosomal amplification results in a decreased susceptibility to this class of antifungal $(5,22)$. Point mutations in ERGII such as $\mathrm{Y} 132 \mathrm{H}$ (tyrosine 132 is replaced by a histidine), T315A (threonine 315 replaced by alanine) or R476K (arginine 476 replaced by lysine) have been shown to decrease the affinity of the target for an azole $(19,30,43)$. Numerous publications have listed other ERGII mutations, but unfortunately the effect of the mutation on azole sensitivity was not always tested in these studies.

The third way in which fungi achieve effective resistance to azoles is to circumvent or compensate for the toxic consequences of the azole-induced depletion of ergosterol and coincidental accumulation of 14-methylated precursors. For example, it was shown in Saccharomyces cerevisiae that a strain deficient in Erg 11 p activity only survived in the presence of a concomitant defect in the $\Delta^{5.6}$ desaturase, encoded by the ERG3 gene (16). In C. albicans, ERG3- deficient strains were found to be azole resistant (17). It was hypothesized that resistance to fluconazole was due to the combination of the presence of substantial quanti-

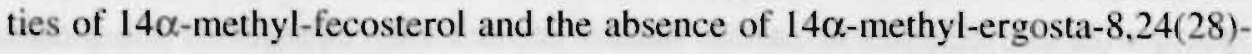
diene-3 $\beta, 6 \alpha$-diol (3,6-diol).

Despite the numerous recent molecular genetic studies on azole resistance. little attention has been paid to the details of inhibition of the ergosterol biosynthetic pathway in clinical azole resistant Candida albicans strains. In this study, we have investigated the effects of itraconazole on ergosterol biosynthesis in a series of matched clinical isolates that were biochemically characterized previously in the pivotal study of Sanglard et al. (27). 


\section{MATERIAL AND METHODS.}

\section{Strains.}

The $C$. albicans strains used in this study originated from the Institute of Microbiology (Centre Hospitalier Universitaire Vaudois, Switzerland). The strains were isolated from AIDS patients with oropharyngeal Candida infections. Identification of the yeast isolates and their clonal relatedness were described by Sanglard et al. (27). Yeasts were maintained as glycerol stocks at $-80^{\circ} \mathrm{C}$. The inocula for each individual experiment were prepared from these glycerol stocks to minimize the possible influences of genotypic or phenotypic instability. Table I summarizes the biochemical characterization of the isolates.

\section{MIC determination.}

To verify that the strains showed azole susceptibility phenotypes similar to the original published characteristics, MICs were determined spectrophotometrically by a broth microdilution method (24) based on the NCCLS M27A protocol (23). The MIC was the lowest concentration that inhibited growth by more than $50 \%$; this end-point showed the best reproducibility and correlation with results from the NCCLS broth macrodilution method. Quality control yeasts Candida krusei ATCC 6258 and Candida parapsilosis ATCC 22019 were tested in parallel and were inhibited at MICs in the correct ranges for the antifungals tested (23).

\section{Sterol synthesis experiments.}

To study sterol synthesis in C. albicans. yeasts were grown in $100 \mathrm{ml}$ CYG medium (casein hydrolysate [Merck. Darmstadt. Germany], yeast extract [Difco, Detroit. Mich.]. glucose, each at a concentration of $5 \mathrm{~g} \mathrm{liter}^{-1}$ ) in $500 \mathrm{ml}$ Erlenmeyer flasks in a reciprocating shaker set at 100 strokes per minute at $37^{\circ} \mathrm{C}$ as described before (33). Radiolabeled $\left[2-{ }^{14} \mathrm{C}\right]$ acelate $(5 \mu \mathrm{Ci}$; specific activity: $58 \mu \mathrm{Ci} \mathrm{mmol}{ }^{-1}$ ) was added immediately prior to inoculation. Itraconazole was 
dissolved in dimethyl sulfoxide (DMSO) (10 mM stock solution; $7.05 \mathrm{mg} \mathrm{ml}^{-1}$ ), further diluted in $100 \%$ DMSO, and added to the incubation mixtures at a final solvent concentration of $0.1 \%$. In control experiments a similar amount of DMSO was added. After 24 h of growth, cells were collected by centrifugation at $1500 \times \mathrm{g}$, the cell pellet washed with saline $(0.15 \mathrm{M} \mathrm{NaCl})$ and homogenized with acid-washed glass beads (diameter $0.40-0.45 \mathrm{~mm}$ ) in a $20 \mathrm{ml}$ scintillation vial in a Retsch ${ }^{\circ}$ laboratory mixer mill 2000 set at maximum speed for 5 minutes. The homogenate was quantitatively separated from the glass beads by sequential washings. The homogenates were supplemented with one volume of $15 \% \mathrm{KOH}$ dissolved in $90 \%$ ethanol and saponified at $84^{\circ} \mathrm{C}$. Non-saponifiable lipids were extracted with one volume of $n$-heptane. The heptane extracts were scanned spectrophotometrically from 200 to $330 \mathrm{~nm}$ to quantify sterols with a $\Delta^{5.7}$ conjugated double bond system. At a wavelength of $281 \mathrm{~nm}, \Delta^{5.7}$ desaturated sterols could be specifically detected and quantified using an $\varepsilon_{281}$ of 11200 . The linearity of this method was checked against a standard curve with authentic ergosterol. Heptane extracts were then dried with a stream of $\mathrm{N}_{2}$ and sterols were separated by both thin layer chromatography and by HPLC analysis as described previously (36). Sterol fractions were identified by reference to authentic standards and by GCMS. To quantify the effect of itraconazole on growth under these conditions, cell concentrations were determined with a Coulter counter as described earlier (34). Clustering and size of the cells was examined with a Becton Dickinson FACScalibur ${ }^{8}$ flow cytometer and with phase-contrast microscopy.

\section{PCR amplification and sequence analysis of C. albicans ERG25 and ERG3 genes.}

To amplify the $E R G 25$ gene encoding at least part of the 4-demethylase we used primers adjacent to the ORF using the sequence deposited by Johnson et al. (Genbank accession number AF051914). All subsequent numbering is according to this sequence. Vector $\mathrm{NTi}^{\mathrm{i}}$ was used to detect optimal primer pairs to amplify the entire ORF. As a sense primer $5^{\prime}$ ATTGTTATATTTCAACATATACATATTCC $3^{\circ}$ was used (nucleotides 7-35 of AF051914) whereas the anti- 
Itraconazole induced inhibition of the 3-ketoreductase

sense primer was 5'AAACATTGAGAAGTTGTACACATATACT3' (nucleotides 1065-1038 of AF051914). The heat activatable AmpliTaq Gold ${ }^{\circ}$ (Perkin-Elmer, Foster City, Ca, 0.5 units) was used with $2.5 \mathrm{mM} \mathrm{MgCl}$. DNA from Candida albicans strains was prepared by the Qiagen DNA extraction method according to the procedures of the manufacturer with zymolyase ( $60 \mathrm{U}$; $5000 \mathrm{U} \mathrm{g}^{-1}$; Arthrobacter lutens; Seikagaku Kogyo, Tokyo, Japan) used as the cell-wall degrading enzyme. The PCR parameters were $10 \mathrm{~min}$ at $94^{\circ} \mathrm{C}$ to activate the polymerase and then 30 cycles of 1 min annealing at $48^{\circ} \mathrm{C}, 2 \mathrm{~min}$ elongation at $72^{\circ} \mathrm{C}$ and $1 \mathrm{~min}$ denaturation at $92^{\circ} \mathrm{C}$. After the reaction the $1059 \mathrm{bp}$ PCR product was cleaned up with a Qiagen ${ }^{\star}$ PCR cleanup kit and a sample was separated on a $1 \%$ agarose gel with Boehringer molecular weight standard VI. The $1059 \mathrm{bp}$ amplification products from the different isolates were sequenced on both strands using the PCR primers and internal primers every $300 \mathrm{bp}$ (name. sequence, nucleotide position, direction: Ca ERG25-01, TTCCATCCATTATGTC, 458, sense; Ca ERG25-02; CCGATTGTTTGGTGTC; 716, sense; Ca ERG25-03, GTTACCAGTGATAAGAC, 745, antisense; Ca ERG25-04, CATGGTAAACATCTACC, 318, antisense; Ca ERG25-05, GTCTTCCATTAGTAATG, 103, sense). Primers were designed by visual inspection of the sequence for stretches of 16-18 nucleotides of normal composition (40\%$60 \%$ GC, no palindromes, no homopolymeric stretches). Primers were ordered from Eurogentec (Seraing, Belgium) and were synthesized according to the Bcyanoethylphosphoramidite method. Sequencing reactions were performed with the ABI Prism BigDye Terminator Cycle Sequencing Ready Reaction Kit used according to the instructions of the manufacturer (Perkin-Elmer), except that half of the volume of terminator mix was replaced by HalfTerm (GenPak Ltd. Brighton. UK). Sequencing reactions were run on an Applied Biosystems 377 XL DNA sequencer (Perkin-Elmer). Sequences were assembled from the individual runs into single contig sequences with the aid of the Sequencher software (Gene Codes Corporation. Ann Arbor, MI). Ambiguity positions were scored by setting the threshold as low as $30 \%$ (i.e. secondary peaks at $30 \%$ of primary peak results in ambiguity call) and by inspecting all of the ambiguity calls on all available readings.

To amplify the $E R G 3$ gene from the three related strains similar techniques were 


\section{Chapter 3}

used. Numbering of nucleotides is according to the sequence deposited by Miyazaki et al. (Genbank accession number AF069752). As a sense primer 5'ACAGTTTCCCATTTTCCTTCCAA3' was used (nucleotides 208-230 of AF069752) whereas the antisense primer was 5'CATCTTTGTTTTGGACCATTGACTAGAGCTCGGG3' (SacI restriction site + nucleotides 1578-1554 of AF069752). PCR was performed as described above. The 1380 bp amplification products were sequenced on both strands using the PCR primers and internal primers every 300 bp (name, sequence, nucleotide position, direction: Ca ERG3-01, CCCAGCTACTGATTTC, 683, sense; Ca ERG3-02; TGAAATCAGTAGCTGG; 699, antisense; Ca ERG3-03, TTACACTGGCCATCTG, 1071, sense; Ca ERG3-04, GCATGAGAAGCAAATGG, 1150, antisense). 


\section{RESULTS}

\section{MIC determination.}

In previous papers, Sanglard et. al. described different resistance mechanisms in series of sequential isogenic Candida albicans isolates from five AIDS patients suffering from OPC. $(27,29,31)$. The results from these studies are summarized in Table 1. To verify that no changes in susceptibility were induced during shipment or with the initial subcultivation to prepare the glycerol stock, MICs of all 16 isolates were redetermined for fluconazole, ketoconazole and itraconazole. In addition the amphotericin B sensitivity was also measured. Results obtained are summarized in Table 2 . Taking the well documented variation of azole sensitivity testing into account $(23,41)$, an excellent correlation between the two determinations with a correlation coefficient of 0.87 was found, indicating that the sensitivities of the strains were not significantly altered. Only minor differences in amphotericin B sensitivity were found among the 16 isolates, demonstrating that they were not cross-resistant to this polyene antifungal. 
TABLE 1. Strains tested and their published resistance mechanisms $(27,29-31)$

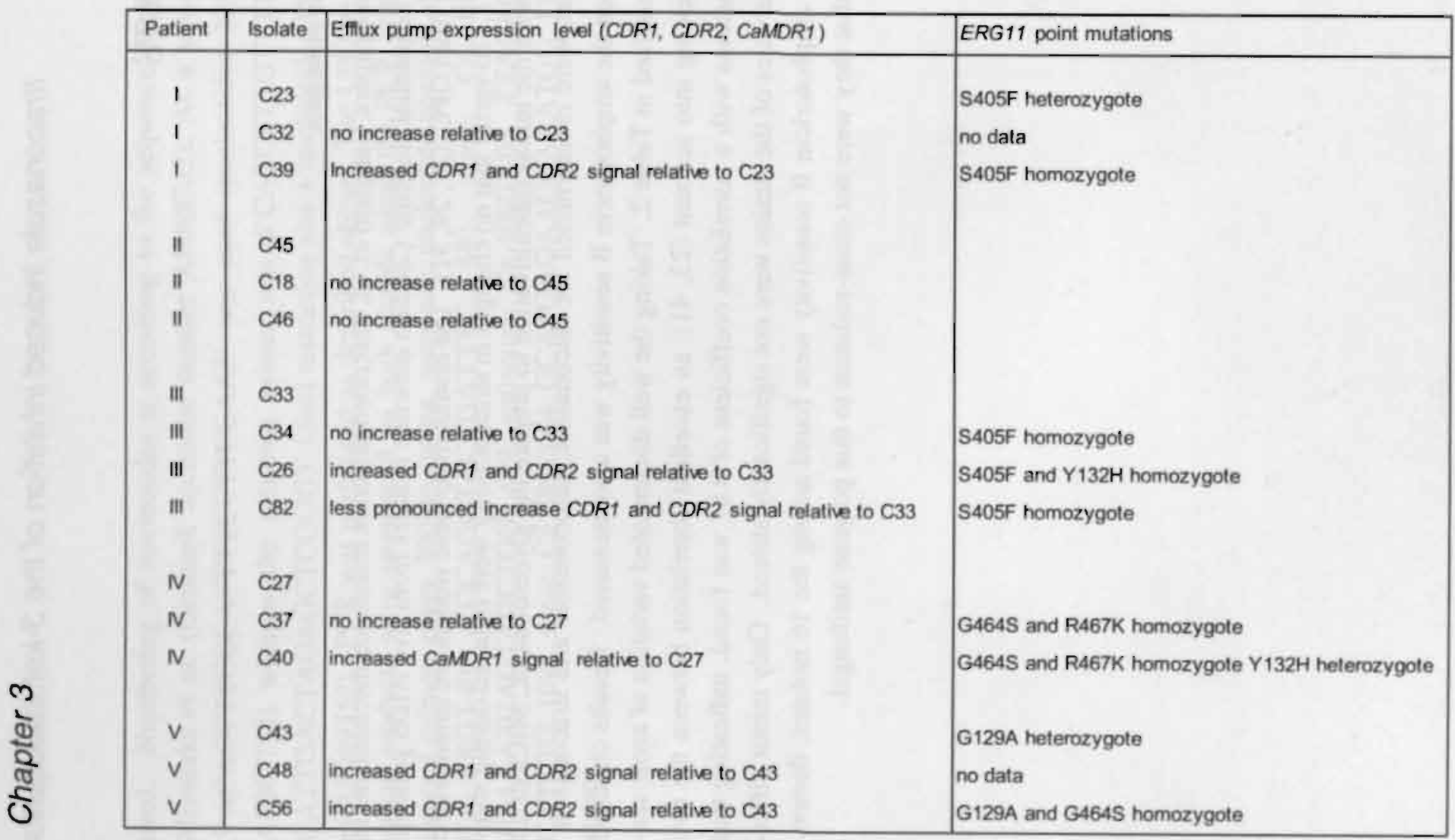




\section{Itraconazole induced inhibition of the 3-ketoreductase}

TABLE 2. In vitro susceptibilities of $C$, albicans isolates. MIC values are expressed in $\mu g / m$ l.

\begin{tabular}{|c|c|c|c|c|c|c|c|c|}
\hline Patient: & Isolate & Fluconazole* & Ketoconazole & litraconazole & Fluconazole & Ketoconazole & Itraconazole & Amphotericin B \\
\hline I & $\mathrm{C} 23$ & 1 & 0.015 & 0.0625 & 1.6 & 0.05 & 0.05 & 0.63 \\
\hline 1 & $\mathrm{C} 32$ & 8 & 0.0312 & 0.125 & 6.3 & 0.1 & 0.2 & 0.63 \\
\hline 1 & C 39 & 32 & 0.125 & 0.125 & 25 & 0.2 & 0.4 & 0.63 \\
\hline$\|$ & $\mathrm{C} 45$ & 1 & 0.015 & 0.0312 & 0.8 & 0.025 & 0.025 & 0.63 \\
\hline \| & $\mathrm{C} 18$ & 2 & 0.015 & 0.0625 & 0.4 & $\leq 0.025$ & $\$ 0.025$ & 0.63 \\
\hline$\|$ & $\mathrm{CA6}$ & 2 & 0.015 & 0.0625 & 0.8 & $\$ 0.025$ & 0.025 & 0.63 \\
\hline III & $\mathrm{C} 33$ & 0.25 & 0.015 & 0.0312 & 0.2 & $\$ 0.025$ & $\leq 0.025$ & 0.32 \\
\hline III & C34 & 2 & 0.015 & 0.0625 & 1.6 & 0.05 & 0.05 & 0.32 \\
\hline III & $\mathrm{C} 26$ & $>128$ & 4 & $>2$ & $>100$ & 6.3 & $>25$ & 0.16 \\
\hline III & C82 & 32 & 0.5 & 1 & 25 & 0.4 & 0.4 & 0.63 \\
\hline N & $\mathrm{C} 27$ & 1 & 0.015 & 0.0312 & 0.4 & 50.025 & 0.05 & 0.63 \\
\hline N & $\mathrm{C} 37$ & 8 & 0.0325 & 0.0625 & 6.3 & 0.1 & 0.05 & 0.63 \\
\hline N & $\mathrm{CAO}$ & 128 & 2 & 1 & 50 & 1.6 & 0.8 & 0.63 \\
\hline V & $\mathrm{CA3}$ & 0.25 & 0.015 & 0.0312 & 0.2 & $\leq 0.025$ & $\varsigma 0.025$ & 0.63 \\
\hline V & $\mathrm{CAB}$ & 64 & 2 & 1 & 100 & 0.4 & 0.4 & 0.63 \\
\hline V & 056 & 128 & 4 & $>2$ & 100 & 1.6 & 0.8 & 0.63 \\
\hline
\end{tabular}

-MIC values as published by Sanglard et al. (27) 


\section{Sterol synthesis experiments.}

In a pilot study, the sterol composition of all 16 isolates grown in control conditions was analyzed. The results are presented in Table 3 . In control conditions most isolates, except C48, C56 and to a lesser extent C26, contained ergosterol as the only predominant sterol. In isolates $\mathrm{C} 48$ and $\mathrm{C} 56$, both related to $\mathrm{C} 43$. substantial accumulation of $14 \alpha$-methyl-ergosta- $8,24(28)$-diene- $3 \beta, 6 \alpha$-diol at a level as high as $20-30 \%$ of total sterol was found. In the related azole-sensitive isolate $\mathrm{C} 43$, this sterol comprised only 2.2 percent of the sterols isolated. This 14-methylated-dihydroxy-sterol is normally found only after treatment with an azole as described initially by Ebert $e t$ al. in Ustilago maydis treated with etaconazole (7) and by Vanden Bossche et al. in C. albicans (34). The three isolates from patient $\mathrm{V}$ were selected for further sterol analysis and the impact of itraconazole treatment on these isolates was investigated. In Table 4 the growth yields and the effects of itraconazole on cell count and ergosterol content of the three isolates are summarized. The inhibition profiles for both parameters measured are shown in Fig. 1. In control conditions, $\mathrm{C} 43$ reached a higher yield of cells as measured by Coulter counter. At stationary phase C43 samples ( $100 \mathrm{ml}$ culture) contained $201 \pm 24 \times 10^{8}$ cells compared to $127 \pm 10 \times 10^{8}$ cells for $\mathrm{C} 48$ and to $111 \pm 6 \times 10^{8}$ cells for $\mathrm{C} 56$. The Wilcoxon rank-sum statistical analysis suggests that isolates $\mathrm{C} 48$ and $\mathrm{C} 56$ behaved significantly differently from isolate C43. It could be argued that this decrease in yield was the result of a more pronounced clustering because the Coulter Counter does not discriminate between single cells and multi-cellular clusters. To eliminate this possibility we checked the size distribution of the cultures with flow cytometry and looked at the morphology in a microscope. In Fig. 2, the forward scatter histograms are shown for all three isolates grown for $24 \mathrm{~h}$ in CYG medium. In control conditions both isolates $\mathrm{C} 48$ and $\mathrm{C} 56$ contained more single cells relative to the $\mathrm{C} 43$ strain, represented on the graph by the S-region. The position of the multi-cellular particles region (M) was similar for all three isolates, indicating a similar degree of clustering. This was confirmed in the microscopical examination. The contents of $\Delta^{5,7}$ diene-containing sterols (in control conditions ergosterol for all three strains) extracted from the cultures were found to be similar in all three isolates (Table 4). This implies a higher cellular ergosterol content in C48 (82 fg.cell $\left.{ }^{-1}\right)$ and C56 


\section{Itraconazole induced inhibition of the 3-ketoreductase}

TABLE 3. Sterols found in cultures of the Candida albicans isolates: results from pilot experiments

\begin{tabular}{|c|c|c|c|c|c|}
\hline \multirow[t]{2}{*}{ Patient } & \multirow[t]{2}{*}{ Isolate } & \multicolumn{4}{|c|}{$\%$ of sterols } \\
\hline & & $\begin{array}{l}\text { 14-methyl-ergosta-8,24(28)- } \\
\text { diene-3,6diol }\end{array}$ & Ergosterol & Obtusifolioli & trimethylsterols ${ }^{*}$ \\
\hline I & $\mathrm{C} 23$ & 2.4 & 90.7 & 2.5 & 4.4 \\
\hline 1 & C32 & 2.5 & 91.7 & 1.6 & 4.2 \\
\hline 1 & C39 & 1.6 & 91.9 & 1.0 & 5.5 \\
\hline ॥ & C45 & 1.5 & 89.9 & 4.3 & 4.3 \\
\hline II & C18 & 3.4 & 88.6 & 3.8 & 4.2 \\
\hline II & C46 & 4.9 & 89.6 & 26 & 2.91 \\
\hline III & C33 & 1.9 & 91.2 & 1.9 & 5.0 \\
\hline III & C34 & 0.5 & 90.6 & 2.4 & 6.5 \\
\hline III & C26 & 8.1 & 89.4 & 0.0 & 2.5 \\
\hline III & C82 & 3.2 & 89.1 & 2.4 & 5.3 \\
\hline IV & $\mathrm{C} 27$ & 1.5 & $89 . B$ & 2.2 & 6.4 \\
\hline N & C37 & 5.4 & 87.0 & 2.6 & 5.0 \\
\hline iv & $\mathrm{C} 40$ & 5.3 & 90.8 & 1.0 & 2.8 \\
\hline V & $\mathrm{C} 43$ & 2.5 & 89.2 & 1.7 & 5.4 \\
\hline v & $\mathrm{C} 48$ & 30.7 & 60.4 & 1.7 & 4.7 \\
\hline V & C56 & 20.9 & 73.7 & 1.0 & 3.0 \\
\hline
\end{tabular}

"The trimethylsterol fraction is a mixture of lanosterol and eburicol

TABLE 4. Yield of cells and ergosterol content of $100 \mathrm{ml}$ culture in stationary growth conditions.

\begin{tabular}{|c|c|c|c|c|c|c|c|c|c|c|}
\hline & \multicolumn{4}{|c|}{$\mathrm{C} 43$} & \multicolumn{2}{|c|}{ C48 } & \multicolumn{4}{|c|}{$\operatorname{cs} 6$} \\
\hline 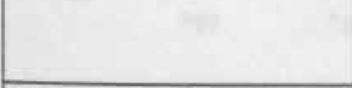 & & Yleid" & & $\begin{array}{c}\text { IC50 } \\
\text { itraconazole } \\
\mu \mathrm{M}\end{array}$ & Yiald• & $\begin{array}{c}\text { ICSO } \\
\text { Itraconazole } \\
\mu \mathrm{M}\end{array}$ & & Yield & & $\begin{array}{c}\text { ICS0 } \\
\text { Itraconazole } \\
{ }_{\mu} \mathrm{M}\end{array}$ \\
\hline Coulter counter $\left(10^{3}\right.$ cells) & 201 & $t$ & 24 & 0.03 & $127 \pm 10 \cdots$ & 0.07 & 111 & \pm & 6. & 0.1 \\
\hline (ug s 5 ? diene stercl) & 1068 & $t$ & 125 & 0.02 & $1049 \pm 169$ & 0.1 & 921 & $t$ & 81 & 0.12 \\
\hline
\end{tabular}

* Average \pm SD of at least 6 data

" P value $<0,05$ determined by Witcoxon statistical analysis 
a

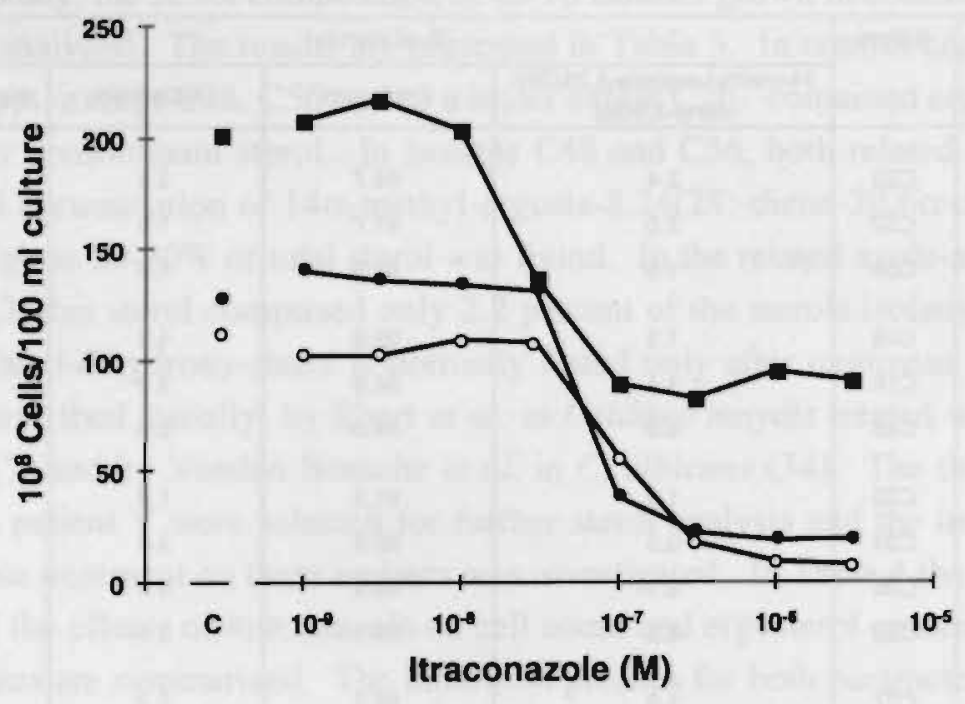

b

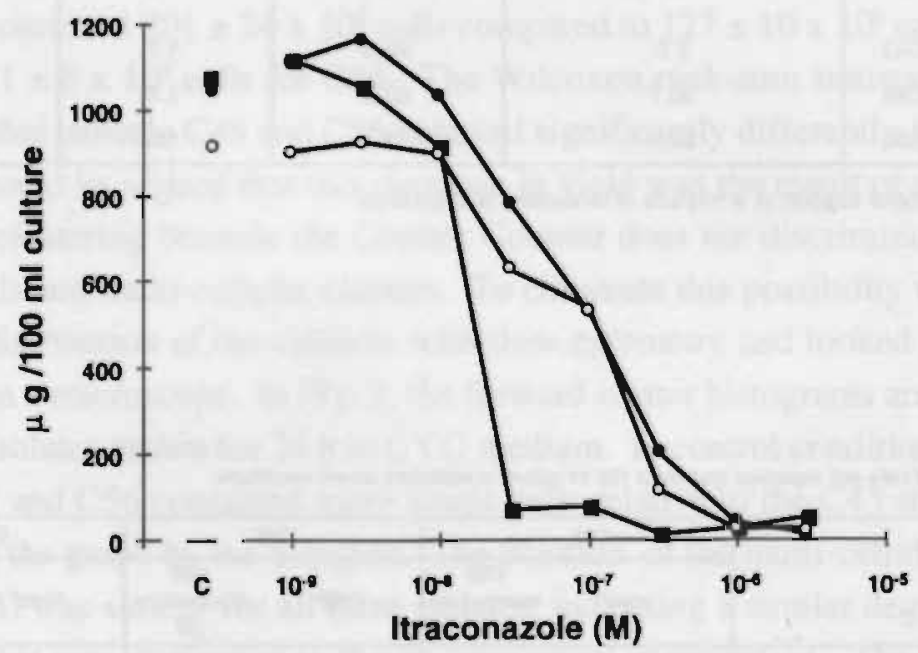

FIG. 1. Effects of itraconazole on C. albicans strains C43 (ם). C48 (O) and C56 $(O)$ a) growth measured by Coulter Counter, b) the ergosterol content measured by the absorption at $281 \mathrm{~nm}$ of a heptane extract obtained from $\mathrm{C} 43$ $(\square), C 48(O)$ and C56 (O). Results shown are the average of at least three independent experiments. 

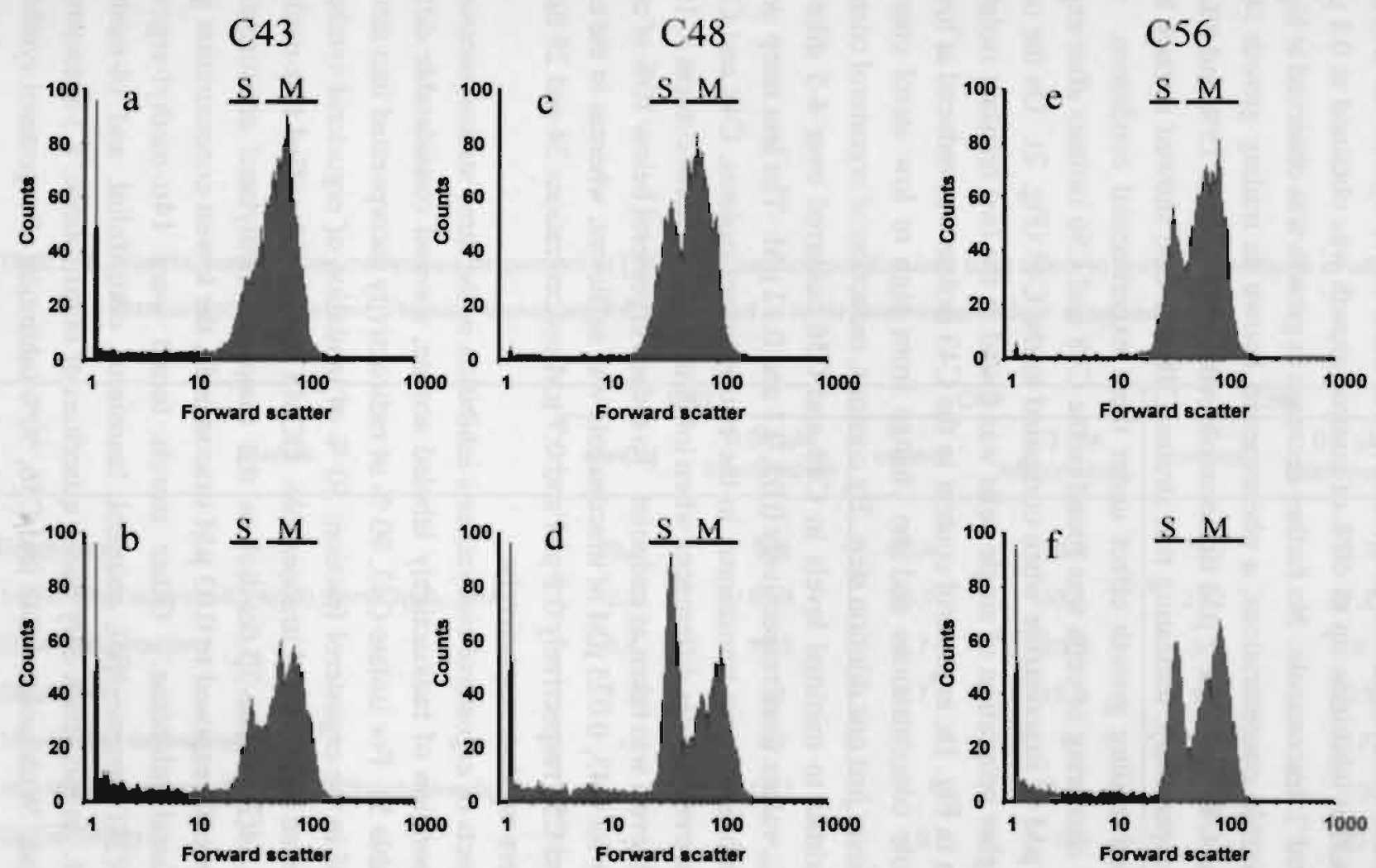

FIG. 2. Histograms of the forward scatter of cultures of $C$. albicans strains $C 43(a, b), C 48(c, d)$ and $C 56(e, f)$ grown for $24 \mathrm{~h}$ in $\mathrm{CYG}$ medium in control conditions $(\mathrm{a}, \mathrm{c}, \mathrm{e})$ or after exposure to $3 \mu \mathrm{M}$ of itraconazole $(\mathrm{b}, \mathrm{d}, \mathrm{f})$. The single cells are found in region $\mathrm{S}$, whereas region $\mathrm{M}$ represents multi-cellular clusters. 
( $83 \mathrm{fg}$.cell $\left.{ }^{-1}\right)$ as compared to $\mathrm{C} 43\left(53 \mathrm{fg} \mathrm{cell}^{-1}\right)$. As could be expected from the previous MIC determinations, itraconazole was most active against the $\mathrm{C} 43$ isolate. Maximal inhibition up to $40 \%$ of control growth was obtained at $0.1 \mu \mathrm{M}$ $\left(0.07 \mu \mathrm{g} \cdot \mathrm{ml}^{-1}\right)$ itraconazole. No further decrease in growth was observed at higher itraconazole concentrations, a phenomenon known as trailing growth (41). For strains $\mathrm{C} 48$ and $\mathrm{C} 56,1 \mu \mathrm{M}$ itraconazole reduced growth to $15 \%$ and $8 \%$ of control, respectively, indicating that strains C48 and C56 showed a much less pronounced trailing growth effect under these experimental conditions. No enhanced clustering of cells was found in the C48 and C56 isolates after exposure of $3 \mu \mathrm{M}$ of itraconazole when compared to the $\mathrm{C} 43$ (Fig. 2). On the contrary a higher proportion of single cells was found in the two resistant isolates. As shown in Fig. 1b, ergosterol content in the $\mathrm{C} 43$ isolate was reduced at lower itraconazole concentrations and the change from high to low sterol content occurred over just one dilution step. By contrast, reduction of ergosterol content from maximal to minimal levels in C48 and C56 occurred over 4-5 dilution steps. IC $_{50}$ values were respectively $0.02,0.1$ and $0.12 \mu \mathrm{M}$. The less steep slope of the inhibition curve transitions in the two resistant isolates, C48 and C56, resulted in even greater differences when inhibition of ergosterol content to $10 \%$ of control levels was taken as endpoint. To reduce ergosterol below $10 \%$ of control levels for $\mathrm{C} 43,0.025 \mu \mathrm{M}$ of itraconazole was sufficient, whereas in the case of $\mathrm{C} 48$ and $\mathrm{C} 56$ respectively $0.6 \mu \mathrm{M}$ and $0.7 \mu \mathrm{M}$ concentrations 24 and 28 times higher were needed, respectively.

The products of ergosterol biosynthesis inhibition in the three strains, measured by incorporation of radioactively labeled acetate, showed considerable differences (Table 5). For isolate $\mathrm{C} 43.90 \%$ of radioactivity incorporated into sterols was found in the ergosterol fraction: $50 \%$ of inhibition of ergosterol synthesis was achieved at $0.002 \mu \mathrm{M}$ itraconazole. GCMS analysis identified $14 \alpha$-methylergosta-8,24(28)-diene-3 $\beta, 6 \alpha$-diol as the major 14-methylated accumulation product in cells exposed to $0.03 \mu \mathrm{M}$ itraconazole, the lowest concentration giving maximal inhibiton. Other sterols found were $14 \alpha$-methyl-ergosta$5,7,22,24(28)$ tetraene-3 $3 \mathrm{ol}$, eburicol, lanosterol, obtusifoliol, and 14-methylfecosterol. In this strain only minor quantities of obtusifolione, a 3-ketosteroid. were found. With isolates C48 and C56, 50\% inhibition of ergosterol synthesis 
TABLE 5. Sterols composition expressed as percent of $\left[{ }^{14} \mathrm{C}\right]$ acetate incorporated into total sterol in control conditions or after itraconazole treatment. Results shown are the average of at least three independent experiments.

\begin{tabular}{|c|c|c|c|c|c|c|}
\hline \multirow[b]{2}{*}{ Sterols } & \multicolumn{2}{|c|}{$\mathrm{C} 43$} & \multicolumn{2}{|c|}{$\mathrm{C} 48$} & \multicolumn{2}{|c|}{$\mathrm{C56}$} \\
\hline & control & $\begin{array}{c}0.03 \mu \mathrm{M} \\
\text { Itraconazole }\end{array}$ & control & $\begin{array}{c}0.3_{\mu} \mathrm{M} \\
\text { Itraconazole }\end{array}$ & control & $\begin{array}{c}0.3 \mu \mathrm{M} \\
\text { Itraconazole }\end{array}$ \\
\hline Ergosterol & 89.2 & 0.6 & 60.4 & 10.4 & 73.7 & 17.3 \\
\hline 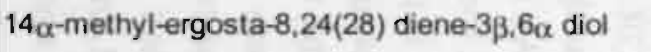 & 2.5 & 51.4 & 30.7 & 33.1 & 21.1 & 27.2 \\
\hline Eburicol/Lanosterol & 5.4 & 18.9 & 4.7 & 20.9 & 3.2 & 16 \\
\hline Obtusifolial & 1.7 & 13 & 1.7 & 13.9 & 1.3 & 15.3 \\
\hline $14 \alpha$-methyl-fecosterol & - & 1.7 & - & - & - & 2.7 \\
\hline $14 \alpha$-methyl-ergosta-5,7,22,24(28)-tetraene-3 $\beta$ ol & - & 12.7 & - & 6.6 & - & 1.3 \\
\hline Obtusifolione & - & 1 & 3.5 & 15 & 1 & 20 \\
\hline IC50 value $\mu \mathrm{M}$ itraconazole ${ }^{*}$ & & 0.002 & & 0.05 & & 0.04 \\
\hline
\end{tabular}


was reached at $0.05 \mu \mathrm{M}$ and $0.04 \mu \mathrm{M}$ itraconazole, respectively. In the absence of azole antifungals, both isolates accumulated significant amounts of $14 \alpha$ methyl-ergosta-8,24(28)-diene-3 $\beta, 6 \alpha$-diol. The radioactivity incorporated into this 3,6-diol increased slightly when these isolates were incubated in the presence of low itraconazole concentrations. After exposure to $0.3 \mu \mathrm{M}$ itraconazole, in addition to the accumulating sterols described above, substantial quantities of obtusifolione were formed. This indicated that, in these isolates, itraconazole interfered with the 4-demethylation process as well as with cytochrome P450 catalyzed $14 \alpha$-demethylation. Accumulation of obtusifolione after exposure to itraconazole was not observed in any of the 13 other strains studied (data not shown).

\section{ERG25 and ERG3 sequence analysis.}

Obtusifolione is a substrate for the 3-ketoreductase stage in the 5-step 4demethylation process as shown in Fig. 3. So far, ERG25 is the only gene identified in Candida albicans in this process and its product, the 4-methyloxidase, catalyzes at least three of the five reactions required (1). Gachotte et al. identified the ERG26 gene catalyzing the decarboxylase step in $S$. cerevisiae (10). Only the 3-ketoreductase reaction has not yet been assigned to a gene. To investigate whether mutations in the ERG25 gene, specific to both resistant isolates, contributed to the inhibition of the 3-ketoreduction, we sequenced the ERG25 alleles of the three isolates, as those of two unrelated strains (Candida albicans ATCC44858 and B59630). All isolates from patient V tested were heterozygote in the $5^{\circ}$-untranslated region for the presence of 4 or 5 repeats of the sequence ATTT starting at position 67 in the EMBL accession AF051914. The sequences obtained from the reference strains were identical, strain B59630 contained four ATTT repeats as found in the Genbank deposited sequence obtained from $C$. albicans strain CAI-8, whereas strain ATCC44848 contained 5 ATTT repeats. The ERG25 sequences of the two unrelated strains, B59630 and ATCC44848 were identical to the published sequence, whereas five heterozygote but silent mutations, A412A/C, A421A/G, A640A/T, A661A/G and G706G/T were found, identical in C43, C48 and C56. This sequence analysis brings additional 


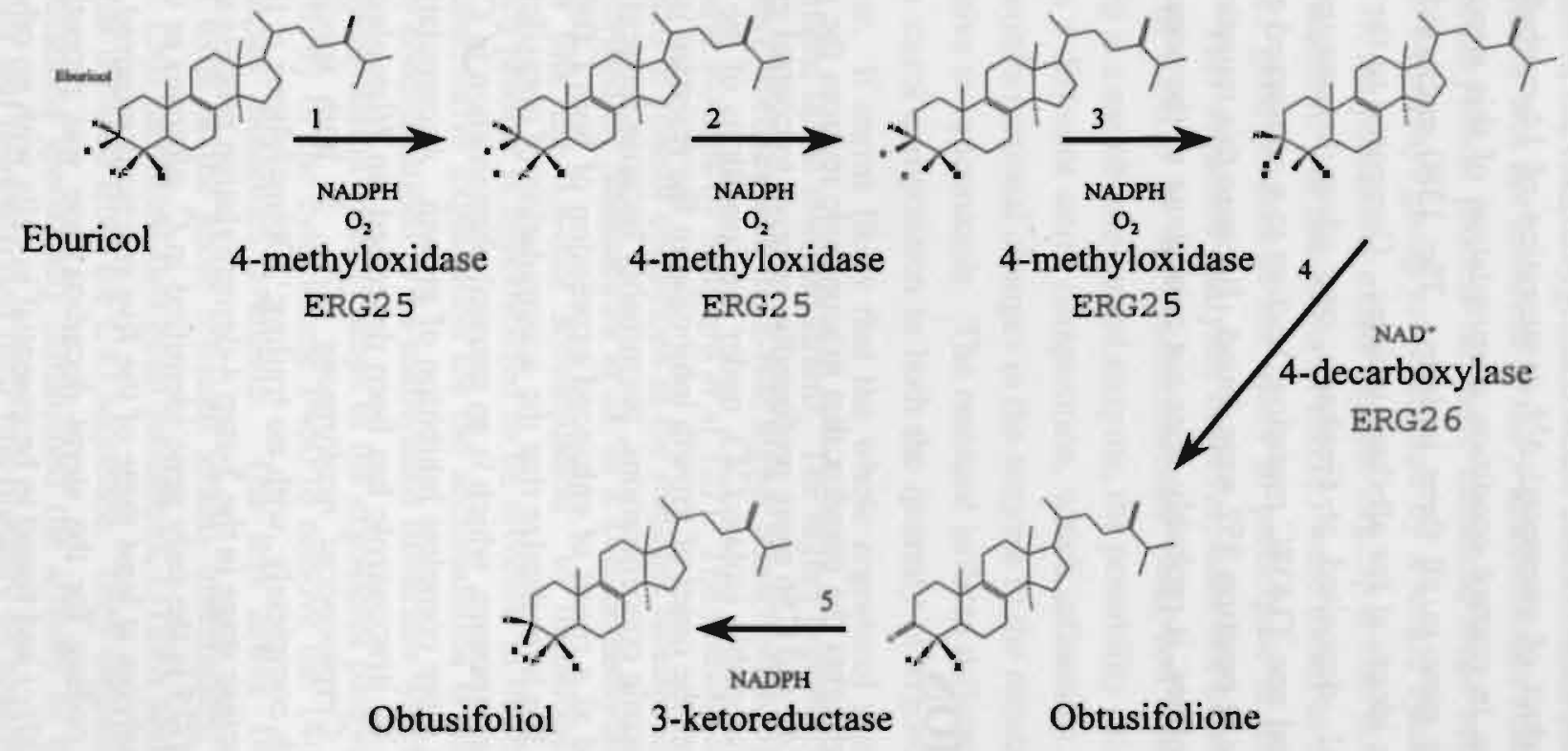

FIG. 3. The $\mathrm{C}_{4}$-demethylation process during ergosterol biosynthesis. Reactions are shown to remove the first $\mathrm{C}_{4}$ methyl group. To remove the second methyl group, the entire process is repeated. 
support for the relatedness of the strains investigated here.

The $\Delta^{5.6}$-desaturase is encoded by ERG3. It is hypothesized that 3,6-diol is the presumed product of attempted $\Delta^{5.6}$ desaturation of 14-methylated precursors (14). Because in control condition accumulation of this sterol was seen, we sequenced the gene in all three isolates. The 1380 nucleotide amplification products were identical for all three isolates. Compared to the sequence of $C$. albicans B311, deposited at Genbank, one silent heterozygote substitution A1223A/G and one T1438C mutation, leading to a conserved change of valine into an alanine at position 352 were found. Because this mutation was identical in all three isolates, it probably does not contribute to the accumulation of the 3,6-diol.

\section{DISCUSSION}

This study highlights the paradox that itraconazole reduces the growth of resistant isolates C48 and C56 more profoundly, relative to control growth, than that of a parent susceptible isolate $\mathrm{C} 43$, under the conditions of the present tests in vitro. However the onset of growth inhibition in the resistant isolates occurs at higher itraconazole concentrations, presumably because intracellular azole content is reduced as a result of enhanced expression of both $C D R I$ and $C D R 2$ in these strains. We hypothesize that the accumulation of obtusifolione as a result of itraconazole exposure, which is an unusual phenomenon in C. albicans, contributes to the more complete inhibition of growth. Accumulation of obtusifolione induced by itraconazole has been described in Histoplasma capsulatum $(35,42)$ and Cryptococcus neoformans (37). In both species itraconazole inhibits growth completely, with no trailing. Obtusifolione is the substrate for the 3-ketoreductase stage in the 5-step 4-demethylation process as shown in Fig. 3. So far, ERG25 is the only gene identified in $C$. albicans in this process and its product catalyzes at least three of the five reactions required. In $S$. cerevisiae the gene coding for the sterol decarboxylase was recently identified as ERG26 (YGLO0Ic) and found to be essential in cells with no other deficiency in 
the sterol biosynthetic pathway (10). The authors of this study concluded that the accumulation of the toxic oxygenated sterol intermediates prevented growth and that the ERG26 was not involved in the 3-ketoreductase reaction. Because in the $14 \alpha$-demethylation process all three chemical steps necessary for the removal of the 14-methyl group are catalyzed by a single cytochrome P450 ( ERGI1, CYP 5l), the possibility exists that the Erg25p is also involved in the 3ketoreductase reaction. No mutations in ERG25 were found in our isolates and thus the ERG25 gene product is not likely to participate in the obtusifolione accumulation. This sequence analysis, however, does not conclusively eliminate the role of ERG25 in the 3-ketoreductase catalyzed reaction. Indeed, because Erg 25 p is a membrane-bound enzyme, the possibility exists that indirect effects such as a different sterol composition, which influences membrane fluidity, induces conformational changes in the enzyme in the resistant strains, rendering it sensitive to itraconazole. The resistant isolates differed from the sensitive strain in sterol composition in both the quantity of ergosterol and in the 3,6-diol content. It seems likely that the whole ergosterol synthetic pathway may be upregulated in the resistant strains. The higher ergosterol content in the resistant isolates correlates with the 2 -fold higher transcription signal for ERGII described in these isolates by Sanglard et al. (27). The unusual accumulation of 3.6-diol observed in control conditions in the resistant isolates studied here was

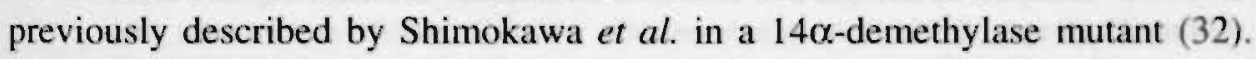
We could not link the 3,6-diol accumulation to mutations in the ERG3 sequence, which product is hypothesized to be involved in the formation of the 3.6-diol. An alternative explaration for the accumulation is that it arises as a result of higher concentrations of 14-methylated substrates which could be generated by an upregulation of early steps in the ergosterol pathway followed by insufficient activity of the cytochrome P450 to remove the $14 \alpha$-methyl group from all substrate molecules available. The less active 14 $\alpha$-cemethylase enzyme could exist in the azole resistant strains investigated here. In fact, Sanglard et al. (30) identified two point mutations. G129A and G464S, in the C56 ERGII that differed from the $\mathrm{C} 43$ sequence. They elegantly showed that these point mutations specifically diminished the affinity of the proteins for azole antifungals and demonstrated their functionality by heterologous overex- 
Chapter 3

pression in a $S$. cerevisiae strain. However, these mutations might have affected other features of these proteins, particularly their functional integrity.

From this study it can be concluded that, as already shown by others $(8,20)$, multiple changes are found in clonally related clinical isolates. The observed azole resistance is probably due to the combination of multiple factors that often evolve sequentially during treatment. This complicates the interpretation of mechanistic resistance studies and highlights a need to obtain multiple clonal isolates from a patient at frequent intervals.

\section{Acknowledgements}

We thank H. Schreuders, T. Verhulst, A. Schijfs and L. Van Nuffel for their excellent technical skills and B. van den Hazel for interesting discussions. 


\section{References}

1 Bard, M., D. A. Bruner, C. A. Pierson, N. D. Lees, B. Biermann, L. Frye, C. Koegel. and R. Barbuch. 1996. Cloning and characterization of ERG25, the Saccharomyces cerevisiae gene encoding C-4 sterol methyl oxidase. Proc. Natl. Acad. Sci. 93:186-190.

2 Bodey, G. P. 1997. Resistance to antimicrobial agents revisited. Curr, opinion Infect. Dis. 10:419-421.

3 De Muri, G. P., and M. K. Hostetter. 1995. Resistance to antifungal agents. Pediatr. Clin. North Am. 42(3):665-685.

4 Denning, D. W., G. G. Baily, and S. V. Hood. 1997. Azole resistance in Candida. Eur. J. Clin. Microbiol. Infect. Dis. 16:261-280.

5 Doignon, F., M. Aigle, and P. Ribereau-Gayon. 1993. Resistance to imidazoles and triazoles in Saccharomyces cerevisiae as a new dominant marker. Plasmid 30:224-233.

6 Dupont, B. 1995 Azole antifungal agents : emerging and inherent resistance. Current opinion in Infectious Diseases. 8:424-427.

7 Ebert, E., J. Gaudin, W. Muecke, K, Ramsteiner, C. Vogel, and H. Fuhrer. 1983. Inhibition of ergosterol biosynthesis by etaconazole in Ustilago maydis. Z. Naturforsch. 38C:28-34.

8 Franz, R., S. L. Kelly, D. C. Lamb, D. E. Kelly, M. Ruhnke, and J. Morschhäuser. 1998. Multiple molecular mechanisms contribute to a stepwise development of fluconazole resistance in clinical Candida albicans strains. Antimicrob. Agents Chemother. 42:3065-3072.

9 Frosco, M., and J. F. Barrett. 1998. Importance of antifungal drug-resistance : clinincal significance and need for novel therapy. Exp. Opin. Invest. Drugs. 7(2):175-198.

10 Gachotte, D., R. Barbuch. J. Gaylor, E. Nickel, and M. Bard. 1998. Characterization of the Saccharomyces cerevisiae ERG26 gene encoding the C-3 sterol dehydrogenase (C4 decarboxylase) involved in sterol biosynthesis. PNAS 95(23):13794-9.

II Hartman. P. G.. and D. Sanglard. 1997. Inhibitors of ergosterol as antifungal agents. Curr. Pharm. Design. 3:177-208.

12 Hitcheock, C. A. K. J. Barrett-Bee, and N. J. Russell. 1986. The lipid composition of azole-sensitive and azole-resistant strains of Candida albicans. J. Gen. Microbiol. 132:2421-2431. 
13 Johnson, E. M., and D. W. Warnock. 1995. Azole drug resistance in yeast. J. Antimicrob. Chemother. 36:751-755.

14 Joseph-Horn, T., D. W. Hollomon, J. Loeffler, and S. Kelly. 1995. Cross-resistance to polyene and azole drugs in Cryptococcus neoformans. Antimicrob. Agents Chemother. 39:1526-1529.

15 Joseph-Horn, T., and D. W. Hollomon. 1997. Molecular mechanisms of azole resistance in fungi. FEMS Microbiol. Lett. 149:141-149.

16 Kelly, S. L., D. C. Lamb, A. J. Corran, B. C. Baldwin, and D. E. Kelly. 1995. Mode of action and resistance to azole antifungals associated with the formation of $14 \mathrm{a}$-methylergosta-8,24(28)-dien-3b,6a -diol. Biochem. Biophys. Res. Comm. 197:428-432.

17 Kelly, S. L., D. C. Lamb, D. E. Kelly, N. J. Manning, J. Loeffler, H. Hebart, U. Schumacher, and H. Einsele. 1997. Resistance to fluconazole and cross-resistance to amphotericin B in Candida albicans from AIDS patients caused by defective sterol $\Delta^{5.6-}$ desaturation. FEBS Lett. 400:80-82.

18 Kolaczkowski, M., and A. Goffeau. 1997. Active efflux by multidrug transporters as one of the strategies to evade chemotherapy and novel practical implications of yeast pleiotropic drug resistance. Pharmacol. Ther. 76:219-242.

19 Lamb, D. C., D. E. Kelly, W.-H. Schunck, A. Z. Shyadehi, M. Akhtar, D. J. Lowe, B. C. Baldwin, and S. L. Kelly. 1997. The mutation T315A in Candida albicans sterol 14 $\alpha$ demethylase causes reduced enzyme activity and fluconazole resistance through reduced affinity. J. Biol. Chem. 272:5682-5688.

20 Lopez-Ribot, J., R. K. McAtee, L. N. Lee, W. R. Kirkpatrick, T. C. White, D. Sanglard, and T. F. Paterson. 1998. Distinct patterns of gene expression associated with development of fluconazole resistance in serial Candida albicans isolates from human immunodeficiency virus-infected patients with oropharyngeal candidiasis. Antimicrob. Agents Chemother, 42:2932-2937.

21 Marichal, P., and H. Vanden Bossche. 1995. Mechanisms of resistance to azole antifungals. Acta Biochemica Polonica, 42:509-516.

Marichal P., H. Vanden Bossche, F. C. Odds, G. Nobels, D. W. Warnock, Vincent Timmerman, C. Van Broeckhoven, S. Fay, and P. Mose-Larsen. 1997. Molecular biological characterization of an azole-resistant Candida glabrata isolate. Antimicrob. Agents Chemother. 41:2229-2237.

National Committee for Clinical Laboratory Standards. 1995. Reference method for broth dilution susceptibility testing of yeasts. Tentative standard M27-A. National Committee for Clinical Laboratory Standards, Villanova, P.. 
Odds, F. C., L. Vranckx, and F. Woestenborghs. 1995. Antifungal susceptibility testing of yeasts: Evaluation of technical variables for test automation. Antimicrob. Agents Chemother, 39:2051-2060.

25 Odds, F. C. 1998. Should resistance to azole antifungals in vitro be interpreted as prediciting clinical non-response? Drug Resistance Updates. 1:11-15.

Rex, J. H., M. G. Rinaldi, and M. A. Pfaller. 1995. Resistance of Candida species to fluconazole. Antimicrob. Agents Chemother. 39:1-8.

Sanglard, D., K. Kuchler, F. Ischer, J. L. Pagani, M. Monod, and J. Bille. 1995. Mechanisms of resistance to azole antifungal agents in Candida albicans isolates from AIDS patients involve specific multidrug transporters. Antimicrob. Agents Chemother. 39: $2378-2386$.

28 Sanglard, D., F. Ischer, M. Monod, and J. Bille. 1996. Susceptibilities of Candida albicans multidrug transporter mutants to various antifungal agents and other metabolic inhibitors Antimicrob. Agents Chemother. 40: 2300-2305.

29 Sanglard, D., F. Ischer, M. Monod, and J. Bille. 1997. Cloning of Candida albicans genes conferring resistance to azole antifungal agents: characterization of $C D R 2$, a new multidrug ABC transporter gene. Microbiology, 143:405-416.

30 Sanglard, D., F. Ischer, L. Koymans, and J. Bille. 1998. Amino acid substitutions in the cytochrome P450 lanosterol 14 $\alpha$-demethylase (CYP5I) from azole-resistant Candida albicans clinical isolates contributing to the resistance to azole antifungal agents. Antimicrob. Agents Chemother. 42:241-253.

31 Sanglard D., F. Ischer, D. Calabrese, M. de Micheli, and J. Bille. 1998. Multiple resistance mechanisms to azole antifungals in yeast clinical isolates. Drug Resistance Updates. 1:255-265.

32 Shimokawa, O. Y. Kato, K. Kawano, and H. Nakayama. 1989. Accumulation of $14 \alpha-$ methyl-ergosta-8,24(28)-diene-3 $\beta, 6 \alpha$-diol in $14 \alpha$-demethylation mutants of Candida albicans: genetic evidence for the involvement of 5-desaturase. Biochem. Biophys. Acta. 1(M)3:15-19.

33 Vanden Bossche, H., G. Willemsens, W. Cools, W. Lauwers, and L. Le Jeune. 1978. Biochemical effects of miconazole on fungi. II. Inhibition of ergosterol biosynthesis in Candida albicans. Chem. Biol. Interact. 21:59-78.

Vanden Bossche, H., P. Marichal, J. Gorrens, D. Bellens, H. Verhoeven, M.-C. Coene, W. Lauwers, and P. A. J. Janssen. 1987. Interaction of azole derivatives with cytochrome $\mathbf{P} 450$ systems in yeast, fungi, plants and mammalian cells. Pestic. Sci, 21:289306. 
35 Vanden Bossche, H., P. Marichal, J. Gorrens, D. Bellens, M.-C. Coene, W. Lauwers, L. Le Jeune, H. Moereels, and P. A. J. Janssen. 1990. Mode of action of antifungals of use in immunocompromised patients. p. 223-243. In H. Vanden Bossche, D.W.R. MacKenzie, G. Cauwenbergh, J. Van Cutsem, E. Drouhet, and B. Dupont (eds.). Mycoses in AIDS patients. Plenum Press. New York. N.Y.

36 Vanden Bossche, H., P. Marichal, F. C. Odds, L. Le Jeune, and M.-C. Coene. 1992. Characterization of an azole-resistant Candida glabrata isolate. Antimicrob. Agents Chemother., 36:2602-2610.

37 Vanden Bossche, H., P. Marichal, L. Le Jeune, M.-C. Coene, J. Gorrens, and W. Cools. 1993. Effects of itraconazole on cytochrome P-450-dependent sterol 14 $\alpha$-demethylation and reduction of 3-ketosteroids in Cryptococcus neoformans. Antimicrob. Agents Chemother. 37:2101-2105.

38 Vanden Bossche, H., P. Marichal, F. C. Odds. 1994. Molecular mechanisms of drug resistance in fungi. Trends Microbiol. 2:393-400.

39 Vanden Bossche, H.. 1997. Mechanisms of antifungal' resistance. Rev. Iberoam. Micol. 14:44-49.

40 Vanden Bossche, H., F. Dromer, L. Improvisi, M. Lozano-Chiu, J. H. Rex, and D. Sanglard. 1998. Antifungal drug resistance in pathogenic fungi. Medical Mycology 36(suppl.1):119-128.

41 Warnock, D. W., and E. M. Johnson. 1997. Antifungal drug susceptibility testing. Curr. Opinion Infect. Dis. 10:444-448.

42 Wheat, J., P. Marichal, H. Vanden Bossche, A. Le Monte, and Patricia Connolly. 1997. Hypothesis on the mechanism of resistance to fluconazole in Histoplasma capsulatum. Antimicrob. Agents Chemother. 41:410-414.

White, T. C. 1997. The presence of an R467K amino acid substitution and loss of allelic variation correlate with an azole-resistant lanosterol $14 \alpha$-demethylase in Candida albicans. Antimicrob. Agents Chemother. 41:1488-1494.

White, T.C., R. A. Bowden, K. A. Marr. 1998. Clinical, cellular and molecular factors that contribute to antifungal drug resistance. Clin. Microbiol. Rev. 11:382-402. 




\section{Synergic effects of tacrolimus and azole}

\section{antifungal agents against azole-resistant}

\section{Candida albicans strains}

Shigefumi Maesakia, Patrick Marichal ${ }^{b}$, Mohammad Ashraf Hossaina, Dominique Sanglard ${ }^{\mathrm{c}}$, Hugo Vanden Bossche ${ }^{\mathrm{b}}$ and Shigeru Kohno

"The Second Department of Internal Medicine, Nagasaki University School of Medicine, 1-7-1 Sakamoto, Nagasaki 852-8501, Japan; 'Anti-Infectives Research Departments, Janssen Research Foundation, Turnhoutseweg 30. B2340 Beerse. Belgi,m7: 'Institute de Microbiologie, Centre Hospitalier Universitaire Vaudois, 1011 Lausanne, Switzerland

Running title : Synergic effects of tacrolimus and azoles Journal of Antimicrobial Chemotherapy, 1998, 42, 747-753 


\section{Summary}

We investigated the effects of combining tacrolimus and azole antifungal agents in azole-resistant strains of Candida albicans by comparing the accumulation of $\left[{ }^{3} \mathrm{H}\right]$ itraconazole. The $C D R l$-expressing resistant strain $\mathrm{C} 26$ accumulated less itraconazole than the CaMDR-expressing resistant strain $\mathrm{C} 40$ or the azole-sensitive strain B2630. A CDRI-expressing Saccharomyces cerevisiae mutant, DSY415, showed a marked reduction in the accumulation of both fluconazole and itraconazole. A CaMDR-expressing $S$. cerevisiae mutant, DSY416, also showed lower accumulation of fluconazole, but not of itraconazole. The addition of sodium azide, an electron-transport chain inhibitor, increased the intracellular accumulation of itraconazole only in the C26 strain, and not in the C40 or B2630 strains. Addition of tacrolimus, an inhibitor of multidrug resistance proteins, resulted in the highest increase in itraconazole accumulation in the $\mathrm{C} 26$ strain. The combination of itraconazole and tacrolimus was synergic in azoleresistant $C$. albicans strains. In the $\mathrm{C} 26$ strain, the MIC of itraconazole decreased from $>8$ to $0.5 \mathrm{mg} / \mathrm{L}$ when combined with tacrolimus. Our results showed that two multidrug resistance phenotypes (encoded by the $C D R I$ and $C a M D R$ genes) in $C$. albicans have different substrate specificity for azole antifungal agents and that a combination of tacrolimus and azole antifungal agents is effective against azole-resistant strains of $C$. albicans. 


\section{Synergic effects of tacrolimus and azoles}

\section{INTRODUCTION}

A number of mechanisms of azole resistance in Candida albicans have already been described. ${ }^{1-6}$ One of these is increased synthesis of ergosterol in azoleresistant strains. This increase is thought to result from enhanced activity of the cytochrome P450 14 $\alpha$-demethylase and/or from increased amounts of cytochrome $\mathrm{P} 450$ in microsomal fractions. ${ }^{2}$ Lamb et al. have recently described mutations in this enzyme that reduce its affinity for azoles. ${ }^{7.8}$ Recent studies have also demonstrated an energy-dependent drug efflux mechanism in $C$. albicans similar to the mechanism described for resistance of cancer cells to anticancer agents. ${ }^{3.5}$ In tumour cells the multidrug resistance (MDR) phenotype is characterized by resistance to a broad spectrum of cytotoxic agents. This high level of cross-resistance is due to increased expression of P-glycoprotein, a membrane glycoprotein. In humans this protein is encoded by the $M D R I$ gene: it pumps cytotoxic agents out of cells in an energy-dependent manner. ${ }^{9}$ A phenotype similar to MDR, called pleiotropic drug resistance, has been reported in Saccharomyces cerevisiae. and is conferred by several PDR genes ${ }^{10}$ including PDR5, which encodes a putative transmembrane pump which could play an important role in the resistance to antifungal agents. " $\mathrm{A}$ homologue, $C D R I$, has been cloned in $C$. albicans by functional complementation of $p d r 5$. The protein encoded by the $C D R I$ gene is thought to be a drug efflux protein in the ATP binding cassette $\left(\mathrm{ABC}\right.$ ) family. ${ }^{12}$ Another $C$. albicans gene, CaMDRI, originally termed the $B E N^{r}$ gene, resembles genes encoding the major facilitators superfamily (MFS) of MDR proteins."

Verapamil and the newly characterized immunosuppressant tacrolimus, both of which compete with cytotoxic drugs for binding sites on P-glycoprotein, can potentially reverse the MDR phenotype. ${ }^{13-15}$ By themselves these compounds generally have little or no effect on tumour cells, but when used in combination with anti-neoplastic agents, they decrease (and in some instances eliminate) drug resistance.

In the present study, we investigated the combined effects of azole antifungal agents and MDR inhibitors, such as tacrolimus, against azole-resistant strains of C. albicans. We also examined the drug efflux mechanism in clinical isolates of 
azole-resistant $C$. albicans strains by comparing the intracellular concentrations of itraconazole in these strains with those in sensitive strains. $S$. cerevisiae mutants containing MDR transporter genes from $\mathrm{C}$. albicans were used to demonstrate the energy-dependent drug efflux mechanisms.

\section{MATERIALS AND METHODS}

\section{Strains, media and compounds.}

Two strains of $C$. albicans (C26 and C40) isolated from AIDS patients with oropharyngeal candidiasis, and maintained at the Institute of Microbiology, Centre Hospital Universitaire Vaudois, and one strain (B2630) from culture collections at the Janssen Research Foundation were used in the present study. B2630 was azole-sensitive. C26 was azole-resistant and overexpressed CaMDR mRNA, while C40 was azole-resistant and overexpressed CaMDR mRNA.5 Species determination was performed using standard procedures. All strains were maintained at $-80^{\circ} \mathrm{C}$. C. albicans strains were grown in $\mathrm{CYG}$ medium with $0.5 \%$ casein hydrolysate (Merck. Darmstadt. Germany), $0.5 \%$ yeast extract (Difco. Detroit. MI. USA) and 0.5\% glucose (Difco).

The following $S$. cerevisiae strains. described by Sanglard $e t a / .^{5}$ were used in the present study. DSY415 and DSY416 were isogenic to DSY566 (MATa $\triangle P D R 5$ (STSI)::TRPI ura3-52 lys2-801 amber ade2-101 ochre his3-200 leu21) but contained the plasmid YEp24 (containing $C D R I$ and YEp24/BEN respectively). Yeast nitrogen base synthetic medium (YNB; Difco), supplemented with the required amino acids and $2 \%$ glucose was used as the growth medium for $S$. cerevisiae strains.

Three types of azole antifungal agent were used in the present study: fluconazole (from Pfizer, Sandwich. UK), and ketoconazole and itraconazole (from the Janssen Research Foundation, Beerse. Belgium). These compounds were dissolved in dimethylsulphoxide (DMSO): the final concentration of DMSO was $<1 \%$ of the total volume of medium.

Verapamil and tacrolimus were obtained from Eisai Co. (Tokyo, Japan) and Fujisawa Pharmaceutical Inc. (Osaka, Japan), respectively. Verapamil was dis- 
solved in DMSO, and tacrolimus was dissolved in methanol for the preparation of stock solution.

\section{MIC determination.}

C. albicans isolates. The stock solution was diluted 100 fold with susceptibility testing culture medium and a series of ten two-fold diluted solutions was prepared. These solutions were pipetted in $100 \mu \mathrm{L}$ volumes in rows of wells of flatbottomed microdilution plates (Falcon 3072: Becton Dickinson, Lincoln Park, NJ, USA). The final concentrations of fluconazole ranged from 128 to 0.25 $\mathrm{mg} / \mathrm{L}$, and those of ketoconazole and itraconazole ranged from 8 to $0.02 \mathrm{mg} / \mathrm{L}$, in two-fold serial dilutions. The MIC of antifungal agents was determined by the microdilution method using the 96-well flat-bottomed microdilution plate modified from the macrodilution method of the National Committee for Clinical Laboratory Standards (NCCLS). ${ }^{16}$ C. albicans cells from deep-frozen stock cultures were inoculated into $5 \mathrm{~mL}$ of CYG broth and incubated at $37^{\circ} \mathrm{C}$ for $18-24$ $\mathrm{h}$ with shaking. The final inoculum size was adjusted to $10^{3} \mathrm{cfu} / \mathrm{mL}$. MICs were determined as the minimum concentration of the antifungal agents yielding at least $80 \%$ inhibition of the growth compared with the growth of control.

\section{S. cerevisiae isolates.}

The yeast cells were grown for $48 \mathrm{~h}$ at $30^{\circ} \mathrm{C}$ in YNB medium supplemented with the required amino acids but uracil was omitted. An inoculum was prepared to a cell density of $10^{5}$ cells $/ \mathrm{mL}$. A $20 \mu \mathrm{L}$ volume of YNB medium containing the required amino acids was pipetted into each well. After completion of the serial dilution. $180 \mu \mathrm{L}$ of the inoculum was added to each well, to prepare a total of $200 \mu \mathrm{L}$ per well. The optical density (OD) of each well was determined on the microtitre plate after $48 \mathrm{~h}$ of incubation at $30^{\circ} \mathrm{C}$.

\section{Accumulation of intracellular ${ }^{3} \mathrm{H}$-labelled itraconazole and fluconazole.}

C. albicans cells were incubated at $37^{\circ} \mathrm{C}$ for $14 \mathrm{~h}$ in $\mathrm{CYG}$ while $S$. cerevisiae cells were incubated at $30^{\circ} \mathrm{C}$ for $48 \mathrm{~h}$ in YNB medium supplemented with amino acids. Cells were inoculated into fresh CYG medium and then grown until they reached exponential phase. The cells were harvested by centrifugation at $5000 \mathrm{~g}$ 
for $5 \mathrm{~min}$, and washed twice with $20 \mathrm{~mL}$ of phosphate-buffered saline (PBS). Cells were resuspended in $1 \mathrm{~mL}$ of CYG medium to a concentration of $2.5 \times 10^{8}$ cells $/ \mathrm{mL}$. A volume of $10 \mu \mathrm{L}$ of $\left[{ }^{3} \mathrm{H}\right]$ itraconazole (Janssen Research Foundation) was used, adjusted to give a final concentration of $3 \mathrm{nM}$ and a specific activity of $1.6 \times 10^{5} \mathrm{dpm} / \mathrm{nmol}$. The $C$. albicans and $S$. cerevisiae cells were incubated at $37^{\circ} \mathrm{C}$ and $30^{\circ} \mathrm{C}$, respectively, in $10 \mathrm{~mL}$ glass tubes with continuous shaking at $300 \mathrm{rpm}$ in an orbital shaker. After $60 \mathrm{~min}$ incubation, 100 $\mu \mathrm{L}$ samples of yeast cells were collected by centrifugation at $9000 \mathrm{~g}$ for $2 \mathrm{~min}$ and the pellets were washed three times with $1 \mathrm{~mL}$ of ice-cold CYG medium containing $10 \mu \mathrm{M}$ of unlabelled itraconazole. The pellet was suspended in 500 $\mu \mathrm{L}$ of PBS and the radioactivity of cells was determined by liquid scintillation counting with Opti-Phase (Wallac, Darmstadt, Germany) as a scintillant and counted in a Packard counter. ${ }^{17}$

Accumulation of $\left[{ }^{3} \mathrm{H}\right]$ fluconazole was measured as described by Sanglard et al. ${ }^{5}$ using Spin-X filters (Costar, Cambridge, MA, USA). A total of $5 \mu \mathrm{L}$ of [ $\left.{ }^{3} \mathrm{H}\right] \mathrm{flu}-$ conazole (Amersham, Amersham, UK), dissolved in ethanol to give a final concentration of $2.165 \mathrm{nM}$ and specific activity of $5 \times 10^{6} \mathrm{dpm} / \mathrm{nmol}$, was added to $1 \mathrm{~mL}$ of the cell suspension. After $60 \mathrm{~min}$ incubation, $100 \mu \mathrm{L}$ of yeast cells were placed in a Spin-X centrifuge tube filter $(0.45 \mu \mathrm{m}$ nylon filter $)$. The tube was centrifuged at $9000 \mathrm{~g}$ for $30 \mathrm{~s}$. The cells were washed with $20 \mu \mathrm{M}$ of unlabelled ice-cold fluconazole dissolved in CYG medium and the process was repeated three times. The cells were resuspended and their radioactivity was determined by liquid scintillation counting as described above.

\section{Combined effects of azole antifungal agents and MDR inhibitors}

One hundred microlitres of the yeast suspension (final concentration adjusted to $10^{3} \mathrm{cfu} / \mathrm{mL}$ ), including each MDR inhibitor (at $10^{-5}, 10^{-4}$ or $10^{-3} \mathrm{M}$ ), was added to each well of the microdilution plate containing antifungal agents. The optical density of the contents of each well was measured at $405 \mathrm{~nm}$ with a microdilution plate reader after incubation for $48 \mathrm{~h}$ at $37^{\circ} \mathrm{C}$ and growth inhibition was calculated relative to the control culture. 


\section{RESULTS}

Intracellular accumulation of $\left[{ }^{3} \mathrm{H}\right]$ itraconazole in azole-sensitive and -resistant $C$. albicans strains

In order to investigate the multidrug efflux mechanism, regulated by the $C D R I$ and $C a M D R$ genes in isolates of $C$. albicans, we measured the accumulation of itraconazole in azole-resistant $C$. albicans strains. The susceptibilities of $C D R I$ expressing resistant $\mathrm{C} 26$ strains and $C a M D R$ expressing $\mathrm{C} 40$ strains to azole antifungal agents are shown in Table I. Both strains showed high resistance to fluconazole, but strain $\mathrm{C} 40$ was less resistant to itraconazole. The intracellular concentration of $\left[{ }^{3} \mathrm{H}\right]$ itraconazole was markedly reduced in $C D R l$-expressing resistant strain $\mathrm{C} 26$. In contrast, high concentrations of itraconazole accumulated in CaMDR-expressing resistant strain C40, as in the sensitive strain B2630 (Table I).

Table I. Accumulation of itraconazole in azole-resistant and-sensitive C. albicans strains

$\begin{array}{lcccc}\text { Strain }^{\mathrm{a}} & \text { fluconazole } & \begin{array}{c}\text { MIC }(\mathrm{mg} / \mathrm{L})^{\mathrm{b}} \\ \text { ketoconazole }\end{array} & \text { itraconazole } & \begin{array}{c}\text { itraconazole } \\ \text { accumulation } \\ \text { (nmol) }^{\circ}\end{array} \\ \text { C26 } & >128 & >8 & >8 & 0.41 \pm 0.10 \\ \text { C40 } & 128 & >8 & 0.5 & 0.91 \pm 0.20 \\ \text { B2630 } & 0.13 & 0.032 & 0.016 & 0.94 \pm 0.11\end{array}$

${ }^{3}$ C26. CDR1-expressing azole-resistant C. albicans strain; C40, CaMDR-expressing azole-resistant C. albicans strain; B2630, azole-sensitivo $C$. albicans strain. "Measured by the microdilution method described in Materiais and methods "Accumulation data are the mean concentration \pm SD of seven measurements in $10^{\circ}$ cells. 
Intracellular accumulation of $\left[{ }^{3} \mathrm{H}\right]$ itraconazole and $\left[{ }^{3} \mathrm{H}\right]$ fluconazole in $S$. cerevisiae mutants

The strain DSY415, which contained the CDRI gene, was resistant to all three azole compounds tested in the present experiment (Table II). Strain DSY416, which contained the CaMDR gene, showed only acquired resistance to fluconazole but no shifts in MICs to itraconazole. Accumulation of fluconazole was reduced in DSY415 and DSY416 strains, while accumulation of itraconazole was only reduced in the DSY415 strain. Accumulation of itraconazole in DSY416 strain was higher than that in DSY566 strain (Table II).

Table ॥

Strain" fluconazole $\begin{gathered}\text { MIC }\left(\mathrm{mg} / \mathrm{L}^{b}\right. \\ \text { ketoconazole }\end{gathered}$ itraconazole $\begin{gathered}\text { accumulation (nmol) } \\ \text { fluconazole }\end{gathered} \quad$ itraconazole

$\begin{array}{lccccc}\text { DSY415 } & >128 & >16 & >2 & 0.004 \pm 0.001 & 0.42 \pm 0.09 \\ \text { DSY416 } & >128 & >0.25 & 0.03 & 0.005 \pm 0.001 & 1.81 \pm 0.36 \\ \text { DSY566 } & 0.5 & 0.25 & 0.03 & 0.020 \pm 0.003 & 1.30 \pm 0.29\end{array}$

"DSY415 and DSY416 contained C. albicans CDR1 and CaMDR genes respectively. cloned into YEp24. The PDR5 (STS1) deletion mutant DSY566 was a parent strain of DSY415 and DSY416.

'Each transformant was grown at $30^{\circ} \mathrm{C}$ overnight in YNB medium with required amino acids, but uracil was omitted. MICs were determined by the microdilution methocl described in Materials and methods.

'Accumulation data are the mean concentration \pm SD of seven measurements in $10^{\circ}$ cells.

Intracellular accumulation of $\left[{ }^{3} \mathrm{H}\right]$ itraconazole in azole-resistant $C$. albicans strains inoculated with respiratory or MDR inhibitors

The effect of sodium azide $\left(\mathrm{NaN}_{3}\right)$ as an electron-transport chain inhibitor on the accumulation of itraconazole was examined by the addition of $10^{-4} \mathrm{M}$ of $\mathrm{NaN}_{3}$; in culture. This resulted in a marked increase in accumulation of itraconazole in 
the $C D R 1$-expressing resistant strain $\mathrm{C} 26\left(1.40 \mathrm{nmol} / 10^{9}\right.$ cells). No effects of $\mathrm{NaN}_{3}$ were noted in the CaMDR-expressing resistant strain $\mathrm{C} 40\left(0.83 \mathrm{nmol} / 10^{9}\right.$ cells) and the sensitive strain B2630 (0.94 nmol/10 $0^{9}$ cells). We also measured the effects of representatives of different classes of respiratory inhibitors on itraconazole accumulation. Only carbonyl cyanide m-chlorophenylhydrazone $(\mathrm{CCCP})$, at a final concentration of $10^{-4} \mathrm{M}$. induced a small increase in the concentration of itraconazole in the $C D R I$-expressing resistant strain $\mathrm{C} 26$, but other respiratory inhibitors, oligomycin and antimycin $A$ (at final concentrations of $10^{-5} \mathrm{M}$ ), had no effect. In the CaMDR-expressing resistant strain $\mathrm{C} 40$, accumulation of itraconazole was not increased by the addition of respiratory inhibitors. Increased accumulation was also noted in the sensitive strain B2630 (Figure 1).

To investigate the role of MDR proteins in azole resistant $C$. albicans cells, we examined the effects of known MDR-protein inhibitors on the accumulation of itraconazole. The highest increase (4.6-fold increase) in intracellular accumulation of itraconazole was observed in the $C D R I$-expressing resistant strain $\mathrm{C} 26$ incubated with tacrolimus (final concentration, $10^{-4} \mathrm{M}$ ). Accumulation was also increased in the CaMDR-expressing resistant strain C40 (1.6-fold increase) and a small increase was also observed in the sensitive strain B2630 (1.3-fold increase). Verapamil had no effect on the uptake of the itraconazole either in the resistant or sensitive strains (Figure 1).

\section{Combined effect of MDR inhibitors and azole antifungal agents}

The inhibitory effect of tacrolimus alone (from $10^{-7}$ to $10^{-3} \mathrm{M}$ ) did not influence the growth of yeast cells. Verapamil also had no effect on the growth of cells when used at concentrations similar to those of tacrolimus (data not shown ).

The turbidity of the cells incubated with $10^{-5}$ to $10^{-3} \mathrm{M}$ of tacrolimus and azole antifungal agents is shown in Figure 2. Tacrolimus reduced the itraconazole MIC of azole-resistant $\mathrm{C} 26$ from 8 to $0.5 \mathrm{mg} / \mathrm{L}$. The MICs of itraconazole in strain $\mathrm{C} 40$ decreased from 0.5 to $0.06 \mathrm{mg} / \mathrm{L}$ in the presence of tacrolimus. Similar synergic effects were observed in strain $\mathrm{C} 40$ after incubation with tacrolimus and ketoconazole. 


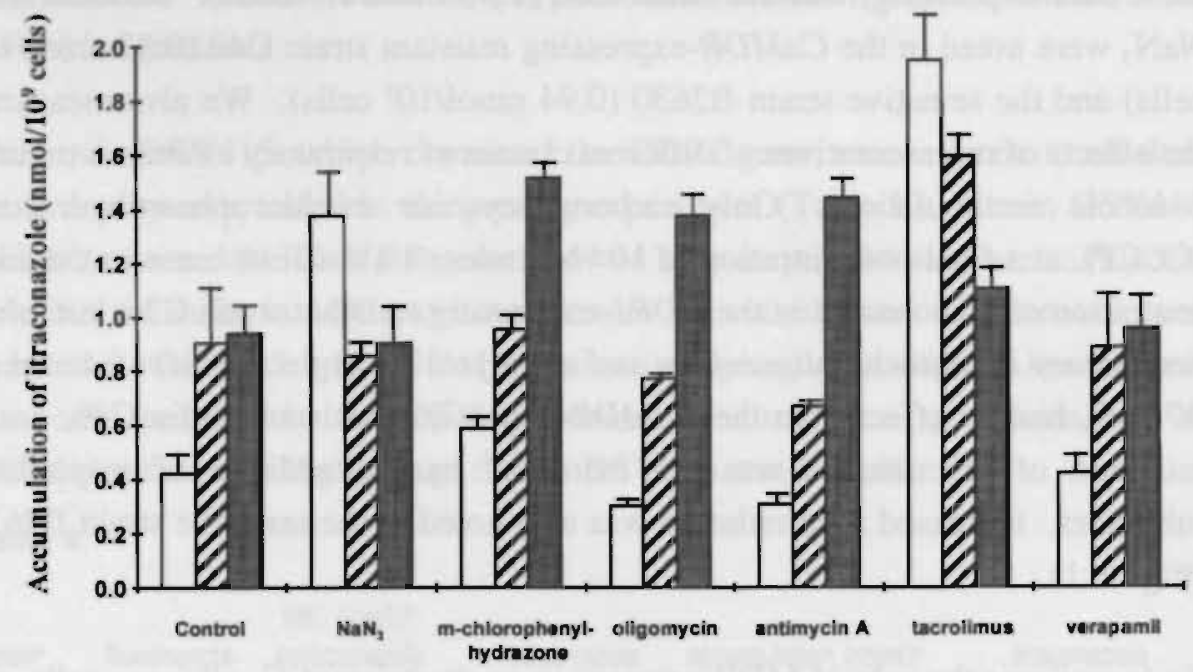

Figure 1. Effects of energy inhibitors, tacrolimus. and verapamil on $\left[{ }^{3} \mathrm{H}\right]$ itraconazole accumulation in azole-resistant and -sensitive $C$ albicans strains. Accumulation of itraconazole was measured after the addition of the following compounds: sodium azide $\left(\mathrm{NaN}_{3}\right)$. m-chlorophenylhydrazone (CCCP), tacrolimus, and verapamil (final concentrations $10^{-4} \mathrm{M}$ ), antimycin A, oligomycin (final Concentration $10^{-5} \mathrm{M}$ ). Values for the control culture are expressed as mean \pm S.D. of seven determinations. Other values are means $\pm \mathrm{SD}$ of three experiments using itraconazole. ( $\square$ ) CDR1-expressing resistant $\mathrm{C} 26$ strain, ( $\square$ ) CaMDR-expressing resistant $\mathrm{C} 40$ strain and (D) sensitive B2630 strain.

Figure 2. The turbidity of the cell growth incubated with azole antifungal agents and tacrolimus. One hundred microlitres of each MDR inhibitor, at concentrations ranging from $10^{-5}$ to $10^{-3} \mathrm{M}$, were added to each well of the microdilution plate including the antifungal agents, then $100 \mu \mathrm{L}$ of the yeast suspension (final concentration adjusted to $10^{3} \mathrm{cfu} / \mathrm{mL}$ ) was added to each plate. The optical density of each well was measured at $405 \mathrm{~nm}$ with at microdilution plate reader after incubation for $48 \mathrm{~h}$ at $37^{\circ} \mathrm{C}$ and growth inhibition was calculated relative to the control culture. The concentrations of tacrolimus were $0(0) .10^{-5}(0), 10^{-4}(9)$ and $10^{-3} \mathrm{M}(\square)$ with azole antifungalagents fluconazole (a). itraconazole (b). and ketoconazole (c). The values are means of three measurements. 

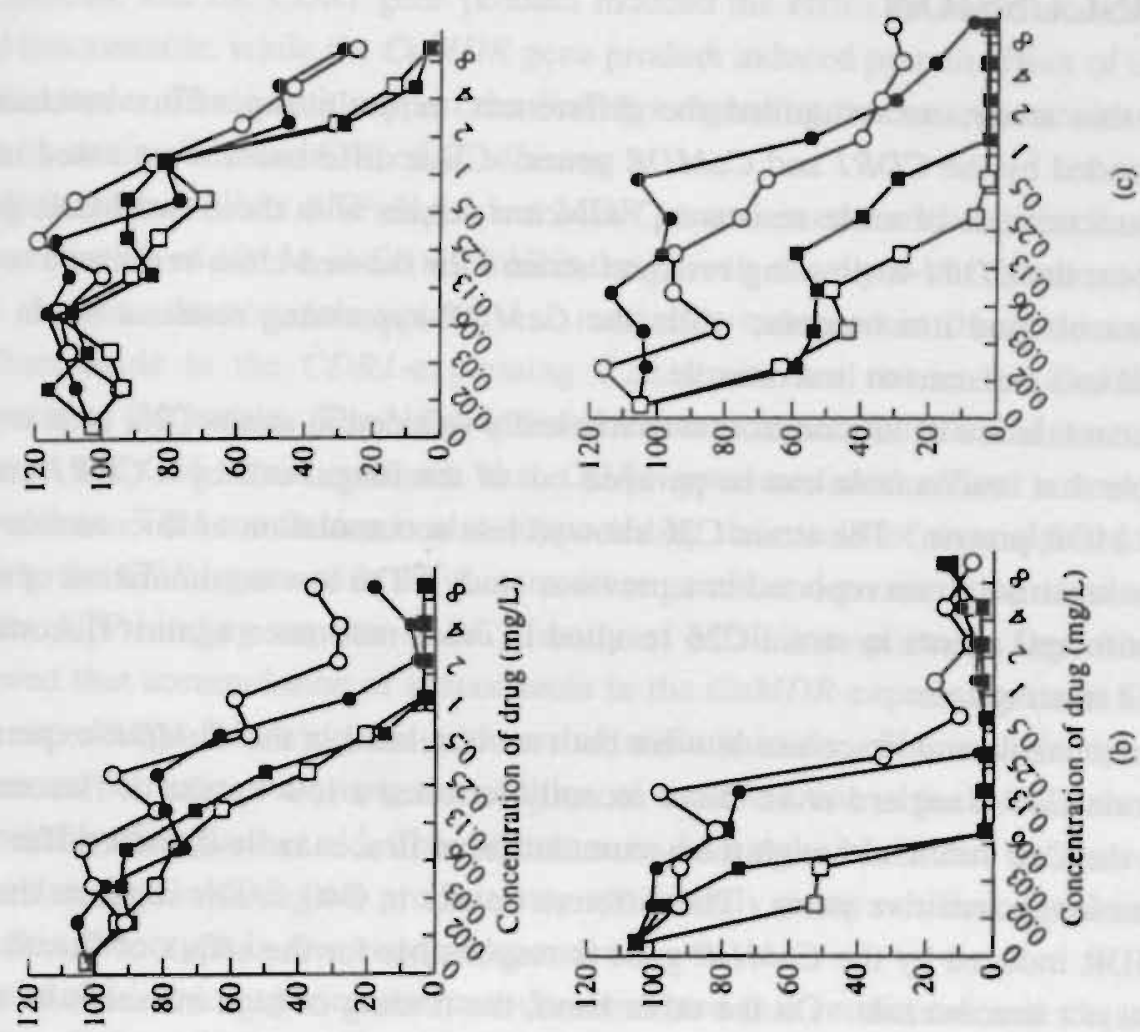

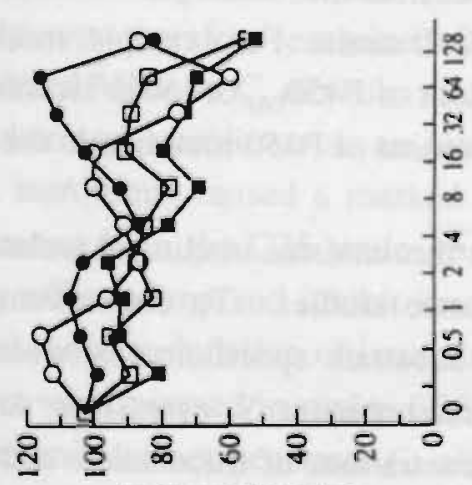

(\%) पाM018 วA!IEIวУ

กำ

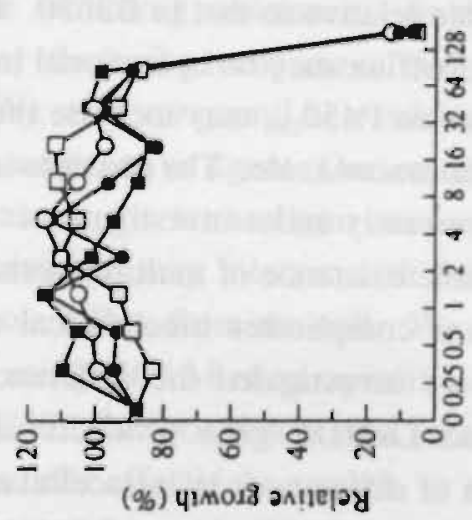

ษ 


\section{DISCUSSION}

In this study, we examined the differences in multidrug efflux mechanism encoded by the $C D R I$ and $C A M D R$ genes. Clear differences were noted in the characteristics of azole-resistant $C$. albicans strains with these two MDR genotypes: the $C D R I$-expressing resistant strain $\mathrm{C} 26$ showed cross-resistance to fluconazole and itraconazole, while the CaMDR-expressing resistant strain $\mathrm{C} 40$ was less resistant to itraconazole.

Accumulation of itraconazole was markedly reduced in strain $\mathrm{C} 26$, so it is possible that itraconazole can be pumped out of the fungal cell by a CDRI-encoded MDR protein. The strain C26 showed less accumulation of fluconazole than the sensitive strain reported in a previous study. ${ }^{5}$ The low accumulation of azole antifungal agents in strain $\mathrm{C} 26$ resulted in cross-resistance against fluconazole and itraconazole.

Fluconazole and itraconazole were both accumulated in the CaMDR-expressing strain C40. Sanglard et al. ${ }^{5}$ have recently reported a low uptake of fluconazole in the $\mathrm{C} 40$ strain, although the accumulation of itraconazole did not differ from that in the sensitive strain. The different uptake in $\mathrm{C} 40$ strains suggests that the MDR induced by the CaMDR gene is responsible for the efflux of fluconazole but not itraconazole. On the other hand, the finding of high intracellular accumulation of itraconazole cannot explain why the $\mathrm{C} 40$ strain has a high MIC of itraconazole relative to that in $\mathrm{B} 2630$. It is possible that other mechanisms that cause drug efflux may be operational in the $\mathrm{C} 40$ strain. For example, mutation of cytochrome $\mathrm{P} 450_{\mathrm{DM}}$ may increase the content of $\mathrm{P} 450_{\mathrm{DM}}$ or lower its binding affinity for itraconazole. The possible involvement of $\mathrm{P} 450$ mutation in the $\mathrm{C} 40$ strain is currently under investigation.

The possible existence of multiple resistance mechanisms in clinical isolates of C. albicans complicates biochemical resistance studies. To circumvent this problem we investigated the difference in substrate specificity, between the $C D R I$ and $C a M D R$ gene products using recombinant $S$. cerevisiae strains. Detection of differences in intracellular concentrations of fluconazole and itraconazole between DSY415 and DSY416 strains confirmed the results from studies of the susceptibility to azole antifungal agents. The results, shown in Table 
II, indicate that the CDRI gene product induced the efflux of both fluconazole and itraconazole, while the CaMDR gene product induced protein efflux of only fluconazole. These data support the findings regarding itraconazole accumulation in strains $\mathrm{C} 26$ and $\mathrm{C} 40$ of $C$. albicans.

Sodium azide inhibits ATP-dependent MDR protein in mammalian cells. ${ }^{18}$ At a concentration of $10^{-4} \mathrm{M}$, it did not inhibit the growth of cells in our cultures (data not shown). Itraconazole uptake was markedly increased in the presence of sodium azide in the CDRI-expressing C26 strain, but not in the CaMDRexpressing $\mathrm{C} 40$ strain. The $\mathrm{NaN}_{3}$-induced increase in accumulation of itraconazole in the C26 strain indicates that CDRI gene-mediated efflux is energydependent. This conclusion is also supported by the results of an analysis comparing the $C D R I$ gene with the $S$. cerevisiae genome. demonstrating similarity to the ATP-binding cassette $(\mathrm{ABC})$ family of MDR transporters. Our results showed that accumulation of itraconazole in the CaMDR-expressing strain C40 did not change following the addition of sodium azide. Fluconazole uptake increased 6.1 times following the addition of sodium azide in the $\mathrm{C} 40$ strain. as reported by Sanglard et al. ${ }^{5}$ The difference in the uptake of the two azoles suggests that the CaMDR gene product may specifically pump out fluconazole and that this phenotype is also energy-dependent.

Results of in-vitro experiments have demonstrated that certain calcium channel blockers ${ }^{19-20}$ and immunosuppressants ${ }^{15}$ inhibit the binding of P-glycoprotein to anticancer drugs, and hence overcome multidrug resistance. In the present study, we therefore examined whether these P-glycoprotein inhibitors also inhibited MDR in $C$. albicans strains. We used verapamil as a calcium channel blocker and tacrolimus as an immuno-suppressive agent. Our results showed that tacrolimus caused a marked increase in the intracellular accumulation of itraconazole in the $\mathrm{C} 26$ strain: thus tacrolimus may interact with the common drug efflux pump and inhibit itraconazole efflux from the cell. We also measured the accumulation of itraconazole using $10^{-4} \mathrm{M}$ of verapamil: no obvious effect was observed in strains $\mathrm{C} 26$ and $\mathrm{C} 40$. One possible reason for this is that verapamil did not penetrate $C$. albicans cells effectively enough, or contact of verapamil with the cell was not sufficient to change the MDR protrein.

Azole-resistant $C$. albicans strains are isolated with increasing frequency from 
patients with advanced AIDS complicated by oropharyngeal candidiasis and treated with fluconazole. Some of these resistant strains show cross-resistance to itraconazole or ketoconazole. ${ }^{21}$ Amphotericin B is considered as an effective antifungal agent but the clinical use of the drug is limited because of serious adverse effects. Thus, it is necessary to develop new effective antifungal agents or new strategies for azole resistant $C$. albicans infections.

Tacrolimus is a new immunosuppressant used clinically in the prevention of allograft rejection. ${ }^{22}$ Recent studies have demonstrated that tacrolimus has antifungal activity against Malassezia furfur, a lipophilic yeast and a member of the normal skin microflora, and this property is involved in the clinical efficacy of tacrolimus in patients with atopic dermatitis. ${ }^{24}$ Unfortunately, tacrolimus showed no antifungal activity against Candida spp. in the present study. However, the combination of tacrolimus at a concentration of $10^{-3} \mathrm{M}$ and azole antifungal agents (except for fluconazole) showed synergic effects against azole resistant $C$. albicans strains. Increased intracellular concentrations of azole antifungal agents may explain the synergy between azole antifungal agents and tacrolimus.

Invasive candidiasis often develops in immuno compromised patients with bone marrow transplantation or other organ transplantation. Immunosuppressive. agents have been used to prevent allograft rejections. Azole antifungal agents are administered to these patients as prophylaxis against fungal infections. ${ }^{24}$ The synergy between tacrolimus and itraconazole shown in this study indicates that the latter agent could be used as prophylaxis in patients treated by immunosuppressive agents such as tacrolimus.

\section{ACKNOWLEDGEMENTS}

We thank Dr F. G. Issa. from the Department of Medicine, University of Sydney, Australia. for careful reading and editing of the manuscript. 


\section{Synergic effects of tacrolimus and azoles}

\section{REFERENCES}

1. Marichal, P. \& Vanden Bossche, H. (1995) Mechanisms of resistance to azole antifungals. Acta Biochimica Polonica 42.509 - 16.

2. Vanden Bossche, H., Marichal, P 8 Odds. F. C. (1994) Molecular mechanisms of drug resistance in fungi. Trends in Microbiology 2, 393-400.

3. Albertson, G. D., Niimi, M., Cannon, R. D \& Jenkinson, H F (1996). Multiple efflux. mechanisms are involved in Candida albicans fluconazole resistance. Antimicrobial Agents and Chemotherapy 40, 2835-41.

4. Goldway. M. Tett. D. Schmidt. R. Oppenheim. A. B \& Koltin. Y. (1995) Multiple resistance in Candida albicans disruption of the $B E N^{\prime}$ gene. Antimicrobial Agents and Chemotherapy 39, 422-6.

5. Sanglard, D., Kuchler. K. Ischer, F., Pagani, J. L., Monad, M. \& Bille J. (1995). Mechanisms of resistance to azole antifungal agents in Candida albicans isolates from. AIDS patients involve specific multidrug transporters. Antimicrobial Agents and Chemotherapy 39, 2378-86.

6. Sanglard. D., Ischer. F. Monod, M. \& B8ille, J. (1996). Susceptibilities of Candida albicans multidrug transporter mutants lo various antifungal agents and other metabolic inhibitors. Antimicrobial Agents and Chemotherapy 40. 2300-5.

7. Lamb, D. C., Kelly, D. E., Schunck, W. H., Shyadehi, A. Z., Akhtar, M., Lowe, D. J. et a/. (1997). The mutation T315A in Candida albicans sterol 14a-demethylase causes reduced enzyme activity and fluconazole resistance through reduced activity. Journal of Biological Chemistry 272, 5682-8.

8. White. T. C. (1997). The presence of an R467K amino acid substitution and loss of allel. ic variation correlate with an azole resistant lanosterol $14 \alpha$-demethylase in Candida albicans. Antimicrobial Agents and Chemotherapy 41,1488-94.

9. Bellamy. W. T. (1996). P-glycoproteins and multidrug resistance, Annual Review of Pharmacology and Toxicology 36. 161-3.

10. Meyers, S., Schauer, W.. Batzi. E., Wagner, M.. Goffeau, A. \& Golin. J. (1992). Interaction of the yeast pleiotropic drug resistance genes PDR' $j$ and PDR5. Current Genetics 21. 431-6.

11. Leonard, P. J., Rathod. P. K. 8. Golin, J. (1994). Loss of function mutation in the yeast multiple drug resistance gene PDR5 causes a reduction in chloramphenicol efflux. Antimicrobial Agents and Chemotherapy 38, 2492-4. 
12. Prasad, R.. De Wergifosse, P., Goffeau. A. \& Balzi, E. (1995). Molecular cloning and characterisation of a novel gene of Candida albicans, CDRI, conferring multiple resistance to drugs and antifungals. Current Genetics 27, 320-9.

13. Ross, D. D., Wooten, P. J., Sridhara, R., Ordonez, J. V., Lee, E. J. 8 Schiffer. C. A. (1993). Enhancement of daunorubicin accumulation, retention, and cytotoxicity by verapamil or cyclosporin $\mathrm{A}$ in blast cells from patients with previously untreated acute myeloid leukemia. Blood 82, 1288-99.

14. Arceci, R. J., Stieglitz, K. 8 Bierer, B. E. (1992). Immunosuppressants FK506 and rapamycin function as reversal agents of the multidrug resistance phenotype. Blood $\mathbf{8 0}$. 1528-36.

15. Saeki, T., Ueda, K., Tanigawara, Y., Hori, R. 8 Komano, T (1993). Human P-glycoprotein transports cyclosporin A and FK506 Journal of Biological Chemistry 268. 6077-80.

16. Yamaguchi, H., Uchida. K., Kume, H., Shinoda, T., Watanabe, K., Kusunoki, T. et al. (1994). Report of the committee of clinical laboratory standards. Japanese Joumal of Medical Mycology 36, 61 -86.

17. Marichal, P., Gorrens, J., Coene, M. C., LeJeune, L. 8 Vanden Bossche, H. (1995). Origin of differences in susceptibility of Candida krusei to azole antifungal agents. Mycoses 38.111 -7.

18. Ambudkar, S. V., Lelong, I. H., Zhang, J., Cardareili, C. O., Gottesman, M. M. \& Pastan, L. (1992). Partial purification and reconstitution of the human multidrug-resistance pump: Characterization of the drug stimulatable ATP hydrolysis. Proceedings of the National Academy of Sciences of the USA 89. 8472-6.

19. Abbaszadegan, M. R., Foley, N. E., Gleason Guzman, M. C. 8 Dalton, W. S. (1996). Resistance to the chemosensitizer verapamil in a multi-drug-resistant (MDR) human multiple myeloma cell line. International Journal of Cancer 66, 506- 14.

20. Broxterman, H. J., Pinedo, H. M., Kuiper, C. M., Kaptein, L. C. M., Schuurhuis, G. J. 8 Lankelman, J. (1988). Induction by verapamil of a rapid increase in ATP consumption in multidrug resistant tumor cells. FASEB Journal 2, 2278-82.

21. Laguna, F., Rodriguez Tudela, J. L.. Martinez Suarez, J. V., Polo, R., Valencia, E., Diaz Guerra. T. M. et al. (1996). Patterns of fluconazole susceptibility in isolates from human immunodeficiency virus-infected patients with oropharyngeal candidiasis due to Candida albicans. Clinical Infectious Diseases 24.124-30.

22. Fay, J. W., Wingard. J. R., Antin, J. H., Collins. R. H., Pineiro. L. A., Blazar. B. R. et al. (1996). F.K506 (tacrolimus) monotherapy for prevention of graft-versus-host disease after histocompatible sibling allogenic bone marrow transplantation. Blood 87, 3514-9. 


\section{Synergic effects of tacrolimus and azoles}

23. Nakagawa, H., Etoh. T., Yokota, Y., Ikeda, F., Hatano, K., Teratani, N. et al. (1996). Tacrolimus has antifungal activities against Malassezia furfur isolated from healthy adults and patients with atopic dermatitis. Clinical Drug Investigation 12, 244-50.

24. Lam, H. H. 8 Althaus. B. L. (1995). Antifungal prophylaxis in bone marrow transplant. Annals of Pharmacotherapy 29, $921-4$. 



\section{Molecular biological characterization of}

\section{an azole-resistant Candida glabrata}

\section{isolate}

Patrick Marichal, ${ }^{1 *}$ Hugo Vanden Bossche, ${ }^{1}$ Frank C. Odds, ${ }^{1}$ Geert Nobels, ${ }^{1}$ Walter Luyten, ${ }^{2}$ David W. Warnock, ${ }^{3}$ Vincent Timmerman, ${ }^{4}$ Christine Van Broeckhoven, ${ }^{4}$ Stephen Fay, ${ }^{5}$ and Peter Mose-Larsen ${ }^{5}$

Anti-Infectives Research Departments, ${ }^{\prime}$ Functional Genomics, ${ }^{2}$ Janssen Research Foundation, Beerse, and Laboratory of Neurogenetics, Department of Biochemistry, Born Bunge Foundation (BBS), Flanders Interuniversity Institute for Biotechnology (VIB), University of Antwerp (UIA), Antwerp, ${ }^{3}$ Belgium; Public Health Laboratory, Mycological Reference Laboratory Bristol, England ${ }^{2}$, and Institute for Medical Microbiology, Aarhus University, Aarhus, Denmark

Running title: Azole resistance in C. glabrata Antimicrobrul Age'nts and Che'mothe'rapy, 1997, 4I(I1)), 2229-2237 
Chapter 5

\section{SUMMARY}

Two isolates of Candida glabrata, one susceptible and one resistant to azole antifungals, were previously shown to differ in quantity and activity of the cytochrome P-450 14 $\alpha$-lanosterol demethylase which is the target for azole antifungals. The resistant isolate also had a lower intracellular level of fluconazole, but not of ketoconazole or itraconazole, than the susceptible isolate. In the present study a 3.7-fold increase in the copy number of the CYP5I gene, encoding the $14 \alpha$-lanosterol demethylase, was found. The CYP5I mRNA transcript in the resistant isolate was eight times greater than it was in the susceptible isolate. Hybridization experiments on chromosomal blots indicated that this increase in copy number was due to duplication of the entire chromosome containing the CYP5I gene. The phenotypic instability of the resistant isolate was demonstrated genotypically: a gradual loss of the duplicated chromosome was seen in successive subcultures of the isolate in fluconazole-free medium and correlated with reversion to susceptibility. The greater abundance of the amplified chromosome induced pronounced differences in the protein patterns of the susceptible and revertant isolates versus that of the resistant isolate, as demonstrated by two-dimensional gel electrophoresis (2D-GE). Densitometry of the 2D-GE product indicated upregulation of at least 25 proteins and downregulation of at least 76 proteins in the resistant isolate. 


\section{INTRODUCTION}

The incidence of life-threatening fungal infections has increased dramatically over the last decade. The antifungal agents available to treat these infections can be divided into four groups according to their modes of action. They impair membrane integrity (polyenes), interact with microtubules (griseofulvin), or inhibit macromolecule synthesis (flucytosine) or ergosterol biosynthesis (azoles, morpholines, and allylamines). For treatment of systemic Candida infections only polyenes, flucytosine, and azoles are used.

Resistance to flucytosine is common and usually arises from the loss or mutation of cytosine permeases (the enzymes involved in its uptake), of enzymes involved in the conversion of flucytosine to phosphorylated derivatives of 5-fluorouracil, the antifungally active metabolite, or of enzymes involved in its incorporation into RNA (37). Resistance to amphotericin B, a polyene, has been seldom observed in the clinic during its use for three decades. Most amphotericin B-resistant isolates contain abnormally low numbers of ergosterol molecules in their plasma membranes, thereby limiting the numbers of available binding sites for the polyene and thus preventing the membrane damage.

Up to the late eighties, azole resistance was also a rare phenomenon and limited to chronic mucocutaneous candidiasis patients. The AIDS epidemic, caused by the human immuno-deficiency virus (HIV) type I, drastically changed the situation. Large-scale prophylactic and therapeutic use of fluconazole led to both the occurrence of fluconazole-resistant Candida albicans isolates and to increased colonization of patients with other Candida species, such as $C . k r u s e i$ and $C$. glabrata, that are less sensitive to fluconazole than $C$. albicans (25).

Despite the numerous reports on resistance only a few mechanistic studies were published until recently, when some multidrug resistance proteins were identified in $C$. albicans. The identification of the CaMDRI gene (8) (initially designated $B E N^{r}$ ) as a member of the major facilitators and that of $C D R J(24)$ as a member of the ATP-binding bassette $(A B C)$ family have boosted the number of studies concerning these transport molecules. Indeed, it has been shown that $C D R /$ expression confers resistance not only to all types of the antifungal azoles but also to other ergosterol biosynthesis inhibitors such as the squalene epoxi- 
dase inhibitor terbinafine (26) and the $\Delta 14$-reductase and/or $\Delta 8-7$-isomerase inhibitor (23) amorolfine $(2,4,29,30)$. By contrast, expression of CaMDRI results in resistance only to fluconazole and not to other azoles, possibly because of this agent's hydrophilic properties (29). Recently it has been demonstrated by Sanglard et al. that overexpression of CaMDRI in Saccharomyces cerevisiae confers resistance to terbinafine, implying that terbinafine is a substrate for this transporter (31).

Several homologs to these two multidrug resistance genes have now been identified, indicating that in $C$. albicans, as in S. cerevisiae, a plethora of transport systems which could contribute to lower intracellular levels of antifungals exists. Studies dealing with other possible underlying resistance mechanisms, such as alteration or overproduction of a target enzyme, changes in membrane composition, and mutation of other ergosterol biosynthesis genes are limited in number $(9,12,16,32,35,36)$. We previously studied two $C$. glabrata isolates, one sensitive (prefluconazole treatment) and one resistant (posttreatment). It was concluded that resistance to fluconazole was at least partly due to both a lower intracellular fluconazole content and to an increased P-450-dependent ergosterol synthesis, whereas only the latter contributed to itraconazole resistance (36). The increased ergosterol synthesis, measured in intact cells and in subcellular fractions, was attributed to an increased cellular content and activity of cytochrome P-450 14 $\alpha$-lanosterol demethylase $\left(\mathrm{CYP}_{51}\right.$ product of the CYP51 gene; also called ERG11 in S. cerevisiae and ERG16 in C. albicans) and to an increased squalene epoxidase or oxidosqualene cyclase activity (36). This increase of squalene epoxidase activity was thought to be the origin of crossresistance to terbinafine. We also demonstrated the phenotypic instability of azole resistance in the posttreatment isolate by showing a gradual increase in susceptibility to azoles when the isolate was repeatedly subcultured in fluconazole-free medium (36). After 115 subcultures the itraconazole sensitivity of the posttreatment isolate was similar to that of the pretreatment isolate, whereas fluconazole sensitivity was only partly restored even after 159 subcultures (36).

In the present study we have directly examined the content and expression of gene CYP5I, in pretreatment (susceptible), posttreatment (resistant), and revertant (mostly susceptible) isolates of $C$. glabrata from the previous publication 
Azole resistance in C. glabrata

(36) and have used two-dimensional electrophoresis of cellular proteins in the three isolates to allow direct visualization of the complex changes in protein synthesis that accompany the azole resistant phenotype.

\section{MATERIALS AND METHODS}

\section{Strains}

C. glabrata B57148 (originally isolated as 173/8) was isolated from the midstream urine of a 57-year-old female patient before treatment with intravenous ciprofloxacin and $400 \mathrm{mg}$ of fluconazole once daily. Satisfactory levels of fluconazole were achieved in both the patient's blood ( up to $44 \mathrm{mg} \mathrm{liter}^{-1}$ ) bile ( up to $58 \mathrm{mg} \mathrm{liter}^{-1}$ ) and urine (up to $141 \mathrm{mg} \mathrm{liter}^{-1}$ ). Strain B57149 (originally isolated as 2895) was isolated from the mid-stream urine of the same patient after 9 days of treatment (38). To study its phenotypic and genotypic stability strain B57149 was repeatedly subcultured up to 159 times in CYG medium (casein hydrolysate [Merck, Darmstadt, Germany], yeast extract [Difco, detroit, USA], glucose, each at a concentration of $5 \mathrm{~g} \mathrm{liter}^{-1}$ ). This isolate, with a revertant phenotype to azole susceptibility (36), was designated B57149-159. To ensure experimental reproducibility with strains demonstrating unstable phenotypes, stock suspensions in $10 \%$ glycerol were prepared from these cultures and stored at $-70^{\circ} \mathrm{C}$ to provide sufficient starting material for each individual experiment to begin with the same inoculum. The isolates used in this study were genotypically typed and compared with at least five unrelated clinical $C$. glabrata isolates by restriction fragment length polymorphism (RFLP) analyses of genomic DNA with HindIII, Hinfl, and BgllI as the restriction enzymes as described by Smith et al. (33). Arif et al. (1) reported that RFLP analysis with Hintt was the most suitable typing technique for differentiation of $C$. glabrata. isolates. To increase the probability of clonal relatedness, hybridization of EcoRI digests with a highly discriminatory oligonucleotide probe a gift from D. Soll, University of lowa) was performed and revealed again identical patterns for the B57148, B57149, and B57149-159 isolates used in this study. This pattern differed substantially from those found with 20 unrelated clinical $C$. glabra$t a$ isolates. 


\section{Media.}

C. glabrata strains were grown in either $\mathrm{CYG}$ medium or in $\mathrm{PYG}_{2}$ medium (10 $\mathrm{g}$ of polypeptone [Becton Dickinson, Sparks, Md.], $10 \mathrm{~g}$ of yeast extract [Difco] and $40 \mathrm{~g}$ of glucose liter ${ }^{-1}$ ).

\section{MIC determination.}

MICs were determined spectrophotometrically by a broth microdilution method (22) based on the National Committee for Clinical Laboratory Standards (NCCLS) reference method (19). The MIC was the lowest concentration that inhibited growth by more than $50 \%$; this end-point showed the best correlation with results from the NCCLS broth macrodilution method. Quality control yeasts C. krusei ATCC 6258 and Candida. parapsilosis ATCC 22019 were tested in parallel and were inhibited at MICs in the correct ranges for the antifungals tested (19).

\section{Drug uptake.}

Accumulation experiments with $\left[{ }^{3} \mathrm{H}\right]$ itraconazole (specific activity, $75 \mathrm{mCi}$ mmol $^{-1}$; Janssen Research Foundation, Beerse, Belgium) and $\left[{ }^{14} \mathrm{C}\right]$ fluconazole (specific activity, $6.8 \mathrm{mCi} \mathrm{mmol}^{-1}$; gift from Pfizer Central Research, Sandwich, United Kingdom) were performed as described previously (36).

\section{Isolation of DNA (I) Isolation of DNA for restriction analysis and Southern blotting.}

Stationary phase cells $\left(6 \times 10^{9}\right)$ grown in CYG medium were collected by centrifugation at $1.500 \mathrm{xg}$, washed twice in TE 1 buffer $(10 \mathrm{mM}$ Tris, $1 \mathrm{mM}$ EDTA [pH 7.5]) and resuspended in $6 \mathrm{ml} 0.9 \mathrm{M}$ sorbitol-0.1 M EDTA- $14 \mathrm{mM} \beta$-mercaptoethanol pH 7.5. Zymolyase (180U; $5000 \mathrm{U} \mathrm{g} \mathrm{g}^{-1}$; Arthrobacter lutens; Seikagaku Kogyo, Japan) was added for spheroplast formation, and the mixture was incubated for $60 \mathrm{~min}$ at $30^{\circ} \mathrm{C}$ with mild agitation. For quantification of spheroplast formation, $50 \mathrm{ml}$ of cell suspension and $950 \mathrm{ml}$ of water (MilliQplus, Millipore, Bedford. Mass.) were combined and the absorbance at $600 \mathrm{~nm}$ was measured $20 \mathrm{~s}$ after the dilution. Typically absorbance decreased by 80 to $90 \%$ after 60 min of incubation with Zymolyase. Spheroplasts were collected 
by centrifugation, suspended in $3 \mathrm{ml}$ of $\mathrm{TE}_{2}$ buffer ( $50 \mathrm{mM}$ Tris, $50 \mathrm{mM}$ EDTA. [pH 8.0]), and lysed with the addition of $0.3 \mathrm{ml}$ of $10 \%$ sodium dodecyl sulfate (SDS). After a $30-m i n$ incubation at $65^{\circ} \mathrm{C}$ proteins were precipitated by the addition of $1 \mathrm{ml}$ of $5 \mathrm{M}$ potassium acetate. After a 2-h incubation in ice, precipitated proteins were removed by $10 \mathrm{~min}$ of centrifugation at $15,000 \times \mathrm{g}$ at $4^{\circ} \mathrm{C}$. The supernatant thus obtained was phenol extracted according to the protocols of Sambrook et al. (28). Nucleic acids were precipitated from the aqueous phase by the addition of 0.1 volumes of $3 \mathrm{M}$ sodium acetate and 2 volumes of $100 \%$ ethanol $\left(-20^{\circ} \mathrm{C}\right)$. The pellet was collected after centrifugation for $10 \mathrm{~min}$ at $10,000 \times g$ at $4^{\circ} \mathrm{C}$. The pellet was rinsed with $50 \%$ ethanol, air dried, and resuspended in $3.5 \mathrm{ml} \mathrm{TE}_{1}$ buffer, and $150 \mu \mathrm{l}$ DNase-free RNase $\left(10 \mathrm{mg} \mathrm{ml}^{-1}\right.$ in 10 $\mathrm{mM}$ sodium acetate $[\mathrm{pH} 7.0]$ ) was added. After $30 \mathrm{~min}$ at $37^{\circ} \mathrm{C}$ insoluble material was precipitated by $10 \mathrm{~min}$ centrifugation at $8000 \mathrm{xg}$ and the DNA in the supernatant was precipitated with 1 volume of isopropanol. The pellet was rinsed with $50 \%$ isopropanol and suspended in $500 \mu \mathrm{l} \mathrm{TE} \mathrm{L}_{1}$ buffer. The DNA concentration was determined in a spectrofluorimeter (excitation, $345 \mathrm{~nm}$; emission $460 \mathrm{~nm})$ after addition of $2.5 \mathrm{ml}$ of bisbenzimide $\left(0.1 \mu \mathrm{g} \mathrm{ml}^{-1}\right)$. The signal thus obtained was linear for final DNA concentrations between 0.04 and $5 \mu \mathrm{g}$ $\mathrm{ml}^{-1}$.

(ii) Isolation of chromosomal grade DNA.

Intact chromosomes were isolated according to the method of Den Dunnen et al. (6). C. glabrata strains were grown to a density of up to $5 \times 10^{7}$ cells $\mathrm{ml}^{-1}$ in CYG medium. Fifty-milliliter aliquots of these cultures were centrifuged at $1.500 \times \mathrm{g}$ and resuspended at a concentration of $1.5 \times 10^{9} \mathrm{cells} \mathrm{ml}^{-1}$ in CPE buffer (40 mM citric acid, $120 \mathrm{mM} \mathrm{Na}_{2} \mathrm{HPO}_{4}[\mathrm{pH} 6.0$ ], with $2 \mathrm{ml}$ of $0.8 \mathrm{M}$ EDTA [pH $8.0]$ added per $50 \mathrm{ml}$ ). An equal volume of $2 \%$ low-melting point agarose (Seaplaque GTG; FMC. Rockland. Maine) dissolved in CPE buffer at $60^{\circ} \mathrm{C}$ was added to the cell suspension, and the suspension was mixed gently and distributed immediately in small lots into the precooled DNA plug kit (Bio-Rad, Hercules, Calif.). The plugs were placed in the refrigerator for $1 \mathrm{~h}$. The solidified plugs were incubated for $2 \mathrm{~h}$ at $30^{\circ} \mathrm{C}$ in $2 \mathrm{ml} \mathrm{CPE}$ buffer containing NOVOZYM 234 (Novo Biolabs, Bagsvaerd, Denmark) (2 mg ml-1). The plugs 
were washed twice in $\mathrm{TE}_{1}$ buffer and incubated for $48 \mathrm{~h}$ at $50^{\circ} \mathrm{C}$ in $2 \mathrm{ml} 0.8 \mathrm{M}$ EDTA containing $100 \mu \mathrm{g}$ of pronase $\left(20 \mathrm{mg} \mathrm{mi}^{-1}\right)$ and $100 \mu \mathrm{l}$ of $20 \%$ Sarkosyl. Plugs were thoroughly washed four times with $\mathrm{TE}_{1}$ and were treated twice for $30 \mathrm{~min}$ at $50^{\circ} \mathrm{C}$ with $10 \mathrm{ml}$ of $\mathrm{TE}_{1}$ buffer containing $10 \mu \mathrm{l}$ of $14 \mathrm{mM}$ phenylmethylsulfonyl fluoride stock solution in (dimethyl sulfoxide). Plugs were stored at $4^{\circ} \mathrm{C}$ in $0.8 \mathrm{M}$ EDTA, pH 8.0 .

\section{Isolation of RNA.}

To minimize degradation by RNases, all glassware used was baked for $8 \mathrm{~h}$ at $180^{\circ} \mathrm{C}$ and all solutions, if possible, were treated with $0.1 \%$ diethylpyrocarbonate and subsequently autoclaved. Samples of $10^{10}$ cells from $16-\mathrm{h}$ CYG medium cultures of $C$. glabrata strains were used to inoculate 500 -ml volumes of $\mathrm{PYG}_{2}$ medium in 500-ml Erlenmeyer flasks equipped with water-traps. Cultures were agitated for $6 \mathrm{~h}$ on a magnetic stirrer at $30^{\circ} \mathrm{C}$. Cells $\left(4 \times 10^{10}\right)$ were collected by centrifugation and resuspended in $2 \mathrm{ml}$ of GTC buffer (6 M guanidine thiocyanate, $5 \mathrm{mM}$ sodium citrate $2 \mathrm{H}_{2} \mathrm{O}, 0.1 \mathrm{M} \beta$-mercaptoethanol, $0.5 \%$ sodium lauryl-sarcosinate $[\mathrm{pH} 7.0]$ in a $25-\mathrm{ml}$ glass tube. Glass beads $(0.45 \mathrm{~mm}$ diameter) were added up to the meniscus. Cells were homogenized by vortexing 15 times at high speed for $20 \mathrm{~s}$ each with intermittent cooling on ice. The glass beads were washed four times with GTC buffer. The pooled homogenates were layered onto $28 \mathrm{ml} 5.7 \mathrm{M} \mathrm{CsCl}$ containing $10 \mathrm{mM}$ EDTA in sterile polyallomer centrifuge-tubes (Beckman, Palo Alto, Calif.). After $16 \mathrm{~h}$ of centrifugation at $135,000 \times \mathrm{g}$ at $20^{\circ} \mathrm{C}$ in a Beckman Optima L70 ultracentrifuge with a Beckman SW28 swing-out rotor, the RNA pellet was collected and washed with $70 \%$ ethanol, air-dried, and suspended in $100 \mu \mathrm{l}$ of $\mathrm{TE}_{1}$ buffer containing $0.1 \%$ SDS. RNA was dissolved by incubation at $65^{\circ} \mathrm{C}$ and intermittent vortexing. The RNA was stored at $-70^{\circ} \mathrm{C}$.

\section{Electrophoresis. (i) DNA restriction digests.}

Isolated DNA was digested enzymatically according to the instructions of Boehringer. Denatured DNA digests were separated in $0.8 \%$ agarose NA (Pharmacia, Uppsala, Sweden) in $1 \times$ TBE buffer ( $10 \times$ TBE buffer is $0.45 \mathrm{M}$ Tris, $0.44 \mathrm{M}$ boric acid and $10 \mathrm{mM}$ EDTA [pH 8.0] containing ethidium bromide 
( $0.5 \mu \mathrm{g} \mathrm{ml}^{-1}$ ) by applying an electric field of $1 \mathrm{~V} \mathrm{~cm}^{-1}$ overnight in a Bethesda Research Laboratories Horizon 11.14 submarine electrophoresis apparatus.

(ii) Pulsed field electrophoresis.

Chromosomes of $C$. glabrata were separated in $1 \%$ pulsed-field certified agarose in $0.5 \times \mathrm{TBE}$ at $14^{\circ} \mathrm{C}$ with a Bio-Rad contourclamped homogeneous electric field (CHEF) mapper DRII. To separate the whole set of chromosomes at low resolution (100 to $1,800 \mathrm{~kb}$ ), the separation variables were: run-time, 27 h $52 \mathrm{~min}, 6 \mathrm{~V} \mathrm{~cm}^{-1}$; $120^{\circ}$; initial switch time $12.55 \mathrm{~s}$; and final switch time, $3 \mathrm{~min}$ $0.01 \mathrm{~s}$. For increased resolution in the $300-$ to $700-\mathrm{kb}$ range, the settings used were as follows: run-time $35 \mathrm{~h} 14 \mathrm{~min}$ at $6 \mathrm{~V} \mathrm{~cm}^{-1}, 120^{\circ}$; initial switch time 35.4 $\mathrm{s}$; and final switch time $1 \mathrm{~min} 3.8 \mathrm{~s}$. Chromosomes were visualized by staining the gel for $30 \mathrm{~min}$ in $1 \mu \mathrm{g}$ of ethidium bromide $\mathrm{ml}^{-1}$ in $0.5 \times \mathrm{TBE}$ and subsequent destaining in MilliQ water. S. cerevisiae chromosomal markers ( Bio-Rad) were used for size calibration.

\section{(iii) RNA.}

RNA samples $(6 \mu \mathrm{l})$ were denatured by the addition of $18 \mu \mathrm{l}$ of denaturation solution containing, per milliliter, $640 \mu \mathrm{l}$ formamide, $230 \mu \mathrm{l}$ of formaldehyd, and $130 \mu \mathrm{l}$ of $10 \mathrm{x}$ running-buffer ( $10 \mathrm{x}$ running buffer was $0.4 \mathrm{M}$ MOPS [morpholine propanesulfonic acid], $0.1 \mathrm{M}$ sodium acetate. $3 \mathrm{H}_{2} \mathrm{O}, 0.01 \mathrm{M}$ EDTA [pH $7.2]$ ) and $15 \mathrm{~min}$ incubation at $60^{\circ} \mathrm{C}$. Denatured RNA samples were immediately chilled on ice, $6 \mu \mathrm{l}$ of dye solution (15\% Ficoll $70,0.25 \%$ bromophenol blue. $0.25 \%$ xylene cyanol) was added, and the mixture was separated overnight at $1 \mathrm{~V} \mathrm{~cm}^{-1}$ in a $1 \%$ agarose gel dissolved in $1 \mathrm{x}$ running buffer supplemented with $18 \%$ formaldehyde.

\section{Southern blotting.}

Alkaline vacuum transfer was used to blot agarose-separated DNA restriction digests to nylon Zeta-probe membranes (Bio-Rad) according to the instructions of the manufacturer of the vacuum-blot apparatus (Pharmacia). Pulsed-fieldseparated gels were capillary blotted for $72 \mathrm{~h}$ with $10 \mathrm{x} \mathrm{SSC} \mathrm{(} \mathrm{20x} \mathrm{SSC} \mathrm{is} 3 \mathrm{M}$ $\mathrm{NaCl}$ plus $300 \mathrm{mM}$ sodium citrate) after $15 \mathrm{~min}$ depurination in $0.2 \mathrm{M} \mathrm{HCl}$, two 
15-min denaturation (0.5 M NaOH, 1.5 M NaCl), and two 15-min neutralization (1.5 M NaCl, 0.5 M Tris-HCl, I mM EDTA, [pH 7.2]). Membranes were baked at $80^{\circ} \mathrm{C}$ for $2 \mathrm{~h}$ to immobilize the DNA on the membranes.

\section{Northern blotting.}

RNA formaldehyde agarose gels were blotted under 40 mbar of vacuum with 20x SSC buffer for $3 \mathrm{~h}$ and baked between filter paper sheets for $2 \mathrm{~h}$ at $80^{\circ} \mathrm{C}$. RNA was visualized by staining with $0.02 \%$ methylene blue- $0.3 \mathrm{M}$ sodium acetate, $\mathrm{pH} 5.5$ for $15 \mathrm{~min}$ followed by a $10 \mathrm{~min}$ wash in diethylpyrocarbonatetreated MilliQ water.

Probes. (i) CYP51 (ERG11; encoding cytochrome P-450 14 $\alpha$-lanosterol demethylase.

A 24-mer antisense oligonucleotide, TAG CCA CCA GTT GTA TCA AGA CGA, was used to detect the cytochrome P-450 gene or its mRNA transcript. This sequence was conserved in $S$. cerevisiae, Candida tropicalis, and C. albicans.

(ii) ACTI .

Actin, a 988-bp AccI-AvaII fragment of pYactI (20) (obtained from J.L. Looper) containing the $S$. cerevisiae $A C T l$ gene, was used as a probe.

(iii) ERGI..

Squalene epoxidase, a 618 bp PCR-amplified $C$. glabrata fragment was used as a probe. PCR primers were designed from conserved regions from the published ERGl sequences for the following species: $S$. cerevisiae (11), Rattus norvegicus (27) and Mus musculus (13). PCR forward primer: GTTGCTTTTGTTCATGGTAGATTC; the PCR reverse primer was CGACAGTCATACCACCACCAGT. PCR conditions were as follows; 30 cycles, annealing at $52^{\circ} \mathrm{C}$ for $1 \mathrm{~min}$, elongation at $72^{\circ} \mathrm{C}$ for $2 \mathrm{~min}$, and denaturation at $92^{\circ} \mathrm{C}$ for $1 \mathrm{~min}$. The 618-bp amplification product was sequenced by the dideoxy-dye terminator method with an ABI 373A Sequencer from Applied Biosystems (14). The sequence is given in Fig. 7 . 


\section{Probe labeling.}

The oligonucleotide was end-labeled with $\left[\gamma^{-32}\right.$ P]ATP (ICN-Flow, Costa Mesa, Calif.) by using the Ready-To-Go T4 polynucleotide kinase kit (Pharmacia) according to the instructions of the manufacturer. Other probes were randomly labeled with $\left[\alpha-{ }^{32} \mathrm{P}\right] \mathrm{dCTP}$ (ICN-Flow), also by using the Ready-To-Go random labeling kit (Pharmacia).

\section{Hybridization.}

Membranes were prehybridized for $1 \mathrm{~h}$ in $50 \mathrm{ml}$ Denhardt's solution (3x SSC, $1 \%$ SDS, $5 x$ Denhardt [50x Denhardt is $1 \%$ \{wt/vol $\}$ Ficoll $400,1 \%\{w \mathrm{w} / \mathrm{vol}]$ polyvinylpyrrolidone, $1 \%$ [wt/vol\} Bovine serum albumin], $0.1 \mathrm{mg}$ of salmon testis DNA ml${ }^{-1}$ ) and hybridized overnight at $45^{\circ} \mathrm{C}$ for the oligonucleotide labeling or at $65^{\circ} \mathrm{C}$ for the random labeled probes (28). After hybridization, membranes were rinsed once with $2 \times$ SSC and washed once for 15 min with $2 \times$ SSC$1 \%$ SDS at room-temperature and three times for 10 min with $0.2 x$ SSC- $1 \%$ SDS at the hybridization temperature. The damp membrane was sealed in a plastic bag, and radioactive fractions were visualized on Reflection X-ray films (Dupont NEN, Bad Hamburg, Germany) with an intensifying screen exposed at $-70^{\circ} \mathrm{C}$. The radioactive markings on the film were digitized with a video-camera and quantified with Image 1.41 software (36).

Labeled probes were stripped from the membranes by boiling for 15 to $30 \mathrm{~min}$ in $0.1 \times$ SSC- $1 \%$ SDS. The process was validated by exposing the stripped membranes again to an auto-radiography film.

\section{Protein labeling and two-dimensional protein separation.}

Exponentially growing $C$. glabrata cells $\left(3 \times 10^{6}\right.$ cells) were labeled for $2 \mathrm{~h}$ in $333 \mu \mathrm{l}$ in a methionine-deficient Dulbecco's modified essential growth medium supplemented with $333 \mu \mathrm{Ci}\left[{ }^{35} \mathrm{~S}\right]-$ methionine (Dupont NEN; specific activity, $1.175 \mathrm{Ci} \mathrm{mmol}^{-1}$ ). Labeled cells were collected by centrifugation. washed in MilliQ water, recentrifuged, decanted, and immediately frozen in liquid nitrogen. Samples were stored at $-70^{\circ} \mathrm{C}$ until further processing.

Frozen pellets were thawed in $120 \mu \mathrm{l}$ lysis buffer $(9.5 \mathrm{M}$ urea. $2 \%$ \{wt/vol\} Nonidet-P40 [NP40]. 2\% [wt/vol] ampholines [pH range 7 to 9; Pharmacia]. 5\% 
[wt/vol] 2-mercaptoethanol) and sonicated in an ice-ethanol cooling bath for three 5-s intervals with 30 -s cooling intervals between. Samples were then shaken at room temperature for a minimum of $4 \mathrm{~h}$. The degree of $\left[{ }^{35} \mathrm{~S}\right]$ methionine incorporation was then determined.

Polyacrylamide gels $(3.5 \%, 185$ by $1.55 \mathrm{~mm}, 8 \mathrm{M}$ urea, $2 \%$ NP-40) containing for the IEF (isoelectric focusing) gels (2\% ampholines at a $\mathrm{pH}$ range of 3.5 to $10,2 \%$ ampholines at a $\mathrm{pH}$ range of 5 to 7 , and $2 \%$ servalytes at a $\mathrm{pH}$ range of 5 to 7 [Serva, Heidelberg, Germany]). Because considerable variation was found among different batches of ampholytes, the actual mixture of ampholytes was calibrated. Phosphoric acid (10 mM) was used as the anode buffer and degassed $\mathrm{NaOH}(20 \mathrm{mM}$ ) was used as the cathode. IEF gels were prefocused at $1,200 \mathrm{~V}$, $133 \mu \mathrm{A}$ (limiting values) per tube until the limiting values were reached. Then, $5 \times 10^{5}$ trichloroacetic acid-precipitable $\mathrm{dpm}$ was applied to the IEF gels, and samples were overlaid with overlay buffer ( $8 \mathrm{M}$ urea, $0.8 \%$ ampholines at a $\mathrm{pH}$ range of 5 to 7 , and $0.2 \%$ ampholines at a $\mathrm{pH}$ range of 3.5 to 10). Electrophoresis was carried out at $1,200 \mathrm{~V}$ and $133 \mu \mathrm{A}$ (limiting per gel) for $18 \mathrm{~h}$. The gels were then extruded with compressed air and equilibrated for 6 minutes before being frozen at $-70^{\circ} \mathrm{C}$ until needed. For the second dimension gel electrophoresis, gels were thawed quickly in a water bath $\left(80^{\circ} \mathrm{C}\right)$, incubated for $2 \mathrm{~min}$ at room-temperature, and loaded onto $12.5 \%$ polyacrylamide gels (200 by 200 by $1 \mathrm{~mm}$ ) at $20^{\circ} \mathrm{C}$. The gels were run in slowly $(5 \mathrm{~mA}$ per gel for $1 \mathrm{~h}$ ), followed by $15 \mathrm{~mA}$ per gel until the bromophenol blue line reached the bottom of the slab gel. The gels were fixed for 45 mins in $45 \%$ methanol-7.5\% acetic acid, and then they were treated for $45 \mathrm{~min}$ in Amplify (Amersham, Bucks, England) to enhance the fluorographic detection, dried and exposed to X-ray film (type XB-200; XOmat, United Kingdom) at $-70 \mathrm{C}$ for 5 days. The developed images were then compared either visually or with an image-processing computer by using the Bio Image 2D program, version 6.03, on a Sun workstation. Molecular weight and isoelectric point values were assigned with reference to known $S$. cerevisiae proteins.

\section{Nucleotide sequence accession number.}

The GenBank entry for the C. glabrata squalene epoxidase fragment is AF006033. 


\section{RESULTS}

\section{Effects of antifungal agents on growth.}

Fluconazole-resistant $C$. glabrata isolate B57149 was cross-resistant to other azole antifungals that are inhibitors of the cytochrome P-450 $14 \alpha$-lanosterol demethylase reaction in ergosterol biosynthesis and to amorolfine, an inhibitor of the $\Delta 14$-reductase and/or $\Delta 8$-7-isomerase (23), but not to 5-flucytosine, a compound inhibiting cellular DNA and RNA synthesis. Repetitive subculturing of the resistant $C$. glabrata isolate in fluconazole-free medium was shown to be sufficient to fully restore susceptibility to itraconazole both in CYG medium, as described previously (36), and in RPMI medium (Table 1). However, despite 159 subcultures, the revertant still exhibited resistances to fluconazole, ketoconazole, and amorolfine that were higher than those of the pretreatment isolate by one or two dilution levels. The maintenance of some resistance is more pronounced in the shaken CYG culture conditions used in the previous paper (36) than in those reported in this paper, which involved RPMI medium. By the broth microdilution method, all $C$. glabrata isolates were found to be insensitive to terbinafine, which is in accordance with the reported MIC values $\left(>128 \mu \mathrm{g} . \mathrm{ml}^{-}\right.$ 1) for this inhibitor for this species. (18)

Table 1: Effects of azole antifungal agents, 5-flucytosine, terbinafine and amorolfine on growth of C. glabrata isolates B57148, B57149, B57149-73", B57149$111^{\mathrm{a}}$ and B57149-159a. Data shown are the range of quadruplicate tests with the isolates

\begin{tabular}{|c|c|c|c|c|c|}
\hline & \multicolumn{4}{|c|}{ IC50 ( $\left.\mu \mathrm{g} \cdot \mathrm{ml}^{-1}\right)$} & \multirow{3}{*}{$\begin{array}{l}\text { Revertant } \\
\text { B57149-159 }\end{array}$} \\
\hline & \multirow{2}{*}{$\begin{array}{l}\text { Pretreatment } \\
\text { B57148 }\end{array}$} & \multicolumn{2}{|c|}{ Post-ireaiment } & \multirow[b]{2}{*}{ B57149-111 } & \\
\hline & & B57149 & B57149-73 & & \\
\hline 5-Flucytosine & $\leq 0.13$ & $\leq 0.13$ & $<0.13$ & $<0.13$ & $\leq 0.13$ \\
\hline Fluconazole & $16-32$ & $256-512$ & $32-256$ & 64 & $32-64$ \\
\hline Ketoconazole & $0.5-1$ & $8-16$ & $1-4$ & $1-2$ & $0.5-2.0$ \\
\hline Itraconazole & 1.0 & $4-16$ & 1.0 & 1.0 & $0.5-1.0$ \\
\hline Terbinafine & $>16$ & $>16$ & $>16$ & $>16$ & $>16$ \\
\hline Amorolfine & $2-4$ & $>16$ & 8 & 8 & $4-8$ \\
\hline
\end{tabular}

a B57149-73, B57149-111 and B57149-159 are respectively the $73^{\text {th }}, 111^{\text {th }}$ and the $159^{\text {th }}$ subculture of B57149 in fluconazole-free medium 


\section{Intracellular drug level.}

Under aerobic conditions 8 times more itraconazole $\left(576 \mathrm{pmol} / 10^{9}\right.$ cells) than fluconazole $\left(72 \mathrm{pmol} / 10^{9}\right.$ cells) was found in B57148 cells. (Table 2) In the resistant isolate, this ratio was even higher (14-fold; itraconazole : $490 \mathrm{pmol} / 10^{9}$ cells; fluconazole: $36 \mathrm{pmol} / 10^{9}$ cells). In the $159^{\text {th }}$ subculture, a similar high value ( 13 -fold, itraconazole : $480 \mathrm{pmol} / 10^{9}$ cells; fluconazole: $38 \mathrm{pmol} / 10^{\circ}$ cells) was found. Both the intracellular contents of fluconazole and itraconazole exhibited a statistically significant decrease in the resistant isolate. However the fluconazole content dropped to $50 \%$ of the sensitive isolate, whereas for itraconazole only a $15 \%$ decrease was found. The intracellular contents for both itraconazole and fluconazole did not change significantly with repeated subcultivation.

Table 2: Cellular contents $\mathrm{s}^{\mathrm{a}, \mathrm{b}}$ of fluconazole and itraconazole in C. glabrata isolates; $\mathrm{B} 57148, \mathrm{~B} 57149$, and B57149-159\%.

cellular content (pmol/ $\left.10^{9} \mathrm{cells}\right)$

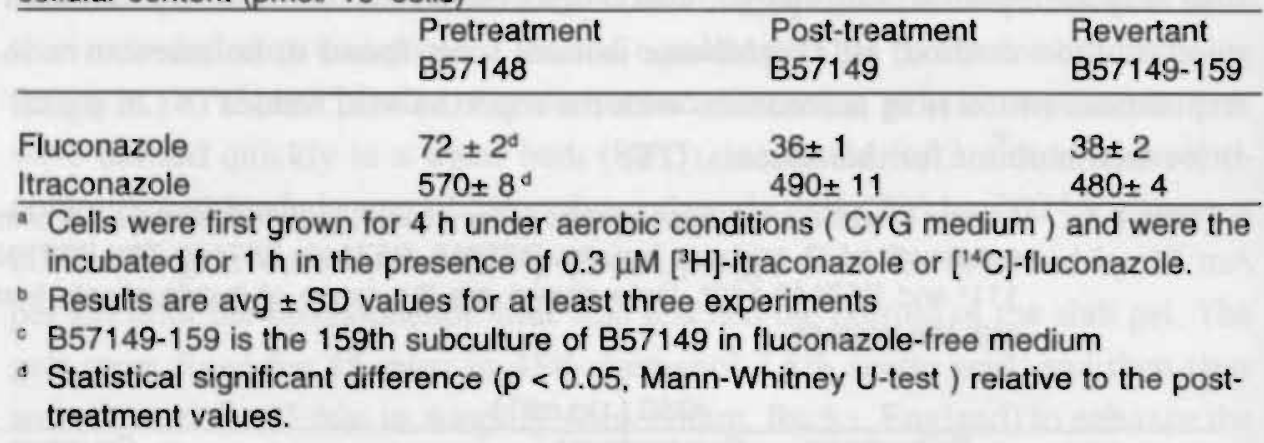

Molecular biological approach. The increased cytochrome P-450 and squalene epoxidase and/or oxidosqualene cyclase activities in B57149 described in a previous paper (36) could be due to an increased copy number of the genes coding for these enzymes. To compare the relative copy number in the different $C$. glabrata isolates. genomic DNA was restricted with HindIII, separated by electrophoresis, transferred to nylon membranes, and hybridized with appropriate probes. As a reference probe the $A C T l$ gene, encoding actin, was chosen. This 


\section{Azole resistance in C. glabrata}

probe revealed two bands, at 6.3 and $3.5 \mathrm{~kb}$, in the Southern blot (Fig. 1) because the probe contained an internal HindIII restriction site, which is conserved in the unknown $C$. glabrata sequence. No differences were seen in intensities of the hybridization signals for the three isolates of C. glabrata, B57148, B57149, and B57149-159, with the $A C T 1$ probe relative to that of the ethidium bromide signal, suggesting that the copy number of the $A C T I$ gene was constant. However,

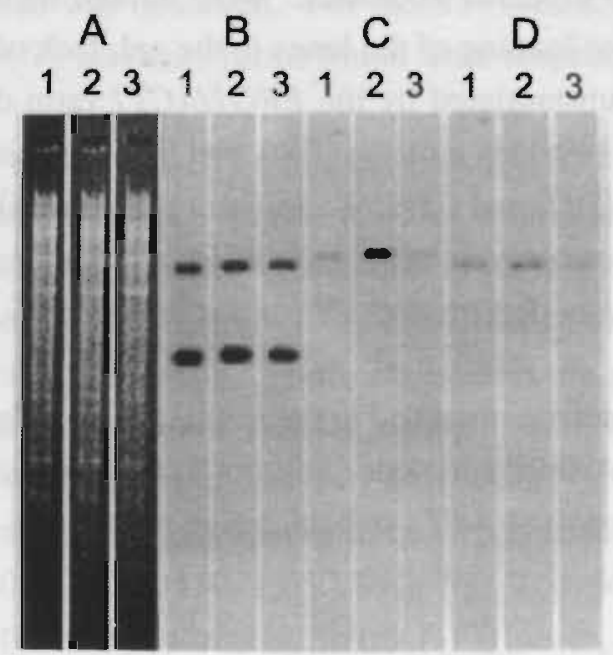

Fig. 1: A: Ethidium bromide stained Hindlll restriction patterns of genomic DNA isolated from C. glabrata isolates B57148 (lane 1), B57149 (lane 2) and B57149-159 (lane3). Two $\mu \mathrm{g}$ of DNA was digested and separated in $0.8 \%$ agarose.

B-D: Southern blot of vacuum-transferred digests, sequentially probed with [32P] labeled $A C T(B), C Y P 51$ oligonucleotide probe (C), and ERG1 probe (D). Between the different hybridizations, the membrane was stripped in boiling $0.1 \times$ SSC $1 \%$ SDS. Radioactive fractions were visualized by autoradiography at $-70^{\circ} \mathrm{C}$ and quantitated by densitometry.

substantial differences were seen among DNA samples from the three isolates with respect to the hybridization signals obtained with the P-450 oligonucleotide probe. Indeed, for the B57148 isolate a CYP5I/ACTI band intensity ratio of 0.07 was found. This ratio increased to 0.26 in the resistant B57149 strain, an increase of 3.7-fold. For the revertant isolate, B57149-159, the ratio was 0.06 . similar to that found for the B57148 isolate. Similar ratios were found when dif- 
ferent amounts of DNA were loaded on the gel (results not shown). The CYP51-probe hybridized to a single $6.7-\mathrm{kb}$ fragment in all three isolates. Southern blots of DNA digested with restriction enzymes other than HindIII also showed single hybridization bands, indicative of amplification of a fairly large fragment. With the ERGI probe, a completely different result was obtained. The band intensities, and thus, presumably, the relative copy numbers of the gene encoding the squalene epoxidase, were almost identical for all three isolates. Due to uneven loading of the lanes in the gel, lack of overexpression of the ERGI gene was substantiated by the ERGI/ACTI ratio data. For the B57148, $\mathrm{B} 57149$ and $\mathrm{B} 57149-159$ isolates ERGI/ACTI intensity ratios found were, respectively $0.07,0.07$, and 0.05 . To rule out the possibility that the $B 57148$ or B57149 isolates were polyclonal, the CYP5I copy numbers of single colonies (6 for each isolate) were determined. Variation in the copy number was less than $10 \%$.

Greater differences were observed at the transcription level (Fig. 2). Five micrograms of total RNA was sufficient to obtain a clear hybridization signal with all probes used. A constant $A C T I$ hybridization signal was seen for all three iso-

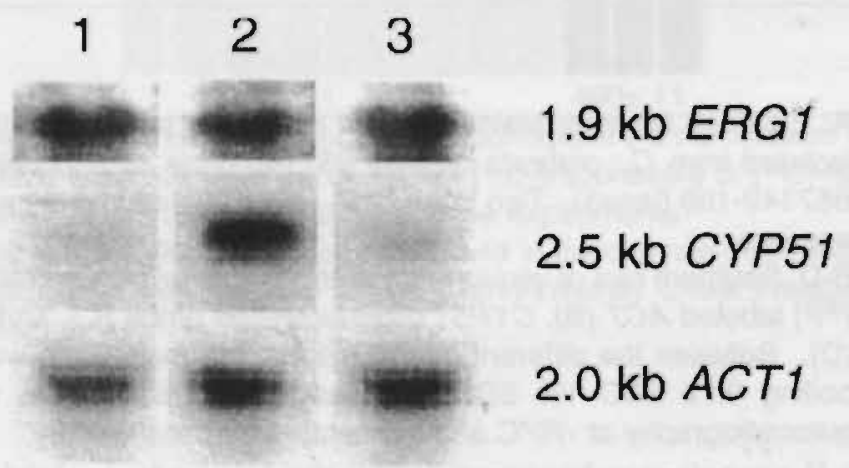

Fig. 2: Northern blot of total RNA isolated from C. glabrata isolates B57148 (1). B57149 (2), and B57149-159 (3). RNA was purified by means of a CsClgradient centrifugation as described in Materials and Methods. Five $\mu \mathrm{g}$ RNA was loaded for electrophoresis. After vacuum-transfer to a Zetaprobe membrane, the blot was stained with methylene blue to verify the quality of the RNA preparation and equal loading. Hybridization, stripping. visualization, and quantification were as described in the legend for Fig. 1. 
lates tested, which allowed us to use it as a reference.

The CYP5I/ACTI hybridization intensity ratio for the $C$. glabrata B57148 isolate $(0.04)$ was eight times lower than that found in the B57149 isolate $(0.3)$ and almost two times lower than the value for the B57149-159 (0.08) isolate. Again, similar values were found when other quantities of RNA were loaded on the gel (results not shown). With the ERGI probe, a constant level of transcription in all three isolates was observed. For the B57148, B57149, and B57149159 isolates $E R G I / A C T I$ intensity ratios found were respectively $0.04,0.04$ and 0.03 .

The increase in copy number of CYP5I in the resistant B57149 isolate could be due to an amplification of a large fragment. This should increase the size of a chromosome sufficiently to induce a visible shift in mobility of the chromosome involved after a chromosomal separation. In Fig. 3 the results for the CHEF-separated chromosomes of the three $C$. glabrata isolates are given. By comparison with size-markers, it was found that the sizes of the different chromosomes correlated very well with those published by Doi et al. (7). In their publication they hypothesized that $C$. glabrata contained twelve chromosomes with lengths of $2,100,1,720,1.420,1,380,1,150,1,050,990,760,720,640,520$, and $510 \mathrm{~kb}$. In the present study the chromosomal patterns for all three $C$. glabrata isolates were found to be identical. No major shift in mobility was observed, but the 760- to 720-kb region of the B57149 isolate showed increased ethidium bromide staining. It is generally accepted that the ethidium bromide staining intensity of a band is proportional to its DNA content and the size of the band. In Fig. 3B the ethidium bromide staining intensities, normalized on the 1.420 -kb chromosome, are given for the three isolates. A small increase in intensity is seen for the largest chromosome, which contains the RNA coding sequences. A more substantial increase is seen in the 760- to 720 -kb region. indicating an increase in the copy number of at least one chromosome in that region. Further confirmation of this hypothesis was found with hybridization experiments. The ACTI probe hybridized to the $1,420-\mathrm{kb}$ band, and both the CYPSI and the ERGI probes hybridized with the 760 - to 720 -kb region. When the signal ratios for each isolate relative to ACTI were determined, again only that of CYP5I was increased for the resistant B57149 isolate. No such increase was seen with the 

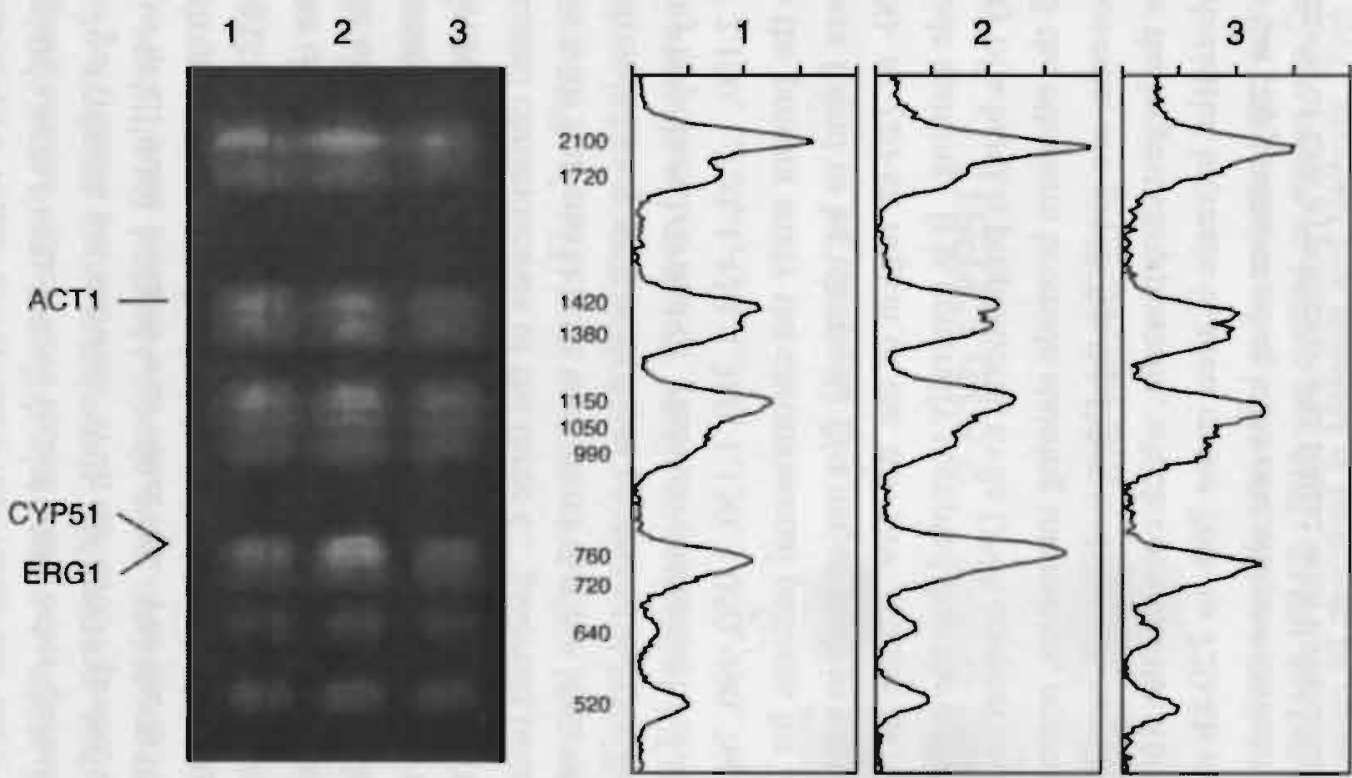

Fig. 3 : A: Ethidium bromide staining of CHEF separated chromosomal DNA of C. glabrafa isolates B57148 (lane 1), B57149 (lane 2), and B57149-159 (lane 3). Contour-clamped homogenous electric field electrophoresis (CHEF) was run under following conditions : run-time $27 \mathrm{~h} 52 \mathrm{~min}, 6 \mathrm{~V} \mathrm{~cm} \mathrm{~cm}^{-1}, 120^{\circ}$, initial switch time $12.55 \mathrm{~s}$ and final switch time $3 \mathrm{~min} 0.01 \mathrm{~s}$.

At the left side the location where the [MP] labeled CYP51 oligonucleotide probe, ACT1 and ERG1 probe hybridized to a Southern blot of capillary-transferred chromosomes is given. Hybridization, stripping, visualization, and quantification was as described in the legend of Figure 1. At the right side the estimated sizes of the chromosomes are given. Estimates were calculated from S. cerevisiae chromosomal size markers.

B: Intensity profiles of the ethidium bromide stained chromosomes shown in A. Intensities were normalized on the $1420 \mathrm{~kb}$ choromosome. 
ERGI probe, a finding in complete agreement with that concerning the hybridization signals of the restriction digests. The fact that both probes hybridized to the same region is consistent with the chromosomal amplification theory only if this region contained more than one chromosome, and the ERGI and CYP5I- genes are located on different chromosomes. To verify this hypothesis, a higher-resolution separation in the region was performed. As shown in Fig. 4, the 760- to 720-kb region contained not two but three chromosomes, and from the hybridization experiments with $E R G I$ and $C Y P 5 I$ probes, it could be

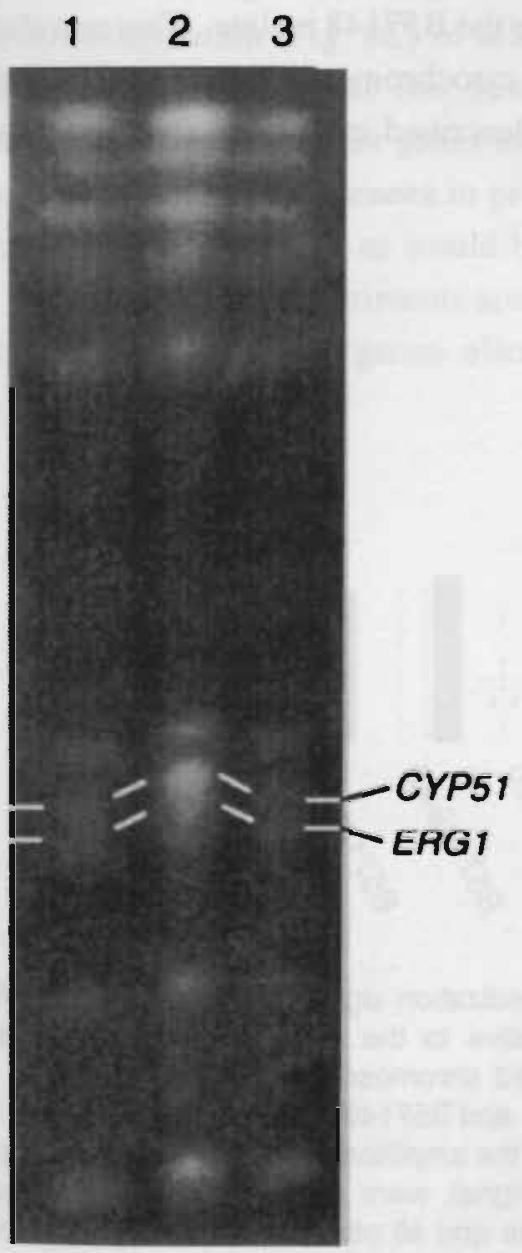

Fig. 4: Ethidium bromide staining of CHEF separated chromosomal DNA of $C$. glabrata isolates B57148 (lane 1), B57149 (lane 2), and B57149-159 (lane 3). Higher resolution CHEF electrophoresis was run under the following conditions : run-time $35 \mathrm{~h} 14$ $\min , 6 \mathrm{~V} \mathrm{~cm}^{-1}, 120^{\circ}$, initial switch time $35.4 \mathrm{~s}$ and final switch time 1 min $3.8 \mathrm{~s}$. At the right side the location where the [ $\left.{ }^{2} \mathrm{P}\right]$ labeled CYP51 oligonucleotide probe and ERG1 probe hybridized to a Southern blot of capillary-transferred chromosomes is given. Hybridization, stripping, visualization, and quantification was as described in the legend of Figure 1. 
concluded that ERGI is located on the 720 -kb chromosome, whereas CYP5I is located on the 740-kb chromosome, the chromosome that showed increased ethidium bromide staining. In Fig. 5 the normalized intensity ratios relative to the ACTI signal obtained in chromosomal blots are given for the B57148, B57149 isolates and also for several subcultures of the B57149 isolate. Again, B57149 contained almost four times more CYP5I than the B57148 isolate, a value which correlates with the amplification ratio found in the restriction digests and Southern blots. A gradual loss of amplification was seen upon repeated subculture of B57149 in fluconazole-free medium. After 40 subcultures almost the same value was found as for the B57148 isolate. This correlates with the gradual decrease of microsomal cytochrome P-450 content and the regained susceptibility of these isolates as described in Table 1 and in the pre-

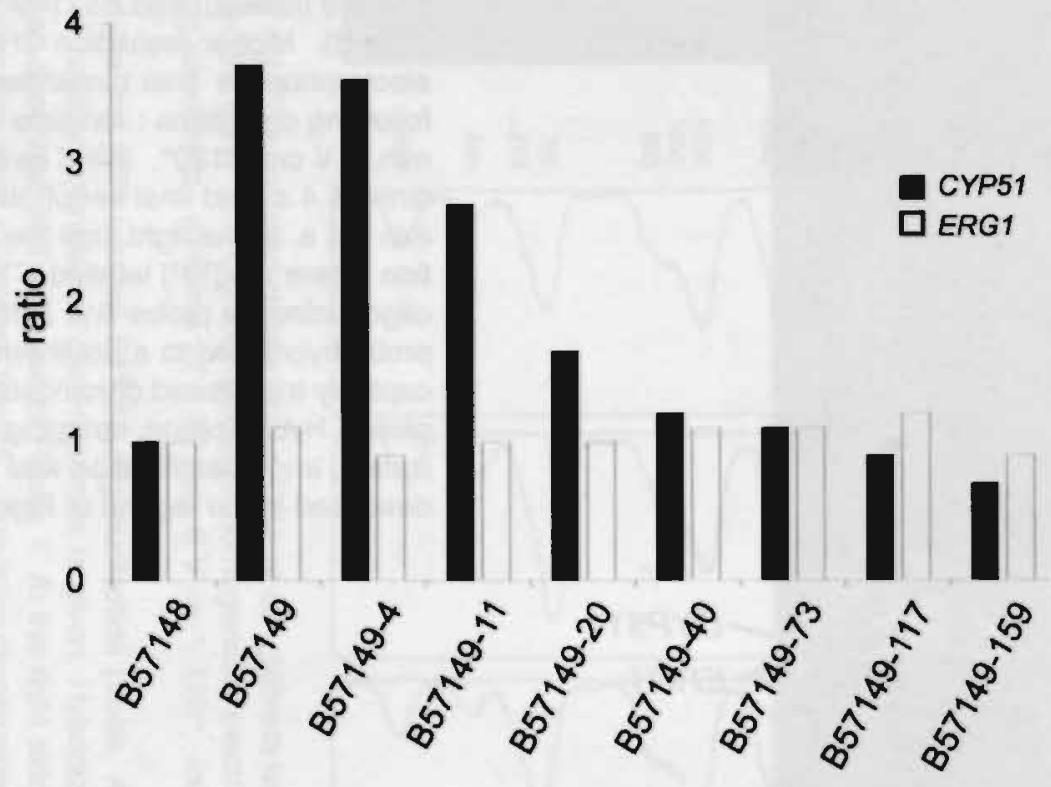

Fig. 5: Ratio of the intensities of the hybridization signals obtained with CYP51 probe and the ERG1 probe relative to the signal of the ACT1 probe obtained with the CHEF separated chromosomal DNA isolated from $C$. glabrata isolates B57148, B57149, and B57149 after 4, 11, 20, 40,73, 117 . and 159 subcultures. To visualize the amplification of the hybridization signal ratio's, relative to the $A C T 1$ signal, were normalized so that all ratio data for isolate B57148 equals one and all other ratios are reported relative to this standard. 


\section{Azole resistance in C. glabrata}

vious paper (36). The signal of the ERGI remained constant for all isolates tested.

The amplification of an entire chromosome would be expected to have tremendous effects on the protein expression in the cells. Indeed, when $\left[{ }^{35} \mathrm{~S}\right]$ methionine-labeled proteins were extracted from these $C$. glabrata strains and separated by two-dimensional gel electrophoresis, out of 1,377 proteins identified, 25 were upregulated by more than a factor of three and 76 were downregulated by the same factor (Fig. 6). Figures $6 \mathrm{~B}$ and $6 \mathrm{C}$ show selected regions of the pictures shown in Fig. 6A at a higher magnification to demonstrate the up- (Fig. 6B) or downregulation (Fig. 6C) of selected proteins in the resistant isolate. These figures demonstrate that the observed chromosome duplication resulted in pleotropic effects on other genes in addition to the CYP5I gene and that the disappearance of the differences in proteins expressed correlated with reversion to the nonduplicated state, as would be expected for mutations involving chromosome duplication. Experiments are ongoing to identify the upregulated products to verify if their coding genes also map to this amplified chromosome. 
A
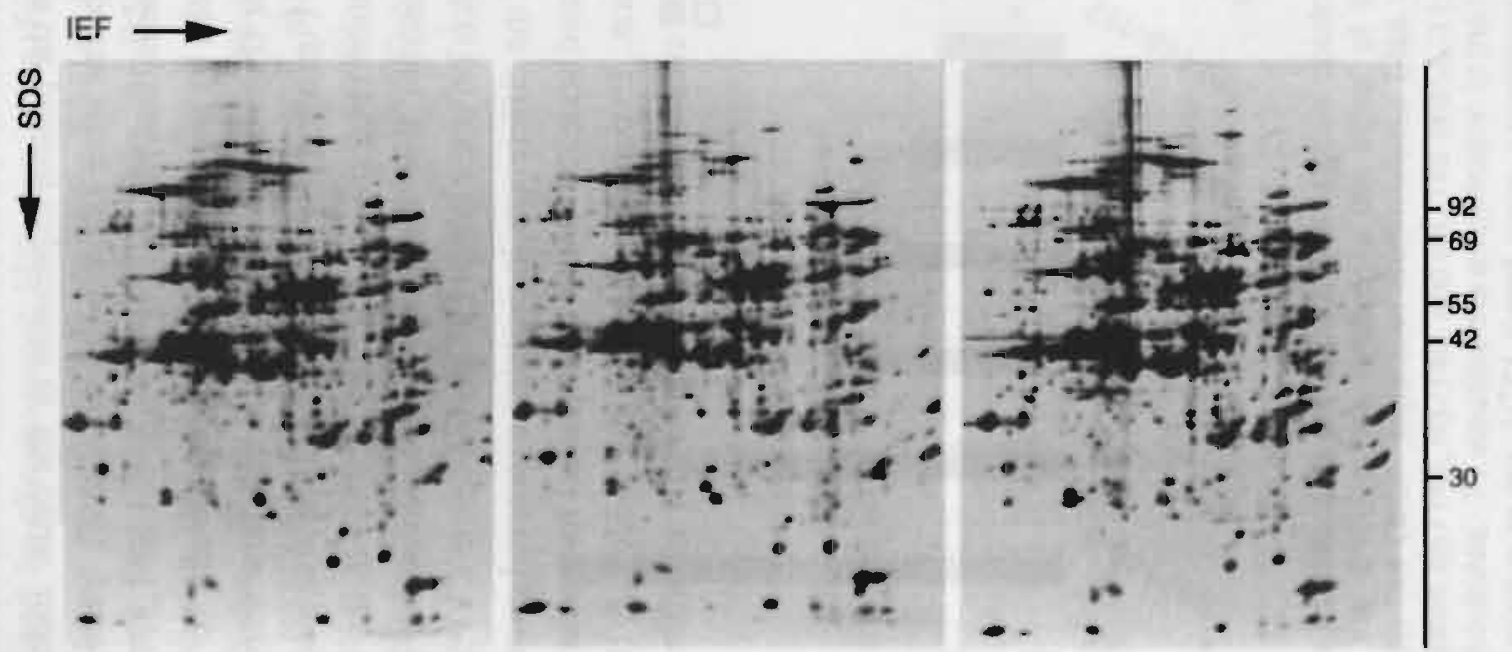

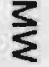 \\ $\stackrel{\overrightarrow{\mathrm{O}}}{\mathrm{\omega}}$}

1

2

3

Fig. 6: A: Two dimensional IEF-SDS polyacrylamide gel electrophoresis (PAGE) gels of proteins extracted from $C$. glabrata isolates B57148 (1), B57149 (2), and B57149-159 (3).

B-C: Higher magnification of selected regions of pictures shown in A. Arrows indicate proteins that were up- or down-regulated in the B57149 isolate relative to their intensity in both the B57148 and B57149-159 isolates. 

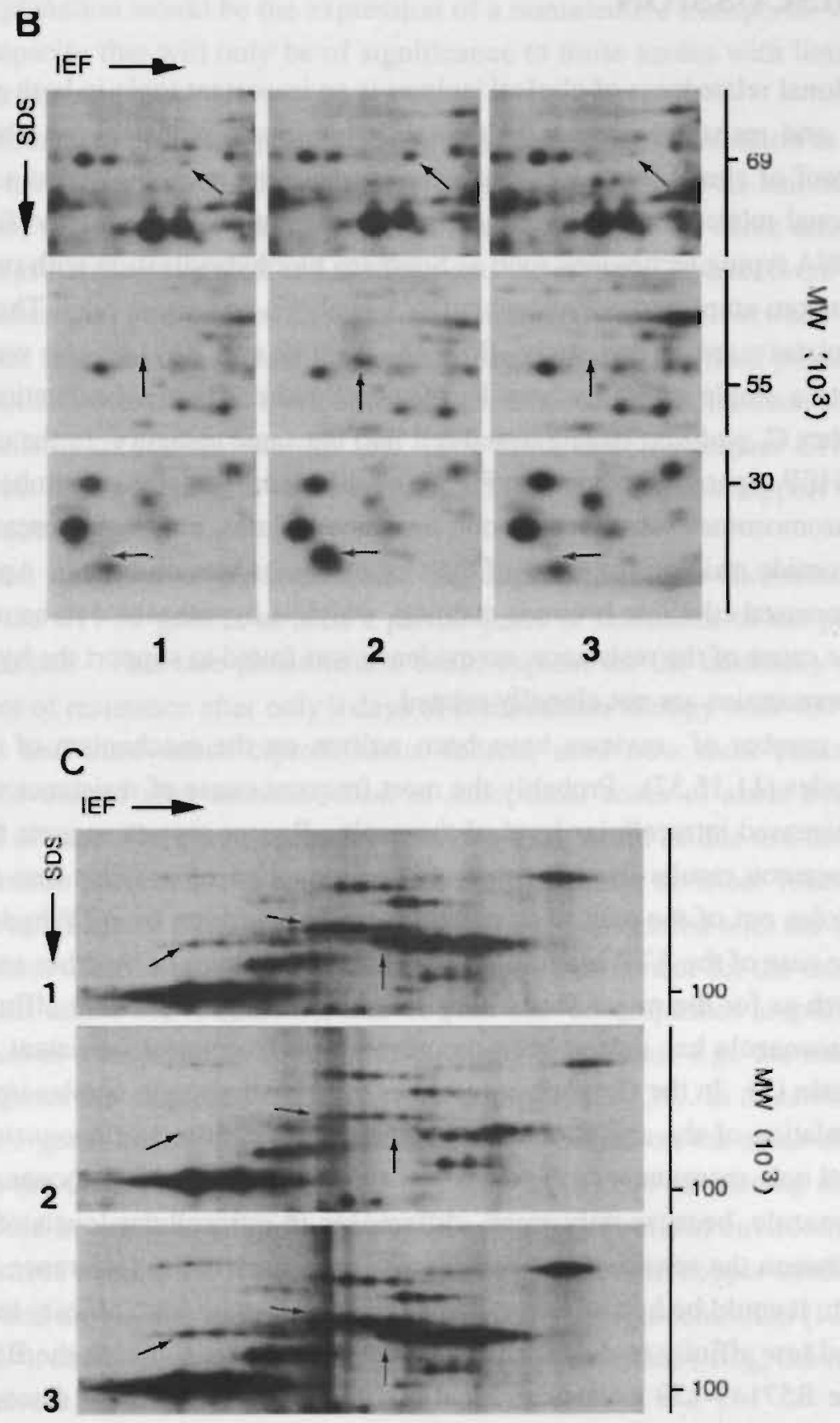


\section{DISCUSSION}

Clonal relatedness of clinical isolates is an important topic in both epidemiologic and resistance studies. Although it is almost impossible to obtain a $100 \%$ proof of clonal relatedness, one can increase the probability that a statement of clonal relatedness is true by applying different available highly discriminatory DNA typing techniques such as Southern blot hybridization with probes, RFLP, random amplified polymorphic DNA analysis, or karyotyping. The $C$. glabrata isolates used in this study, B57148, B57149 and B57149-159 were classified into a single group by both RFLP and Southern blot hybridization. No single other $C$. glabrata isolate tested fell into the same catagory. In the chromosomal CHEF separations shown in Fig. 3, no differences in size or number of resolved chromosomes were seen among the three isolates, although increased ethidium bromide staining for some of the chromosomes was observed. Apart from this increased ethidium bromide staining, which is hypothesized to be at least partly the cause of the resistance, no evidence was found to support the hypothesis that these strains are not clonally related.

A number of reviews have been written on the mechanism of resistance to azoles $(11,15,37)$. Probably the most frequent cause of resistance to azoles is a decreased intracellular level of the azole. Recent reports suggest that this phenomenon results from the presence or induction of proteins that transport the azoles out of the cell. Active export could be driven by ATP hydrolysis, as in the case of the ATP-binding-cassette class of proteins or by other energy sources such as for the major facilitators. Such an energy-dependent efflux system for fluconazole has indeed been described for a fluconazole-resistant $C$. glabrata strain (5). In the $C$. glabrata isolates used in this study, similar impaired accumulation of the azole could contribute significantly to fluconazole resistance and only marginally to the cross-resistance observed with ketoconazole and itraconazole, because only small differences in intracellular levels of these drugs between the sensitive and resistant isolates were found (reference 36 and table II). It could be hypothesized that a transporter with high affinity to fluconazole and low affinity to the other two azoles is expressed in both the B57149 and in the B57149-159 isolates and that this limits the intracellular fluconazole level. 
Azole resistance in C. glabrata

Another explanation would be the expression of a nonselective transporter with a limited capacity that will only be of significance to those azoles with limited intracellular contents.

Another mechanism by which yeasts can develop resistance is a mutation in the target enzyme which in the case of the azoles is the CYP $\mathrm{P}_{51}(14 \alpha$-lanosterol demethylase). Because in a previous study it was shown that the azole sensitivities of the isolated enzymes of the sensitive and the resistant isolates were the same, no attempts were made to make sequence comparisons between the CYP51 genes from the two yeasts. Overproduction of $\mathrm{P}-450$ is a third possibility for induction of resistance. Until now only evidence from recombinant studies was available to demonstrate this (3). The up to threefold-higher CYP5I mRNA levels found in clinical azole resistant $C$. albicans isolates support this hypothesis (29).

In the present study we have demonstrated that duplication of the chromosome containing the CYP5I gene is at least a partial cause of resistance of the posttreatment isolate. This rare phenomenon could explain for the unusually fast development of resistance after only 9 days of combination therapy with $400 \mathrm{mg}$ fluconazole and intravenous ciprofloxacin. Indeed, until now most cases of resistance developed after administration of suboptimal doses of azole over a long period of time. The chromosomal duplication itself could be due to a defect in the separation process of the chromosomes during cellular division. Whether the clinical treatment or other environmental parameters interfered with the separation process itself or provided the ideal selection environment for the mutated cell is still unknown. It is known that $C$. glabrata accomplishes amplification of genes as a response to environmental stress conditions; e.g., the metallothionein genes are amplified after exposure to copper (34. 39). In S. cerevisiae the CUPI gene, coding for a metallothionein, is located on the same chromosome as the CYP5I (ERGII) (17). In this way the CYP5I-containing chromosome could be prone to amplification upon exposure of cells to environmental copper stress conditions. However only small differences in copper sensitivity were found among the azole-sensitive ( $50 \%$ inhibitory concentration $\left[\mathrm{IC}_{50}\right]$, $\left.0.3 \mathrm{mg} \cdot \mathrm{ml}^{-1}\right)$, azole-resistant $\left(\mathrm{IC}_{50}, 0.5 \cdot \mathrm{mg} \cdot \mathrm{ml}^{-1}\right)$ and revertant $\left(\mathrm{IC}_{50} .0 .5 \mathrm{mg}\right.$. $\mathrm{ml}^{-1}$ ) C. glabrata isolates. 
Other still-unanswered questions are why the posttreatment isolate is crossresistant to other nonazole ergosterol biosynthesis inhibitors such as amorolfine and why $C$. glabrata lacks susceptibility to terbinafine. In a previous study it was shown that in a subcellular ergosterol biosynthesis system using $C$ : glabrata B57148 protein, terbinafine inhibited ergosterol formation by $50 \%$ at $5 \times 10^{-8}$ $M$ (36). This is twice the concentration needed by itraconazole to induce the same effect. In that study it was also shown that 3.3 times more fluconazole than itraconazole was needed to inhibit the cytochrome P-450 in a microsomal fraction $\left(\mathrm{IC}_{50 \mathrm{~s}}\right.$ were $112 \mathrm{nM}$ for fluconazole versus $34 \mathrm{nM}$ for itraconazole). However in intact cells much higher concentrations of fluconazole are needed to inhibit growth. Terbinafine has no effect, even up to $16 \mu \mathrm{g} \cdot \mathrm{ml}^{-1}$. It is possible that a lower intracellullar content contributes to this phenemenon. It has to be examined whether constitutive expression of a major facilitator such as CaMDRI, which takes both fluconazole and terbinafine, but not itraconazole, as a substrate (31), contributes. Four-times-higher concentrations of terbinafine $\left(\mathrm{IC}_{50}, 2 \times 10^{-7} \mathrm{M}\right)$ were needed to inhibit ergosterol synthesis in the $\mathrm{B} 57149$ isolate, and in this strain 2.2 times more lanosterol was formed from squalene, indicating a doubled squalene epoxidase and/or oxidosqualene cyclase activity (36). No ERGl gene amplification in the resistant isolate was found. Furthermore it was found that this gene is located on a different chromosome. The likelihood that the $C$. glabrata ERGI probe, which was PCR amplified with conservedregion primers, was not coding for the squalene epoxidase is small, because of the high sequence homology with the published $S$. cerevisiae ERGI sequence (11). Indeed, in Fig. 7 the best-fit alignment is given between the $C$. glabrata PCR amplification product and the ERGIsc. The numbering used is that of the Saccharomyces sequence. Over the 618-bp segment an identity of $77 \%$ at the nucleotide level and of $83 \%$ at the amino acid level was found. It is possible that higher levels of NADPH-cytochrome P-450 reductase, a coenzyme in the squalene epoxidase reaction, contributed to the terbinafine resistance, but no increased activity of this enzyme was measured in the resistant isolate (36). Another likely explanation for the shift in the subcellular sensitivity of ergosterol synthesis to terbinafine is an affinity alteration of the squalene epoxidase enzyme by specific mutations in the resistant isolate. More underlying mecha- 


\section{Azole resistance in C. glabratal}

Fig 7: $\quad$ Nucleotide and amino-acid sequence aligment of the $618 \mathrm{bp}$ PCR product amplified from C. glabrata DNA with the sequence of Saccharomyces cerevisiae ERG1 gene (11). Sequence of the probe was determined using Dideoxy Dye Terminator ${ }^{\mathrm{rM}}$ Chemistry on the ABI $373 \mathrm{~A}$ Sequencer from Applied Biosystems.

10

30

16

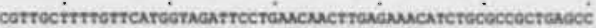

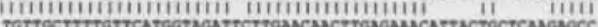

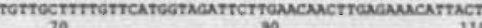

70 90 110

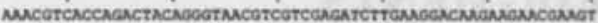

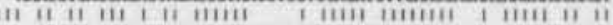

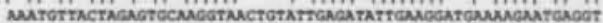

130
150

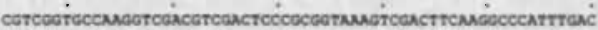

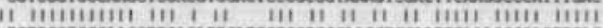

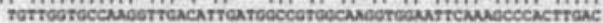

100 210

730

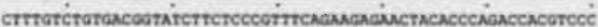

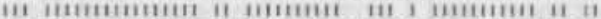

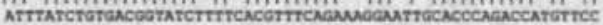
250
250

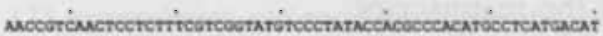

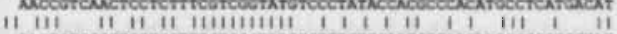

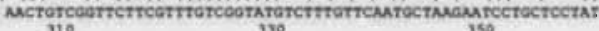
310 390 350

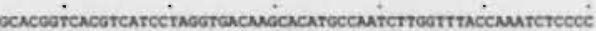

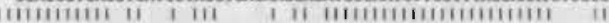

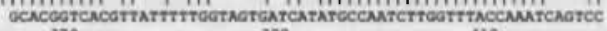
370 390 410

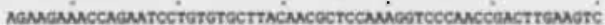

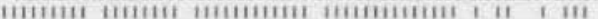

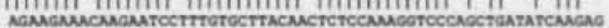
(3)
40 -

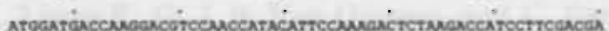

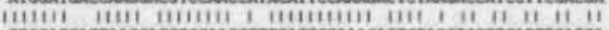

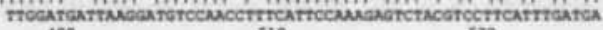
490 510 $53 \mathrm{e}$

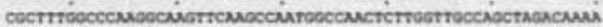

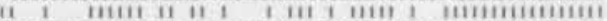

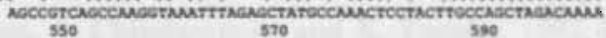

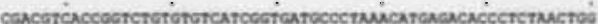

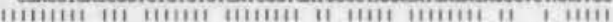

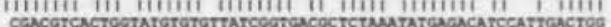
610

reotecrstancresces,

1111111111111111

roorog̣tarascrotcod

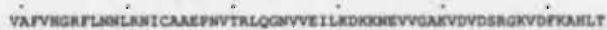

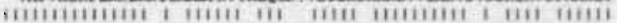

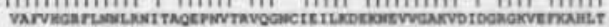
220 240 260

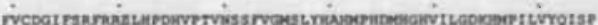

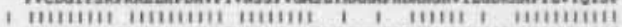

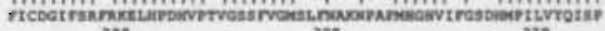
200 300 320

E⿱宀⿻上丨

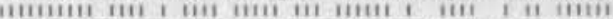

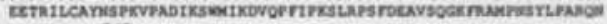
340

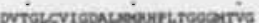

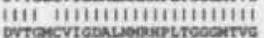


Chapter 5

nisms of resistance could perhaps be elucidated from the identification of the 25 strongly upregulated and 76 downregulated proteins in the two-dimensional gel analysis. Knowing the identities of other expressed genes located on the amplified chromosome could also contribute to the unravelling of the resistance enigma.

\section{ACKNOWLEDGMENTS}

We thank Marcel Borgers for interesting and stimulating discussions, Dennis Everaerts, Hans Schuurman, Wouter Bruinzeel, and Jos Gorrens for their excellent technical assistance, and Lambert Leijssen and Griet Van Houdt for help in the preparation of the manuscript.

V.T. is a research assistant of the National Fund for Scientific Research (NFRS), Belgium. 


\section{REFERENCES}

1. Arif, S., T. Barkham, E. G. Power, and S. A. Howell. 1996. Techniques for investigation of an apparent outbreak of infections with Candida glabrata. J. Clin. Microbiol. 34:2205-2209.

2. Cannon, R. D., M. Niimi, G. D. Albertson, and H. F. Jenkinson. 1996. CDR 1-mediated fluconazole resistance in Candida albicans. ASM Conference on Candida and Candidiasis: Biology, pathogenesis, and management march 24-27, 1996, San Diego, California.

3. Chen, C., T. G. Turi, D. Sanglard, and J. C. Loper. 1987. Isolation of the Candida tropicalis gene for $\mathrm{P} 450$ lanosterol demethylase and its expression in Saccharomyces cerevisiae. Biochem. Biophys. Res. Commun. 146:1311-1317.

4. Clark, F. S., T. Parkinson, C. A. Hitchcock, and N. A. R. Gow. 1996. Correlation between rhodamine 123 accumulation and azole sensitivity in Candida species: possible role for drug efflux in drug resistance. Antimicrob. Agents Chemother. 40:419-425.

5. Crombie, T., D. J. Falconer, and C. A. Hitchcock. 1995. Fluconazole resistance due to energy-dependent drug efflux in Candida glabrata. Antimicrob. Agents Chemother. 39:1696-1699.

6. Den Dunnen, J. T., Liang P., G. J. B. Van Ommen, and C. Van Broeckhoven. 1995. Mutation detection and diagnosis using PFGE. In: A.P. Monaco. (ed.), Pulsed field gel electrophoresis, a practical approach. Oxford University Press, New York, N.Y.

7. Doi, M., M. Homma, A. Chindamporn and K. Tanaka. 1992. Estimation of chromosome number and size by pulsed-field gel electrophoresis (PFGE) in medically important Candida species. J. Gen. Microbiol. 138: 2243-2251.

8. Fling, M.E., J. Kopf, A. Tamarkin, J.A. Gorman. H.A. Smith, and Y. Koltin. 1991. Analysis of a Camdida albicans gene that encodes a novel mechanism for resistance to benomyl and methotrexate. Mol. Gen. Genet. 227:318-329.

9. Hitchcock. C. A., K. Barett-Bee, and N. J. Russell. 1986. The lipid composition of azole-sensitive and azole-resistant strains of Candida albicans. J. Gen. Microbiol. 132:2421-2431.

10. Hitchcock, C. A. 1993. Resistance of Candida albicans to antifungal agents. Biochem. Soc. Trans. 41:1039-1047. 
11. Jandrositz, A., F. Turnowsky, and G. Högenauer. 1991. The gene encoding squalene epoxidase from Saccharomyces cerevisiae : cloning and characterization. Gene 107:155160.

12. Kelly, S. L., D. C. Lamb, A. J. Corran, B. C. Baldwin, and E. D. Kelly. 1995. Mode of action and resistance to azole antifungals associated with the formation of $14 \mathrm{a}$-methylergosta-8,24(28)-dien-3 b-6 a-diol. Biochem. Biophys. Res. Commun., 207:910-915.

13. Kosuga, K., S. Hata, T. Osumi, J. Sakakibara, and T. Ono. 1995. Nucleotide sequence of cDNA for mouse squalene epoxidase. Biochim. Biophys. Acta 1260:345-348.

14. Lee, L. G. M, C. R. Connell, S. L. Woo, R. D. Cheng, B. T. Mc Ardle, C. W. Fuller, N. D. Halloran and R. K. Wilson. 1992. DNA sequencing with dye-labeled terminators and T7 DNA polymerase : effects of dyes and dNTPs on incorporation of dye-terminators and probability analysis of termination fragments. Nucleic Acids Res. 20:2471-2483.

15. Marichal, P., and H. Vanden Bossche. 1995. Mechanisms of resistance to azole antifungals. Acta Biochim. Pol. 42:509-516.

16. Marichal, P., J. Gorrens, M.-C. Coene, L. Le Jeune, and H. Vanden Bossche. 1995. Origin of differences in susceptibility of Candida krusei to azole antifungal agents. Mycoses 38:111-117.

17. Mewes, H. W., K. Albermann, K. Heumann, S. Liebl, and F. Pfeiffer. 1997. MIPS - A database for protein sequences, homology data and yeast genome information. Nucleic Acids Res. 25:28-30.

18. Mieth, H. 1993. In vitro and in vivo activities of terbinafine. p. 137-149. In: J. W. Rippon and R. A. Fromtling (ed.), Cutaneous antifungal agents, Marcel Dekker, New York, N.Y.

19. National Committee for Clinical Laboratory Standards. 1995. Reference method for broth dilution susceptibility testing of yeasts. Tentative standard M27-T. National Committee for Clinical Laboratory Standards, Villanova, Pa.

20. Ng, R. and J. Abelson. 1980. Isolation and sequence of the gene for actin in Saccharomyces cerevisiae. Proc. Natl. Acad. Sci. USA 77:3912-3916.

21. Odds, F. C., 1993. Resistance of yeasts to azole-derivative antifungals. J. Antimicrob. Chemother. 31:463-471.

22. Odds, F. C., L. Vranckx, and F. Woestenborghs. 1995. Antifungal susceptibility testing of yeasts: evaluation of technical variables for test automation. Antimicrob. Agents Chemother. 39:2051-2060. 
23. Polak, A., 1988. Mode of action of morpholine derivatives. Ann. N. Y. Acad. Sci. 544:221-228.

24. Prasad, R., P. Dewegifosse, A. Goffeau, and E. Balzi. 1995. Molecular cloning and characterization of a novel gene of Candida albicans, CDR1, conferring multiple resistance to drugs and antifungals. Curr. Genet. 27:320-329.

25. Rex, J. H., M. G. Rinaldi, M. A. Pfaller. 1995. Resistance of Candida species to fluconazole. Antimicrob. Agents Chemother. 39:1-8.

26. Ryder, N. S., 1985. Specific inhibition of fungal sterol biosynthesis by SF 86-327, a new allylamine antimycotic agent. Antimicrob. Agents Chemother. 27:252-256.

27. Sakakibara, J., R. Watanabe, Y. Kannai, T. Ono. 1995. Molecular cloning and expression of rat squalene epoxidase. J. Biol. Chem. 270:17-20.

28. Sambrook, J., E. F. Fritsch, and T. Maniatis.. 1989. Molecular cloning: a laboratory manual, $2^{\text {nd }}$ ed. Cold Spring Harbor Laboratory, Cold Spring Harbor, N.Y.

29. Sanglard, D., K. Kuchler, F. Isher, J. L. Pagani, M. Monod, and J. Bille. 1995. Mechanisms of resistance to azole antifungal agents in Candida albicans isolates from AIDS patients involve specific multidrug transporters. Antimicrob. Agents Chemother. 39:2378-2386.

30. Sanglard, D., F. Isher, M. Monod, and J. Bille. 1996. Susceptibilities of Candida albicans multidrug transporter mutants to various antifungal agents and other metabolic inhibitors. Antimicrob. Agents Chemother. 40:2300-2305.

31. Sanglard, D., F. Isher, M. Monod, J. Bille. 1997. Cloning of Candida albicans genes conferring resistance to azole antifungals agents; characterization of CDR2, a new multidrug ABC transporter gene. Microbiology 143:405-16.

32. Smith, K.J., D. W. Warnock, Kennedy C. T. C. 1986. Azole resistance in Candida albicans. J. Med. Vet. Mycol. 24:133-144.

33. Smith, R. A., C. A. Hitchcock, E. G. V. Evans, C. J. N. Lacey, and D. J. Adams. I989. The identification of $C$. albicans strains by restriction fragment length polymorphism analysis of DNA. J. Med. Vet. Mycol, 27:431-434.

34. Thorvaldsen, J. L.. R. K. Mehra, W. Yu, A. K. Sewell and D. R. Winge. 1995. Analysis of copper-induced metallothionein expression using autonomously replicating plasmids in Candida glabrata. Yeast 11:1501-1511. 


\section{Chapter 5}

35. Vanden Bossche, H., P. Marichal, J. Gorrens, D. Bellens, H. Moereels, and P. A. J. Janssen. 1990. Mutation in cytochrome P450-dependent 14 $\alpha$-lanosterol demethylase results in decreased affinity for azole antifungals. Biochem Soc. Trans. 18:56-59.

36. Vanden Bossche, H., P. Marichal, F. C. Odds, L. Le Jeune, and M.-C. Coene. 1992. Characterization of an azole-resistant Candida glabrata isolate. Antimicrob. Agents Chemother. 36:2602-2610.

37. Vanden Bossche, H., P. Marichal, F. C. Odds. 1994. Molecular mechanisms of drug resistance in fungi. Trends Microbiol. 2:393-400.

38. Warnock, D. W., J. Burke, N. J. Cope, E. M. Johnson, N. A. Van Fraunhofer, and E. W. Williams. 1988. Fluconazole resistance in Candida glabrata. Lancet ii: 1310.

39. Zhou, P., D. J. Thiele. 1993. Rapid transcriptional autoregulation of a yeast metalloregulatory transcription factor is essential for high-level copper detoxification. Genes Dev. 7:1824-1835. 


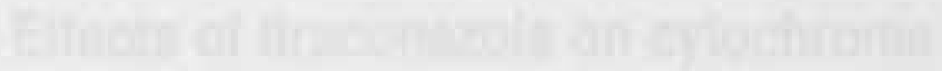

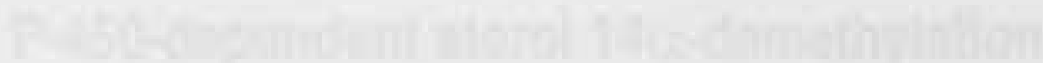

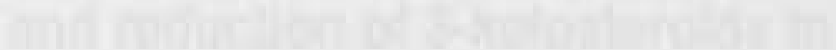

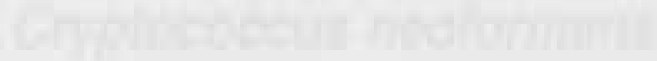





\section{Effects of itraconazole on cytochrome}

\section{P-450-dependent sterol $14 \alpha$-demethylation}

and reduction of 3-ketosteroids in

\section{Cryptococcus neoformans}

Hugo Vanden Bossche, Patrick Marichal, Ludo Le Jeune, Marie-claire Coene, Jos Gorrens and Willy Cools

Division of Medicinal Chemistry and Pharmacology, Janssen Research Foundation, B-2340 Beerse, Belgium

Running title: Effects of itraconazole on crgosterol synthesis Antimicrobial Agents and Chemotherapy, 37(10), 2101-2105 


\section{SUMMARY}

As in other pathogenic fungi, the major sterol synthesized by Cryptococcus neoformans var. neoformans is ergosterol. This yeast also shares with most pathogenic fungi a susceptibility of its cytochrome P-450-dependent ergosterol synthesis to nanomolar concentrations of itraconazole. Fifty percent inhibition of ergosterol synthesis was reached after $16 \mathrm{~h}$ of growth in the presence of $6.0 \pm$ $4.7 \mathrm{nM}$ itraconazole, and complete inhibition was reached at approximately 100 $\mathrm{nM}$ itraconazole. This inhibition coincided with the accumulation of mainly eburicol and the 3-ketosteroid obtusifolione. The radioactivity incorporated from $\left[{ }^{14} \mathrm{C}\right]$ acetate in both compounds represents $64.2 \% \pm 12.9 \%$ of the radioactivity incorporated into the sterols plus squalene extracted from cells incubated in the presence of $10 \mathrm{nM}$ itraconazole. The accumulation of obtusifolione as well as eburicol indicates that itraconazole inhibits not only the $14 \alpha$-demethylase but also (directly or indirectly) the NADPH-dependent 3-ketosteroid reductase, i.e. the enzyme catalyzing the last step in the demethylation at $\mathrm{C}-4$. This latter inhibition obviates the synthesis of 4,4-demethylated $14 \alpha$-methylsterols that may function at least partly as surrogates of ergosterol. Eburicol and obtusifolione are unable to support cell growth, and the 3-ketosteroid has been shown to disturb membranes. The complete inhibition of ergosterol synthesis and the accumulation of the 4,4,14-trimethylsterol and of the 3-ketosteroid together with the absence of sterols, such as $14 \alpha$-methylfecosterol and lanosterol, which can partly fulfill some functions of ergosterol, are at the origin of the high activity of itraconazole against $C$. neoformans. Fifty percent inhibition of growth was achieved after $16 \mathrm{~h}$ of incubation in the presence of $3.2 \pm 2.6 \mathrm{nM}$ itraconazole. 


\section{INTRODUCTION}

Itraconazole is an ergosterol biosynthesis inhibitor in many fungi (18, 20-22). This triazole antifungal agent has been shown to inhibit the cytochrome P-450dependent $14 \alpha$-demethylation of lanosterol or 24-methylene-24,25-dihydrolanosterol (eburicol) in, for example, Candida albicans, Candida glabrata, Candida lusitaniae, Aspergillus fumigatus, Trichophyton mentagrophytes, and Histoplasma capsulatum. In all these fungi, the interaction of itraconazole with the $14 \alpha$-demethylase results in a decreased availability of ergosterol and a concomitant accumulation of a variety of $14 \alpha$-methylsterols. For example, complete inhibition of ergosterol synthesis was achieved in $C$. albicans after $1 \mathrm{~h}$ of contact with itraconazole concentrations as low as $10 \mathrm{nM}$ (21). After $24 \mathrm{~h}$ of incubation, ergosterol synthesis was completely blocked at $30 \mathrm{nM}$ (18) and at $300 \mathrm{nM}$ ergosterol, concentrations decreased below the detection level, i.e., $<5$ fg per cell (20).

Ergosterol has an essential regulatory function in processes of cell proliferation (1). Furthermore, ergosterol-depleted membranes are more permeable to glucose and other small polar nolecules and ions (7) and a number of $14 \alpha$-methylated sterols impair membrane functions and affect membrane-bound enzymes (17). Thus, the itraconazole-induced inhibition of the $14 \alpha$-demethylase is at the origin of a cascade of perturbations which together lead to the gross antifungal activity of this triazole derivative.

In vitro and in vivo data document the high activity of itraconazole against Cryptococcus neoformans (2). So far, sterol synthesis in this yeast has not been studied. In this article, we prove that ergosterol is the main sterol synthesized by $C$. neoformans and present evidence to suggest that itraconazole's activity against $C$. neoformans originates from its interaction with the $14 \alpha$-demethylation of eburicol and (directly or indirectly) with the final step in the 4-demethylation reaction. 


\section{MATERIALS AND METHODS}

\section{Culture methods.}

The $C$. neoformans var. neoformans isolate (B42419. ATCC 32265) was maintained on Sabouraud agar slants at $37^{\circ} \mathrm{C}$. A loopful from a 24 -h slant was inoculated in Sabouraud broth and incubated for $48 \mathrm{~h}$ at $37^{\circ} \mathrm{C}$. A $0.2 \mathrm{ml}$ sample from this culture was used to inoculate a 500 -ml Erlenmeyer flask filled with $100 \mathrm{ml}$ of PYG medium containing polypeptone, yeast extract, and glucose (each at 1 $\mathrm{g} /$ liter), and the mixture was incubated for $24 \mathrm{~h}$ at $37^{\circ} \mathrm{C}$ in a reciprocating shaker (100 strokes per min). To study the effects of itraconazole (R 51211 , Janssen Pharmaceutica) on growth, volumes of $0.2 \mathrm{ml}$ of the $24 \mathrm{~h}$ culture were used to inoculate $500-\mathrm{ml}$ Erlenmeyer flasks with $100 \mathrm{ml}$ of PYG medium. Itraconazole and/or dimethyl sulfoxide (DMSO) was added to the medium before inoculation. After $16 \mathrm{~h}$ of growth at $37^{\circ} \mathrm{C}$ in a reciprocating shaker, the total number of cells was counted with a Coulter Counter (25).

\section{Sterol synthesis.}

To evaluate the effects of itraconazole on sterol synthesis in C. neoformans, 100 $\mathrm{ml}$ of PYG medium was supplemented with $\left[{ }^{14} \mathrm{C}\right]$ acetate (specific activity, 58 $\mu \mathrm{Ci} / \mathrm{mmol}$; Radiochemical Center, Amersham, United Kingdom) and different concentrations of itraconazole and/or DMSO immediately before inoculation. Inoculation and growth conditions were as described above. After $16 \mathrm{~h}$ of contact, cells were harvested by centrifugation at $1,500 \times \mathrm{g}$ for $5 \mathrm{~min}$, washed twice with distilled water, and homogenized as described before (25). The homogenates were supplemented with an equal volume of $15 \% \mathrm{KOH}$ in $90 \%$ ethanol. The suspensions were heated for $1 \mathrm{~h}$ at $85^{\circ} \mathrm{C}$ in a water bath and cooled. and the unsaponifiable lipids were extracted with $n$-heptane (UV spectrography) (24). Total radioactivity in the heptane extract was determined by liquid scintillation counting with Opti-Phase (Pharmacia) as a scintillant. The heptane extracts were dried under a stream of nitrogen and dissolved in minimal volumes of methanol-water (95:5). Sterols were separated by high-performance liquid chromatography (HPLC) on a Varian 9010 liquid chromatograph equipped with a Varian 9095 automatic injector, a Varian 9065 Polychrom detector, and a 
Berthold LB507A HPLC radioactivity monitor with Pico Aqua (Canberra Packard) as a scintillant and connected with a Compaq $386 / 33$ computer. A Zorbax $\mathrm{C}_{18}$ column ( 250 by $4.6 \mathrm{~mm}, 5 \mu \mathrm{m}$, Du Pont) was eluted with methanolwater (95:5) at a flow rate of $1 \mathrm{ml} / \mathrm{min}$ for $25 \mathrm{~min}$, after which the solvent was changed to $100 \%$ methanol. Retention times of the HPLC fractions were calculated relative to the retention time of ergosterol. To separate obtusifolione from eburicol, a second HPLC system was used. A Supelco LC18 column (150 by $4.6 \mathrm{~mm}, 5 \mu \mathrm{m}$; Supelco, Inc.) was eluted with acetonitrile-water (94:6) at a flow rate of $2 \mathrm{ml} / \mathrm{min}$ for $25 \mathrm{~min}$, after which the solvent was changed to $100 \%$ acetonitrile.

\section{Identification of sterols.}

Sterols were identified according to their retention times relative to those of standards and/or by gas chromatographic(GC)-mass spectrometric analysis. The spectra were recorded on a Finnigan 4500 mass spectrometer coupled to a Finnigan (model 9610) gas chromatograph. GC separations of the sterols present in the HPLC fractions were achieved with an Ultra 2 fused-silica capillary column ( $12 \mathrm{~m}$ by $0.32 \mathrm{~mm}$ [inside diameter]; film thickness, $0.5 \mu \mathrm{m}$; Hewlett Packard), using helium as a carrier gas at a flow rate of $1 \mathrm{ml} / \mathrm{min}$. The column temperature was programmed at $12^{\circ} \mathrm{C} / \mathrm{min}$ (initial temperature, $50^{\circ} \mathrm{C}$; final temperature, $310^{\circ} \mathrm{C}$ ). The transfer line temperature was $320^{\circ} \mathrm{C}$; the ion source temperature was kept at $180^{\circ} \mathrm{C}$. The electron energy was maintained at $73 \mathrm{eV}$, and the emission current was maintained at $300 \mu \mathrm{A}$.

\section{Protein content.}

The protein contents of the homogenates were determined by the Bio-Rad method, with bovine albumin used as the standard. 


\section{RESULTS}

\section{Effects of itraconazole on growth.}

The results summarized in Fig. 1 show itraconazole's growth inhibitory effect: on the $C$. neoformans var. neoformans isolate used. Fifty percent inhibition wa: achieved after $16 \mathrm{~h}$ of growth in the presence of $3.2 \pm 2.6 \mathrm{nM}$ itraconazole.

Sterol composition of $C$. neoformans grown under control conditions Analysis by HPLC of the heptane extract from untreated $C$. neoformans collect ed after $16 \mathrm{~h}$ of growth revealed three sterols and a fraction with the same reten tion time as squalene. The latter contained $11.4 \% \pm 3.6 \%$ of the radioactivity

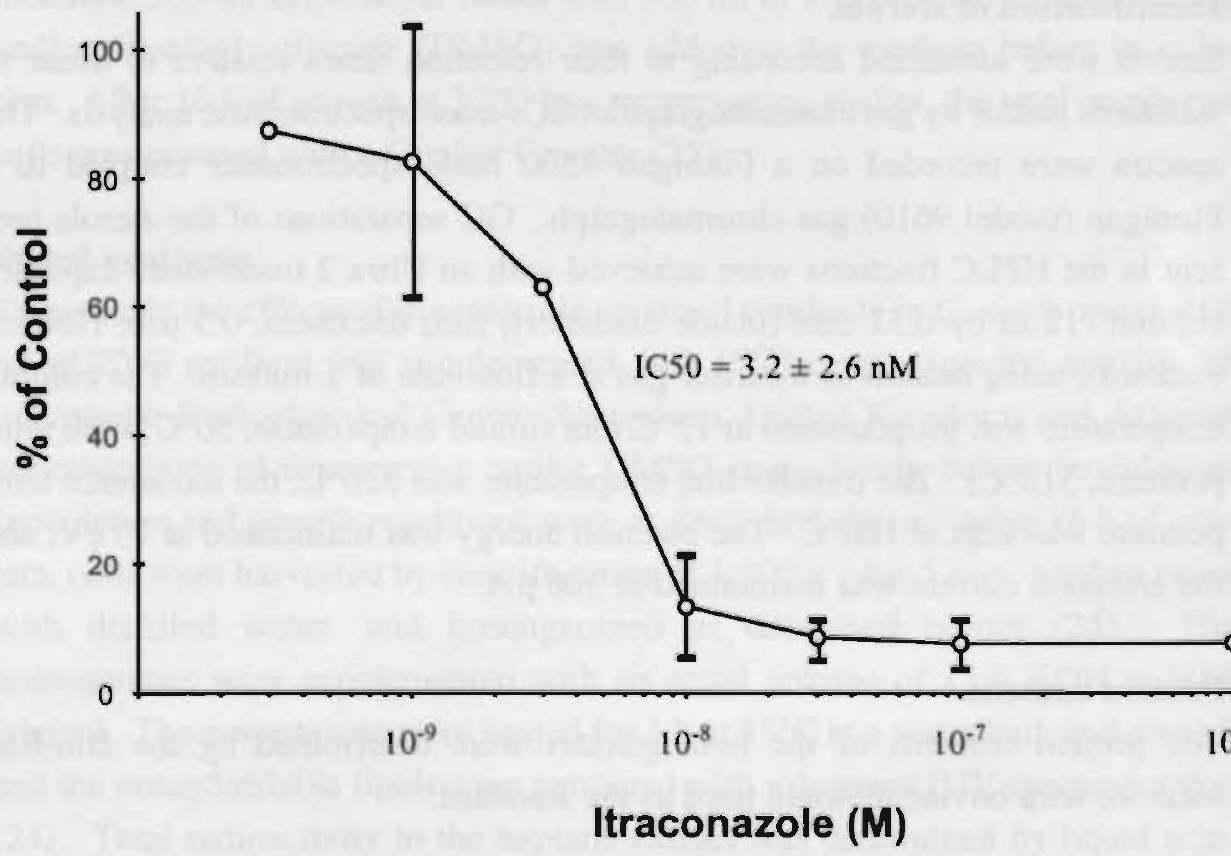

FIG. 1: Elfects of itraconazole on growth of $C$. neoformans. Itraconazole and/a DMSO was added to PYG medium immediately before inoculation, and the total number of cells was counted with a Coulter Counter after $16 \mathrm{~h}$ of incu bation. Effects of itraconazole are expressed as percent of control Pesults are the means of at least three experiments. Control cultures con tain $30.9 \times 10^{6} \pm 16.3 \times 10^{6} \mathrm{cells} / \mathrm{ml}$ (mean \pm standard deviation of 26 experiments). IC50, $50 \%$ inhibitory concentration. 

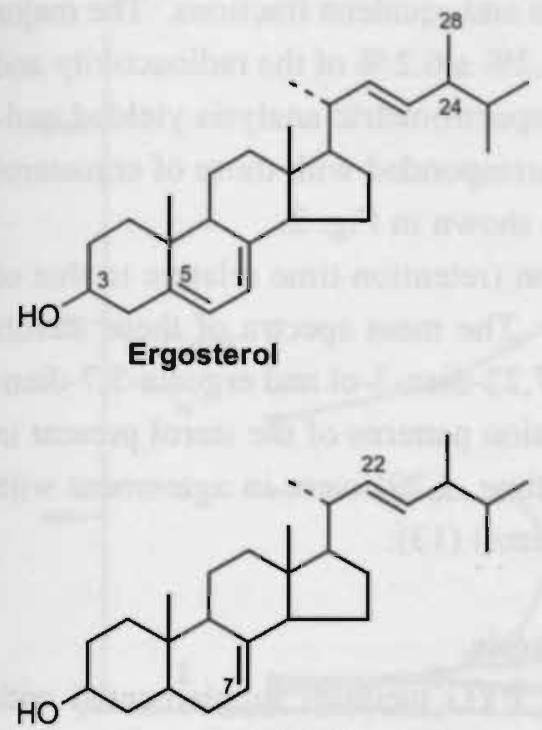

Ergosta-7,22-dien-3-ol

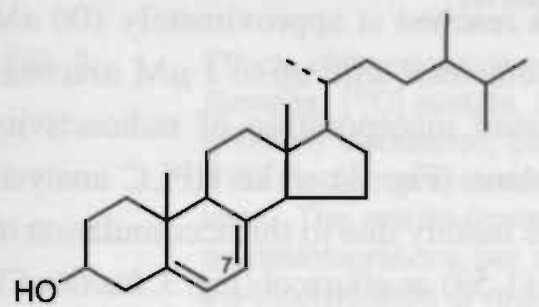

Ergosta-5,7-dien-3-ol

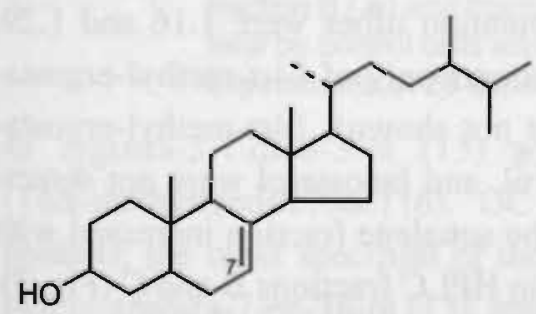

Ergosta-7-en-3- $\beta$ ol

(Fungisterol)

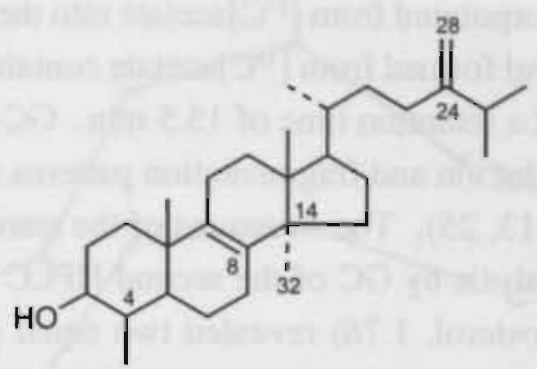

4,14-Dimethyl-ergosta-8,24(28)-dien-3-ol (Obtusifoliol)

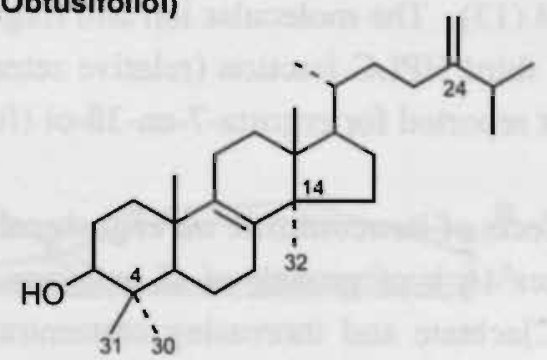

24-Methylenedihydrolanosterol (Eburicol)

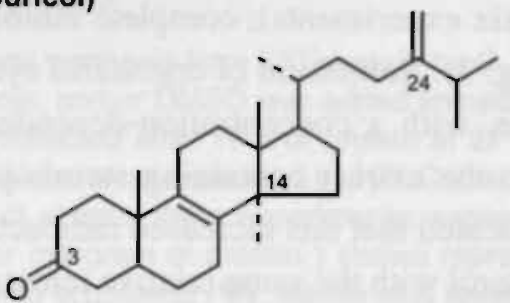

14-Methyi-ergosta-8,24(28)-dien-3-one (14-Methylfecosterone)

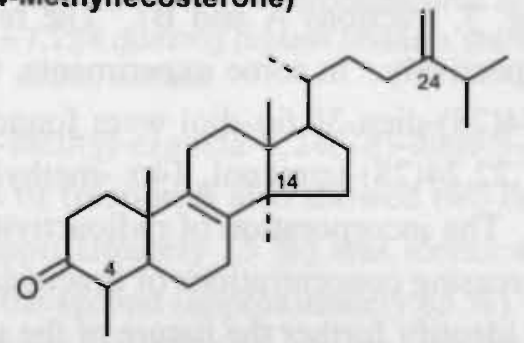

4,14-Dimethyl-ergosta-8,24(28)-dien-3-one (Obtusifolione)

FIG. 2: $\quad$ Sterols and 3-ketosteroids extracted from $C$. neoformans grown under control conditions and/or in the presence of itraconazole. 
incorporated from $\left[{ }^{14} \mathrm{C}\right]$ acetate into the sterols and squalene fractions. The major sterol formed from $\left[{ }^{14} \mathrm{C}\right]$ acetate contained $74.2 \% \pm 6.2 \%$ of the radioactivity and had a retention time of $15.5 \mathrm{~min}$. GC-mass spectrometric analysis yielded molecular ion and fragmentation patterns that corresponded with those of ergosterol $(4,13,25)$. The structures of the sterols are shown in Fig. 2.

Analysis by GC of the second HPLC fraction (retention time relative to that of ergosterol, 1.76) revealed two equal peaks. The mass spectra of these sterols were identical to those reported for ergosta-7,22-dien-3-ol and ergosta-5,7-dien3-ol (13). The molecular ion and fragmentation patterns of the sterol present in the third HPLC fraction (relative retention time, 1.29) were in agreement with that reported for ergosta-7-en-3B-ol (fungisterol) (13).

\section{Effects of itraconazole on ergosterol synthesis.}

After $16 \mathrm{~h}$ of growth of $C$. neoformans in PYG medium supplemented with $\left[{ }^{14} \mathrm{C}\right]$ acetate and increasing concentrations of itraconazole, $50 \%$ inhibition of ergosterol synthesis was achieved at $6.0 \pm 4.7 \mathrm{nM}$ (means \pm standard deviations of six experiments); complete inhibition was reached at approximately $100 \mathrm{nM}$ (Fig. 3). Inhibition of ergosterol synthesis coincided with up to $1 \mu \mathrm{M}$ itraconazole, with a concentration-dependent increased incorporation of radioactivity into the extract containing sterols plus squalene (Fig. 3). The HPLC analysis indicated that this increased radioactivity was mainly due to the accumulation of a sterol with the same relative retention time (1.59) as eburicol (Fig. 3, fraction C). In addition to ergosterol and eburicol, two minor sterol fractions were present (Fig. 3, fractions A and B). The relative retention times were 1.16 and 1.29, respectively. In some experiments, trace amounts only of $14 \alpha$-methyl-ergosta8,24(28)-dien-3B,6 $\alpha$-diol were found (results not shown); $14 \alpha$-methyl-ergosta$5,7,22,24(28)$-tetraenol, $14 \alpha$-methylfecosterol, and lanosterol were not detected. The incorporation of radioactivity into the squalene fraction increased with increasing concentrations of itraconazole, as in HPLC fractions B and C (Fig. 3). To identify further the nature of the sterols present. HPLC fractions $\mathrm{A}$ to $\mathrm{C}$ were separated from the sterol extracts from $C$. neoformans grown for $16 \mathrm{~h}$ in the presence of $10 \mathrm{nM}$ itraconazole and analyzed by GC-mass spectrometry. HPLC fraction A contained 2 sterols for which the mass spectra were identical to those 


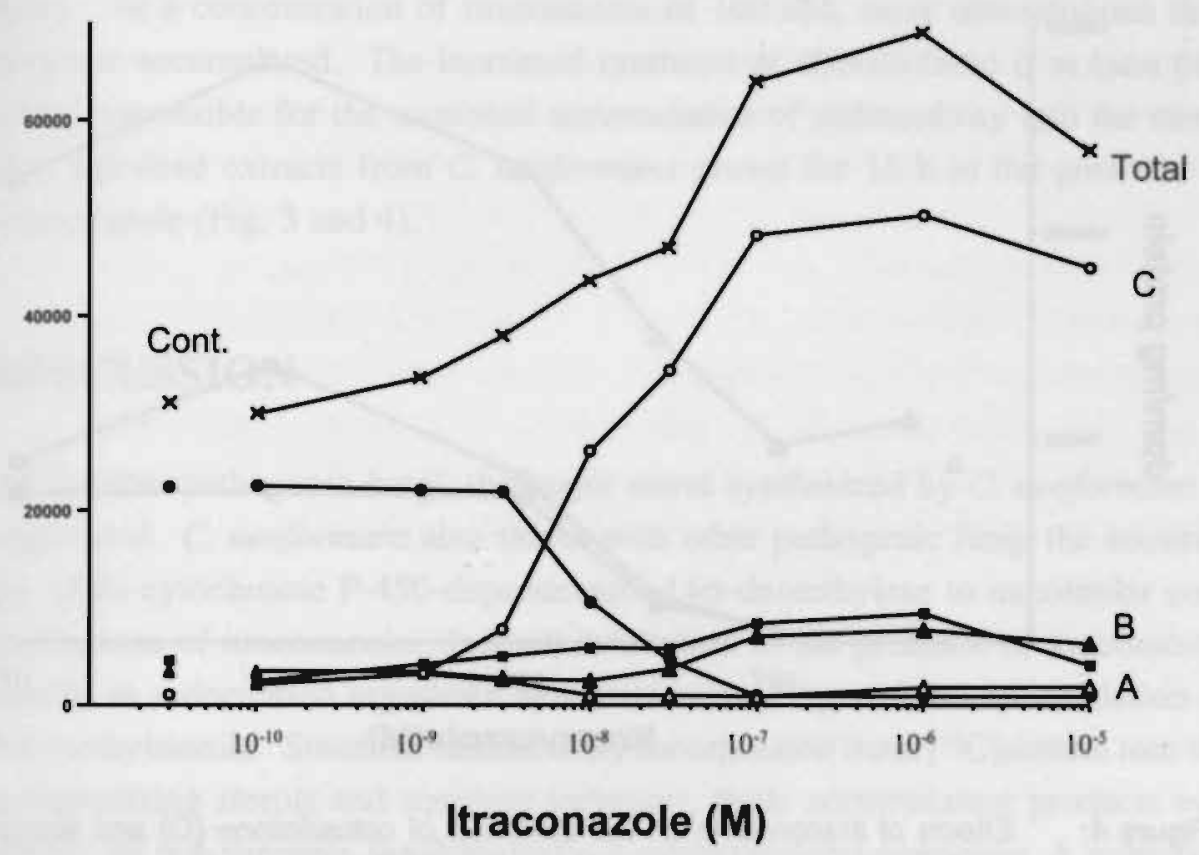

FIG. 3: Effects of itraconazole on ergosterol synthesis from [ [ $\left.{ }^{14} \mathrm{C}\right]$ acetate by $C$. neoformans. $\left[{ }^{14} \mathrm{C}\right]$ acetate, itraconazole, and/or DMSO was added immediately before inoculation; cells were collected after $16 \mathrm{~h}$ of growth at $37^{\circ} \mathrm{C}$ in PYG medium and sterols and squalene were separated by HPLC (first system). The results (mean values of at least three experiments; expressed as desintegrations per minute per milligram of protein ) shown represent the incorporation of radioactivity into ergosterol (๑), sterols plus squalene $(X)$, fraction $C$ (contains eburicol plus obtusifolione) $(\mathrm{O})$, squalene (E), fraction $B(\mathbf{A})$ and fraction $A$ ( $\Delta$ ). The radioactivity incorporated into ergosterol by control cells was $22,057 \pm 7,224$ dpmimg protein (mean \pm standard experiments of 20 experiments). Cont., control.

of ergosta-5,7-dien-3-ol (13) and 14 $\alpha$-methyl-ergosta-8,24(28)-dien-3-one (14 $\alpha$-methylfecosterone) (6). GC analysis of fraction B also showed two components: the mass spectrum of the first (approximately $15 \%$ ) was identical to that of ergosta-7-en-3B-ol (13), and that of the second (approximately $85 \%$ ) was in agreement with the spectrum reported for obtusifoliol $(4,12,25)$. The three sterols and $14 \alpha$-methylfecosterone all together contained $4.2 \% \pm 2.8 \%$ of the radioactivity incorporated from $\left[{ }^{14} \mathrm{C}\right]$ acetate into the sterols plus squalene pre- 


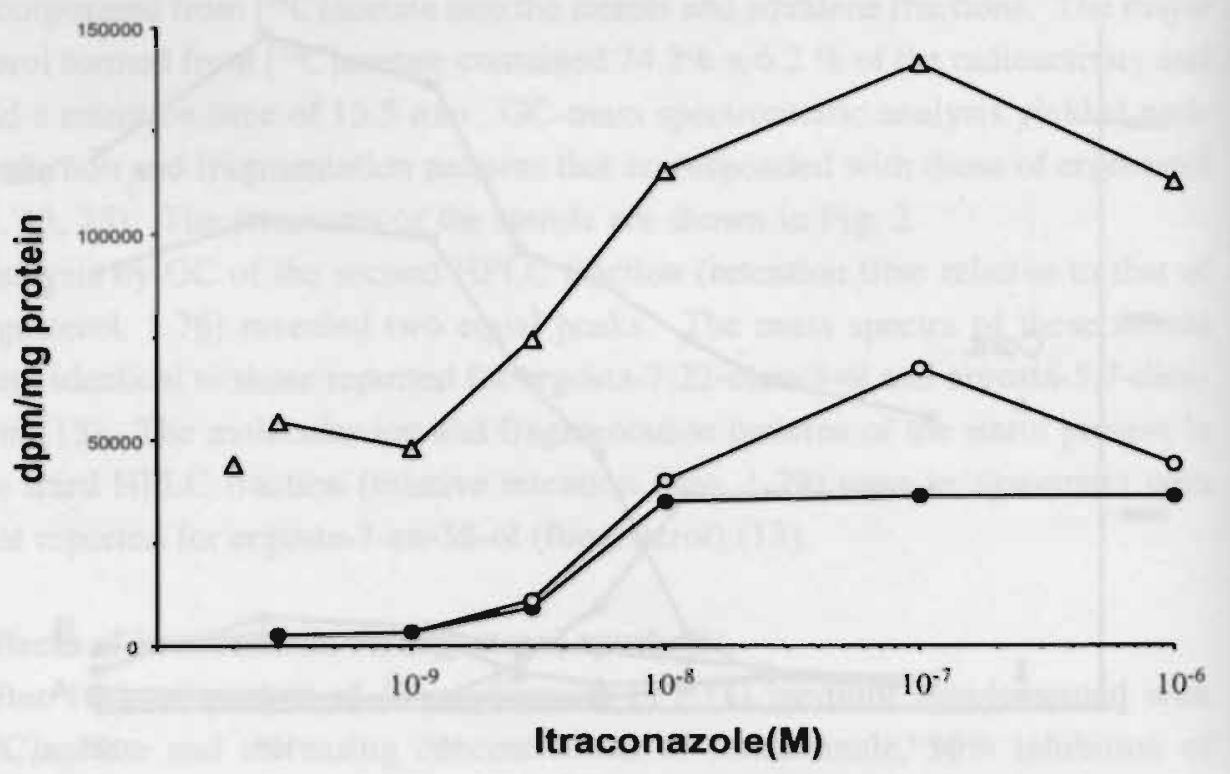

Figure 4: Effects of itraconazole on the synthesis of obtusifolione $(O)$ and eburicol (O) by $C$. neoformans grown for $16 \mathrm{~h}$ in PYG medium. Sterols were separated by the second HPLC system and identified according their relative retention times and by GC-mass spectrometry. Radioactivity (desintegrations per minute per milligram of protein) incorporated into the sterols plus squalene is also shown $(\Delta)$. C: control.

sent in the heptane extract, whereas the radioactivity incorporated into fraction $\mathrm{C}$ represented $64.2 \% \pm 12.9 \%$. This fraction contained almost equal amounts of two compounds. The mass spectrum of the first showed molecular ion and fragmentation patterns in agreement with those described by Kerkenaar et al. (6) for the 3-ketosteroid 4,14 $\alpha$-dimethyl-ergosta-8,24(28)-dien-3-one (obtusifolione). The mass spectrum of the second component was identical to that of eburicol $(12,25)$.

To study further the effects of increasing concentrations of itraconazole on the accumulation of obtusifolione, a second HPLC system was used that separated the 3-ketosteroid from eburicol. Both were identified according their relative retention times (1.33 and 1.69) and by GC-mass spectrometry. As shown in Fig. 4. itraconazole induced a concentration-dependent accumulation of obtusifo- 
lione. At a concentration of itraconazole of $100 \mathrm{nM}$, more obtusifolione than eburicol accumulated. The increased synthesis of obtusifolione is at least partially responsible for the increased accumulation of radioactivity into the sterol plus squalene extracts from $C$. neoformans grown for $16 \mathrm{~h}$ in the presence of itraconazole (Fig. 3 and 4).

\section{DISCUSSION}

As in other pathogenic fungi, the major sterol synthesized by $C$. neoformans is ergosterol. C. neoformans also shares with other pathogenic fungi the sensitivity of its cytochrome P-450-dependentent $14 \alpha$-demethylase to nanomolar concentrations of itraconazole. Indeed, incubation in the presence of itraconazole results in a decreased ergosterol synthesis coinciding with an accumulation of 14-methylsterols. Since the radioactivity incorporated from $\left[{ }^{14} \mathrm{C}\right]$ acetate into the accumulating sterols and squalene increases, these accumulating products evidently do not suppress the 3-hydroxy-3-methylglutaryl-coenzyme A reductase as has been described for, e.g., 24,25-epoxidocholesterol (15). As with A. fumigatus (19), H. capsulatum (20) and Malassezia ovale (23), itraconazole induces the accumulation of large amounts of eburicol. Membrane integrity requires the inserted sterol component to lack C-4 methyl groups (10). Thus, an accumulation of eburicol will adversely affect the growth of $C$. neoformans since its two methyl groups at $\mathrm{C}-4$ will grossly perturb membrane function. Although eburicol was a predominant sterol found in itraconazole-treated $C$. neoformans, it still represented only about a quarter of all the sterols extracted from treated cells, a situation quite different from that of $M$. ovale, which accumulated eburicol almost exclusively when exposed to itraconazole (23).

Obtusifolione was quantitatively the major sterol found in itraconazole-treated $C$. neoformans: the effects of the antifungal agent on this yeast therefore resemble those previously observed with $H$. capsulatum (20). Prerequisites for both the condensing and liquefying effects of sterols in membranes are a planar ring system and a long flexible chain at C-17 (8). For sterols to function in the lipid layer of membranes there is also a requirement that the polar group at $\mathrm{C}-3$ act as 
a $\mathrm{H}$ donor in hydrogen bonding with the ester carbonyl moiety of the fatty acid associated with the phospholipid, directly or by way of a water bridge (10). The studies of Nes et al. prove that the $\mathrm{B}-\mathrm{OH}$ group at $\mathrm{C}-3$ is essential for activity and cannot be replaced by a keto group (10). Furthermore, 3-ketosteroids have been shown to destabilize the lipid bilayer structure and to inhibit the growth of sterolrequiring mycoplasmas (3). When incorporated in erythrocytes, they greatly increased the permeability and fragility of the membranes (3). Therefore, the itraconazole-induced accumulation of obtusifolione and eburicol in $C$. neoformans (this study) and in the yeast form of $H$. capsulatum (20) may explain the high sensitivity of both yeasts to itraconazole. Indeed, $50 \%$ inhibition of growth is achieved at concentrations as low as $3.2 \mathrm{nM}$ (this study) and $1.7 \mathrm{nM}$ (20), respectively.

Preliminary results indicate that obtusifolione (approximately $18 \%$ at $500 \mathrm{nM}$ ) and eburicol (approximately $27 \%$ ) also accumulate in $A$. fumigatus (unpublished results), with 14 $\alpha$-methyl-ergosta-8,24(28)-dien-3B-6 $\alpha$-diol (3,6-diol), obtusifoliol and $14 \alpha$-methylfecosterol appearing in similar (3,6-diol) or lower concentrations (19). Obtusifolione and eburicol (see above) and the 3,6-diol (5) are unable to support normal growth. The 3,6-diol is unable to sustain growth even in the presence of ergosterol (5). Nevertheless, compared with $C$. neoformans, itraconazole concentrations almost six-times higher are required to reach $50 \%$ growth inhibition (19). In contrast with C. neoformans treated with $100 \mathrm{nM}$ itraconazole, A. fumigatus grown in the presence of $500 \mathrm{nM}$ itraconazole still synthesizes trace amounts of ergosterol and accumulates $14 \alpha$-methylfecosterol (19). The latter 4,4-demethylated sterol is believed to be functional in fungal membranes (11). It can satisfy bulk membrane requirements (14, 16). The trace amounts of ergosterol synthesized by A. fumigatus may fulfill the highly specific roles of ergosterol, i.e., the sparking and/or critical domain function. The absence of both sterols in itraconazole-treated $C$. neoformans together with the accumulation of obtusifolione and eburicol may be at the origin of itraconazole's greater potency against this yeast.

The accumulation of both eburicol and obtusifolione proves that itraconazole is an inhibitor of the $14 \alpha$-demethylase; accumulation of the 3-ketosteroid indicates that the antifungal agent also interferes with the last step in the demethylation at 
C-4. The removal of the first methyl group requires NADPH, molecular oxygen, a cyanide-sensitive factor and cytochrome $b_{5}$. The first intermediate formed is a C-4 alcohol that is oxidized to a C-4 aldehyde and further to $4 \alpha$-carboxy- $4 B$ methyl-3-ketosterol, which is then decarboxylated by a NAD-dependent 4decarboxylase to yield the $4 \alpha$-methyl-3-ketosteroid obtusifolione. The final step is the reduction of the 3-keto group to a $3 B$-hydroxyl group by the NADPHdependent 3-ketosteroid reductase. The second demethylation at $\mathrm{C}-4$ follows the same reaction sequence and is catalyzed by the same microsomal enzymes (9). The intermediate formed is $14 \alpha$-methylfecosterone, a minor component found in C. neoformans treated with $10 \mathrm{nM}$ itraconazole.

Our studies do not permit the conclusion that itraconazole acts directly on the 3 ketosteroid reductase or that the inhibition observed is secondary to its interaction with the cytochrome P-450-dependent demethylase. Indeed, it is possible that $14 \alpha$-methylated sterols have a lower affinity for the reductase. This is at the moment under investigation. However, regardless of the outcome of the latter study, the results presented here indicate that the growth-inhibitory effect of itraconazole on $C$. neoformans is the result of an interaction with both the cytochrome P-450-dependent $14 \alpha$-demethylase and the NADPH-dependent 3ketosteroid reductase. This combined effect completely blocks not only ergosterol synthesis but also that of 4,4-demethylated-14 $\alpha$-methylsterols that may otherwise function partly as ergosterol surrogates.

\section{ACKNOWLEDGEMENTS}

We are grateful to F. C. Odds and M. Janssen for their critical review of the manuscript and L. Geentjens for manuscript preparation. 


\section{REFERENCES}

1. Dahl, C., and J. Dahl. 1988. Cholesterol and cell function, p. 147-171. In P. L. Yeagle (ed.), Biology of cholesterol. CRC Press, Boca Raton, Fla.

2. Denning, D. W., R. M. Tucker, J. S. Hostetler, S. Gill, and D. A. Stevens. 1990. Oral itraconazole therapy of cryptococcal meningitis and cryptococcosis in patients withs AIDS, p. 305-324. In H. Vanden Bossche, D. W. R. Mackenzie, G. Cauwenbergh, J. Van Cutsem, E. Drouhet, and B. Dupont (ed.), Mycoses in AIDS patients. Plenum Press, New York.

3. Galley, J., and B. De Kruijf. 1982. Correlation between molecular shape and hexagonal $\mathrm{H}_{\mathrm{t}}$ phase promoting ability of sterols. FEBS Lett. 143:133-143.

4. Hart, D. T., W. Lauwers, G. Willemsens, H. Vanden Bossche, and F. R. Opperdoes. 1989. Perturbation of sterol biosynthesis by itraconazole and ketoconazole in Leishmania mexicana mexicana infected macrophages. Mol. Biochem. Parasitol. 33:123-134.

5. Kelly, S. L., J. Rowe, and P. F. Watson. 1991. Molecular genetic studies on the mode of action of azole antifungal agents. Biochem. Soc. Trans. 19:796-798.

6. Kerkenaar, A., J. M. van Rossum, G. G. Versluis, and J. W. Marsman. 1984. Effects of fenpropimorph and imazalil on sterol biosynthesis in Penicillium italicum. Pestic. Sci. 15:177-187.

7. Long, M. T., C. C. Steel, and E. I. Mercer. 1988. Location of squalene accumulation and physiological effects of ergosterol depletion in naftifine-grown yeast. Biochem. Soc. Trans. 16: 1044-1045.

8. Marichal, P., H. Vanden Bossche, H. Moereels, and R. Brasseur. 1990. Mode of insertion of azole antifungals and sterol in membranes, p. 27-42. in R. Brasseur (ed.), Molecular description of molecular membranes by computer aided conformational analysis, , vol. 2. CRC Press, Boca Raton, Fla.

9. Mercer, E. I. 1984. The biosynthesis of ergosterol. Pestic. Sci. 15:133-155.

10. Nes, W. D., G. G. Janssen, F. G. Crumley, M. Kalinowska, and T. Akihisa. 1993. The structural requirements of sterols for membrane function in Saccharomyces cerevisiae: Arch. Biochem. Biophys. 300:724-733.

11. Orth, A. B., and H. D. Sisler. 1990. Mode of action of terbinafine in Ustilago maydis and characterization of resistant mutants. Pestic. Biochem. Physiol. 37:53-63. 
12. Patterson, G. W. 1984. Chemical and physical methods in the analysis of plant sterols, p. 293-323. In W. D. Nes, G. Fuller, and L.-S. Tsai (ed.), Isopentenoids in plants, biochemistry and function. Marcel Dekker, Inc., New York.

13. Rahier, A., and P. Benveniste. 1989. Mass spectral identification of phytosterols, p. 223-250. In: W. D. Nes, and E. J. Parish (ed.), Analysis of sterols and other biologically significant steroids. Academic Press, Inc., San Diego, Calif.

14. Rodriguez, R. J., C. Low, C. D. K. Bottema, and L. W. Parks. 1985. Multiple functions for sterols in Saccharomyces cerevisiae. Biochim. Biophys. Acta 837:336-343.

15. Taylor, F. R., A. A. Kandutsch, A. K. Gayen, J. A. Nelson, S. Phirwa, and T. A. Spencer. 1986. 24,25-Epoxysterol metabolism in cultured mammalian cells and repression of 3-hydroxy-3-methylglutaryl-CoA reductase. J. Biol. Chem. 261:15039-15044.

16. Taylor, F. R., R. J. Rodriguez, and L. W. Parks. 1983. Requirement for a second sterol biosynthetic mutation for the viability of a sterol C-14 demethylation defect in Saccharomyces cerevisiae. J. Bacteriol. 155:64-68.

17. Vanden Bossche, H. 1990. Importance and role of sterols in fungal membranes, p. 135157. In P. J. Kuhn, A. P. Trinci, M. J. Jung, M. W. Goosey, and L. G. Copping (ed.), Biochemistry of cell walls and membranes in fungi. Springer Verlag, Berlin.

18. Vanden Bossche, H., J. Heeres, L. Backx, P. Marichal, and G. Willemsens. 1993. Discovery, chemistry, mode of action and selectivity of itraconazole, p. 263-283. In J. W. Rippon, and R. A. Fromtling (ed.), Cutaneous antifungal agents. Marcel Dekker, Inc., New York.

19. Vanden Bossche, H., P. Marichal, H. Geerts, and P. A. J. Janssen. 1988. The molecular basis for itraconazole's activity against Aspergillus fumigatus, p. 171-197, In H. Vanden Bossche, D. W. R. Mackenzie and G. Cauwenbergh (ed.), Aspergillus and aspergillosis. Plenum Press, New York.

20. Vanden Bossche, H., P. Marichal. J. Gorrens, D. Bellens, M.-C. Coene, W. Lauwers, L. Le Jeune, H. Moereels, and P. A. J. Janssen. 1990. Mode of action of antifungais of use in immunocompromised patients. Focus on Candida glabrata and Histoplasma capsulatum. p. 223-243, In H. Vanden Bossche. D. W. R. Mackenzie, G. Cauwenbergh, J. Van Cutsem, E. Drouhet, and B. Dupont (ed.), Mycoses in AIDS patients. Plenum Press, New York.

21. Vanden Bossche, H., P. Marichal, J. Gorrens, M.-C. Coene, G. Willemsens, D. Bellens, I. Roels, H. Moereels, and P. A. J. Janssen. 1989. Biochemical approaches to selective antifungal activity. Focus on azole antifungals. Mycoses 32 (Suppl. 1):35-52. 


\section{Chapter 6}

22. Vanden Bossche, H., P. Marichal, J. Gorrens, H. Geerts, and P. A. J. Janssen. 1988. Mode of action. studies. Basis for the search of new antifungal drugs. Ann. N.Y. Acad. Sci. 544:191-207.

23. Vanden Bossche, H., P. Marichal and H. Moereels. 1993. Molecular mechanisms of antifungal activity and fungal resistance: focus on inhibitors of ergosterol biosynthesis, p. 179-197. In B. Maresca, G. S. Kobayashi, and H. Yamaguchi (ed.), Molecular biology and its application to medical mycology. Springer-Verlag, Berlin.

24. Vanden Bossche, H., P. Marichal, F. C. Odds, L. Le Jeune, and M.-C. Coene. 1992. Characterization of an azole-resistant Candida glabrata isolate. Antimicrob. Agents Chemother. 36:2602-2610.

25. Vanden Bossche, H., G. Willemsens, W. Cools, W. F. J. Lauwers, and L. Le Jeune. 1978. Biochemical effects of miconazole on fungi. II. Inhibition of ergosterol biosynthesis in Candida albicans. Chem.-Biol. Interact. 21:59-78. 




\section{Origin of differences in susceptibility of Candida krusei to azole antifungal agents}

P. Marichal, J. Gorrens, M.-C. Coene, L. Le Jeune and H. Vanden Bossche

Division of Medicinal Chemistry and Pharmacology; Janssen Research Foundation, B-2340 Beerse, Belgium

Running title. Susceptibility of $C$. krusei to azoles

Mycoses 38. $111-117(1995)$ 


\section{SUMMARY.}

Two Candida krusei isolates were used to compare the effects of fluconazole, ketoconazole and itraconazole on growth and ergosterol synthesis, and to measure intracellular drug contents. Fifty per cent inhibition $\left(\mathrm{IC}_{50}\right)$ of growth was achieved at $0.05-0.08 \mu \mathrm{M}$ itraconazole and $0.56-1.2 \mu \mathrm{M}$ ketoconazole, whereas 91- $>100 \mu \mathrm{M}$ fluconazole was needed to reach the $\mathrm{IC}_{50}$-value. Similar differences in sensitivity to these azole antifungal agents were seen when their effects on ergosterol synthesis from $\left[{ }^{14} \mathrm{C}\right]$ acetate were measured after $4 \mathrm{~h}$ and $24 \mathrm{~h}$ of growth. However, when the effects of the azoles on ergosterol synthesis from $\left[{ }^{14} \mathrm{C}\right]$ mevalonate by subcellular fractions were measured, fluconazole was only 2.3-6.1 times less active than itraconazole, and the $\mathrm{IC}_{50}$ values for ketoconazole were almost similar to those obtained with itraconazole. These results indicate that differences in susceptibility to itraconazole and ketoconazole are unrelated to differences in affinity for the $C$. krusei cytochrome P450. The much lower growth-inhibitory effects of fluconazole can also be explained partly only by a lower affinity for the P450-dependent $14 \alpha$-demethylase. The differences in sensitivity of both $\mathrm{C}$. krusei isolates appeared to arise from differences in the intracellular itraconazole, ketoconazole and fluconazole contents. Depending on the experimental conditions, these isolates accumulated 6-41 times more itraconazole than ketoconazole and the intracellular ketoconazole content was $3.0-19.0$ times higher than that of fluconazole. 


\section{Effects of itraconazole on ergosterol synthesis}

\section{INTRODUCTION}

Until the late 1970s Candida albicans was the species of the genus Candida most often involved in systemic fungal infections. In the early $1980 \mathrm{~s}, C$. tropicalis emerged as a major pathogen in neutropenic cancer patients [1]. In more recent years infections due to non-albicans and non-tropicalis species, such as C. glabrata, C. krusei, C. lusitaniae and C. parapsilosis, have increased [1-6]. The reason that $C$. tropicalis emerged as an important pathogen in neutropenic cancer patients was the increased intensity of cytoreductive treatment regimens now used in leukaemia and bone marrow transplant patients and the capacity of this opportunistic fungus to exploit this deficit in host defenses [1]. These treatment regimens give rise to increased mucosal damage and longer episodes of neutropenia. Both the mucosal barrier damage and the neutropenia contribute to the susceptibility of the host to infections with C. tropicalis [1].

Changes in the spectrum of Candida infections may also be associated with changes in treatment practices. For example, the introduction of ketoconazole permitted a dramatic improvement in the management of patients with chronic mucocutaneous candidiasis. However, long-term treatment was required and this form of treatment led to reports of treatment failure or relapse owing to the apparent development of azole resistance [3]. More recently, the introduction of the hydrophylic fluconazole altered the fungal flora. This triazole derivative is much more active against $C$. albicans and $C$. tropicalis than against different strains of $C$. glabrata, and $C$. kruse $i$ isolates are natively resistant to fluconazole (MIC $50 \mu \mathrm{g} \mathrm{ml}^{-1}$ ) [7-10]. Treatment with fluconazole suppressed relatively susceptible Candida species such as $C$. albicans and $C$. ropicalis while permitting the overgrowth of less sensitive or resistant Candida species [1, 2]. The use of not only fluconazole but also of the antibacterial agent norffoxacin seems to be a factor for the risk of colonization by the less virulent and fluconazole-resistant C. kruse $i$ [1]. In contrast to fluconazole, both ketoconazole [minimum inhibitory concentration (MIC) $0.2 \mu \mathrm{g} \mathrm{ml}^{-1}$ ) and itraconazole (MIC: $0.05 \mu \mathrm{g} \mathrm{ml}^{-1}$ ) [8] are active against $C$. krusei. The fact that $C$. krusei strains are resistant to fluconazole but sensitive to itraconazole and to a lesser extent to ketoconazole may arise from differences in intracellular accumulation of the drugs or from differences 
in the affinity of these azoles for the cytochrome P450-dependent sterol $14 \alpha$ demethylase ( $\left.\mathrm{P} 450_{51} ; \mathrm{P} 450_{14 \mathrm{DM}}\right)$. In this paper we prove that resistance to fluconazole and the lower activity of ketoconazole may arise from a decreased intracellular accumulation of these azoles rather than from lower affinity for the C. krusei $14 \alpha$-demethylase.

\section{MATERIALS AND METHODS}

\section{Strains and culture methods.}

Two isolates of $C$. krusei (B 69267 and 73/126) from culture collections held at the Janssen Research Foundation were used. Strain B 69267 is an oral isolate from a HIV-positive patient; $73 / 126$ is from an oral surveillance culture of a nonimmunosuppressed surgical patient.

Inocula were prepared in 5-ml broth cultures (10-fold dilution in sterile water of a medium containing pancreatic casein digest [Merck, Darmstadt, Germany], $30 \mathrm{~g} \mathrm{I}^{-1}$; yeast extract [Difco Laboratories, Detroit, USA]. $30 \mathrm{~g} \mathrm{l}^{-1}$; glucose (Difco), $60 \mathrm{~g} \mathrm{l}^{-1}$; morpholinepropanesulfonic acid (MOPS; Acros Chimica, Geel, Belgium), $100 \mathrm{~g} \mathrm{l}^{-1}$; tris-(hydroxymethyl)-aminomethane (Tris; Acros Chimica), $\left.30 \mathrm{~g} \mathrm{l}^{-1}\right)$ for $18-24 \mathrm{~h}$ at $30^{\circ} \mathrm{C}$ and rotated at 20 r.p.m. as previously described by Odds [11, 12]. Aliquots $(0.5 \mathrm{ml})$ of this culture were used to inoculate $100 \mathrm{ml}$ of CYG medium (casein hydrolysate-yeast extract-glucose, each $5 \mathrm{~g} \mathrm{l}^{-1}$ [13]). Cells were grown at $37^{\circ} \mathrm{C}$ in a reciprocating shaker for $64 \mathrm{~h} ; 0.2-\mathrm{ml}$ aliquots were used to inoculate $100 \mathrm{ml}$ of CYG medium and after $24 \mathrm{~h}$ of growth [14], aliquots were used to inoculate the experimental media.

To evaluate the effects of itraconazole, ketoconazole and fluconazole on growth, $0.2-\mathrm{ml}$ aliquots of the above-described culture were used to inoculate a $500 \mathrm{ml}$ Erlenmeyer flask filled with $100 \mathrm{ml}$ of CYG medium. The azole antifungals and/or dimethyl sulfoxide (DMSO) were added to the medium before inoculation. After $24 \mathrm{~h}$ of growth at $37^{\circ} \mathrm{C}$ in a reciprocating shaker $(100$ strokes per min), the total number of cells was counted with a Coulter Counter [14]. 
Sterol synthesis by intact cells.

To study sterol synthesis in C. krusei, $100 \mathrm{ml}$ of CYG medium was supplemented with $5 \mu \mathrm{Ci}\left[2-{ }^{14} \mathrm{C}\right]$ acetate (specific activity, $56 \mu \mathrm{Ci} \mathrm{mmol}^{-1}$; Radiochemical Center, Amersham, UK) and different concentrations of azole antifungal and/or DMSO immediately before inoculation. Inoculation and growth conditions were as deseribed above. After $24 \mathrm{~h}$ of contact cells were harvested by centrifugation at $1,500 \times \mathrm{g}$ for $5 \mathrm{~min}$, washed twice with distilled water, and homogenized as described before [14]. The suspensions were supplemented with an equal volume of $15 \% \mathrm{KOH}$ in $90 \%$ ethanol, heated for $1 \mathrm{~h}$ at $85^{\circ} \mathrm{C}$ in a water bath and cooled, and the non-saponifiable lipids were extracted with $n$-heptane (for UV spectroscopy) [15]. Total radioactivity in the heptane extract was determined by liquid scintillation counting with Opti-Phase (Wallac) as a scintillant. The heptane extracts were dried under a stream of nitrogen and dissolved in minimal volumes of methanol-water (90:10). Sterols were separated by high-performance liquid chromatography (HPLC) on a Zorbax $\mathrm{C}_{8}$ column [15]. Sterols were eluted with a methanol-water mixture (90:10) for $40 \mathrm{~min}$, after which the column was eluted with pure methanol. Sterols were identified by gas chromatography-mass spectrometry (GC-MS) analysis [16].

In a second series of experiments $1 \mathrm{ml}$ of CYG medium was supplemented with $1.25 \mu \mathrm{Ci}\left[2-{ }^{14} \mathrm{C}\right]$ acetate, different concentrations of azole antifungal and/or DMSO immediately before inoculation with $10^{7} \mathrm{C}$. krusei cells. After $4 \mathrm{~h}$ incubation at $37^{\circ} \mathrm{C}$ in an orbital shaker ( 300 r.p.m.) one volume of $15 \% \mathrm{KOH}$ in $90 \%$ ethanol was added. Mixtures were saponified, sterols extracted and separated as described above.

\section{Sterol synthesis by subcellular fractions}

To prepare the subcellular fractions, the $C$. kruse isolates were grown for $16 \mathrm{~h}$ (of which the last $8 \mathrm{~h}$ was in a reciprocating shaker) in $200 \mathrm{ml}$ of PYG-2 medium $(10 \mathrm{~g}$ of polypeptone, $10 \mathrm{~g}$ of yeast extract. $40 \mathrm{~g}$ of glucose per liter) in 500. $\mathrm{ml}$ Erlenmeyer flasks at $30^{\circ} \mathrm{C}$ [15]. Cells were collected by centrifugation at $1500 \mathrm{~g}$. washed and resuspended in cold homogenization buffer containing 0.1 M potassium phosphate buffer, $30 \mathrm{nM}$ nicotinamide, $5 \mathrm{mM} \mathrm{MgCl}$ and $5 \mathrm{mM}$ glutathione. Cells were broken in a cooled Braun cell homogenizer with glass 
beads (diameter $0.5 \mathrm{~mm}$ ). All subsequent steps were done at $4^{\circ} \mathrm{C}$. The homogenate was differentially centrifuged for $5 \mathrm{~min}$ at $1500 \mathrm{~g}$ and $20 \mathrm{~min}$ at $8000 \mathrm{~g}$. The supernatant ( $\mathrm{S}-8000$ fraction) was used. Ten microliters of $\mathrm{MgCl}_{2}$ $\mathrm{MnCl}_{2}$ (61.0 and $39.6 \mathrm{mg} \mathrm{ml}^{-1}$ respectively) per $\mathrm{ml}$ of $\mathrm{S}-8000$ fraction was added. The incorporation of $\left[{ }^{14} \mathrm{C}\right]$ mevalonate into ergosterol was studied as described previously [15].

\section{Intracellular content.}

Cells were grown for $4 \mathrm{~h}$ (exponential phase) in 500-ml Erlenmeyer flasks, containing $100 \mathrm{ml} \mathrm{CYG} \mathrm{medium,} \mathrm{in} \mathrm{a} \mathrm{reciprocating} \mathrm{shaker} \mathrm{at} 37^{\circ} \mathrm{C}$. Cells were diluted to $250 \times 10^{3}$ cells $\mathrm{ml}^{-1}$ in fresh medium and $1-\mathrm{ml}$ aliquots were added to $3 \mu \mathrm{M}\left[{ }^{3} \mathrm{H}\right]$ itraconazole (specific activity: $75 \mathrm{mCi}^{-1} \mathrm{mmol}^{-1}$; Janssen Research Foundation), $3 \mu \mathrm{M}\left[{ }^{14} \mathrm{C}\right]$ fluconazole (specific activity: $6.8 \mathrm{mCi} \mathrm{mmol}^{-1}$; gift from Pfizer Central Research, Sandwich, UK) or $3 \mu \mathrm{M}\left[{ }^{14} \mathrm{C}\right]$ ketoconazole (specific activity: $7.5 \mathrm{mCi} \mathrm{mmol}^{-1}$; Janssen Research Foundation). After $60 \mathrm{~min}$ of incubation at $37^{\circ} \mathrm{C}$ in an orbital shaker ( 300 r.p.m.) cells were collected by centrifugation $(1500 \mathrm{~g}$ ), washed three times with ice-cold saline containing unlabelled azole solution $(10 \mu \mathrm{M})$. Cells were collected, digested and the radioactivity was determined as described previously [15].

In a second series of experiments, cells (inoculum size: $250 \times 10^{3}$ ) were grown for $24 \mathrm{~h}$ in $1 \mathrm{ml} \mathrm{CYG} \mathrm{medium} \mathrm{at} 37^{\circ} \mathrm{C}$ in an orbital shaker ( 300 r.p.m.) and further incubated for $60 \mathrm{~min}$ in the presence of $3 \mu \mathrm{M}$ of the radiolabelled azoles. Cells were further handled as described for the $4 \mathrm{~h}$ plus $1 \mathrm{~h}$ experiments.

\section{Protein content.}

The protein content of the homogenates and subcellular fractions were determined by the Bio-Rad method, with bovine albumin as the standard. 


\section{RESULTS}

\section{Effects of azole antifungal agents on growth.}

The results summarized in Fig. 1 show the growth-inhibitory effects of itraconazole, ketoconazole and fluconazole on two $C$. kruse $i$ isolates. Fifty per cent inhibition $\left(\mathrm{IC}_{50}\right)$ was achieved after $24 \mathrm{~h}$ of growth of isolate B 69267 in the presence of $0.08 \mu \mathrm{M}$ itraconazole and $1.2 \mu \mathrm{M}$ ketoconazole. Fluconazole was a poor inhibitor of growth: $50 \%$ inhibition was not achieved even at concentrations as high as $100 \mu \mathrm{M}$. The second isolate (73/126) was somewhat more sensitive to this triazole derivative but still $91 \mu \mathrm{M}$ was needed to reach the $\mathrm{IC}_{50}$ value. This isolate was also somewhat more sensitive to ketoconazole and itraconazole. The $\mathrm{IC}_{50}$ values were reached at $0.56 \mu \mathrm{M}$ and $0.05 \mu \mathrm{M}$, respectively.

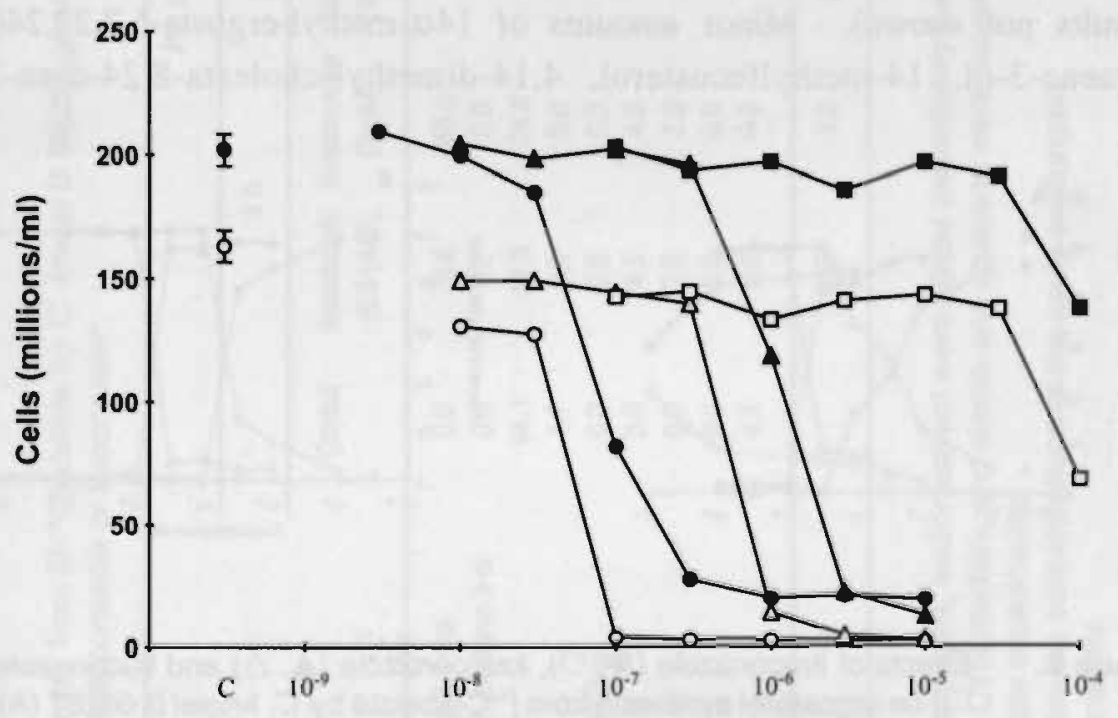

Concentration (M)

Figure 1. Effects of itraconazole $(\bullet, 0)$, ketoconazole $(\boldsymbol{\Delta}, \Delta)$ and fluconazole $(\square, q$ on growth of C. krusei B 69267 (closed symbols) and 73/126, (open symbols). The number of cells was determined after $24 \mathrm{~h}$ of growth in CYG medium. C (mean \pm standard deviation of at least 7 experiments): number of cells after $24 \mathrm{~h}$ of growth in the presence of solvent. Results obtained in the presence of azole antifungals are mean values of at least two experiments. 


\section{Sterol synthesis in intact cells.}

Differences in sensitivity to the azole antifungal agents were further found when their effects were measured on ergosterol synthesis from $\left[{ }^{14} \mathrm{C}\right]$ acetate by both isolates. After $24 \mathrm{~h}$ of incubation $50 \%$ inhibition of ergosterol synthesis was reached at $0.027 \mu \mathrm{M}$ (B 69267) and $0.046 \mu \mathrm{M}$ (73/126) itraconazole. More than 10 times higher concentrations of ketoconazole were needed $\left(\mathrm{IC}_{50}=0.49 \mu \mathrm{M}\right.$ and $0.54 \mu \mathrm{M}$ ) whereas, even in the presence of $100 \mu \mathrm{M}$ fluconazole, ergosterol synthesis was almost not affected (Fig. 2 A and B). Inhibition of ergosterol synthesis coincided with the accumulation of sterols with a methyl group at C-14 (Fig. $2 \mathrm{~A}$ and $\mathrm{B}$; Table 1). In the presence of all three azole antifungals, the major accumulating sterol in isolate B 69267 was 14-methyl-ergosta-8,24 (28)dien-3,6-diol (3,6-diol) (Table 1). Similar results were found with isolate 73/126 (results not shown). Minor amounts of 14 $\alpha$-methyl-ergosta-5,7,22,24(28)tetraene-3-ol, 14-methylfecosterol, 4,14-dimethyl-cholesta-8,24-dien-3-ol,
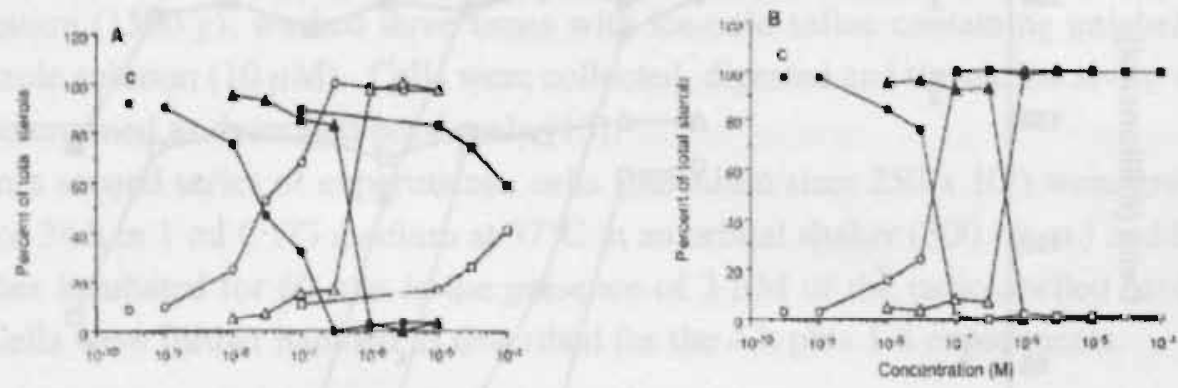

Figure 2. Effects of itraconazole $(0,0)$, ketoconazole $(\Delta, \Delta)$ and fluconazole $(\boldsymbol{\square}$, $\square$ ) on ergosterol synthesis from $\left[{ }^{14} \mathrm{C}\right]$ acetate by C. krusei $\mathrm{B} 69267$ (A) and $73 / 126$ (B). The results (mean values of at least 2 experiments) represent the incorporation into ergosterol (closed symbols) and 14-methylated sterols + squalene (open symbols); $\mathrm{C}=$ control. 
Table 1. Sterols formed from $\left[2{ }^{14} \mathrm{C}\right]$ acetate by $C$. krusei B 69267 grown for 4 or $24 \mathrm{~h}$ in the presence of solvent, itraconazole, ketoconazole or fluconazole ${ }^{a}$.

\begin{tabular}{|c|c|c|c|c|c|c|c|c|}
\hline \multirow{3}{*}{ Sterol formed } & \multicolumn{8}{|c|}{ Per cent of total radioactivity } \\
\hline & \multicolumn{4}{|c|}{$4 \mathrm{~h}$} & \multicolumn{4}{|c|}{$24 \mathrm{~h}$} \\
\hline & Control & $\begin{array}{c}\text { Itraconazole } \\
(0.3 \mu \mathrm{M})^{\mathrm{t}}\end{array}$ & $\begin{array}{c}\text { Ketoconazole } \\
\qquad(3 \mu \mathrm{M})\end{array}$ & $\begin{array}{l}\text { Fluconazol } \\
(100 \mu \mathrm{M})\end{array}$ & Control & $\begin{array}{l}\text { Itraconazole } \\
(0.3 \mu \mathrm{M})\end{array}$ & $\begin{array}{c}\text { Ketoconazole } \\
\qquad(3 \mu \mathrm{M})\end{array}$ & $\begin{array}{c}\text { Fluconazole } \\
(100 \mu \mathrm{M})\end{array}$ \\
\hline 14-methyl-ergosta-8,24(28)-dien-3,6-diol & 0.0 & 76.6 & 68.3 & 46.4 & 8.2 & 74.7 & 72.2 & 38.3 \\
\hline 14-methyl-ergosta-5,7,22,24(28)-tetraene-3-ol & 0.0 & 0.0 & 0.0 & 1.7 & 0.0 & 7.8 & 6.6 & 1.1 \\
\hline ergosterol & 94,1 & 11.8 & 24.8 & 47.0 & 89.9 & 0.5 & 30 & 58.5 \\
\hline 14-methylfecosterol & 1.7 & 0.0 & 0.0 & 0.0 & 0.1 & 1.1 & 4.4 & 0.0 \\
\hline 4,14-dimethyl-cholesta-8,24-dien-3-ol & 0.0 & 0.0 & 0.0 & 0.0 & 0.4 & 2.2 & 0.2 & 0.0 \\
\hline obtusifoliol & 0.0 & 4.5 & 4.8 & 2.2 & 1.1 & 2.3 & 0.0 & 0.0 \\
\hline lanosterol & 0.0 & 7.0 & 2.0 & 2.1 & 0.0 & 3.5 & 3.7 & 0.0 \\
\hline eburicol: & 0.0 & 0.0 & 0.0 & 0.0 & 0.0 & 2.9 & 0.8 & 2.1 \\
\hline squalene & 4.2 & 0.0 & 0.0 & 0.0 & 0.4 & 4.9 & 9.0 & 0.0 \\
\hline $\mathrm{IC}_{30}(\mu \mathrm{M})^{4}$ & & 0.07 & 1.2 & $\geq 100$ & & 0.027 & 0.49 & $>100$ \\
\hline
\end{tabular}

"[2-14 C]acetate, azole antifungals, and/or solvent were added immediately before inoculation, cells were collected after $4 \mathrm{~h}$ or $24 \mathrm{~h}$ of growth at $37^{\circ} \mathrm{C}$ in CYG medium, and sterols and squalene were separated by HPLC. Results presented are mean valves of at least two separate experiments.

"Values in parentheses are the concentrations of the azole antifungals.

'24-methylenedihydrolanosterol.

${ }^{9}$ IC $C_{\text {so: }}$ concentration needed to inhibit ergosterol synthesis from $\left[2{ }^{-14} \mathrm{C}\right]$ acetate by $50 \%$ (calculated from the results shown in Fig. 2). 
Table 2. Sterols and sterol precursors formed from [ $\left[{ }^{14} \mathrm{C}\right]$ mevalonate by subcellular fractions of $C$. krusei B 69267 and $73 / 126$ incubated in the presence of solvent and $1 \mu \mathrm{M}$ of itraconazole, ketoconazole or fluconazoles.

\begin{tabular}{|c|c|c|c|c|c|c|c|c|}
\hline \multirow[b]{2}{*}{ Sterol formed } & \multicolumn{8}{|c|}{ Percent of total radioactivity } \\
\hline & \multicolumn{4}{|c|}{ B 69267} & \multicolumn{4}{|c|}{$73 / 126$} \\
\hline$\sqrt{3}-5$ & Control & Itraconazole & Ketoconazole & Fluconazole & Control & ltraconazole & Ketoconazole & Fluconazole \\
\hline ergosterol & 34.6 & 5.4 & 6.2 & 14.4 & 23.3 & 1.4 & 4.4 & 11.8 \\
\hline 4,14-dimethylsterols & 5.0 & 28.8 & 29.9 & 26.3 & 7.7 & 30.7 & 27.4 & 25.7 \\
\hline 4,4,14-trimethylsterols & 4.6 & 37,4 & 38.1 & 25.8 & 6.1 & 31.5 & 31.7 & 23.8 \\
\hline squalene & 14.5 & 10.2 & 9.9 & 11.3 & 15.1 & 10.3 & 9.8 & 10.2 \\
\hline 2,3-oxidosqualene & 18.4 & 11.9 & 10.4 & 13.1 & 21.9 & 16.7 & 16.1 & 18.2 \\
\hline $2,3,22,23$-dioxidosqualene & 2.7 & 2.5 & 2.6 & 2.3 & 4.5 & 4.5 & 4.0 & 2.4 \\
\hline $\mathrm{IC}_{\mathrm{so}}(\mu \mathrm{M})^{\mathrm{s}}$ & & 0.23 & 0.28 & 1.38 & & 0.53 & 0.57 & 1.25 \\
\hline
\end{tabular}

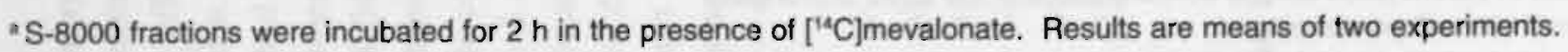
${ }^{\circ} \mathrm{IC}_{\mathrm{s0}}=$ concentration needed to inhibit ergosterol synthesis from $\left[{ }^{19} \mathrm{C}\right]$ mevalonate by $50 \%$. 
obtusifoliol, lanosterol, eburicol and of the acyclic sterol precursor, squalene were found after $24 \mathrm{~h}$ of incubation of $C$. krusei isolate B 69267 with itraconazole, ketoconazole or fluconazole (Table 1). After $4 \mathrm{~h}$ of incubation in the presence of azoles three 14-methylated sterols were found: 3,6-diol, obtusifoliol and lanosterol (Table 1).

\section{Sterol synthesis in subcellular fractions.}

As compared with a subcellular fraction from isolate B 69267, that of isolate $73 / 126$ synthesized about 1.6-times less ergosterol from $\left[{ }^{14} \mathrm{C}\right]$ mevalonate. All three azole antifungal agents inhibited ergosterol synthesis from $\left[{ }^{14} \mathrm{C}\right]$ mevalonate by subcellular fractions of both isolates (Table 2). In contrast with the effects on intact cells, the $\mathrm{IC}_{50}$-values obtained with itraconazole, ketoconazole and fluconazole were much less divergent. Fluconazole was only 2.3-6.1 times less active than itraconazole, and the $\mathrm{IC}_{50}$ values for ketoconazole and itraconazole were almost identical (Table 2). Inhibition of ergosterol synthesis coincided with the accumulation of C-14-methylated sterols (Table 2).

These results further prove that all three azoles inhibit the $14 \alpha$-demethylase and suggest that the differences in growth-inhibitory activity are only partly due to differences in the sensitivity of the $C$. krusei $14 \alpha$-demethylase to these azole antifungals.

\section{Intracellular accumulation of azole antifungals.}

In a series of experiments, cells grown for $4 \mathrm{~h}$ (exponentially growing cells) or $24 \mathrm{~h}$ (stationary phase) were collected and further incubated for $1 \mathrm{~h}$ in medium containing $\left[{ }^{3} \mathrm{H}\right]$ itraconazole. $\left[{ }^{14} \mathrm{C}\right]$ ketoconazole or $\left[{ }^{14} \mathrm{C}\right]$ fluconazole. As compared with isolate B 69267. isolate 73/126 retained somewhat more of the azole antifungals (Table 3 ). This corresponds with its greater growth-inhibitory sensitivity.

Exponentially growing cells retained after $1 \mathrm{~h}$ of incubation 14 (B 69267) and 41 (73/126) times more itraconazole than ketoconazole (Table 3). The intracellular fluconazole content was 2.9 and 3.0 times lower than that of ketoconazole. In stationary phase cells 5.8 and 15.5 times more itraconazole than ketoconazole was accumulating intracellularly and the intracellular fluconazole content was 19 and 6.6 times lower than the ketoconazole content (Table 3). 

conazole ( $\mathrm{IC}_{50}: 27$ - $46 \mathrm{nM}$ ) and resembles more the sensitivity of ergosterol synthesis in C. glabrata ( $\mathrm{IC}_{50}: 22 \mathrm{nM}$ ) [17]. Nevertheless, itraconazole's growthinhibitory effects on $C$. krusei $\left(\mathrm{IC}_{50}: 50-80 \mathrm{nM}\right)$ resemble more the effects on growth of $C$. albicans ( $\left.\mathrm{IC}_{50}: 38 \mathrm{nM}\right)[18]$ than those on C. glabrata $\left(\mathrm{IC}_{50}: 1000\right.$ $\mathrm{nM})$ [15].

As compared with itraconazole $C$. krusei is less susceptible to ketoconazole. This is related not to a decreased affinity to the cytochrome P450-dependent $14 \alpha$-demethylase, but, to a lower intracellular ketoconazole content.

That the $C$. krusei isolates are resistant to fluconazole may be partly related to its low affinity for the $14 \alpha$-demethylase, but the low intracellular accumulation of this hydrophilic azole derivative contributes perhaps much more to the primary resistance of $C$. krusei to fluconazole.

Differences in intracellular contents imply that there are differences between the membrane transport (influx and/or efflux) of itraconazole, ketoconazole and fluconazole. The transport mechanisms involved are at the moment under investigation.

\section{ACKNOWLEDGEMENTS}

We are grateful to Willy Cools and Carl Van Hove for outstanding technical assistance and to Chris Geentjens for secretarial assistance. 


\section{REFERENCES}

1. Wingard, J. R. (1994) Changes in the spectrum of fungal infections in bone marrow transplant patients. Infect. Dis. Clin. Pract. 3 (Suppl. 2), S83-S89.

2. Dupont, B. (1994). Invasive fungal infections caused by yeasts as emerging pathogens. Infect. Dis. Clin. Pract. 3 (Suppl. 2), S78-S82.

3. Vanden Bossche, H., Warnock, D. W., Dupont, B., Kerridge, D., Sen Gupta, S., Improvisi, L., Marichal, P., Odds, F.C., Provost, F. \& Ronin, O. (1994) Mechanisms and clinical impact of antifungal drug resistance. J. Med. Vet. Mycol. 32 (Suppl.), 189-202.

4. Chandrasekar, P. H., Gatny, C. M. \& the Bone Marrow Transplantation Team. (1994). The effect of fluconazole prophylaxis on fungal colonization in neutropenic cancer patients. $J$. Antimicrob. Chemother. 33, 309-318.

5. Persons, D. A., Laughlin, M., Tanner, D., Perfect, J., Gockerman, J. P. \& Hathorn, J. W. (1991) Fluconazole and Candida krusei fungemia. N. Engl. J. Med. $325,1315$.

6. Millon, L., Manteaux, A., Reboux, G., Drobacheff, C., Monod, M., Barale, T. \& MichelBriand, Y. (1994) Fluconazole-resistant recurrent oral candidiasis in human immunodeficiency virus-positive patients: persistence of Candida albicans strains with the same genotype. J. Clin. Microbiol. 32, 1115-1118.

7. Morace, G., Manzara, S. \& Dettori, G. (1991) In vitro susceptibility of 119 yeast isolates to fluconazole, 5-fluorocytosine, amphotericin B and ketoconazole. Chemotherapy 37. 23-31.

8. Troke, P. (1993) In vitro and experimental in vivo activities of fluconazole against some fungi causing cutaneous mycoses. In: Rippon, J.W. \& Fromtling, R.A. (eds) Cutaneous antifungal agents. New York: Marcel Dekker, Inc., pp. 199-214.

9. Pfaller, M. A. \& Barry, A. L. (1994) Evaluation of a novel colorimetric broth in microdilution method for antifungal susceptibility testing of yeast isolates. J. Clin. Microbiol. 32. 1992-1996.

10. Lynch, M. E. \& Sobel, J. D. (1994) Comparative in vitro activity of antimycotic agents against pathogenic vaginal yeast isolates. J. Med. Vet. Mycol. 32, 267-274.

11. Odds, F. C. (1991) Quantitative microculture system with standardized inocula for strain typing, susceptibility testing and other physiologic measurements with Candida albicans and other yeasts.J. Clin. Microbiol. 29, 2735-2740.

12. Odds, F. C. (1992) Antifungal susceptibility testing of Candida spp. by relative growth measurement at single concentrations of antifungai agents. Antimicrob. Agents Chemother. 36, 1727-1737.

13. Vanden Bossche, H., Willemsens, G. \& Van Cutsem, J. (1975) The action of miconazole on the growth of Candida albicans. Sabouraudia 13, 63-73. 


\section{Effects of itraconazole on ergosterol synthesis}

14. Vanden Bossche, H., Willemsens, G., Cools, W., Lauwers, W. F. J. \& Le Jeune, L. (1978) Biochemical effects of miconazole on fungi. II. Inhibition of ergosterol biosynthesis in Candida albicans. Chem. Biol. Interact. 21, 59-78.

15. Vanden Bossche, H., Marichal, P., Odds, F. C., Le Jeune, L. \& Coene, M.-C. (1992) Characterization of an azole-resistant Candida glabrata isolate. Antimicrob. Agents Chemother. 36, 2602-2610.

16. Vanden Bossche, H., Marichal, P., Le Jeune, L., Coene, M. C., Gorrens, J. \& Cools, W. (1993) Effects of itraconazole on cytochrome P-450-dependent sterol 14a-demethylation and reduction of 3-ketosteroids in Cryptococcus neoformans. Antimicrob. Agents Chemother. 37, 2101-2105.

17. Vanden Bossche, H., Heeres, J., Backx, L. J. J., Marichal, P. \& Willemsens, G. (1993) Discovery, chemistry, mode of action, and selectivity of itraconazole. In: Rippon, J.W. \& Fromtling, R.A. (eds) Cutaneous antifungal agents. New York: Marcel Dekker, Inc., pp. 263-283.

18. Vanden Bossche, H., Willemsens, G., Marichal, P., Cools, W. \& Lauwers, W. (1984) The molecular basis for the antifungal activities of $\mathrm{N}$-substituted azole derivatives. Focus on R 51211. In: Trinci, A. P. J. \& Ryley, J. F. (eds) Mode of action of antifungal agents. Cambridge, London: Cambridge University Press, pp. 321-341. 



\section{Hypothesis on the mechanism of resistance to fluconazole in}

\section{Histoplasma capsulatum}

Joe wheat,, Patrick Marichal, ${ }^{2}$ Hugo Vanden Bossche, ${ }^{2}$ Ann Le Monte., and Patricia Connolly'

Department of Medicine and Pathology, Indiana University School of Medicine and Department of Veterans'Affairs Hospital, Indianapolis, Indiana. ' and Department of Comparative Biochemistry, Janssen Research Foundarion. Beerse, Belgium²

Running title: fluconazole resistance in Histoplasma capsulatum Antimicrobial Agents and Che'mothe'r(l)!. Feb. 1997, 4I(2). 4I(1)-4I4 


\section{SUMMARY}

An AIDS patient with disseminated histoplasmosis who improved during treatment with fluconazole but remained fungemic and subsequently relapsed is described. Isolates obtained from blood during therapy showed a progressive increase in fluconazole MIC from 0.625 to $20 \mu \mathrm{g} / \mathrm{ml}$. The pretreatment, or parent, isolate and the posttreatment, or relapse, isolate demonstrated identical genetic patterns by PCR fingerprinting with three different primers. Fluconazole was a less potent inhibitor of the growth of the relapse isolate than of the pretreatment isolate $\left(50 \%\right.$ inhibitory concentration $\left[\mathrm{IC}_{50}\right]=11.7 \mu \mathrm{M}$ versus 30.6 $\mu \mathrm{M}$ ), while itraconazole was more potent (relapse isolate $\mathrm{IC}_{50}=0.0011 \mu \mathrm{M}$ versus pretreatment isolate $\mathrm{IC}_{50}=0.0064 \mu \mathrm{M}$ ). Neither the increased sensitivity to itraconazole nor the decreased activity of fluconazole on the growth of the relapse isolate results from changes in the intracellular content of these agents. To reach $50 \%$ inhibition of ergosterol synthesis in both the parent and relapse isolates, about $2 \mathrm{nM}$ itraconazole was needed; with fluconazole, $50 \%$ inhibition was achieved at $20.9 \mu \mathrm{M}$ and $55.5 \mu \mathrm{M}$, respectively. Resistance to fluconazole may develop during treatment and results from decreased sensitivity of ergosterol synthesis. 
Fluconazole resistance in Histoplasma capsulatum

\section{INTRODUCTION}

Disseminated histoplasmosis is a progressive fatal infection in patients with AIDS. Although treatment is effective, recurrence is common, mandating chronic antifungal suppression to prevent relapse. Amphotericin B is the most effective therapy and the treatment of choice for more severe cases (12). Itraconazole was effective therapy for patients with mild or moderate clinical manifestations, inducing remission in $85 \%$ of cases (10). Itraconazole also was highly effective as maintenance therapy, preventing relapse in $95 \%$ of patients $(10,11)$. High-dose treatment with fluconazole $(800 \mathrm{mg}$ daily) induced remission in $74 \%$ of patients, but nearly one-third relapsed during maintenance treatment with $400 \mathrm{mg}$ daily (13).

The poorer response to fluconazole may be caused by reduced in vitro activity for $H$. capsulatum. Treatment failure may have been caused by development of resistance during therapy in some patients. In this report we describe mechanisms for acquired resistance in isolates from one of these patients.

\section{Case Report}

A 39-year-old human immunodeficiency virus-infected male presented with a 4week history of fever, cough, dyspnea, and weight loss. Abnormal physical findings included a temperature of $37.8^{\circ} \mathrm{C}$ and mild tachypnea (respiratory rate, $24 / \mathrm{min}$ ). Chest radiograph showed diffuse interstitial infiltrates. Laboratory abnormalities included a hemoglobin of $9.1 \mathrm{~g} / \mathrm{dl}, \mathrm{pO}_{2}$ of $65 \mathrm{~mm} \mathrm{Hg}$, alkaline phosphatase of $309 \mathrm{IU} / \mathrm{dl}$, aspartate aminotransferase of $128 \mathrm{IU} / \mathrm{dl}$, and albumin of $3.1 \mathrm{~g} / \mathrm{dl}$. The presumptive diagnosis of histoplasmosis was made when organisms resembling $H$. capsularum var. capsularum were seen by fungal stain of bronchoalveolar lavage fluid and subsequently proven by isolation from the lavage fluid and blood.

Treatment was started with fluconazole $(600 \mathrm{mg}$ daily) through an investigational protocol (AIDS Clinical Trials Group 174/Mycoses Study Group 23 protocol). The patient defervesced and gained $5 \mathrm{~kg}$ over the next 2 months. However, one colony of $H$. capsulatum var. capsulatum was isolated from protocol-mandated blood cultures taken at weeks 8 and 12 of therapy. 
At week 16 , fever to $39.4^{\circ} \mathrm{C}$ recurred, and examination revealed splenomegaly. Blood cultures now grew numerous colonies of $H$. capsulatum var. capsulatum. Fluconazole serum concentration was $37.4 \mu \mathrm{g} / \mathrm{ml}$. Fluconazole was discontinued, and amphotericin B (50 mg) was started daily for two weeks and every other day for another 6 weeks, followed once weekly for 4 months. Maintenance treatment was changed to itraconazole ( $200 \mathrm{mg}$ twice daily) for an additional 2 years without recurrence of histoplasmosis or isolation of $H$. capsulatum var. capsulatum from cultures.

\section{MATERIALS AND METHODS}

\section{MIC determination.}

Susceptibility was measured by the standardized method for yeasts developed by the National Committee for Clinical Laboratory Standards (1) modified for $H$. capsulatum by extending the incubation to 96 to $144 \mathrm{~h}$. Yeast cells were suspended in sterile normal saline and adjusted to a $5 \mathrm{McFarland}$ standard spectrophotometrically at $A_{530}$. Yeast suspensions were diluted 1/100 in RPMI 1640 medium containing $\mathrm{L}$-glutamine and buffered to $\mathrm{pH} 7.0$ with $0.165 \mathrm{M}[3-(\mathrm{N}$ morpholino)propane sulfonic acid] (MOPS) (Whittaker MA Bioproducts). Stock solutions of drugs were made at the following concentrations: amphotericin B, fluconazole, and ketoconazole, $16 \mathrm{mg} / \mathrm{ml}$ in dimethyl sulfoxide (DMSO); itraconazole, $5 \mathrm{mg} / \mathrm{ml}$ in polyethylene glycol $\left(\mathrm{M}_{\mathrm{r}}=200\right)$. Dilutions of these stocks in RPMI were dispensed in tubes ( 12 by $75 \mathrm{~mm}$ ) and the test organisms were added. After 96 to $144 \mathrm{~h}$, depending upon the turbidity in the drugfree control, MICs were determined visually. The MIC was defined as the concentration of drug at which at least $80 \%$ growth inhibition occurred.

\section{Culture methods.}

H. capsulatum isolates were maintained on GY (glucose-yeast extract-L-cysteine-agar, $2 \%-1 \%-0.06 \%-2 \%$ ) slants at $37^{\circ} \mathrm{C}$ for the experiments measuring protein and sterol content and sterol synthesis (7). A loopful from a week-old slant was inoculated in $100 \mathrm{ml}$ of GY medium (glucose-yeast extract-L-cysteine, 


\section{Fluconazole resistance in Histoplasma capsulatum}

$2 \%-1 \% 0.03 \%$ ) containing $20 \mathrm{U}$ of penicillin and $40 \mu \mathrm{g}$ of streptomycin per $\mathrm{ml}$ and cultivated in $500-\mathrm{ml}$ Erlenmyer flasks at $37^{\circ} \mathrm{C}$ for 1 week in a reciprocal shaker. Aliquots $(0.5 \mathrm{ml})$ of this culture were used to inoculate $100 \mathrm{ml}$ of GY medium in 500-ml Erlenmeyer flasks. Cells were grown at $37^{\circ} \mathrm{C}$ aerobically in a reciprocating shaker for $72 \mathrm{~h}$.

To evaluate the effects of itraconazole and fluconazole on growth, the azole derivatives and/or solvent (DMSO [final concentration, $0.1 \%$ ]) were added to the GY medium prior to inoculation with $0.5-\mathrm{ml}$ aliquots of the above-described culture (7). After $48 \mathrm{~h}$ of growth at $37^{\circ} \mathrm{C}$ in a reciprocating shaker, cells were collected by centrifugation and washed twice in physiological saline. The pellet was suspended in $3 \mathrm{ml}$ of water and added to $2 \mathrm{~g}$ of glass beads (diameter, $0.45 \mathrm{~mm}$ ). Cells were shaken vigorously for 20 cycles of $4 \mathrm{~s}$ with $26-\mathrm{s}$ intermittent cooling. The homogenate was separated quantitatively from the glass beads and diluted to $15 \mathrm{ml} \mathrm{(7).} \mathrm{Protein} \mathrm{content} \mathrm{of} \mathrm{the} \mathrm{homogenates} \mathrm{was} \mathrm{deter-}$ mined by the Biorad method, with bovine albumin used as the standard.

\section{Sterol synthesis.}

To study sterol biosynthesis in $H$. capsulatum, $100 \mathrm{ml}$ of GY medium was supplemented with $5 \mu \mathrm{Ci}$ of $\left[{ }^{14} \mathrm{C}\right]$ acetate (specific activity, $58 \mu \mathrm{Ci} / \mathrm{mmol}$ ) and different concentrations of azole antifungal and/or DMSO immediately before inoculation. Inoculation, growth conditions, cell harvest, and homogenization were as described above. The homogenate was supplemented with an equal volume of $15 \% \mathrm{KOH}$ in $90 \%$ ethanol. The mixture was heated for $1 \mathrm{~h}$ at $85^{\circ} \mathrm{C}$ in a water bath and cooled, and the nonsaponifiable lipids were extracted with I volume of $\mathrm{n}$-heptane (Spectrograde). Total radioactivity in the heptane extract was determined by liquid scintillation counting with Opti-phase (Pharmacia) as a scintillant (7). The ergosterol content of the heptane extracts of cell homogenates was determined by measuring the absorption difference between 292 and $282 \mathrm{~nm}$. An ergosterol standard curve was used to calculate the ergosterol contents. To separate, quantify, and identify the sterols, the heptane extracts were dried under a stream of nitrogen and dissolved in minimal volumes of methanol-water (95:5). Sterols were separated by high-performance liquid chromatography (HPLC) on a Varian 9010 liquid chromatograph equipped with 
a Varian 9095 automatic injector, a Varian 9065 Polychrom Detector, and a Berthold LB507 HPLC radioactivity monitor with Pico Aqua (Canberra Packard) as a scintillant and connected with a Compaq 386/33 computer (8). Sterols were identified according to their retention times relative to those of standards and/or by gas chromatographic-mass spectrometric analysis (8).

\section{Intracellular content.}

Cells were grown for $24 \mathrm{~h}$ (exponential phase) in 500-ml Erlenmeyer flasks, containing $100 \mathrm{ml}$ of GY medium, in a reciprocating shaker at $37^{\circ} \mathrm{C}$. To these cultures, $300 \mathrm{nM}\left[{ }^{3} \mathrm{H}\right]$ itraconazole (specific activity, $15.0 \mathrm{mCi} / \mathrm{mmol}$; Janssen Research Foundation) or $300 \mathrm{nM}\left[{ }^{14} \mathrm{C}\right]$ fluconazole (specific activity, 4.81 $\mathrm{mCi} / \mathrm{mmol}$; gift from Pfizer Central Research Sandwich United Kingdom) were added. After $1 \mathrm{~h}$ of incubation at $37^{\circ} \mathrm{C}$, cells were collected by centrifugation and washed three times with ice-cold saline containing $10 \mu \mathrm{M}$ unlabelled azole. Cells were homogenized as described above, and the homogenates were digested with hydrogen peroxide-perchloric acid (4), and the radioactivity was determined as described previously (5).

\section{PCR.}

The isolates were grown in the mould phase in potato dextrose broth (Difco Laboratories, Detroit, Mich.). The mould cultures were ground under liquid nitrogen to degrade the cellular structure and release the nucleic acids. The isolates were further lysed in $50 \mathrm{mM}$ Tris $62.5 \mathrm{mM}$ EDTA-2\% sodium dodecyl sulfate. The lysates were then purified through cesium chloride gradients and phenol-chloroform-isoamyl alcohol extractions. The purified DNA was checked for concentration by agarose gel electrophoresis prior to amplification. Three distinct primers previously shown to have high discriminatory power for Histoplasma ( $\geq 27 \mathrm{nt}$ ) were used (3). Sequences for the primers were as follows: H1, GGCCATAGAGTCTTGCAGACAAACTGC; H2, AACGTTCATGATAACTTCTGCTCTTCATCG; H3, AAGCTTGCATTTGTGTTCCTTGATAAGTG. The amplification was performed in a 9600 thermocycler (Perkin Elmer) by using standard PCR mixes. Agarose gel electrophoresis was performed in a $1.3 \%$ gel at $70 \mathrm{~V}$ for $4 \mathrm{~h}$ and visualized with $8 \mu \mathrm{l}$ of ethidium 
bromide at $10 \mathrm{mg} / \mathrm{ml}$. The DNA bands were visualized and photographed under UV light.

\section{RESULTS}

\section{MICs.}

Numerous colonies were present at base line, but only a single colony was noted at weeks 8 and 12 of therapy, when the patient appeared to be improving clinically. Numerous colonies again were isolated at relapse at week 16 , suggesting that the isolate had become resistant to fluconazole. Fluconazole MICs were $0.62 \mu \mathrm{g} / \mathrm{ml}$ for the pretreatment isolate (parent isolate), $1.25 \mu \mathrm{g} / \mathrm{ml}$ at week $8,2.5$ $\mu \mathrm{g} / \mathrm{ml}$ at week 12 , and $20 \mu \mathrm{g} / \mathrm{ml}$ at week 16 (relapse isolate). Itraconazole MICs were $0.004 \mu \mathrm{g} / \mathrm{ml}$ for all isolates. The fluconazole blood concentration on a specimen taken during the last week of therapy was $37.4 \mu \mathrm{g} / \mathrm{ml}$.

\section{PCR fingerprinting.}

PCR fingerprinting with three random primers showed identical amplification patterns for the pretreatment and the relapse isolate (Fig. la). The patterns were different from those obtained with several unrelated $H$. capsulatum strains. Results using primer 3 are shown in Fig. $1 \mathrm{~b}$. This indicates that the parent and the relapse isolate are clonal.

\section{Effects of itraconazole and fluconazole on growth and ergosterol content.} Growth was measured by determining the protein content of cells collected after $48 \mathrm{~h}$ of growth in the presence of fluconazole or itraconazole. Compared with its effect on growth of the pretreatment (parent) isolate (50\% inhibitory concentration $\left[\mathrm{IC}_{S_{0}}\right]=11.7 \mu \mathrm{M}$ [or $38.4 \mu \mathrm{g} / \mathrm{ml}$ based on a molecular weight of $306 ; 1$ $\mu \mathrm{M}=0.3 \mu \mathrm{g} / \mathrm{ml}]$ ), fluconazole was a three-times less-potent inhibitor of the growth of the relapse isolate $\left(\mathrm{IC}_{50}=30.6 \mu \mathrm{M}[100 \mu \mathrm{g} / \mathrm{ml}]\right.$ ) (Fig. 2). However, itraconazole was a six-times more-potent growth inhibitor of the relapse isolate $\left(\mathrm{IC}_{50}=0.0011 \mu \mathrm{M}[0.0016 \mu \mathrm{g} / \mathrm{ml}\right.$ based on a molecular weight of $705: 1 \mu \mathrm{M}=$ $0.7 \mu \mathrm{g} / \mathrm{ml}]$ ) than of the pretreatment isolate ( IC $_{50}=0.0064 \mu \mathrm{M}[0.009$ $\mu \mathrm{g} / \mathrm{ml}]$ ).Similar results were found when ergosterol content was measured spec- 

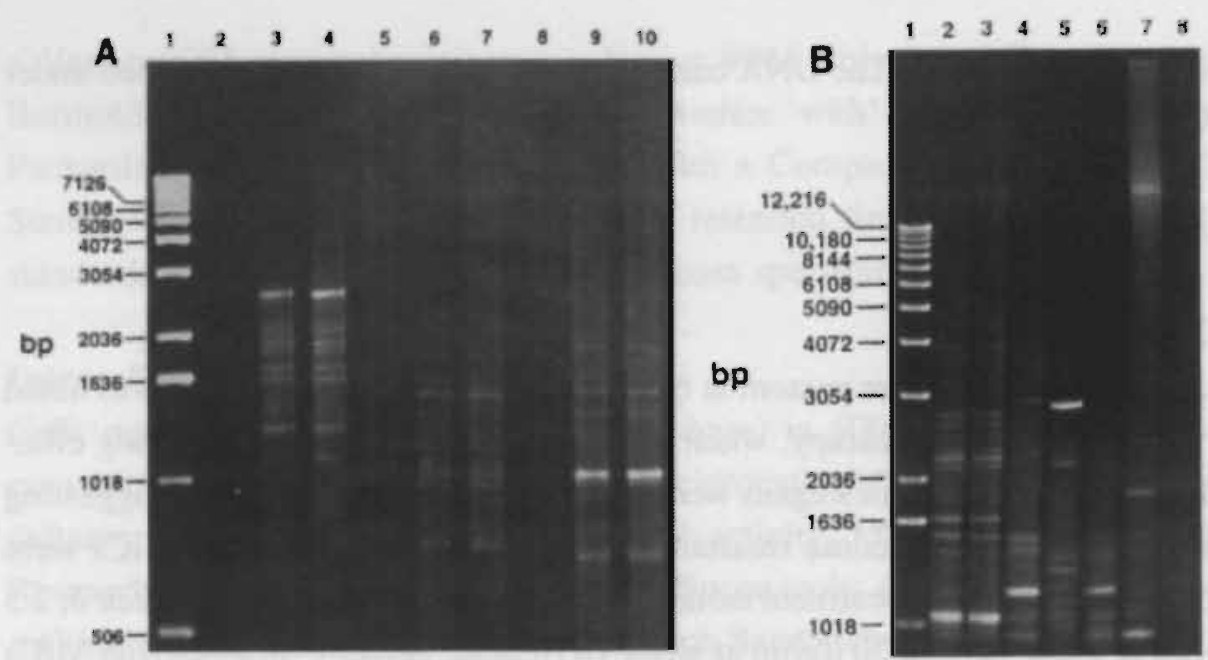

FIG. 1.

(A) PCR of the patient's parent and relapse isolates with primer 1 (lanes3 and 4), primer 2 (lanes 6 and 7), and primer 3 (lanes 9 and 10).

(B) PCR amplification pattern for the patient's baseline isolate and standard control strains of $H$. capsulatum var. capsulatum with primer 3 . Lanes: 1 , molecular weight markers; 2 through 8 , DNA from the patient's parent isolate (lane 2) and relapse isolate (lane 3 ) and from control isolates G217b (lane 4), G186 (lane 5), G184 (lane 6), G222 (lane 7), and Downs (lane 8); $9, \mathrm{H}: \mathrm{O}$ blank.

trophotometrically (Fig. 2). A 50\% decrease in ergosterol content of the relapse isolate required $0.001 \mu \mathrm{M}$ itraconazole $(0.0014 \mu \mathrm{g} / \mathrm{ml})$, whereas $0.0048 \mu \mathrm{M}$ $(0.0068 \mu \mathrm{g} / \mathrm{ml})$ was needed to reach a $50 \%$ decrease of the ergosterol content of the pretreatment isolate. With fluconazole the $\mathrm{IC}_{50}$ was five times higher for the relapse isolate $\left(\mathrm{IC}_{50}=25.8 \mu \mathrm{M}[84.3 \mu \mathrm{g} / \mathrm{ml}]\right)$ than for the pretreatment isolate $\left(\right.$ IC $\left._{50}=5.3 \mu \mathrm{M}[17.3 \mu \mathrm{g} / \mathrm{ml}]\right)$.

\section{Effects on ergosterol biosynthesis.}

Ergosterol and ergosta-5, 22-diene-3- $\beta$-ol are the main sterols formed from $\left[{ }^{14} \mathrm{C}\right]$ acetate in both parent and relapse isolates (Fig. 3). In the pretreatment isolate, itraconazole was a more potent inhibitor of ergosterol synthesis than fluconazole ( $\mathrm{IC}_{\mathrm{s0}}=0.0017 \mu \mathrm{M}[0.002 \mu \mathrm{g} / \mathrm{ml}]$ versus $20.9 \mu \mathrm{M}[68.3 \mu \mathrm{g} / \mathrm{ml}]$, respectively). In the relapse strain, whereas $0.0018 \mu \mathrm{M}$ itraconazole $(0.0025 \mu \mathrm{g} / \mathrm{ml})$ continued to inhibit ergosterol synthesis by $50 \%$, the $\mathrm{IC}_{50}$ of fluconazole rose to 


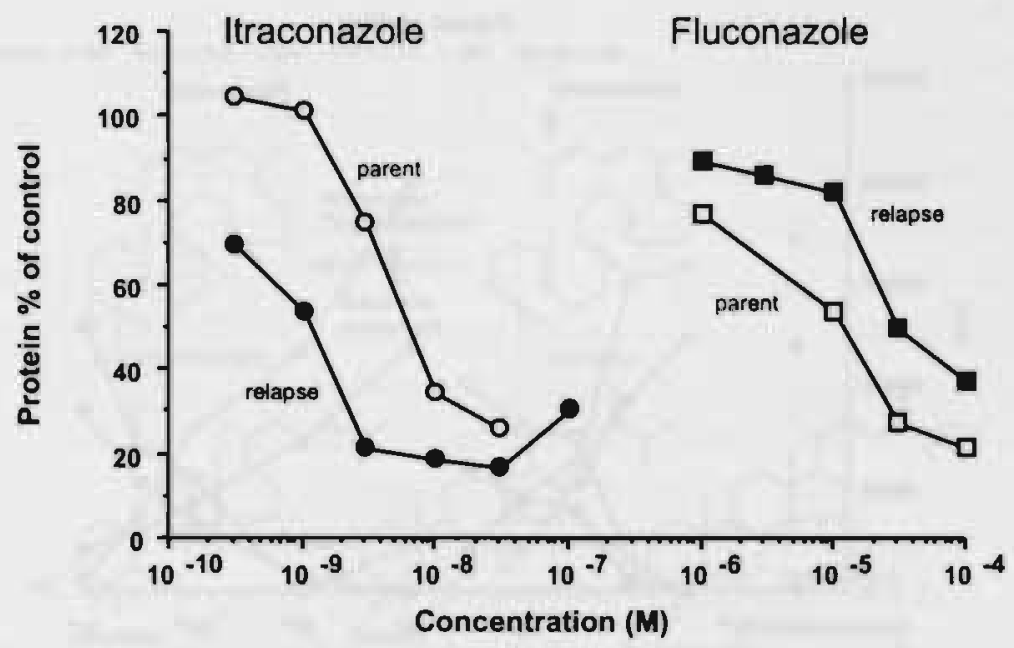

Itraconazole

Fluconazole

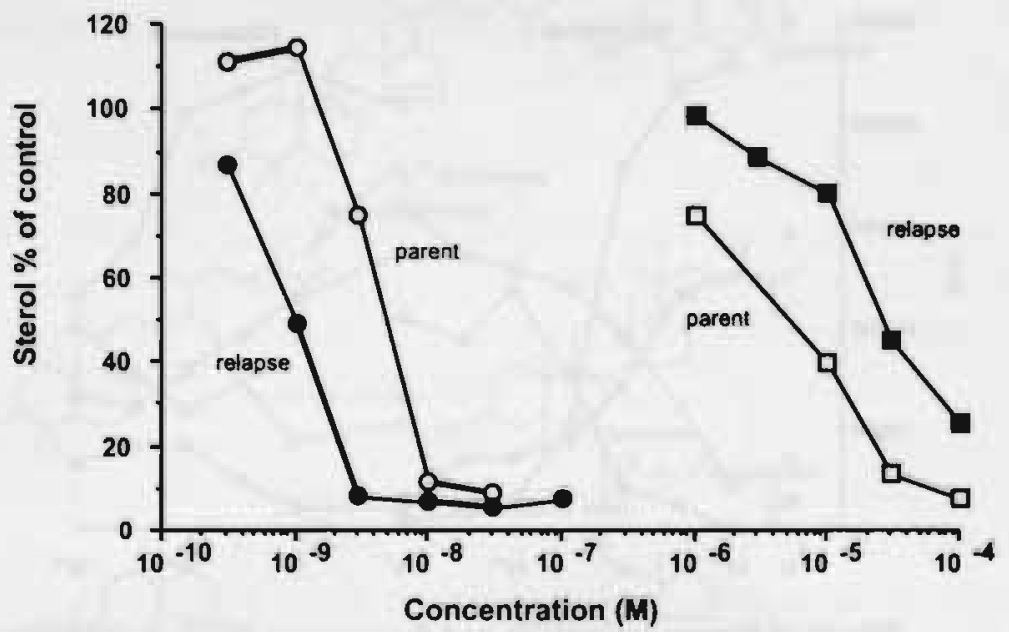

FIG. 2. Effects of fluconazole and itraconazole on the protein and ergosterol content of parent and relapse isolates. Growth of $H$. capsulatum was measured by determining the protein content of cells collected after $48 \mathrm{~h}$ of growth in the presence of fluconazole or itraconazole. Ergosterol was measured by UV spectroscopy of parent and relapse isolates grown for 48 h. 

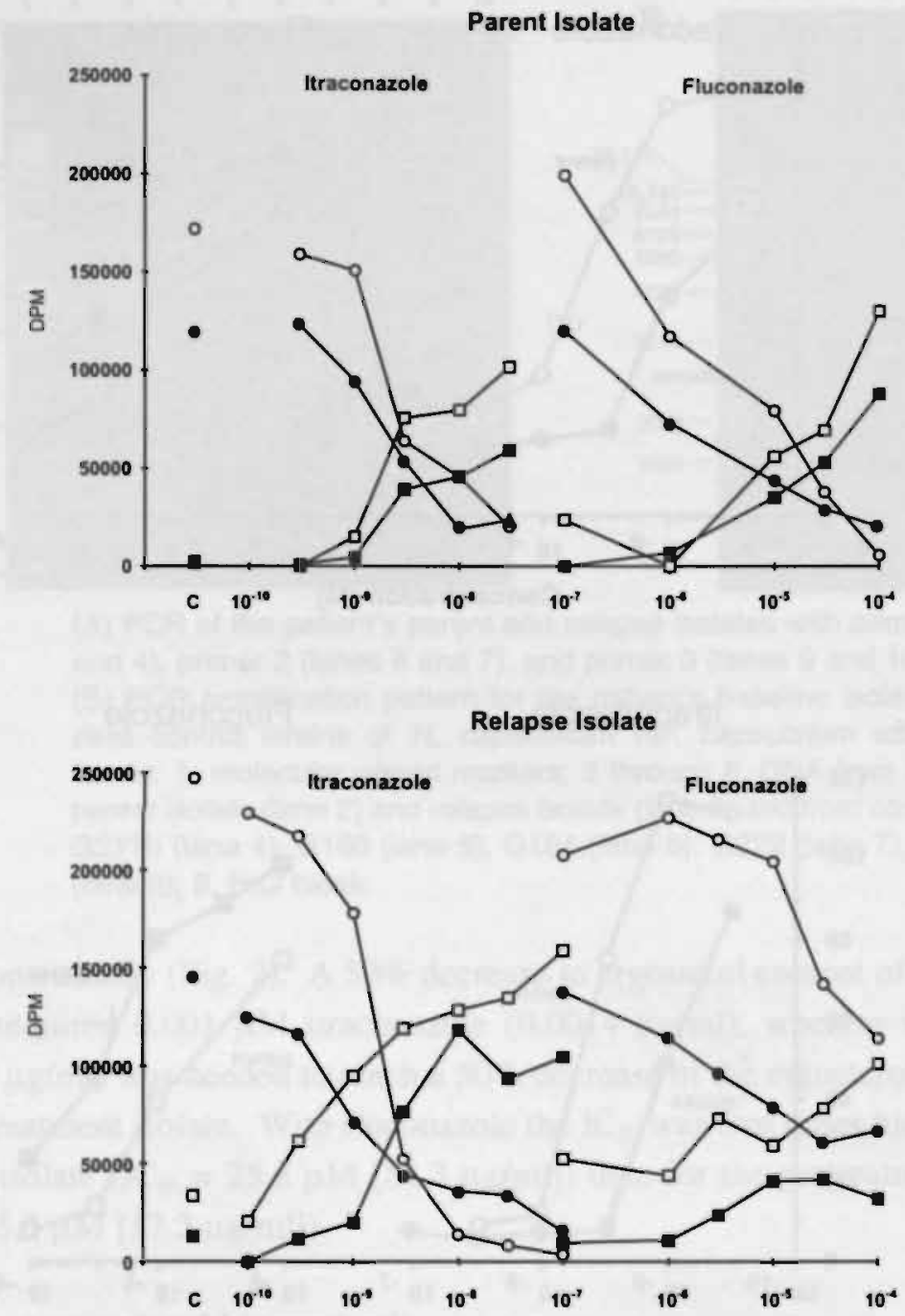

FIG. 3. Effects of itraconazole (ITZ) and fluconazole (FCZ) on ergosterol synthesis from $\left[{ }^{14} \mathrm{C}\right]$ acetate by the patent and relapse isolate. Time of incubation was $48 \mathrm{~h}$ in GY medium. Drug and $\left[{ }^{14} \mathrm{C}\right]$ acetate were added immediately before inoculation. Sterols formed are: ergosterol (O), ergosta-5, 22diene-3-ol (๑), obtusifolione $(\square)$, and eburicol (24-methylene-dibydrolanosterol) (ם). Results for controls (ergosterol synthesis in the presence of solvent DMSO) are depicted inside the left-hand margin by the datum points that are not connected by lines. Results are mean values from four experiments. 


\section{Fluconazole resistance in Histoplasma capsulatum}

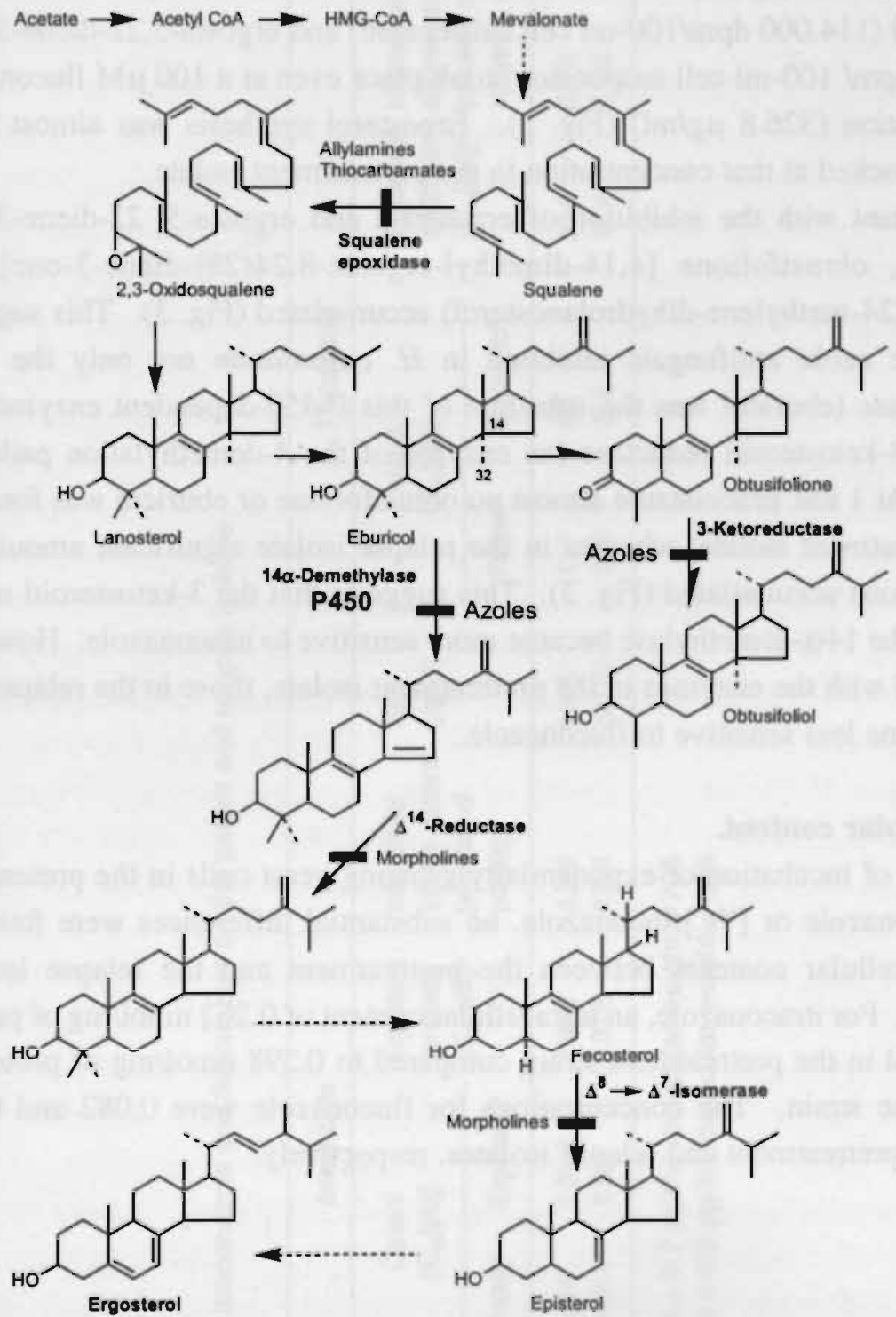

FIG. 4. Ergosterol biosynthesis pathway. Azole antifungals inhibit the cytochromeP-450 dependent $14 \alpha$-demethylase. This coincides with the accumulation of lanosterol, eburicol, and obtusifoliol. In H. capsulaturn the 3-ketosteroid obtusifolione also accumulates. From Vanden Bossche et al., Trends in Microbiology, 1994, with permission of the publisher (9). 
$55.4 \mu \mathrm{M}(181.0 \mu \mathrm{g} / \mathrm{ml})$. In the relapse isolate, substantial synthesis of both ergosterol (114,000 dpm/100-ml cell suspension) and ergosta-5,22-diene-3- $\beta$-ol ( $67,000 \mathrm{dpm} / 100-\mathrm{ml}$ cell suspension) took place even at a $100 \mu \mathrm{M}$ fluconazole concentration (326.8 $\mu \mathrm{g} / \mathrm{ml}$ ) (Fig. 3). Ergosterol synthesis was almost completely blocked at that concentration in the pretreatment isolate.

Concomitant with the inhibition of ergosterol and ergosta-5, 22-diene-3- $\beta$-ol synthesis, obtusifolione [4,14-dimethyl-ergosta-8,24(28)-diene-3-one] and eburicol (24-methylene-dihydrolanosterol) accumulated (Fig. 3). This suggests that these azole antifungals inhibited in $H$. capsulatum not only the $14 \alpha$ demethylase (eburicol was the substrate of this P-450-dependent enzyme) but also the 3-ketosteroid reductase (an enzyme of the 4-demethylation pathway; Fig. 4). At $1 \mathrm{nM}$ itraconazole almost no obtusifolione or eburicol was found in the pretreatment isolate, whereas in the relapse isolate significant amounts of obtusifolione accumulated (Fig. 3). This suggests that the 3-ketosteroid reductase and the $14 \alpha$-demethylase became more sensitive to itraconazole. However, compared with the enzymes in the pretreatment isolate, those in the relapse isolate became less sensitive to fluconazole.

\section{Intracellular content.}

After $1 \mathrm{~h}$ of incubation of exponentially growing yeast cells in the presence of $\left[{ }^{3} \mathrm{H}\right]$ itraconazole or $\left[{ }^{14} \mathrm{C}\right]$ fluconazole, no substantial differences were found in the intracellular contents between the pretreatment and the relapse isolates (Table 1). For itraconazole, an intracellular content of $0.262 \mathrm{nmol} / \mathrm{mg}$ of protein was found in the pretreatment strain compared to $0.298 \mathrm{nmol} / \mathrm{mg}$ of protein in the relapse strain. The concentrations for fluconazole were 0.082 and 0.103 nmol for pretreatment and relapse isolates, respectively. 
TABLE 1. Effect of itraconazole and fluconazole on the parent and relapse isolates

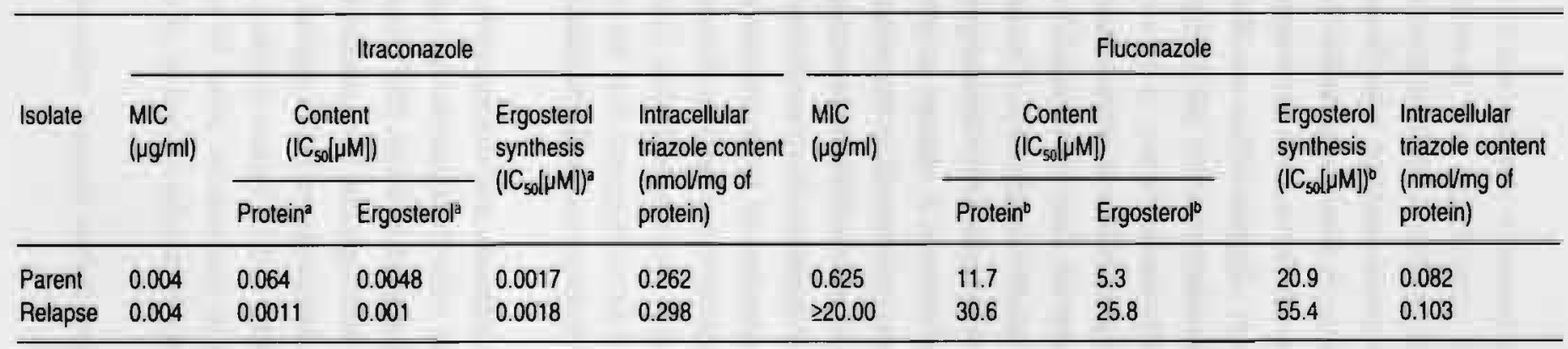

Itraconazole: $1 \mu \mathrm{M}=0.7 \mu \mathrm{g} / \mathrm{ml}$; molecular weight $=705$

"Fluconazole: $1 \mu \mathrm{M}=0.3 \mu \mathrm{g} / \mathrm{ml}$; molecular weight $=306$ 


\section{DISCUSSION}

Fluconazole is a less effective treatment for histoplasmosis than is amphotericin $\mathrm{B}$ or itraconazole. Relapse is more common with fluconazole than with amphotericin B or itraconazole (11a). A likely reason for fluconazole's inferior efficacy in histoplasmosis appears to have been its reduced antifungal activity for H. capsulatum var. capsulatum. Typical MICs are 50-fold higher with tluconazole $(0.62$ to $1.25 \mu \mathrm{g} / \mathrm{ml})$ than itraconazole $(\leq 0.019 \mu \mathrm{g} / \mathrm{ml})$ (14). Also, resistance may arise during fluconazole therapy.

One possible cause for the higher MICs of pretreatment isolates of $\mathrm{H}$. capsulatum var. capsulatum to fluconazole than itraconazole is reduced uptake or more rapid efflux of fluconazole from the fungal cell. The intracellular content of fluconazole was threefold lower than that of itraconazole in the pretreatment and relapse isolates (Table 1). However, a change in intracellular content of fluconazole or itraconazole was not observed in the relapse isolate as compared to the pretreatment isolate. Thus, neither the increased susceptibility to itraconazole nor the decreased susceptibility to fluconazole in the relapse isolate results from changes in intracellular content of these triazole antifungal agents.

Reduced susceptibility of ergosterol synthesis to fluconazole appears to explain the inducible resistance noted in the relapse isolate (Table 1). Reduced accumulation of eburicol and obtusifolione suggests that the cytochrome P-450-dependent $14 \alpha$-demethylase and 3-ketosteroid reductase became less sensitive to fluconazole.

Cross resistance between fluconazole and itraconazole was not observed. Of 16 patients who failed treatment with fluconazole in a clinical trial, MICs to fluconazole increased at least fourfold in $9(56.2 \%)$ failure isolates. Itraconazole MICs remained $\leq 0.019 \mathrm{mg} / \mathrm{ml}$ in all but one of these failure isolates and was $0.077 \mu \mathrm{g} / \mathrm{ml}$ in that isolate. MICs above $0.077 \mu \mathrm{g} / \mathrm{ml}$ to itraconazole were not observed in 67 primary isolates and 16 failure isolates tested, including 10 failure isolates for which MICs to fluconazole were $10 \mu \mathrm{g} / \mathrm{ml}$ or more. This disparity highlights the difference in modes of action of itraconazole and fluconazole.

Interestingly, while the relapse isolate showed reduced antifungal activity with 
fluconazole, the activity of itraconazole was even greater (Table 1 ). The $\mathrm{IC}_{\mathrm{S}_{0}}$ for protein and ergosterol content was significantly lower for the relapse than the pretreatment isolate, as was that for ergosterol synthesis. Induction of large amounts of obtusifolione by low concentrations of itraconazole in the relapse isolate suggests that the 3-ketosteroid reductase of the relapse isolate is more susceptible to itraconazole than is that of the parent isolate. Since 3-ketosteroids, such as obtusifolione, may destabilize the lipid bilayer and increase the fragility of membranes $(2,6)$, the increased amounts of obtusifolione formed in the relapse isolate incubated in the presence of itraconazole may explain the enhanced sensitivity to this triazole derivative.

In conclusion, this case illustrates the risk for relapse of histoplasmosis during treatment with fluconazole. Acquisition of resistance to fluconazole caused by reduced sensitivity of ergosterol synthesis appears to be responsible for the increased MIC of the relapse isolate. Cross resistance did not occur with itraconazole. Additional studies are needed to elucidate the mechanism of fluconazole resistance. Investigation of the effects on P-450-dependent $14 \alpha$-demethylase and 3-ketosteroid reductase will establish the role of these Histoplasma enzymes in the mechanism of action and development of resistance to these azole derivatives.

\section{ACKNOWLEDGMENTS}

This work was supported by grants from the National Institutes of Health AIDS Clinical Trials Group (grant no. A125859-09) and General Clinical Research Center (grant no. MOIRR00750) and Mycoses Study Group (grant no. Nôl-AI15082) of the National Institute of Allergy and Infectious Diseases and The Department of Veteran's Affairs. We appreciate the excellent technical assistance of Mr. J. Gorrens. 


\section{REFERENCES}

1. Fromtling, R A, J. N. Galgiani, M. A. Pfaller, A. Espinel-Ingroff, K. F. Bartizal, M. S. Bartlett, B. A. Body, C. Frey, G. Hall, G. D. Roberts, F. B. Nolte, F. C. Odds, M. G. Rinaldi, A. M. Sugar, and K. Villareal. 1993. Multicenter evaluation of a broth macro-dilution antifungal susceptibility test for yeasts. Antimicrob. Agents Chemother. 37:39 45 .

2. Galley, J., and B. De Kruiff. 1982. Correlation between molecular and hexagonal $\mathbf{H}_{11}$ phase promoting ability of sterols. FEBS Lett. 143:133-143.

3. Kersulyte, D., J. P. Woods, E. J. Keath, W. E. Goldman, and D. E. Berg. 1992. Diversity among clinical isolates of Histoplasma capsulatum detected by polymerase chain reaction with arbitrary primers. J. Bacteriol. 174:7075-7079.

4. Mahin, D. T., and R. T. Lofoerg. 1966. A simplified method of sample preparation for determination of tritum, carbon 14 or sulfur 35 in blood or tissue by liquid. scintillation counting. Anal. Biochem. 16:500-509.

5. Marichal, P., J. Gorrens, M.-C. Coene, L. Le Jeune, and H. Vanden Bossche. 1995. Origin of differences in susceptibility of Candida krusei to azole antifungal agents. Mycoses 38:111-117.

6. Vanden Bossche, H., L. Koymans, and H. Moereels. 1995. P450 inhibitors of use in medical treatment: focus on mechanisms of action. Pharmacol. Ther. 67:79-100.

7. Vanden Bossche, H., P. Marichal, J. Gorrens, D. Bellen, M.-C. Coene, W. Lauwers, L. Le Jeune, H. Moereels, and P. A. J. Janssen. 1990. Mode of action of antifungals of use in immunocompromised patients, p. 223-243. In H. Vanden Bossche, D. W. R. MacKenzie, G. Cauwenbergh, J. Van Cutsem, E. Drouhet, and B. Dupont (ed.), Mycoses. in AIDS patients. Plenum Press, New York, N.Y.

8. Vanden Bossche, H., P. Marichal, L. Ie Jeune, M.-C. Coene, J. Gorrens, and W. Cools. 1993. Effects of itraconazole on cytochrome P-450-dependent sterol $14 \alpha$-demethylation and reduction of 3-ketosteroids in Cryptococcus neoformans. Antimicrob. Agents. Chemother. 37:2101-2105.

9. Vanden Bossche, H., P. Marichal, and F. C. Odds. 1994. Molecular mechanisms of drug resistance in fungi. Trends Microbiol. 2:393-400.

10. Wheat, J., R. Hatner, A. H. Korzan, M. T. Linjoco, P. Spencer, R A. Larsen, F. M. Hecht, W. Powderly, and AIDS Clinical Trial Group. 1995. Itraconazole treatment of disseminated histoplasmosis in patients with the acquired immunodeficiency syndrome. Am. J. Med. 98:336 342. 
11. Wheat, J., R. Hafner, M. Wulfsohn, P. Spencer, K. Squires, W. Powderly, B. Wong, M. Rinaldi, M. Saag, R. Hamill, R Mnrphy, P. Connolly-Stringfield, N. Briggs, S. Owens, and NIAID Clinical Trials \& Mycoses Study Group Collaborators. 1993. Prevention of relapse histoplasmosis with itraconazole in patients with the acquired immunodeficiency syndrome. Ann. Intern. Med. 118:610 616.

11a. Wheat, J. 1996. Unpublished data.

12. Wheat, L. J P. A. Connolb-Stringfield, R L. Baker, M. F. Curtman, M. E. Eads, K. S. Israel, S. A. Norris, D. H. Webb, and M. L. Zeckel. 1990. Disseminated histoplasmosis in the acquired immune deficiency syndrome: clinical findings, diagnosis and treatment, and review of the literature. Medicine 69:361-374.

13. Wheat, L., S. Mawhinney, R Hahner, and D. McKinsey. 1994. Fluconazole treatment for histoplasmosis in AIDS: prospective multicenter non-comparative trial, abstr. 1233, p. 214. In Abstracts of the 34th Interscience Conference on Antimicrobial Agents and Chemotherapy. American Society for Microbiology, Washington, D.C.

14. Wheat, L. J. 1996. Unpublished data. 



\section{General discussion and summary}


The aim of the present study was to gain more insights into the mode of action and resistance mechanisms to azole antifungal compounds. The MIC value was used almost exclusively to select isolates for biochemical studies, regardless of the consideration that clinical resistance (treatment failure) is likely to result from multifactorial events, many of which are not related to resistance in the pathogen. The NCCLS antifungal sub-committee has formulated a reference method with good inter- and intra-laboratory reproducibility. This reference method facilitates direct comparison of results between different studies. According to this methodology, MIC values obtained for azoles tend to show a wide distribution among isolates. In FIG. 1 such a distribution is shown for fluconazole and itraconazole against $C$. albicans isolates. The cumulative data presented were taken from three studies $(2,16,17)$.

According to Rex et al. interpretive breakpoints divide the MIC range into three regions, susceptible (S) , susceptible dose-dependent (SDD) and resistant (R) (17). For fluconazole, breakpoints are set at $\leq 8 \mu \mathrm{g} / \mathrm{ml}$ for susceptible isolates whereas isolates with $\mathrm{MIC}>32 \mu \mathrm{g} / \mathrm{ml}$ are regarded as fluconazole resistant (FIG. 1). For isolates with intermediate susceptibility, higher than standard doses of fluconazole are recommended for treatment of patients. For itraconazole the breakpoints are set at $0.125 \mu \mathrm{g} / \mathrm{ml}$ for susceptible isolates, $0.25-0.5 \mu \mathrm{g} / \mathrm{ml}$ for dose-dependent susceptibility and $>0.5 \mu \mathrm{g} / \mathrm{ml}$ for resistant isolates (FIG. 1). These breakpoints are, however, only weakly predictive of clinical non-response as summarized by Odds (14) and Rex et al. (17). Indeed in a review article Odds summarized clinical treatment outcomes for fluconazole and itraconazole. About $90 \%$ of the patients colonized with susceptible isolates were successfully treated with fluconazole (498 out of 547 patients, $91 \%$ ) or itraconazole (174 out of 195 patients, $89 \%$ ). The success rate in patients colonized with either dosedependent susceptible (DDS) isolates or resistant (R) isolates was lower, but still $62 \%$ and $41 \%$ of the patients carrying DDS or R strains responded to fluconazole treatment and respectively $64 \%$ and $56 \%$ in the case of itraconazole. From these results it can be concluded that roughly one out of two patients colonized with resistant isolates can still be successfully treated with an azole compound and that one out of ten patients suffering from infection with a susceptible isolate does not respond to this treatment. A similar trend was recently reported by 

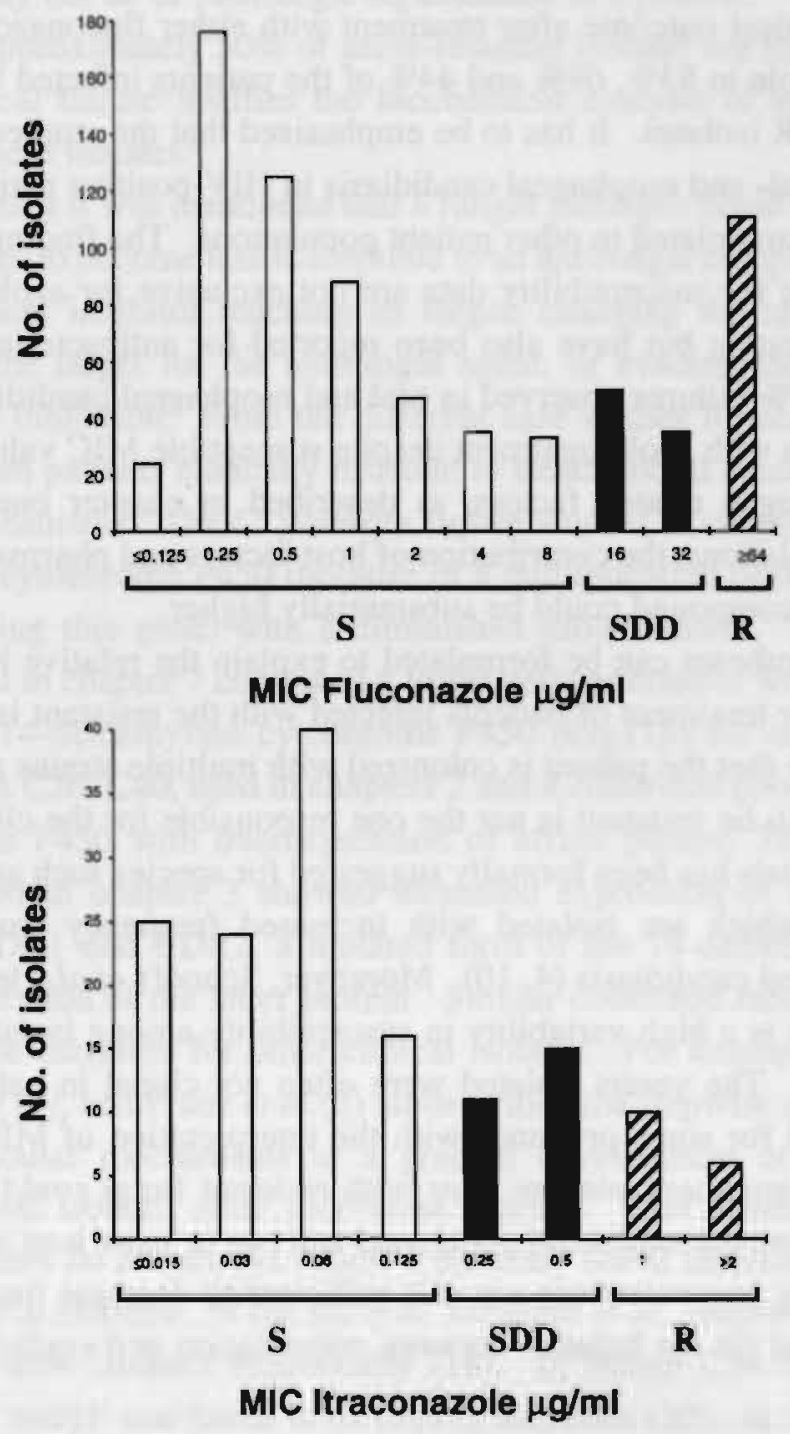

FIG. 1. Histogram of the distribution of MIC values obtained for fluconazole and itraconazole according to the NCCLS reference methodology. Results were taken from Barchiesi et al. (2), Quereda et al. (16), and from Rex et al. (17). At the bottom of the hislogram, the NCCLS interpretative breakpoints are indicated : $S=$ sensitive, $S D D=$ sensitive, dose-dependent, and $\mathrm{R}=$ resistant. 
van der Flier et al. in a retrospective study in Utrecht (23). These authors reported good clinical outcome after treatment with either fluconazole, ketoconazole or itraconazole in $83 \%, 69 \%$ and $44 \%$ of the patients infected with respectively $\mathrm{S}$, DDS, or $\mathrm{R}$ isolates. It has to be emphasized that the studies mentioned here deal with oral- and esophageal candidiasis in HIV-positive patients and the data cannot be extrapolated to other patient populations. The findings of limited predictive value for susceptibility data are not exclusive for azole antifungal susceptibility testing but have also been reported for antibacterial compounds (8, 22). The $10 \%$ failures observed in oral and esophageal candidiasis in HIV-positive patients with azole treatment despite susceptible MIC values, could be due to non-pathogen related factors, as described in chapter one. In non-AIDS patient populations, the contribution of host factors and pharmacokinetic limitations of the compound could be substantially higher.

Several hypotheses can be formulated to explain the relative high clinical success rates for treatment of patients infected with the resistant isolates. One reason could be that the patient is colonized with multiple strains and the organism determined to be resistant is not the one responsible for the clinical symptoms. This hypothesis has been formally suggested for species such as C. glabrata and C. krusei, which are isolated with increased frequency from patients with oropharyngeal candidiasis $(4,10)$. Moreover, Schoofs et al. clearly demonstrated that there is a high variability in susceptibility among isolates from a single mouthwash. The yeasts isolated were often not clonal in nature (21). These findings call for some prudence with the interpretation of MIC values. Other reasons for treatment success rates with resistant fungi could be a synergistic action between the antifungal compound and one or more host molecules, or that subinhibitory concentrations are still sufficient to decrease the virulence of the pathogen and tilt the balance between colonization and eradication in favor of the host.

On the other hand, a single resistant isolate could easily be overlooked if it is spread onto an isolation plate together with an abundance of sensitive cells. To avoid this problem Patterson et al. proposed the use of fluconazole-containing isolation media to enrich the plate for fluconazole-resistant isolates. Systematic use of this technique could, however, overemphasize the presence of resistant 
isolates that may not be of pathologic significance in a patient.

The fact that approximately $50 \%$ of azole-resistant isolates are known to correlate with clinical failure justifies the biochemical analysis of mechanisms of resistance in these isolates.

In the introduction it was mentioned that a fungal pathogen could use three general mechanisms to become less susceptible to an antifungal compound, viz. preventing sufficient inhibitor reaching its target, changing the affinity or stoichiometry of the target for the antifungal agent, or evading the toxic consequences of the inhibition. From the different case studies it became clear that the isolates from patients clinically resistant to treatment all contained multiple resistance mechanisms. The $C$. glabrata isolate studied in chapter 5 combined an increase of cytochrome $\mathrm{P} 450$ (because of a multiplication of the entire chromosome carrying this gene) with a diminished azole content. The $C$. krusei strains reported in chapter 7 combined a lower cellular content with a decreased affinity of its 14-demethylase cytochrome $\mathrm{P} 450$ (Ergllp) for azoles. The $C$. albicans strains $\mathrm{C} 26, \mathrm{C} 40$, used in chapters 2 and 4 combined point mutations in the cytochrome $\mathrm{P} 450$ with overexpression of efflux pumps. The C. albicans strain C56 used in chapter 3 showed increased expression of the ABC-type transporters CDR1 and CDR2, a mutated form of the 14-demethylase and an increased expression of the latter protein. Similar combined mechanisms were described in the literature for other clinical isolates. For example, White(25), Sanglard et al.(19), and Franz et al.(5) all described the stepwise contribution of different molecular mechanisms to a gradual development of resistance in sequential clonal isolates from individual patients. The events observed in sequential isolates do not always follow a perfectly linear increase in resistance mechanisms. For example, in the study of Sanglard et al., isogenic strains C34, $\mathrm{C} 26$ and $\mathrm{C} 82$ were isolated sequentially (18). In isolate C34. a homozygotic point mutation $\mathrm{S} 405 \mathrm{~F}$ was found in its Ergl 1 p sequence (20). In the C26 isolate a high expression of both $C D R I$ and $C D R 2$ was measured in combination with an additional Y132H mutation on both copies of its Ergl lp sequence. The clonally related isolate $\mathrm{C} 82$, isolated 145 days later from the same patient, still overexpressed both $C D R I$ and $C D R 2$ but contained only the $S 405 \mathrm{~F}$ mutation. It is very unlikely that the $\mathrm{Y} 132 \mathrm{H}$ mutation was lost by a back-mutation. A far more 
likely explanation is that at the time $\mathrm{C} 26$ was isolated, the patient was colonized with a population of $C$. albicans of which only a fraction contained the $\mathrm{Y} 132 \mathrm{H}$ mutation. From these examples it can be hypothesized that azole resistance in clinical isolates is the result of multiple concurrent events. This is visualized in FIG. 2, where the combination of possible mechanisms for resistance creation are shown in a single cell.

Within the set of $C$. albicans isolates tested in this study, we could not detect the third mode of resistance, evasion of the toxic accumulation products. No significant accumulation of 14-methylated sterols that were able to replace ergosterol (e.g. 14-methylfecosterol) was measured after exposure to an azole antifungal agent. This type of protection from azole attack was identified previously in a $C$. albicans isolate from a chronic mucocutaneous candidiasis patient (7) and more recently in a $C$. albicans strain isolated from a leukemia patient (13). For the majority of $C$. albicans strains studied, identical accumulation products were seen in resistant and in sensitive isolates albeit that inhibition of the resistant isolates was seen at higher azole concentrations only. It is therefore not surprising that the morphological changes induced by azole treatment are comparable between sensitive and resistant isolates of $C$. albicans when concentrations of azoles are compared that inhibit the cultures to the same extent. Indeed FIG. 3 shows the transmission electron microscope images of C. albicans strains C26 and $\mathrm{C} 40$ in control conditions and after itraconazole treatment. Despite overexpression of $\mathrm{ABC}$ type efflux pumps ( $\mathrm{Cdr} 1 \mathrm{p}$ and $\mathrm{Cdr} 2 \mathrm{p}$ ) in $\mathrm{C} 26$ and overexpression of a major facilitator pump in $\mathrm{C} 40$ in combination with point mutations in the cytochrome $\mathrm{P} 450$ protein in both isolates, similar electron-dense accumulation products are observed within the thickened, irregularly shaped cell wall. In the highly resistant $\mathrm{C} 26$ isolate, the density of the electron-dense particles in the cellwall is lower, but the situation in the $\mathrm{C} 40$ isolate (3d) is indistinguishable from that observed in azole-sensitive isolates as shown in FIG. 5 in chapter 1.

In chapter three, two azole-resistant $C$. albicans isolates were described that accumulated even more cell-toxic intermediates, 3-ketosteroids, resulting in more complete growth inhibition than is sometimes seen with sensitive isolates, even though that inhibition was seen only at higher concentrations of azole. 


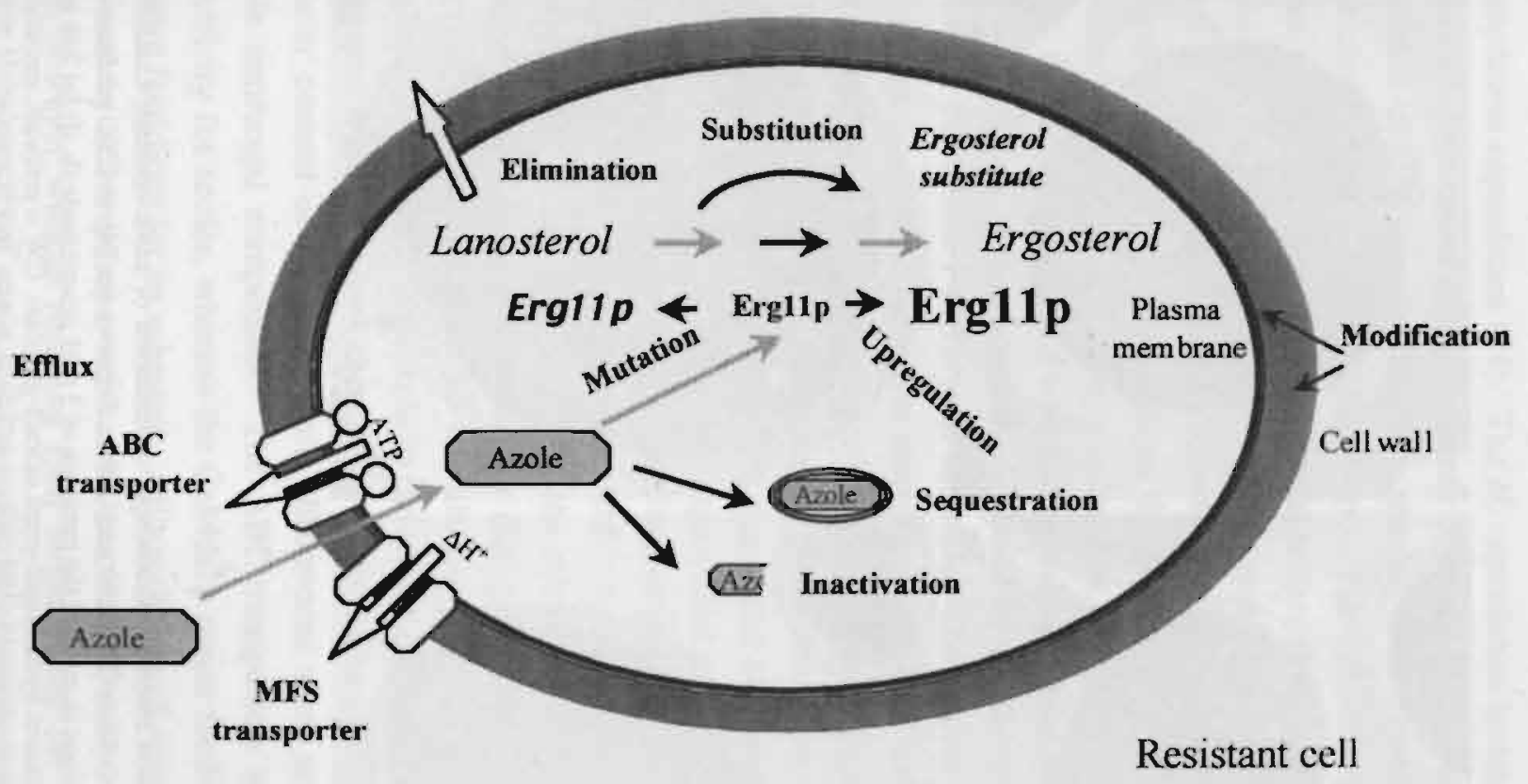

FIG. 2. Azole resistance in clinical isolates is often the result of multiple factors. Factors that prevent active azole from reaching its target: changes in the cell envelope (cell wall + plasmamembrane), (over)-expression of efflux pumps either from the MFS-type or from the ABC-type and, intracellular sequestration or inactivation of the azole are found in addition to factors that interfere with the inhibition by upregulation or mutation of the target and in combination with factors that nullify or compensate for the azole-induced toxic consequences. 


\section{Chapter 9}

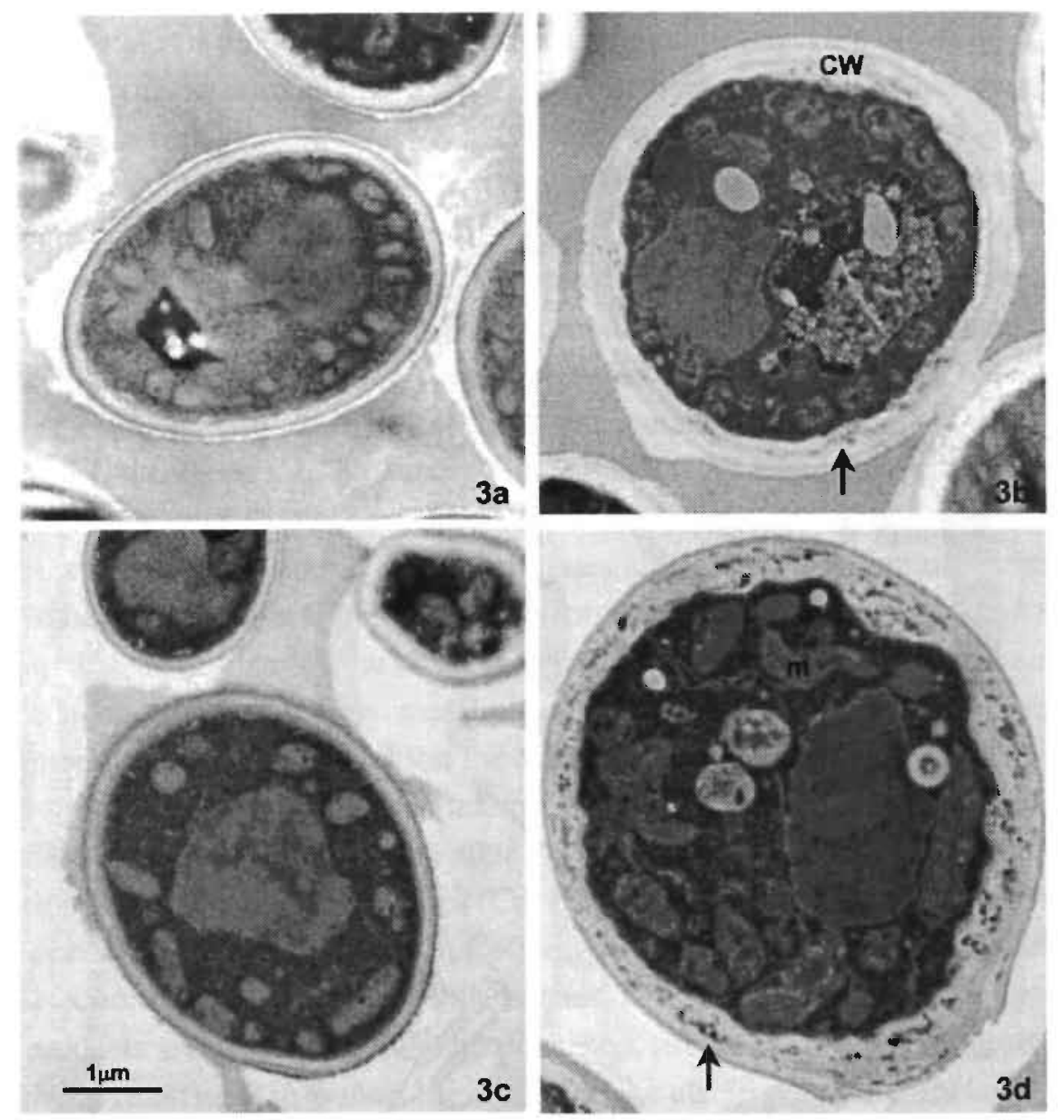

FIG. 3. Transmission electron microscopic examination of azole-resistant Candida albicans cells (strains C26 (a, b) and C40 (c, d) grown for 24h in CYG medium in control conditions $(a, c)$ or in the presence of $3 \mathrm{mM}$ itraconazole $(b, d)$ for $24 \mathrm{~h}$ in $\mathrm{CYG}$ medium (casein hydrolysate-yeast extract-glucose). $\mathrm{CW}=$ cellwall, electron dense particles are indicated by an arrow, $m=$ mitochondria. Bar is $1 \mathrm{mM}$. 
These 3-ketosteroids are hypothesized in chapter 6 to contribute to the fungicidal activity of itraconazole against $\mathrm{Cr}$. neoformans as well as against Histoplasma capsulatum (24). The $H$. capsulatum isolates described in chapter 8 showed differences in the amounts of accumulation products resulting from inhibition of sterol synthesis. The amount of accumulation of 3-ketosteroids correlated with the antifungal activity. The fact that itraconazole was more active against the fluconazole-resistant isolate than against the isolate sensitive to fluconazole as measured by growth or sterol biosynthesis, points to the danger of extrapolation of findings observed for one azole antifungal to another.

In chapter two, focus was given to the contribution of point-mutations in the resistant phenotype of $C$. albicans isolates. A high number of mutations was found, the most important of which are localized in the substrate- or azole- binding pocket in a 3-dimensional model build by homology modeling based on a bacterial cytochrome $\mathrm{P} 450$ crystal structure. The models available, however, are too distant from the $C$. albicans situation to allow in silico design or optimization of antifungals. Models closer to the C. albicans Ergl $1 \mathrm{p}$ structure are needed for this purpose. A candidate could be the Mycobacterium tuberculosis Cyp51p, a soluble cytochrome P450 that could 14-demethylate a sterol precursor (3). The fact that different techniques used to assess the activity of the proteins or their azole sensitivity gave non-perfect matching results, makes the interpretation less than straightforward. Again, it was observed that not all azoles bind with the same affinity to the cytochrome $\mathrm{P} 450$ and that the different azoles have different sensitivities for changes in the sequence, thus corroborating the hypothesis that it is not always permissible to extrapolate results obtained for one particular azole to the whole class of azole antifungals.

In chapter 4 it was shown that the overexpression of efflux pumps reduced the cellular content of azoles. Again, differences were seen between individual azole antifungal compounds. The ABC-transporters seem to have the least specificity for azoles, whereas the CaMdrlp major facilitator efflux transporter is more fastidious for its substrate. Although the cell-associated azole content is lowered by active pumps, substantial amounts of azole still remain cell-associated, however without reaching their target inside the cell. The question of where this "inactive" azole resides in the cell remains unanswered. 
In chapter tive it was shown that the azole-resistant $C$. glabrata isolate was gradually but slowly converted into a susceptible strain upon subcultivation. With most of the C. albicans isolates we studied from HIV patients, resistance was stable. In contrast, Marr et al. showed that resistance in a $C$. albicans isolate from a leukemia patient was readily lost upon subcultivation (11). In this patient resistance evolved rapidly after exposure to fluconazole because of overexpression of $\mathrm{ABC}$-type transporters. A similar situation is found in $C$. dubliniensis, a recently identified species very close to $C$. albicans, where high fluconazole resistance can readily be induced with high frequency (12).

Although it is clear that most clinical isolates express efflux pumps at higher levels than susceptible isolates, it is not yet clear to what extent these pumps contribute to resistance. Moreover, results in the literature on expression levels should be interpreted with care. Most studies use probes to detect mRNA signal for ABC-transporters that are insufficiently specific for measuring only the signal relevant to those pumps that are known to be involved in resistance. Use of such probes could easily lead to overestimations of the importance of the pumps. Western blot analysis or, better, functional assays of pump activity should give more accurate estimates for the presence of pumps in clinical isolates. It is not yet resolved why the pumps are overexpressed, nor does one know their exact function or even how they pump compounds to the exterior. The rapid changes seen in expression of pumps points to an important role of the regulation of the expression of these efflux mechanisms. It is not surprising that several groups are trying to elucidate the transcriptional regulatory networks for the pumps. One could even expect that mutation in transcription factors would have more detrimental effects than mutations in the pumps themselves as has been shown in $S$. cerevisiae (9). It has been shown that the expression of the pumps is readily induced by several factors, such as high temperature, stress or the addition of a variety of compounds including azoles $(6,9)$. With a GFP-cdrlp fusion protein it was found that the distribution of the chimeric protein differed from control distribution upon induction. This observation adds more confusion concerning the precise role of such pumps in azole resistance. 


\section{General discussion and summary}

For a direct biochemical comparison between different isolates it is necessary that the clonal relationship between them is demonstrated with at least one highly discriminating technique. The application of multiple methods could increase the statistical probability of the assumption of clonal relatedness. Moreover, as was mentioned already, it is likely that even if a patient is colonized with only clonally related strains, members of the infecting population contain subtle but important differences. Multiple isolates should be examined to get a more reliable picture of resistance. Because changes or selection upon subcultivation adversely affect the reproducibility of biochemical experiments over time, it is advisable to prepare large glycerol stocks that can be used as starting material for all experiments within a study.

The existence of resistance drives the pharmaceutical industry as well as some biotechnology companies to look for antifungal compounds with a novel mode of action. In the design of the screens one tries to incorporate as much knowledge as possible to detect compounds that are less likely to develop resistance. One could assume that if a novel compound had a fast-acting fungicidal mode of action, such a compound would give less opportunity for the pathogen to develop resistance. In terms of target selection. fast-acting fungicidal inhibitors should target essential pathways for survival of the pathogen. Because modern antifungals should have a broad spectrum and minimal or no side effects, their target should be conserved among fungi and if possible divergent or preferentially absent in the host. To exclude the numerous efflux pumps, one should look for targets that are located at the periphery of the cells, which would mean that inhibitors do not need to enter the cell. As long as such ideal antifungals are not discovered, alternative strategies to improve the efficacy of the available armamentarium of antifungals can be used. The resistant isolates described in the study can be included into the screening panel to detect those compounds that do not suffer from the combined mechanisms of resistance present in a particular isolate. Several investigators are studying synergism between available antifungal compounds with different modes of action whereas others are trying to boost the host defense system with a variety of cytokines. Improved galenic formulations that increase the concentration of the antifungal at the site of infec- 
Chapter 9

tion is another way to limit the number of clinical failures. It is, however, prob. able that there will be a continuous fight with the pathogens, which will surely continue to find ways to try to survive. 


\section{References}

1 Balzi E. and A. Goffeau. 1995. Yeast multidrug resistance: the PDR network. J. Bioenerg. Biomembr. 27: 71-76.

2 Barchiesi, F., R. J. Hollis, D. A. McGough, G. Scalise, M. G. Rinaldi, and M. A. Pfaller. 1995. DNA subtypes and fluconazole susceptibilities of Candida albicans isolates From the oral cavities of patients with AIDS. Clin. Infect. Dis. 20: 634-640.

3 Bellamine, A., Mangla, A.T., Nes, D., \& Waterman M. R. 1998. Is the Mycobacterium tuberculosis CYP51-like P450 a 14 $\alpha$-demethylase. In Program and Abstracts of the Fourth International Symposium on P450 Biodiversity and Biotechnology, Strasbourg, France. IC-11.

Dronda F., M. Alonso-Sanz, F. Laguna, F. Chaves, J. V. Martinez-Suarez, J. L. Rodriguez-Tudela, A. Gonzalez-Lopez, and E. Valencia. 1996. Mixed oropharyngeal candidiasis due to Candida albicans and non-albicans Candida strains in HIV-infected patients. Eur. J. Clin. Microbiol. Infect. Dis. 15(6):446-52.

Franz R., S. L. Kelly, D. C. Lamb, D. E. Kelly, M. Ruhnke, and J. Morschhauser. 1998. Multiple molecular mechanisms contribute to a stepwise development of fluconazole resistance in clinical Candida albicans strains. Antimicrob. Agents Chemother. 42: 3065-3072.

Hernaez M. L., C. Gil., J. Pla, and C. Nombela. 1998. Induced expression of Candida albicans multidrug resistance gene $C D R l$ in response to fluconazole and other antifungals. Yeast 13: $517-526$.

Howel S. A., A. I. Mallet, and W. C. Noble. 1990. A comparison of the sterol content of multiple isolates of the Candida albicans Darlington strain with other clinically azole-sensitive and -resistant stains. J. Appl. Bacteriol. 69: 692-696.

Kreger B. E., D. E. Craven, and W. R. McCabe. 1980. Gram-negative bacteremia. IV. Re-evaluation of clinical features and treatment in 612 patients. Am. J. Med. 68: 344-354.

Krisnamurthy S., V. Gupta, R. Prasad, S. L. Panwar, and R. Prasad. 1998. Expressiun of CDRI, a multidrug resistance gene of Candida albicans: transcriptional activation by heat shock, drugs and human steroid hormones. FEMS Microbiol. Lett. 160: 191-197

10 Maenza J. R., W. G. Merz, M. J. Romagnoli, J. C. Keruly, R. C. Moore, and J. E. Gallant. 1997. Infection due to fluconazole-resistant Candida in patients with AIDS: prevalence and microbiology. Clin. Infect. Dis. 24: 28-34. 
11 Marr K. A., C. N. Lyons, T. rustad, R. A. Bowden, and T. C. White. 1998. Rapid, transient fluconazole resistance in Candida albicans is associated with increased mRNA levels of CDR. Antimicrob. Agents Chemother. 42: 2584-2589.

Moran G. P., D. J. Sullivan, M. C. Henman, C. Mc Creary, B. J. Harrington, D. B. Shanley, and D. C. Coleman. 1997. Antifungal drug susceptibilities of oral Candida dubliniensis isolates from Human Immunodeficiency Virus (HIV)-infected and non-HIVinfected subjects and generation of stable fluconazole-resistant derivatives in vitro. Antimicrob. Agents Chemother. 41(3): 617-623.

13 Nolte F. S., T. Parkinson, D. J. Falconer, S. Dix, J. Williams, C. Gilmore, R. Geller, and J. R. Wingard. 1997. Isolation and characterization of fluconazole- and amphotericin B-resistant Candida albicans from blood of two patients with leukemia. Antimicrob. Agents Chemother. 41: 196-199.

Odds F. C. 1998. Should resistance to azole antifungals in vitro be interpreted as predicting clinical non-response? Drug resistance Updates 1: II-15.

Patterson T. F., S. G. Revankar, W. R. Kirkpatrick, O. Dib, A. W. Fothergill, S. W. Redding, D. A. Sutton, and M. G. Rinaldi. 1996. Simple method for detecting fluconazole-resistant yeasts with chromogenic agar. J. Clin. Microbiol. 34(7): 1794-1797.

16 Quereda C., A. m. Polanco, C. Giner, A. Sanchez-Sousa, E. Pereira, E. Navas, J. Fortun, A. Guerrero, and F. Baquero. 1996. Correlation between in vitro resistance to fluconazole and clinical outcome of oropharyngeal candidiasis in HIV-infected patients. Eur. J. Clin. Microbiol. Infect. Dis. 15: 30-37.

17 Rex, J. H., M. A. Pfaller, J. N. Galgiani, M. S. Bartlett, A. Espinel-Ingroff, M. A. Ghannoum, M. Lancaster, F. C. Odds, M. G. Rinaldi, T. J. Walsh, and A. L. Barry. 1997. Development of interpretive breakpoints for anti-fungal susceptibility testing: conceptual framework and analysis of in vitro/in vivo correlation data for fluconazole, itraconazole, and Candida infections. Clin. Infect. Dis. 24:235-247.

18 Sanglard D., K. Kuchler, F. Ischer, J. L. Pagani, M. Monod, and J. Bille. 1995. Mechanisms of resistance to azole antifungal agents in Candida albicans isolates from AIDS patients involve specific multidrug transporters. Antimicrob. Agents Chemother. 39: 2378-2386.

19 Sanglard D., F. Ischer, D. Calabrese, M. de Micheli, and J. Bille. 1998. Multiple resistance mechanisms to azole antifungals in yeast clinical isolates. Drug Resistance Updates. 1:255-265. 
20 Sanglard D., F. Ischer, L. Koymans, and J. Bille. 1998. Amino acid substitutions in the cytochrome P450 lanosterol 14 $\alpha$-demethylase (CYP51) from azole-resistant Candida albicans clinical isolates contributing to the resistance to azole antifungal agents. Antimicrob. Agents Chemother. 42:241-253.

21 Schoofs A., F. C. Odds, R. Colebunders, M. Ieven, L. wouters, and H. Goossens. 1997. Isolation of Candida species on media with and without added fluconazole reveals high variability in relative growth susceptibility phenotypes. Antimicrob. Agents Chemother. 41(8): $1625-1635$.

22 Thornsberry C., R. N. Jones, A. L. Barry, and P. C. Fuchs. 1982. Antimicrobial susceptibility tests with cefotaxime and correlation with clinical bacteriologic response. Rev. Infect. Dis. 4(suppl): S316-S324.

23 van der Flier M., L. van Elden, J. C. C. Borleffs, M. M. Lipovsky, M. R. Visser, and I. M. Hoepelman. 1999. Falende azol-therapie bij HIV-positieve patienten met mucosale candidose; risicofactoren en in-vitro-gevoeligheid. Nederlands Tijdschrift Med. Microbiol. 7(1): 14-20.

24 Vanden Bossche, H., P. Marichal, J. Gorrens, D. Bellens, M.-C. Coene, W. Lauwers, L. Le Jeune, H. Moereels, and P. A. J. Janssen. 1990. Mode of action of antifungals of use in immunocompromised patients. p. 223-243. In H. Vanden Bossche, D.W.R. MacKenzie, G. Cauwenbergh, J. Van Cutsem, E. Drouhet. and B. Dupont (eds.). Mycoses in AIDS patients. Plenum Press. New York. N.Y.

25 White T. C. 1997. Increased mRNA levels of ERG16, CDR, and MDR1 correlate with increases in azole resistance in Candida albicans isolates from a patient infected with human immunodeficiency virus. Antimicrob. Agents Chemother. 41: 1482-1487. 



\section{Samenvatting}


De laatste jaren is het aantal schimmelinfecties toegenomen, vooral door het stijgende aantal patiënten met een sterk verzwakt immuunsysteem. Deze patiënten blijken drager te zijn van een grote verscheidenheid aan kiemen. Medicatie om deze infecties te bestrijden is beperkt tot slechts een paar klassen van antifungale producten, waarvan de azolen veruit het meest toegepast worden. Azolen remmen de ergosterolbiosynthese in schimmels. De combinatie van het verdwijnen van ergosterol, nodig voor efficiënte celdeling, met een ophoping van metabole voorlopers verstoort de cel zodanig dat dit resulteert in een remming van de groei. Net zoals bij bacteriën en andere micro-organismen treedt er echter ook resistentie op. Het falen van een therapie met antimycotische producten bij patiënten kan verscheidene oorzaken hebben. Een aantal factoren zijn gerelateerd aan de patiënt, andere zijn dan afhankelijk van het gekozen antifungaal product en daamaast zijn er ook factoren die gerelateerd zijn aan de infecterende kiem zelf. Voorbeelden van factoren die afhankelijk zijn van de patiënt zijn de status van het immuunsysteem, de therapietrouw en afwijkende farmacokinetiek. Biochemisch kan men drie grote systemen onderscheiden van resistentiemechanismen. In het eerste systeem verhindert een groep van factoren dat er voldoende actieve inhibitoren ter hoogte van het doel komen ofwel door een defect in de opname ofwel door het terug naar buiten werken van de inhibitor door energieafhankelijke pompen. Er zijn twee typen van pompen: enerzijds deze die een ATP-bindende cassette bevatten (ABC-type) en die ATP verbruiken, en anderzijds de pompen die als bron van energie gebruik maken van de protongradient (MFS-type, "Major Facilitator superfamilie"). Een tweede systeem houdt verband met de veranderingen van het doelwit. Deze verandering kan bijvoorbeeld een verhoogde concentratie zijn of een structurele verandering die de affiniteit van de inhibitor voor het doeleiwit vermindert. Een derde systeem is het wegwerken van de groeiremmende effecten van de azolen. Inderdaad, als de cel onafhankelijk wordt van de aanwezigheid van ergosterol, of als de cel de storende precursoren kan elimineren, omzeilt de cel de gevolgen van de azolgeïnduceerde inhibitie ter hoogte van de sterolbiosynthese.

Het doel van deze studie was om meer inzicht te verwerven in de verschillende resistentiemechanismen aan de hand van biochemische analyse van klinische isolaten behorende tot verschillende species van humane pathogene fungi. 
Finaal wordt beoogd om deze kennis toe te passen tijdens het zoek- en selectieproces van nieuwe antifungale producten. Uit de opgedane ervaring destilleert men richtlijnen om klinische resistentie biochemisch te benaderen.

In hoofstuk 2 wordt het voorkomen van en de bijdrage tot de resistentie van puntmutaties in het cytochroom P450 14a-demethylase (Erg 1 lp) onderzocht via biochemische technieken of via computermodellen. De sequentieanalyse van het $E R G 11$-gen van 7 isolaten resulteerde in 12 aminozuursubstituties, waarvan er zes tot dan niet beschreven waren. Daarenboven werden er nog 16 verschillende stille mutaties gevonden. Twee biochemische technieken werden gebruikt om de affiniteit van het cytochroom P450 voor fluconazol en itraconazol na te gaan. Vier isolaten hadden een verminderde binding met itraconazol. Vijf isolaten vertoonden een meer uitgesproken daling in affiniteit voor fluconazol. Computermodellen werden gebruikt om alle gerapporteerde substituties (29 in aantal) te positioneren. De substituties clusterden in drie regio's. In de eerste twee regio's was alleen de Y132H-substitutie aantoonbaar van belang, terwijl de drie andere belangrijke mutaties terug te vinden zijn in het $\mathrm{C}$-terminale gedeelte. In hoofstuk 3 werd de ergosterolbiosynthese en de gevoeligheid voor azolen geanalyseerd in een set van 16 klinische $C$. albicans-isolaten afkomstig van vijf patiënten. De resistente isolaten van de tweede patiënt vertoonden in controleomstandigheden reeds een abnormaal sterolprofiel en werden daarom uitgekozen voor verder gedetailleerd onderzoek. Na azolbehandeling werd er in deze isolaten een stapeling gevonden van 3-ketosteroïden, wat er op wijst dat azolen in deze $C$. albicans-cellen ook interfereren met de 3-ketoreductasestap van het 4-demethylatieproces. De stapeling van deze toxische 3-ketosteroïden correleerde met een verminderde uitgroei ten opzichte van isolaten waar dit niet het geval was. Er werden geen mutaties gevonden in het ERG25-gen, dat deel uitmaakt van het 4-demethylatieproces. De juiste moleculaire basis voor de opstapeling blijft tot op heden ongekend.

In hoofdstuk vier wordt via itraconazol-accumulatiemetingen aangetoond dat de expressie van $C D R l$, een $A B C$-type transporter, invloed heeft op de cellulaire inhoud van dit lipofiel azol. De expressie van CaMDR, een MFS-type transporter, had daarentegen geen invloed. Dit werd zowel aangetoond met klinische isolaten, die de desbetreffende pomp tot expressie brengen als met heterologe 
expressie van deze pompen in Saccharomyces. Voor fluconazol, werd bevestigd dat dit hydrofiel azol wel door beide pompen als substraat herkend wordt. Tacrolimus en $\mathrm{NaN}_{3}$ zijn in staat om de $C D R l$-gerelateerde vermindering in cellulaire inhoud van itraconazol op te heffen. De combinatie van tacrolimus en itraconazol werkt synergistisch op de groei van azolresistente $C$. albicans.

Voor de azolresistente Candida glabrata-stam beschreven in hoofdstuk 5 werd aangetoond dat de aanwezigheid van meerdere kopieën van het chromosoom dat het cytochroom P450-gen bevat aan de basis ligt van de resistentie. Als gevolg van deze multiplicatie, die niet aanwezig was in de gevoelige moederstam, werd een verhoogde transcriptie van het gen gemeten wat resulteerde in een verhoogde enzymeconcentratie en activiteit. Via 2D-gel-elektroforese werd aangetoond dat de aanwezigheid van meerdere kopieën van dit chromosoom resulteerde in een verhoogde vorming van niet minder dan 25 eiwitten en een sterk verlaagde concentratie van 75 eiwitten. Door herhaalde kweek op een azolvrij medium, verdween de multiplicatie geleidelijk en verliep dit parallel met het terugkeren van de gevoeligheid en de terugkeer naar een 2D-profiel dat gelijkt op dat van de moederstam.

In hoofstuk 6 wordt aangetoond dat itraconazol naast de 14-demethylatiereactie ook interfereert met de 3-ketoreductase in Cryptococcus neoformans. Deze interferenties leidden ertoe dat er substantiële hoeveelheden obtusifolione, een 3-ketosteroïde, zich opstapelen. Vermits dit een toxisch tussenproduct is, kan dit de sterke groei-inhibitie van itraconazol in dit species verklaren.

Hoofdstuk 7 handelt over Candida krusei, een species dat als intrinsiek fluconazolresistent wordt beschreven. Andere azolen omvatten dit species wel in hun spectrum. Via sterolsynthese-experimenten, zowel in intacte cellen als in subcellulaire fracties, en via accumulatieproeven werd aangetoond dat voor fluconazol in deze stammen zeer lage cellulaire concentraties bereikt worden, wat wellicht gedeeltelijk aan de basis ligt van de intrinsieke resistentie.

Twee clonaal gerelateerde stammen van Histoplasma capsulatum, een moederstam geïsoleerd voor behandeling en een "relapse"-isolaaat, geïsoleerd uit dezelfde patiënt na fluconazolbehandeling, werden in vitro vergeleken voor wat betreft groeigevoeligheid en sterolsynthese t.o.v. twee azolen, itraconazol en fluconazol. De "relapse"-stam vertoonde een verminderde gevoeligheid voor flu- 
conazol zowel wat betreft groei als sterolsynthese. Itraconazol daarentegen was zelfs actiever tegen deze "relapse"-stam, zodat deze stammen een negatieve kruisresistentie vertonen voor itraconazol t.o.v. fluconazol.

De selectie van isolaten voor biochemische studies gebeurt voomamelijk op basis van een verhoogde MIC-waarde. Vermits MIC-waarden sterk afhangen van de experimentele omstandigheden, heeft de antifungale NCCLS-deelgroep een referentiemethode beschreven die toelaat op reproduceerbare wijze de gevoeligheid van species te bepalen. Helaas is er geen absolute correlatie tussen MIC-waarden en de voorspelling van klinisch resultaten. Tien percent van de patiënten gekoloniseerd in de mond of luchtpijp met isolaten met een lage MICwaarde reageren onvoldoende op de behandeling. Waarschijnlijk dragen hier andere factoren bij tot de mislukking van de behandeling. De therapie van patiënten waarbij isolaten gevonden werden met hoge MIC-waarden heeft toch nog een slaagkans van $50 \%$. Mogelijke redenen van deze discrepantie zijn, dat de patiënt gekoloniseerd is door meerdere isolaten en het isolaat met een hoge MIC-waarde nauwelijks of niet bijdraagt tot de klinische symptomen, of dat er synergisme bestaat tussen de antifungale behandeling en een of meer gastheerfactoren of, dat gedeeltelijke groeiremming reeds voldoende is om de balans tussen kolonisatie en uitroeiing in het voordeel van de patiënt te laten overhellen. Uit de gedane studies kan men besluiten dat er in klinisch resistente isolaten meestal een combinatie van meerdere resistentiemechanismen tegelijkertijd aanwezig zijn. De aanwezigheid van slechts één type van resistentie geeft waarschijnlijk voor de cellen met deze eigenschap al wel een concurrentieel voordeel, zodat ze onder blijvende selectiedruk een groot deel van de populatie gaan uitmaken. Volgens deze hypothese is het echter onwaarschijnlijk dat alle koloniserende cellen identiek dezelfde eigenschappen hebben, wat voor biochemisch onderzoek het noodzakelijk maakt om meerdere isolaten parallel te onderzoeken. De interpretatie van biochemische analyses is het eenvoudigst wanneer de clonaal gerelateerde moedercel ook ter beschikking is. 

Curriculum Vitae 

Patrick P. J. M. G. Marichal werd op 31 januari 1958 geboren te Antwerpen. In 1976 behaalde hij het humaniora diploma Wetenschappelijke $\mathrm{A}$ aan het Xaveriuscollege te Borgerhout. Na de verdediging van het proefschrift "Effect van oplosbare factoren op de ergosterol biosynthese in Saccharomyces cerevisi$a e "$ behaalde hij in 1981 het diploma van Industrieel Ingenieur Chemie optie Biochemie met grote onderscheiding aan de Katholieke Industriële Hogeschool te Antwerpen. Sinds 1981 is hij werkzaam bij de Janssen Research Foundation in de afdeling Vergelijkende Biochemie, waar hij als Principal Scientist fungi en andere micro-organismen gekoesterd heeft. De focus van zijn onderzoeksgebieden waren toegespits op enerzijds het achterhalen van werkings- en resistentiemechanismen van antischimmel producten en anderzijds op het zoeken naar nieuwe antischimmel producten via target-georienteerd onderzoek. Hij is lid van internationale microbiologische verenigingen ISHAM (International Society of Human and Animal Mycology) en ASM (American Society Microbiology). Zijn onderzoeksresultaten presenteerde hij via publicaties alsook via posters (6) en voordrachten (9) op internationale congressen. Sinds 1996 treedt hij op als vertegenwoordiger van Janssen Research Foundation bij het YIP (Yeast Industry Platform). In 1982 huwde hij met Lieve Heylen en beiden zijn de trotse ouders van Patrick jr. (1984), Stéphane (1987) en Thierry (1992). Met hun vijven vertoeven ze in de nabijheid van de trappisten abdij van Westmalle. 

List of publications 


\section{List of publications}

Marichal P., J. Gorrens, H. Vanden Bossche. 1985. The action of itraconazole and ketoconazole on growth and sterol synthesis in Aspergillus fumigatus and Aspergillus niger. Sabouraudia. 22: 13-21.

Marichal P., J. Gorrens, J. Van Cutsem, H. Vanden Bossche. 1986. Culture media for the study of the effects of azole derivatives on germ tube formation and hyphal growth of $C$. albicans. Mykosen 29(2): 76-81.

Marichal P., J. Gorrens, J. Van Cutsem, F. Van Gerven, H. Vanden Bossche. 1986. Elfects of ketoconazole and itraconazole on growth and sterol synthesis in Pityrosporum ovale. J. Med. Vet. Mycol. 24: 487-489.

Marichal P., H. Vanden Bossche, J. Gorrens, D. Bellens and P. A. J. Janssen. 1988. Cytochrome P-450 of Aspergillus fumigatus - effects of itraconazole and ketoconazole. In : Schuster,I. (Ed) Cytochrome P-450: biochemistry and biophysics. Taylor and Francis, London, UK. Pp 177-180.

Marichal P., H. Vanden Bossche, H. Moereels, and R. Brasseur. 1990. Mode of insertion of azole antifungals and sterols in membranes. In: "Molecular Description of biological membranes by computer aided conformational analysis, vol 2, R. Brasseur, ed., CRC Press, Boca Raton, pp $27-42$.

Marichal P. 1993. Inhibitors of ergosterol biosynthesis. Pharmazie 48 (5), 393, 1993.

Marichal P., J. Gorrens, M.-C. Coene, L. Le Jeune, and H. Vanden Bossche. (1995). Origin of differences in susceptibility of Candida krusei to azole antifungal agents. Mycoses 38, $111-117$.

Marichal, P., and H. Vanden Bossche. 1995. Mechanisms of resistance to azole antifungals. Acta Biochemica Polonica, 42:509-516.

Marichal P., H. Vanden Bossche, F. C. Odds, G. Nobels, D. W. Warnock, Vincent Timmerman, C. Van Broeckhoven, S. Fay, and P. Mose-Larsen. 1997. Molecular biological characterization of an azole-resistant Candida glabrata isolate. Antimicrob. Agents Chemother. 41:2229-2237.

Marichal P. 1999. Mechanisms of resistance to azole antifungal compounds. Cur. Anti-Infect. Invest. Drugs.1(3): 318-333.

Marichal P., L. Koymans, S. Willemsens, D. Bellens, P. Verhasselt, W. Luyten. M. Borgers, F. C. S. Ramaekers, F. C. Odds and H. Vanden Bossche. 1999. Contribution of mutations in the cytochrome $\mathrm{P} 450$ I $4 \alpha$-demethylase (ERGII, CYPSI) to azole resistance in Candida albicans. Accepted in Microbiology 
Marichal P., J. Gorrens, L. Laurijssens, K. Vermuyten, C. Van Hove, L. Le Jeune, P. Verhasselt, D. Sanglard, M. Borgers, F. C. S. Ramaekers ', F. C. Odds and H. Vanden Bossche. 1999. Accumulation of 3-ketosteroids induced by itraconazole in azole-resistant clinical Candida albicans isolates. Accepted in Antimicrob. Agents Chemother.

Vanden Bossche H., J. M. Ruysschaert, F. Defrise-Quertain, G. Willemsens, F. Cornelissen, P. Marichal, W. Cools and J. Van Cutsem. 1982. The interaction of miconazole and ketoconazole with lipids. Biochem. Pharmacol, 31: 2609-2617.

Vanden Bossche H., W. Lauwers, G. Willemsens, P. Marichal, F. Cornelissen and W. Cools,. 1983. Molecular basis for the antimycotic and antibacterial activity of $\mathrm{N}$-substituted imidazoles and triazoles: the inhibition of isoprenoid biosynthesis. Pesticide science 15: 188-198.

Vanden Bossche H., G. Willemsens, W. Cools, P. Marichal, and W. Lauwers. 1983. Hypothesis on the molecular basis of the antifungal activity of $\mathrm{N}$-substituted imidazoles and triazoles. Biochem. Soc. Trans. 11(6):665-667.

Vanden Bossche H., G. Willemsens, P. Marichal, W. Cools, and W. Lauwers. 1984. The molecular basis for the antifungal activities of $\mathrm{N}$-substituted azole derivatives. Focus on R5I2I I. In : Mode of action of antifungal agents, eds. A. P. J. Trinci and J. F. Ryley (Eds.), Britisch Mycological Society, Great Britain, pp 321-341.

Vanden Bossche H., G. Willemsens, P. Marichal. 1984. Cytochrome P-450 inhibitors at the origin of deteriorated fungal membranes. A summary. In: microbial cell wall synthesis and autolysis. Eds. C. nombela. Elsevier Science Publishers pp 307-312.

Vanden Bossche H., W. Lauwers, G. Willemsens, P. Marichal, F. Cornelissen and W. Cools. 1984. Molecular basis for the antimycotic and antibacterial activity of $\underline{\mathrm{N}}$-substitured imidazoles and triazoles : the inhibition of isoprenoid biosynthesis. Pestic. Sci. 15:188-198.

Vanden bossche H., D. Bellens, J. Gorrens, P. Marichal, H. Verhoeven, and Willemsens G. 1985. Yeast and plant cytochrome P-450 enzymes: targers for azole-derivatives. In: Cytochrome P-450, biochemistry, biophysics and induction, eds L. Vereczkey and K. Magyar. Akademia Kiado, Budapest pp 423-429.

Vanden bossche H., P. Marichal, J. Gorrens. 1985. Molecular basis for the antifungal activity of the azole derivatives ketoconazole and itraconazole, model Candida lusitaniae. In: In vitro and in vivo evaluation of antifungal agents. Eds $\mathrm{K}$. Iwata and $\mathrm{H}$. Vanden Boscche, Elsevier Science Publishers pp $101-109$.

Van Gestel J., L. Van Leemput, and P. Marichal. 1986. Quantitative aspects of the antisporulant activity of imazalil, an agricultural fungicide. Drug dev. Res. 8: 325-331. 
Vanden bossche H., D. Bellens, W. Cools, J. Gorrens, P. Marichal, H. Verhoeven, G. Willemsens, R. De coster, D. Beerens, C. Haelterman, M.-C. Coene, I. Lauwers, and L. Le Jeune. 1986. Cytochrome P-450: target for itraconazole. Drug dev. Res. 8: 287-298.

Vanden Bossche H., G. Willemsens, P. Marichal. 1987. Anti-Candida drugs- The biochemical basis for their activity, Crit. Rev Micrbiol, 15: 57-72.

Vanden Bossche H., P. Marichal, J. Gorrens, D. Bellens, H. Verhoeven, M.-C. Coene, W. Lauwers, and P. A. J. Janssen. 1987. Interaction of azole derivatives with cytochrome P-450 isozymes in yeast, fungi, plants, and mammalian cells. Pestic. Sci. 21: 289-306.

Vanden Bossche H., P. Marichal, J. Gorrens, H. Geerts, and P. A. J. Janssen. 1988. Mode of action studies. Basis for the search of new antifungal drugs. Ann. N. Y. Acad. Sci. 544: 191-207.

Vanden Bossche, H., P. Marichal, H. Geerts, and P. A. J. Janssen. 1988. The molecular basis for itraconazole's activity against Aspergillus fumigatus, p. 171-197. In H. Vanden Bossche, D. W. R. Mackenzie and G. Cauwenbergh (ed.), Aspergillus and aspergillosis. Plenum Press, New York.

Vanden Bossche, H., P. Marichal, J. Gorrens, M.-C. Coene, G. Willemsens, D. Bellens, I. Roels, H. Moereels, and P. A. J. Janssen. 1989. Biochemical approaches to selective antifungal activity. Focus on azole antifungals. Mycoses 32 (Suppl. 1):35-52.

Vanden Bossche, H., P. Marichal, J. Gorrens, D. Bellens, M.-C. Coene, W. Lauwers, L. Le Jeune, H. Moereels, and P. A. J. Janssen. 1990. Mode of action of antifungals of use in immunocompromised patients. Focus on Candida glabrata and Histoplasma capsulatum, p. 223243. In $\mathrm{H}$. Vanden Bossche, D. W. R. Mackenzie, G. Cauwenbergh, J. Van Cutsem, E. Drouhet, and B. Dupont (ed.), Mycoses in AIDS patients. Plenum Press, New York.

Vanden Bossche H., P. Marichal, J. Gorrens, D. Bellens, H. Moereels, and P. A. J. Janssen. 1990. Mutation in cytochrome P450-dependent $14 \alpha$-demethylase results in decreased affinity for azole antifungals. Biochem. Soc. Trans. 18: 56-59.

Vanden Bossche, H., P. Marichal, J. Gorrens, M.-C. Coene. 1990. Biochemical basis for the activity and selectivity of oral antifungal drugs. Brit. J. Clin. Practice. 44(suppl 71): 41-46.

Vanden BosscheH., P. Marichal, G. Willemsens, D. Bellens, J. Gorrens, I. Roels, M.-C. Coene, L. Le Jeune, and P. A. J. Janssen. 1990. Saperconazole : a selective inhibitor of the cytochrome P-450-dependent ergosterol synthesis in Candida albicans, Aspergillus fumigatus, and Trichophyton mentagrophytes. Mycoses 33: 335-352.

Brasseur R. E. Goormaghtigh, J. M. Ruysschaert, P. H. Duquenoy, P. Marichal, and H. Vanden Bossche.1991. Lipid-itraconazole interaction in lipid model membranes. J. Pharmacy Pharmacol. 43(3): 167-71. 
Vanden Bossche H. and P. Marichal. 1991. Mode of action of anti-Candida drugs: focus on terconazole and other ergosterol biosynthesis inhibitors. Am. J. Ob. Gynecol. 165(4- 2):1193-1199.

Vanden BosscheH., P. Marichal, G. Willemsens, and P. A. J. Janssen. 1991. Effects of inhibitors on the p-450-dependent metabolism of endogenous compounds in fungi, protozoa, plants and vertebrates. In: Molecular aspects of monooxygenases and bioactivation of toxic compounds eds E. Arinc et al. plenum press. New york. pp 345-363

Vanden Bossche H. and P. Marichal. 1992. Azole antifungals: mode of action. In: Recent progress in antifungal chemotherapy (Yamaguchi H., G. S. Kobayashi, and H. Takahashi. eds.) Marcel Dekker, New York, pp 25-40.

Vanden Bossche, H., P. Marichal, F. C. Odds, L. Le Jeune, and M.-C. Coene. 1992. Characterization of an azole-resistant Candida glabrata isolate. Antimicrob. Agents Chemother. 36:2602-2610.

Vanden Bossche H., P. Marichal, M.-C. Coene, G. Willemsens, L. Le Jeune, W. Cools, and H. Verhoeven. 1992. Cytochrome P450-dependent I $4 \alpha$-demethylase. Target for antifungal agents and herbicides. In: regulation of isopentenoid metabolism. Eds W. D. Nes, E. J. Parish, and J. M. Trzaskos. American Chemical Society, Washington DC. pp 219-230.

Vanden Bossche H., P. Marichal, G. Willemsens. 1992. Therapeutic aspects of cytochrome P450 inhibition. J. Bas. Clin. Physiol, Pharmacol. 3(suppl): 93-94.

Vanden Bossche, H., J. Heeres, L. Backx, P. Marichal, and G. Willemsens. 1993. Discovery, chemistry, mode of action and selectivity of itraconazole $\ln \mathrm{J}$. W. Rippon, and R. A. Fromtling (ed.), Cutaneous antifungal agents. Marcel Dekker, Inc., New York. pp. 263-283.

Vanden Bossche, H., P. Marichal and H. Moereels. 1993. Molecular mechanisms of antifungal activity and fungal resistance: focus on inhibitors of ergosterol biosynthesis. $\ln \mathrm{B}$. Maresca, G. S. Kobayashi, and H. Yamaguchi (ed.), Molecular biology and its application to medical mycology. Springer-Verlag, Berlin. pp. 179-197.

Vanden Bossche H. and P. Marichal. 1993. Is there a role for sterols and steroids in fungal growth and transition from yeast to hyphal-form and vice-versa? An overview. In: Dimorphic Fungi in biology and medicine, Vanden Bossche, H., Odds, F. C., and Kerridge D., eds., Plenum Press, New York, pp 177-190.

Vanden Bossche H., P. Marichal, L. Le Jeune, M.-C. Coene, J. Gorrens, and W. Cools. 1993. Effects of itraconazole on cytochrome P-450-dependent sterol $14 \alpha$-demethylation and reduction of 3-ketosteroids in Cryptococcus neoformans. Antimicrob. Agents Chemother. 37: 2101-2105. 


\section{List of publications}

Vanden Bossche H., P. Marichal, and H. Moereels. 1993. Molecular mechanisms of antifungal activity and fungal resistance: focus on inhibitors of ergosterol biosynthesis. In: Molecular biology and its application to medical mycology. B. Maresca and G. S. Kobayashi and H. Yamaguchi Eds. Springer-Verlag Berlin, pp 179-197.

Vanden Bossche, H., Marichal, P., Odds, F. C. (1994). Molecular mechanisms of drug resistance in fungi. Trends Microbiol 2, 393-400.

Vanden Bossche, H. V., D. W. Warnock, B. Dupont, D. Kerridge, S. Sen-gupta, L. Improvisi, P. Marichal, F. C. Odds, F. Provost, and O. Ronin. 1994. Mechanisms and clinical impact of antifungal drug resistance. J. Med. Vet. Mycol. 32:189-202.

Wheat, J., P. Marichal, H. Vanden Bossche, A. Le Monte, and Patricia Connolly. 1997. Hypothesis on the mechanism of resistance to fluconazole in Histoplasma capsulatum. Antimicrob. Agents Chemother. 41:410-414.

Maesaki S., P. Marichal, M. Ashraf Hossain, D. Sanglard, H. Vanden Bossche, and S. Kohno. 1998. Synergic effects of tacrolimus and azole antifungal agents against azole-resistant Candida albicans strains. J. Antimicrob. Chemother. 42: 747-753.

Maesaki S., P. Marichal, H. Vanden Bossche, D. Sanglard, and S. Kohno. 1999. Rhodamine 6G efflux for the detection of $C D R l$-overexpressing azole-resistant Candida albicans strains. J. Antimicrob. Chemother. 44: 27-31. 


Dankwoord 

$\mathrm{Na}$ het beëindigen van mijn proefschrift rest mij nog de aangename taak een woord van dank te richten tot al diegene die -onder welke vorm dan ook- hebben bijgedragen tot de realisatie van deze thesis. Bewust van het gevaar iemand te vergeten, wil ik toch een aantal mensen speciaal vernoemen. De meeste dank ben ik ongetwijfeld verschuldigd aan Hugo Vanden Bossche niet alleen omdat hij het copromotorschap aanvaard heeft maar veel meer nog voor zijn jarenlange begeleiding en vorming zowel op wetenschappelijk als op persoonlijk vlak. "Hugo, jij hebt mij ingewijd in de fascinerende wereld van de biochemie en mycologie zodat het ook mijn vakgebied geworden is. Dank voor je continue aansporing en je talloze nuttige wenken".

Dank ook aan mijn promotoren Prof. dr. M. Borgers en Prof. dr. F.C.S. Ramaekers om mij de mogelijkheid te bieden te promoveren aan de Universiteit van Maastricht, voor hun vertrouwen, voor de vele inspanningen en steun. Marcel, jou bedank ik speciaal voor je stimulerende pleidooien om biochemische resultaten ook via morfologie te staven als ook voor je onmisbare hulp en begeleiding in het verkennen van de wondere wereld van de microscopie.

Een speciale dank ook voor Prof. dr. Frank Odds. "Frank, via je professionele, kritische maar stimulerende kijk op en kennis van de mycologie heb je in belangrijke mate bijgedragen tot mijn vorming. Dank ook voor je niet-aflatende enthousiasme om mij de geheimen van de engelse taal bij te brengen".

Dr. Paul Janssen en Staf van Reet hebben mij in de mogelijkheid gesteld dit werk te verwezenlijken bij de Janssen Research Foundation waarvoor mijn blijvende erkentelijkheid. I $\mathrm{k}$ wil graag ook mijn oprechte dank betuigen aan alle collegae van de afdeling Vergelijkende Biochemie: Danny Bellens, Inge Beyens, Concha Claes, Paul De Houwer, Jos Gorrens, Leen Laurijssens, Inge Moelans, Geert Nobels, Christel Ooms, Ivan Roels, Heidi Schreuders, Bart Van den Hazel, Cis Van Looveren, Tinne Verhulst, Karen Vermuyten, Staf Willemsens. Bedankt voor jullie vele vruchtbare inspanningen en loyaliteit. Het was fijn om met jullie een team te vormen.

Dank ook aan de mensen van het 'Centrum voor moleculair design' met name vooral Luc Koymans voor de modelling experimenten van het cytochrome P450.

Modern wetenschappelijk werk is ondenkbaar zonder veelvuldige interacties en hulp van andere afdelingen. Dank daarom aan de collegae Marie-Claire Coene, Willy Cools, Lieve Dillen, Hugo Geerts, Ludo Le Jeune, Walter Luyten, Fred Thoné, Carl Van Hove, Luc Van Nuffel, , Peter Verhasselt, Filip Woestenborghs 


\section{Dankwoord}

en zovele anderen.

Dominique Sanglard, Shigefumi Maesaki, Tom Walsh alsook andere collegae en vrienden uit de relatieve kleine wereld van de mycologie dank ik voor hun stimulerende discussies, waaruit telkens nieuwe ideeën voortvloeiden.

Er zijn nog vele anderen die ieder hun steentje bijdragen en zonder wiens hulp dit werk nooit tijdig zou af geraakt zijn. Ik vermeld hier Griet Van Houdt en Leen Geentjens voor onder andere hun administratieve hulp en organisatorische vaardigheden. Lambert Leijssen en zijn equipe ben ik zeer erkentelijk voor de vele posters, figuren en dia's die altijd tijdig klaar waren. Mede hierdoor kreeg dit boek een dimensie meer.

Ik dank in belangrijke mate de leden van de beoordelingscommissie Prof. C. Bruggeman, Prof. Van Dieijen-Visser, Prof Goffeau, Prof. H. Struijker Boudier en Dr. M. de Waard voor het kritisch lezen van het manuscript.

Er zijn ook nog mijn ouders aan wie ik dit werk wil opdragen. Moge dit boek voor hen een compensatie zijn voor hun jarenlange onbaatzuchtige steun. En tot slot Lieve, Patrick Jr., Stéphane en Thierry.........jongens, de computer is weer vrij. 

in 